\title{
Fever management in children under 4 years in childcare centers and well-child clinics
}

Citation for published version (APA):

Peetoom, K. K. B. (2019). Fever management in children under 4 years in childcare centers and well-child clinics. [Doctoral Thesis, Maastricht University]. ProefschriftMaken Maastricht. https://doi.org/10.26481/dis.20190426kp

Document status and date:

Published: 01/01/2019

DOI:

10.26481/dis.20190426kp

Document Version:

Publisher's PDF, also known as Version of record

\section{Please check the document version of this publication:}

- A submitted manuscript is the version of the article upon submission and before peer-review. There can be important differences between the submitted version and the official published version of record.

People interested in the research are advised to contact the author for the final version of the publication, or visit the DOI to the publisher's website.

- The final author version and the galley proof are versions of the publication after peer review.

- The final published version features the final layout of the paper including the volume, issue and page numbers.

Link to publication

\footnotetext{
General rights rights.

- You may freely distribute the URL identifying the publication in the public portal. please follow below link for the End User Agreement:

www.umlib.nl/taverne-license

Take down policy

If you believe that this document breaches copyright please contact us at:

repository@maastrichtuniversity.nl

providing details and we will investigate your claim.
}

Copyright and moral rights for the publications made accessible in the public portal are retained by the authors and/or other copyright owners and it is a condition of accessing publications that users recognise and abide by the legal requirements associated with these

- Users may download and print one copy of any publication from the public portal for the purpose of private study or research.

- You may not further distribute the material or use it for any profit-making activity or commercial gain

If the publication is distributed under the terms of Article $25 \mathrm{fa}$ of the Dutch Copyright Act, indicated by the "Taverne" license above, 


\section{Colofon}

Lay-out: Gijs Brouwer \& Kirsten Peetoom

Cover design: Sue van Gageldonk || www.suevangageldonk.nl

Printed by: ProefschriftMaken || www.proefschriftmaken.nl

This dissertation is printed on recycled paper.

ISBN: 978-94-6380-288-8

COKirsten Peetoom, Maastricht 2019

The research presented in this dissertation was conducted at CAPHRI, Care and Public Health Research Institute, Department of Family Medicine, Maastricht University.

The research in this dissertation was funded by ZonMW.

All rights are reserved. No part of this book may be reproduced or transmitted in any form or by any means, without the written permission from the author or, where appropriate, the publisher of the article. 


\title{
Fever management in children under 4 years in childcare centres and well-child clinics
}

\author{
PROEFSCHRIFT \\ Ter verkrijging van de graad van doctor \\ aan de Universiteit Maastricht, \\ op gezag van de Rector Magnificus, Prof. Dr. Rianne M. Letschert, \\ volgens het besluit van het College van Decanen, \\ in het openbaar te verdedigen op \\ Vrijdag 26 april 2019 om 14.00 uur \\ door \\ Kirsten Kelly Brigitte Peetoom \\ Geboren op 01 oktober 1988 te Haarlemmermeer
}




\section{Promotores}

Prof. dr. J.W.L. Cals

Prof. dr. G.J. Dinant

Prof. dr. R. Crutzen

\section{Beoordelingscommissie}

Prof. dr. F.J.M. Feron (voorzitter)

Dr. G. Elshout (Erasmus Universiteit Rotterdam)

Dr. K. Hedin (Lund University)

Prof. dr. M.W.J. Jansen

Prof. dr. G.D.E.M. van der Weijden 


\section{Contents}

Chapter $1 \quad$ General introduction

$\begin{array}{lll}\text { PART } 1 & \text { Needs assessment } & 19\end{array}$

Chapter 2 Childhood fever: a qualitative study on GPs' experiences 21 during out-of-hours care

Chapter 3 Childhood fever in well-child clinics: a focus group study among doctors and nurses

Chapter $4 \quad$ Most preschool children with fever and common infection symptoms do not consult the family physician

Chapter 5 "I am not a doctor", views of childcare staff on decisionmaking on febrile children: a qualitative study

Chapter 6 Does well-child care education improve consultations and medication management for childhood fever and common infections? A systematic review

PART 2 Development and evaluation of a multicomponent intervention

Chapter 7 Optimising decision making on illness absenteeism due to fever and common infections within childcare centres: development of a multicomponent intervention and study protocol of a cluster randomised controlled trial

Chapter 8 Optimising decision-making among childcare staff on fever and common infections: cluster randomised controlled trial

Chapter 9

General discussion

Summary

Samenvatting

Dankwoord

Curriculum Vitae 

Chapter 1

General Introduction 


\section{INFECTION LOAD AND RELATED HEALTHCARE SERVICE USE IN CHILDREN UNDER 4 YEARS OLD}

Almost all children under 4 years old experience regularly respiratory tract infections or gastro-intestinal tract infections. Subsequently, fever is very common in this age group. Children under 4 years old are more likely to acquire these infections as their immune system is still developing and they lack appropriate hygiene skills to limit disease transmission. The incidence of having an infection is highest in children under 4 years old and declines when the child ages [1-3]. Successively, children attending childcare are particularly prone to acquire infections compared to home-cared children, due to their close contact with other children, but also through indirect transmission via the environment such as toys [4-10]. As a result, children in childcare experience 6 to 12 infection illness episodes per year, resulting in an average of 23 absent days from childcare on a yearly basis [11-14]. Most frequent reasons for childcare absenteeism are fever, respiratory symptoms, ear infections, chicken pox, diarrhoea, and vomiting [3, 15]. Furthermore, childcare absenteeism leads regularly to parents taking time off work to care for their ill child. Approximately $40 \%$ of parental work absenteeism is due to a child's illness [16]. Subsequently, parents are approximately 1.5 days absent from work per child's illness episode $[17,18]$. In turn, children in childcare generate twice as much societal costs compared to home-cared children, in particular due to parental productivity loss [17].

Children under 4 years old suffer mainly from self-limiting infectious diseases that do not require treatment, such as fever, cough, earache or skin infections. Despite this, general practitioners (GPS) frequently see young children with these diseases [19-21]. Approximately $60 \%$ of the consultations in primary care for children under 1 years old are for respiratory symptoms [22]. About 63\% of parents reported in a Dutch survey that they have consulted their GP during regular working hours with their febrile child. In addition, about $44 \%$ of the parents acknowledged they have consulted a GP during out-of-hours care for their febrile child [23]. Subsequently, children under 4 years old are also more frequently seen in general practice with acute respiratory infections and influenza-like illness in comparison to older age groups [19, 21, 24]. See figure 1, derived from the NIVEL primary care database [24]. Previous research also showed that children in childcare have a higher GP consultation rate compared to home-cared children, and are at higher risk for hospital referral $[8,16,25,26]$.

\section{DRIVERS AND STAKEHOLDERS IN FEVER MANAGEMENT}

Hence, GP consultation rates in children under 4 years old are high, while it often concerns self-limiting infections that do not require treatment. This introduction will continue with obtaining insight into which drivers and stakeholders influence parental fever management such as the decision to consult a GP. Especially since fever management is a multidimensional process involving multiple stakeholders. 


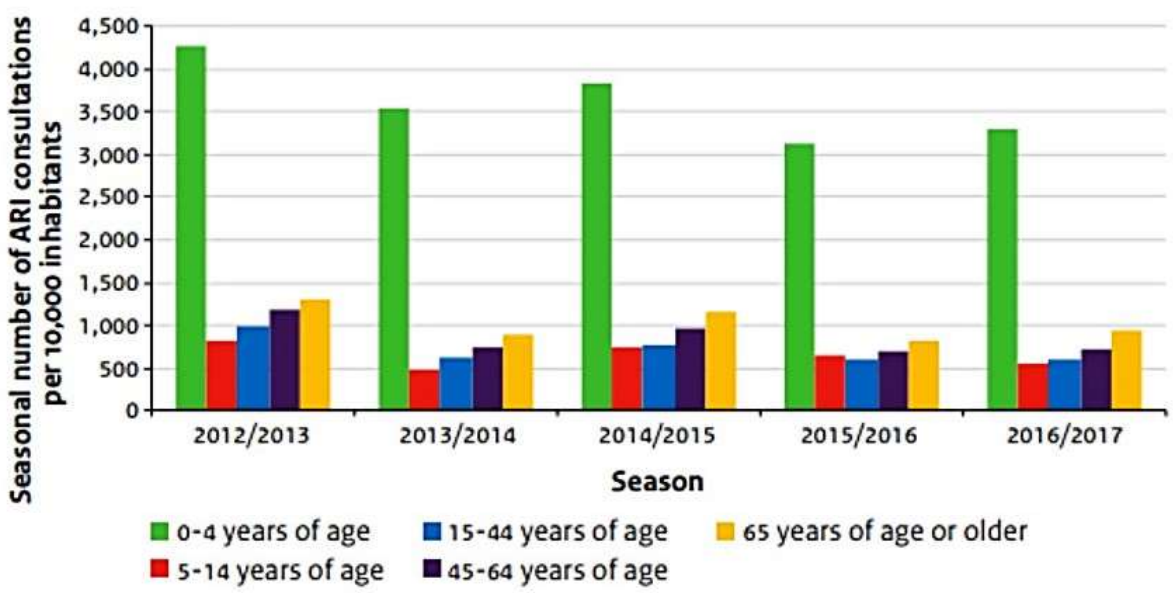

Figure 1 Seasonal cumulative number of patients consulting a GP for acute respiratory infections (ARI) in the respiratory seasons 2012/2013 through 2016/2017, per 10,000 inhabitants, per age category. Source: NIVEL primary care database [24].

\section{Parents}

From the perspective of parents, several drivers of consulting behaviour for childhood fever and common infections can be distinguished. First, an important driver of GP consultations is anxiety towards fever among parents [27, 28]. This anxiety emanates from unrealistic concerns and misconceptions towards fever and is also termed "Fever Phobia" [29, 30]. In line with the Health Belief Model (HBM), the likelihood of consulting a GP is influenced by parents' perception towards severity and threat of illness, the child's susceptibility to illness, benefits and costs of consulting [31]. The perceived threat of illness is affected by the child's current symptoms, how the symptoms affect the child's general appearance, and beliefs regarding harmful consequences. In turn, previous illness experiences, a lack of knowledge, prevailing lay beliefs regarding fever definition, pathophysiology, treatment, and harmful consequences play an important role in assessing severity of illness [27, 28, 32-34]. For example, parents are quickly worried when it comes to fever, as they believe that fever is a disease itself rather than an illness symptom. Besides, they fear that height of fever resembles the severity of underlying illness and that fever can lead to harmful consequences in the child such as brain damage or even death [32,34]. Subsequently, concerns are greater in less experienced parents and decrease with a next child [20,35]. Consequently, parents monitor the body temperature multiple times per day and try to lower the body temperature with paracetamol or sponging. Parents want to lower body temperature because they fear that the chance of febrile seizures increases together with the rise in body temperature or lead to other harmful consequences [36].

In terms of the HBM, consultation rates are influenced by parents' self-efficacy and perceived degree of personal control towards assessing illness' severity and illness management in relation to the perceived threat of illness. In other words, parental self- 
efficacy may decrease as perceived severity of illness increases because they feel uncertain in assessing illness severity and believe that a GP has to be consulted to identify any potential health threats [27, 28, 32]. A lack of both knowledge and previous experience may also lower self-efficacy among parents towards assessing illness severity and illness management $[28,37]$. As a result, parents consult the GP for reassurance, preferably through a physical examination and receiving information and advice on illness management. Next, parents consult the GP because they want their child to be treated to reduce the impact of illness on child and family, or due to perceived pressure by their social network such as family or childcare (CC) staff [23, 27, 28, 37-42]. An ill child not being able to attend childcare is another common reason for parents to consult a GP. In addition, parents showed to sometimes fear to lose their job due to their absenteeism from work due to their child's illness [43]. Next, most parents see childcare staff as an important source of information and want to maintain a good relationship with them. In turn, this may lead to experiencing pressure from CC staff to consult a doctor [39, 44]. However, one study showed that parental knowledge may be a more important predictor of healthcare service use than policies of childcare organisations [45].

\section{Childcare staff}

Previous research has shown that childcare (CC) staff may drive childcare absences, healthcare service use, and productivity loss among parents [28, 39, 44, 46, 47]. CC staff contribute to GP consultations and medication use due to prevailing (defensive) guidelines on illness management, but also as a result of having poor knowledge towards fever pathophysiology and treatment, content of the organisational guidelines on illness management, and the tendency to only permit childcare re-attendance when an antibiotic prescription or doctor's note is provided in some countries [15, 46-48]. As a result, CC staff may apply inappropriate decision-making strategies and trigger unnecessary childcare absences, healthcare service use, or antibiotic prescriptions for fever and respiratory symptoms [47, 49-52]. Vignette studies also show that childcare staff and parents seem to be worried when the child has a fever or rash and lead to more illness absenteeism and healthcare service among parents $[43,53]$.

Research also showed that organisational guidelines on illness management in childcare may vary between organisations and between countries in definition of fever and measuring methods $[46,51]$. Childcare staff tend to exclude children when fever is present, even when the body temperature is below $38^{\circ} \mathrm{C}[15,46,51,54]$. One study showed that childcare staff added $1^{\circ} \mathrm{C}\left( \pm 0.6^{\circ} \mathrm{C}\right)$ to the body temperature that was axillary or orally measured and before applying their exclusion criterion regarding body temperature [51].

\section{Healthcare professionals}

Healthcare professionals may also influence GP consultations for febrile children. For example, in the Netherlands, when parents decide to consult a GP, they first have a telephone contact with trained triage nurses in general practice, during regular hours or out-of-hours care. These nurses triage telephone calls of patients/parents to assign a degree of urgency to illness complaints and to decide if a GP should see the child, or if a telephone 
advice may be sufficient. Triage in general practice is based on the current guideline "Children with Fever" of the Dutch College of General Practitioners [NHG] [55]. A child's age affects triage decisions in GP out-of-hours care. Children $<18$ months are more likely to consult a GP with alarm symptoms such as drinking less or shortness of breath, while in children $\geq 18$ months old, duration of fever $\geq 3$ days, drowsiness, changes in skin colour are more important predictors of consultations. Despite age, parental concerns also increase the urgency for a GP consultation when a child does not show any alarm symptoms [56].

Almost three-quarter of telephone contacts in general practice for children are for children under 4 years old. Approximately one-third of these telephone contacts result in a telephone advice, while two-third is seen by a GP during regular hours [57]. In GP out-ofhours care, about $27 \%$ - $48 \%$ of telephone contacts result in a telephone advice, while 52 $73 \%$ leads to a face-to-face GP consultation [56-58]. In combination with a low incidence of severe infections, only $1 \%$ of young children are referred to the paediatrician or ear-nosethroat specialist for respiratory tract infections [59]. Previous research also showed that fever phobia not only exists in parents but also in healthcare professionals. In turn, since healthcare professionals are an important source of information to parents, they may increase parental worries and trigger avoidable healthcare service use. For example, healthcare professionals may increase worries by placing an emphasis on the body temperature, and by expressing their concerns about possible harmful consequences of fever [60-63]. GPs acknowledged regularly opting for a re-consultation or prescribing antibiotics to reduce anxiety in parents but also for themselves. They acknowledged doing this due to the low incidence of a severe infection but also due to clinical uncertainty towards identifying these severe infections [27]. Physicians may also feel pressured by parents to prescribe antibiotics or write a medical note to accelerate return to childcare [64].

Next to reasons why parents may consult a GP, parents may also perceive barriers to consult. Parents seem to be more cautious in deciding on when to consult than GPs expect $[28,32,33]$. Consultation rates for childhood fever and common infectious symptoms range between $11-56 \%$ in community settings [19, 20,65-67]. Thus, a large part of childhood infections is managed in the community. Parents do prefer to share responsibility with their healthcare professionals towards assessing their child's illness severity, but also may feel guilty that they are bothering the doctor unnecessarily [37].

\section{EXPLORING STARTING POINTS FOR IMPROVING FEVER MANAGEMENT}

In view of the above, parental fever management decisions such as consulting a GP are influenced by different drivers and stakeholders surrounding parents. Parents mainly consult the GP due to fever phobia, lack of knowledge, and a low self-efficacy in assessing illness severity and when to consult a doctor [27-30, 32-34, 37]. Subsequently, triage receptionists, healthcare professionals, family, and childcare staff drive GP consultations $[27,28,39,44,46,47,56-58,60-63]$. Parents but also childcare staff need support in fever management. However, parents are now often only educated on childhood fever when a 
child is ill, while it may be more beneficial to provide education prior to a child becoming ill, to better prepare parents for future illness episodes and reduce GP consultations $[35,68$, 69].

Educational interventions have the potential to improve knowledge, decrease misconceptions, improve management of febrile seizures, and reduce (intention to) physician consultations in parents in general practice or well-child clinics [70-72]. However, most interventions focus solely on improving knowledge to change fever management among parents while there is a need to develop more theory-based interventions to target other determinants of consulting behaviour [68]. In addition, despite the important role of childcare staff in illness management, existing interventions mainly focus on improving hygiene practices in childcare to reduce incidence of infections, illness absenteeism or antibiotic use, and not on supporting the decision-making process to reduce childcare absenteeism.

Research suggests that parents might be most responsive to information when provided in antenatal clinics, baby clinics, or toddler groups [34, 37]. In addition, providing an educational intervention to childcare staff may improve parental knowledge [73]. Education and advice should recognize and address parents' needs, skills, experience and commonly held beliefs about viruses, self-limiting illness, and antibiotics and their key concerns about fever, cough, and meningitis [32, 37]. It was also suggested to enhance sense of personal control to lower uncertainty and to modify perceptions on threat of illness in parents [27, 37]. In line with changing common beliefs, fever phobia may be more a cultural trait than individually learned [30]. Parents access several information sources for information and advice when their child is ill, ranging from their social network (family, well-child clinic professionals, childcare staff) to the Internet, books and leaflets [28, 35]. Parents seek for information to find out if their concerns regarding their child's current symptoms are in place and to identify if they need to consult a GP [28].

Future interventions should therefore focus on changing fever and illness management strategies to reduce the impact of a child's illness on their family and healthcare services use. Current education is mostly provided at the point of care and the potential of educating parents prior to future illness episodes needs exploration. To achieve this, it is important to obtain first insight in the views and experiences regarding decision-making on illness management among different stakeholders, such as well-child clinic professionals and childcare staff.

\section{A BRIEF OVERVIEW OF WELL-CHILD CLINICS AND CHILDCARE FACILITIES IN THE NETHERLANDS}

The organisation of well-child clinics and childcare facilities varies internationally and constitute the main setting of the studies in this dissertation. Therefore, this introduction will continue with a description of well-child clinics and childcare facilities in the Netherlands. 


\section{Well-child clinics (WCC)}

In the Netherlands, well-child clinics are part of the preventive youth healthcare services and focus on children under 4 years old. Main tasks of WCC are to monitor child's health status and development, screening for congenital disorders, providing vaccination jabs, coordinating healthcare, and provide anticipatory guidance to parents [74]. Children visit WCC on a regular basis. Approximately $98 \%$ of children under 4 years old attend the clinic check-ups in the Netherlands [75]. WCC vary internationally in terms of which healthcare professional is responsible for preventive check-ups and vaccinations jabs. For example, in the Netherlands we have specially trained youth doctors and youth nurses, whilst in other countries general practitioners, health visitors, or paediatricians provide this care [76-78].

\section{Childcare facilities and community}

The risk of acquiring fever and respiratory tract infections is highest in childcare facilities [7, 79]. To illustrate, children in large group childcare facilities ( $>6$ children per group) are 2.2 times more likely to acquire a upper respiratory tract infection, 1.6 times more like to obtain an ear infection, and 1.4 times more like to have a gastro-intestinal infection compared to home-cared children, or children in small group facilities $(<6$ children per group)[7]. Especially children younger than 2 years old are susceptible to acquire infections in childcare facilities compared to home-cared children [6]. Despite this, infection incidence was in some studies higher in small-scale childcare homes while absence due to illness was higher in larger childcare facilities, possibly due to differences in guidelines on illness management $[3,80,81]$.

In the Netherlands, the number of children attending childcare facilities has increased substantially in recent decades, as a result of more families with both parents working [8284]. Children aged under 4 years old can attend three types of childcare. Combinations are also possible [85]:

- by their parents or relatives in a home setting;

- by a guest parent/childminder, in a group of maximum six including the guest parent's own child;

- by specially trained staff in a commercial childcare facility, with a ratio of one childcare staff employee per three children (babies; 0 years old) or four children (1-4 years old).

Most children under 4 years old attend childcare facilities and this number increases over age [86] (see figure 2). Approximately $59 \%$ of children under 4 years old attend commercial childcare centres $[87,88]$. Childcare staff focus on nurturing and contributing to the development of children, until a child becomes four years old and goes to school [89].

Municipal public health services [gemeentelijke gezondheidsdienst, GGD] are responsible for quality surveillance and enforcement of childcare facilities and guest parents/childminders in the Netherlands. GGD assesses compliance to standards provided regarding hygiene practices and is an important source of advice to childcare staff. Childcare centres base their exclusion policies regarding ill children on national guidelines. Childcare 
centres are required to report specific contagious infectious diseases to GGD such as meningitis, hepatitis $A / B$, pertussis, gastro-intestinal infectious symptoms, chicken pox, skin infections with spots, pneumonia, or scabies $[89,90]$.

To conclude, educating parents before their child becomes ill may better prepare them for future illness episodes. Well-child clinic professionals and childcare staff seem to be two stakeholders who could provide this information since they both are an important source of information to parents.

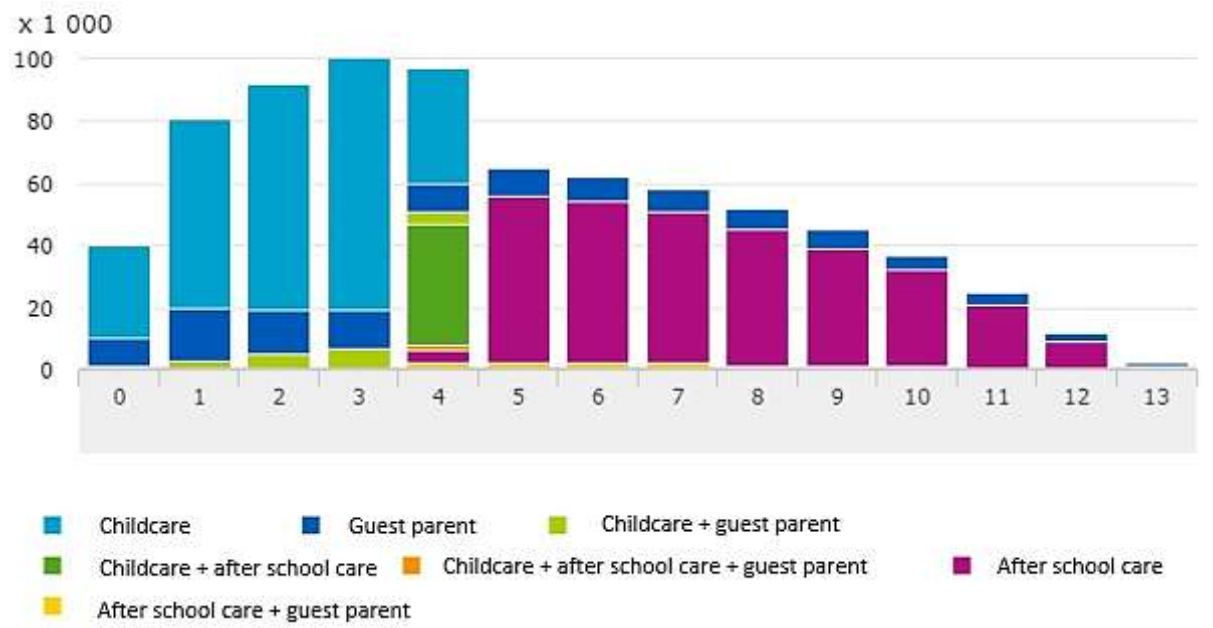

Figure $\mathbf{2}$ Children attending different types of childcare in the Netherlands, by type of care and age (reference year 2015; source [86]).

\section{OBJECTIVE OF THIS DISSERTATION}

This dissertation aims to explore the potential of improving childhood fever management in children under 4 years old in well-child clinics and childcare centres, and to evaluate the effectiveness of a newly developed multicomponent intervention targeting decision-making on childhood fever in childcare centres.

\section{CONTENT OF THIS DISSERTATION}

To achieve this, we first obtained insight in the experiences towards childhood fever management by means of qualitative studies in general practitioners, well-child care professionals (doctors and nurses), childcare staff, and a cross-sectional survey in parents (chapter 2-5). In addition, we systematically reviewed the literature into the effects of preventive information provision in well-child clinics on consultation rates and medication use (chapter 6). Based on these studies, we developed a multicomponent intervention targeting determinants of decision-making (knowledge, attitude, risk perception, selfefficacy, intended behaviour) on illness absenteeism due to childhood fever and common infections among childcare staff. The stepwise approach of Intervention Mapping guided the development process [91]. The study protocol (chapter 7) describes more in-depth the 
development process and how we evaluated the intervention. The multicomponent intervention was evaluated in a cluster randomised controlled trial.

\section{RESEARCH QUESTIONS}

1) What are the experiences and needs of general practitioners, well-child clinics professionals, childcare staff, and parents regarding childhood fever management?

2) What are the effects of implementing the multicomponent intervention on decision-making regarding illness absenteeism due to childhood fever and common infections, and its underlying determinants among childcare staff in childcare centres? 


\section{OUTLINE OF THIS DISSERTATION}

This dissertation provides an overview of the development process and evaluation of a multicomponent intervention targeting decision-making among childcare staff on illness absenteeism due to fever and common infections in children under 4 years old.

Chapter 2 describes a qualitative study exploring experiences of general practitioners $(\mathrm{N}=37)$ towards childhood fever management during GP-out-of-hours care by means of five focus group discussions.

Chapter 3 comprises a qualitative study exploring experiences of well-child clinic professionals $(\mathrm{N}=22)$ towards childhood fever management and their current practices regarding information provision to parents on fever, to identify starting point for future interventions, by means of four focus group discussions.

Chapter 4 reports on the impact of childhood fever and common infections on parents in terms of children's infectious illness incidence, healthcare service use, illness absenteeism, parental productivity losses, by means of a cross-sectional survey in 515 parents with children attending childcare centres.

Chapter 5 explores experiences, attitudes, and knowledge towards childhood fever management among childcare staff $(\mathrm{N}=20)$ by means of semi-structured interviews.

Chapter 6 describes a systematic review into the effects of providing information on childhood fever to parents prior to new illness episodes in well-child clinic settings, on parental practices such as consultation rates and medication use.

Chapter 7 provides the study protocol describing the development of the multicomponent intervention based on the results of chapter $2-6$, the intervention components, and the design of the cluster randomised controlled trial to evaluate the effects of this intervention on illness absenteeism, knowledge, attitude, risk perception, self-efficacy, and intended behaviour.

Chapter $\mathbf{8}$ comprises the evaluation of intervention effects on decision-making on illness absenteeism, knowledge, attitude, risk perception, self-efficacy, and intended behaviour.

Chapter 9 is the general discussion, including a summary of the main findings of chapter 28 , and answers the research questions posed in chapter 1. 


\section{DEFINITIONS OF TERMINOLOGY USED IN DISSERTATION}

\section{Well-child clinics/ WCC [consultatiebureau]}

Preventive youth healthcare in the Netherlands for children under 4 years old for regular check-ups and immunisation jabs.

\section{Childcare centers/centres}

In UK English is the preferred spelling "centre". "Center" is the preferred spelling in American English. We use both terms throughout this dissertation following language preferences of the journal.

We refer with "center/centre" to one unit within a larger childcare organisation where children are being brought to during regular working hours for care and supervision. One organisation may consist of several individual centres.

For example, MIK is a large commercial childcare organisation in the Southern part of Limburg, the Netherlands with 21 childcare centres. MIK provides care to children in the age 0 to 13 years old in different types of care, namely childcare centres [kinderdagverblijven, 0-4 years], preschool groups [peuterspeelzaal, 2-4 years], guest parents [gastouderopvang, $0-13$ years], and after-school care [BSO, 4-13 years]. In total, they provide care to 1389 children in childcare centres, 440 children attending preschool groups, and 4532 children attend after-school care (data retrieved from MIK registry; 14/04/2017).

\section{General practitioner/GP}

Primary care physician, family physician, general practitioner.

\section{GP out-of-hours services}

GP out-of-hours services are consulted outside of regular working hours and patients see a GP that is most often not their own. GPs have a gatekeeper role in the Netherlands

\section{ABBREVIATIONS IN DISSERTATION}

$\begin{array}{ll}\text { GP } & \text { General practitioner } \\ \text { FP } & \text { Family physician } \\ \text { CC } & \text { Childcare } \\ \text { MIK } & \text { Meerwaarde-In-Kinderleven } \\ \text { WCC } & \text { Well-child clinics } \\ \text { GGD } & \text { Gemeentelijke gezondheidsdienst [municipal preventive youth health } \\ & \text { services] } \\ \text { RCT } & \text { Randomised controlled trial }\end{array}$




\section{REFERENCES}

1. Glezen WP. Consideration of the Risk of Influenza in Children and Indications for Prophylaxis. Reviews of infectious diseases. 1980;2(3):408-20.

2. Low M, Almog R, Balicer RD, Liberman N, Raz R, Peretz A, et al. Infectious disease burden and antibiotic prescribing in primary care in Israel. Annals of Clinical Microbiology and Antimicrobials. 2018;17(1):26.

3. Cordell R, MacDonald J, Solomon SL, Jackson LA, Boase J. Illnesses and absence due to illness among children attending child care facilities in Seattle-King County, Washington. Pediatrics.1997;100(5): 850-5.

4. Brady MT. Infectious disease in pediatric out-of-home child care. American journal of infection control. 2005;33(5):276-85.

5. Nesti MM, Goldbaum M. Infectious diseases and daycare and preschool education. Jornal de Pediatria. 2007;83(4):299-312.

6. National Institute of Child Health and Human Development Early Child Care Research Network. Child care and common communicable illnesses: results from the National Institute of Child Health and Human Development Study of Early Child Care. Archives of pediatrics \& adolescent medicine. 2001;155(4):481-8.

7. National Institute of Child Health and Human Development Early Child Care Research Network. Child care and common communicable illnesses in children aged 37 to 54 months. Archives of pediatrics \& adolescent medicine. 2003;157(2):196-200.

8. de Hoog ML, Venekamp RP, van der Ent CK, Schilder A, Sanders EA, Damoiseaux RA, et al. Impact of early daycare on healthcare resource use related to upper respiratory tract infections during childhood: prospective WHISTLER cohort study. BMC medicine. 2014;12:107.

9. Lu N, Samuels ME, Shi L, Baker SL, Glover SH, Sanders JM. Child day care risks of common infectious diseases revisited. Child: care, health and development. 2004;30(4):361-8.

10. Ibfelt T, Engelund EH, Permin A, Madsen JS, Schultz AC, Andersen LP. Presence of pathogenic bacteria and viruses in the daycare environment. Journal of environmental health. 2015;78(3):24.

11. Roberts L, Smith W, Jorm L, Patel M, Douglas RM, McGilchrist C. Effect of infection control measures on the frequency of upper respiratory infection in child care: a randomized, controlled trial. Pediatrics. 2000;105(4 Pt 1):738-42.

12. Pönkä A, Nurmi T, Salminen E, Nykyri E. Infections and other illnesses of children in day-care centers in Helsinki. I: Incidences and effects of home and day-care center variables. Infection. 1991;19(4):230-6.

13. Zomer TP, Erasmus V, Looman CW, Tjon-A-Tsien A, Van Beeck EF, De Graaf JM, et al. A hand hygiene intervention to reduce infections in child daycare: a randomized controlled trial. Epidemiology \& Infection. 2015;143(12):2494-502.

14. Uhari M, Mottonen M. An open randomized controlled trial of infection prevention in child day-care centers. The Pediatric infectious disease journal. 1999;18(8):672-7.

15. Sticher B, Bielicki J, Berger C. Temporary exclusion of ill children from childcare centres in Switzerland: practice, problems and potential solutions. BMC Health Services Research. 2018;18:25

16. Bell DM, Gleiber DW, Mercer AA, Phifer R, Guinter RH, Cohen AJ, et al. Illness Associated with Child Day Care: A Study of Incidence and Cost. American Journal of Public Health. 1989;79(4):479-84.

17. Enserink R, Lugnér A, Suijkerbuijk A, Bruijning-Verhagen $P$, Smit HA, van Pelt W. Gastrointestinal and Respiratory Illness in Children That Do and Do Not Attend Child Day Care Centers: A Cost-of-Illness Study. PLOS ONE. 2014;9(8):e104940.

18. Yin JK, Salkeld G, Lambert SB, Dierig A, Heron L, Leask J, et al. Estimates and determinants of economic impacts from influenza-like illnesses caused by respiratory viruses in Australian children attending childcare: a cohort study. Influenza and Other Respiratory Viruses. 2013;7(6):1103-12.

19. Bruijnzeels M, Foets M, van der Wouden J, van den Heuvel W, Prins A. Everyday symptoms in childhood: occurrence and general practitioner consultation rates.British Journal of Genera Practice.1998;48(426):880-4. 
20. Hay A, Heron J, Ness A. The prevalence of symptoms and consultations in pre-school children in the Avon Longitudinal Study of Parents and Children (ALSPAC): a prospective cohort study. Family practice. 2005;22(4):367-74.

21. National Institute for Health and Care Excellence. Feverish illness in children: Assessment and initial management in children younger than 5 years. Manchester, United Kingdom; 2013. Report No.: CG160.

22. de Jong BM, van der Ent CK, van der Zalm MM, van Putte-Katier N, Verheij TJM, Kimpen JLL, et al. Respiratory symptoms in young infancy: child, parent and physician related determinants of drug prescription in primary care. Pharmacoepidemiology and Drug Safety. 2009;18(7):610-8.

23. de Bont EGPM, Francis NA, Dinant G-J, Cals JWL. Parents' knowledge, attitudes, and practice in childhood fever: an internet-based survey. British Journal of General Practice. 2014;64(618):e10-6.

24. Teirlinck A, Asten Lv, Brandsema P, Dijkstra F, Donker G, AB van Gageldonk-Lafeber, et al. Annual report Surveillance of influenza and other respiratory infections in the Netherlands: winter 2016/2017. Bilthoven, the Netherlands: RIVM [National Institute for Public Health and the Environment]; 2017. Report No.: RIVM 2017-0096.

25. Silverstein $M$, Sales $A E$, Koepsell TD. Health care utilization and expenditures associated with child care attendance: a nationally representative sample. Pediatrics. 2003;111(4 Pt 1):e371-5.

26. van de Pol AC, van der Gugten AC, van der Ent CK, Schilder AG, Benthem EM, Smit HA, et al. Referrals for recurrent respiratory tract infections including otitis media in young children. International journal of pediatric otorhinolaryngology. 2013;77(6):906-10.

27. Cabral C, Lucas PJ, Ingram J, Hay AD, Horwood J. "It's safer to ..." parent consulting and clinician antibiotic prescribing decisions for children with respiratory tract infections: An analysis across four qualitative studies. Social science \& medicine. 2015;136-137:156-64.

28. Ingram J, Cabral C, Hay AD, Lucas PJ, Horwood J. Parents' information needs, self-efficacy and influences on consulting for childhood respiratory tract infections: a qualitative study. BMC family practice. 2013;14:106.

29. Schmitt BD. Fever phobia: misconceptions of parents about fevers. American journal of diseases of children. 1980;134(2):176-81.

30. Pursell E \& Collin J. Fever Phobia: The impact of time and mortality-a systematic review and meta-analysis. International Journal of Nursing Studies. 2016;56:81-9.

31. Rosenstock IM. Why People Use Health Services. The Milbank Quarterly. 2005;83(4).

32. Kai J. What worries parents when their preschool children are acutely ill, and why: a qualitative study. BMJ,. 1996;313(7063):983-6.

33. Wyke S, Hewison J, Russell IT. Respiratory illness in children: what makes parents decide to consult? The British Journal of General Practice. 1990;40(335):226-9.

34. Crocetti M, Moghbeli N, Serwint J. Fever phobia revisited: have parental misconceptions about fever changed in 20 years? Pediatrics. 2001;107(6):1241-6.

35. Sahm L, Kelly M, McCarthy S, O'Sullivan R, Shiely F, Romsing J. Knowledge, attitudes and beliefs of parents regarding fever in children: a Danish interview study. Acta Paediatrica. 2016;105(1):69-73.

36. Edward P. Parental fever phobia and its evolutionary correlates. Journal of Clinical Nursing. 2009;18(2):2108.

37. Kai J. Parents' difficulties and information needs in coping with acute illness in preschool children: a qualitative study. BMJ,. 1996;313(7063):987-90.

38. Francis NA, Crocker JC, Gamper A, Brookes-Howell L, Powell C, Butler CC. Missed opportunities for earlier treatment? A qualitative interview study with parents of children admitted to hospital with serious respiratory tract infections. Archives of disease in childhood. 2011;96(2):154.

39. Ertmann RK, Soderstrom M, Reventlow S. Parents' motivation for seeing a physician. Scandinavian journal of primary health care. 2005;23(3):154-8.

40. Barden LS, Dowell SF, Schwartz B, Lackey C. Current attitudes regarding use of antimicrobial agents: results from physician's and parents' focus group discussions. Clinical pediatrics. 1998;37(11):665-71.

41. Maguire S, Ranmal R, Komulainen S, Pearse S, Maconochie I, Lakhanpaul M, et al. Which urgent care services do febrile children use and why? Archives of disease in childhood. 2011;96(9):810-6. 
42. Jones $\mathrm{CH}$, Neill S, Lakhanpaul M, Roland D, Singlehurst-Mooney H, Thompson M. Information needs of parents for acute childhood illness: determining 'what, how, where and when'of safety netting using a qualitative exploration with parents and clinicians. BMJ open. 2014;4:e003874.

43. Hashikawa AN, Brousseau DC, Singer DC, Gebremariam A, Davis MM. Emergency Department and Urgent Care for Children Excluded From Child Care. Pediatrics. 2014;134(1):e120-7.

44. Skull SA, Ford-Jones EL, Kulin NA, Einarson TR, Wang EE. Child care center staff contribute to physician visits and pressure for antibiotic prescription. Archives of pediatrics \& adolescent medicine. 2000;154(2):180-3.

45. Friedman JF, Lee GM, Kleinman KP, Finkelstein JA. Acute care and antibiotic seeking for upper respiratory tract infections for children in day care: parental knowledge and day care center policies. Archives of pediatrics \& adolescent medicine. 2003;157(4):369-74.

46. Shapiro ED, Kuritsky J, Potter J. Policies for the exclusion of ill children from group day care: an unresolved dilemma. Reviews of infectious diseases. 1986;8(4):622-5.

47. Rooshenas L, Wood F, Brookes-Howell L, Evans MR, Butler CC. The influence of children's day care on antibiotic seeking: a mixed methods study. British Journal of General Practice. 2014;64(622):e302-12.

48. Copeland KA, Duggan AK, Shope TR. Knowledge and beliefs about guidelines for exclusion of ill children from child care. Ambulatory pediatrics. 2005;5(6):365-71.

49. Kahan E, Gross S, Cohen HA. Exclusion of ill children from child-care centers in Israel. Patient education and counseling. 2005;56(1):93-7.

50. Hashikawa AN, Stevens MW, Juhn YJ, Nimmer M, Copeland K, Simpson P, et al. Self-Report of Child Care Directors Regarding Return-to-Care. Pediatrics. 2012;130(6):1046-52.

51. Pappas DE, Schwartz RH, Sheridan MJ, Hayden GF. Medical exclusion of sick children from child care centers: a plea for reconciliation. Southern medical journal. 2000;93(6):575-8.

52. Landis SE, Earp JA, Sharp M. Day-care center exclusion of sick children: comparison of opinions of day-care staff, working mothers, and pediatricians. Pediatrics. 1988;81(5):662-7.

53. Hashikawa AN, Juhn YJ, Nimmer M, Copeland K, Shun-Hwa L, Simpson P, et al. Unnecessary Child Care Exclusions in a State That Endorses National Exclusion Guidelines. Pediatrics. 2010;125(5):1003-9.

54. Juhn YJ, Sauver JS, Shapiro ED, McCarthy PL. How do child care center personnel define fever? Ambulatory Child Health. 2001;7(3-4):143-8.

55. Het Nederlands Huisartsen Genootschap [Dutch college of general practitioners]. Kinderen met koorts [Children with a fever], In: Berger MY BI, Eizenga WH, Elshout G, Gul N, Kool M, Oostenbrink R, Opstelten W, Oteman N., M292016.

56. Monteny M, Berger MY, van der Wouden JC, Broekman BJ, Koes BW. Triage of febrile children at a GP cooperative: determinants of a consultation. The British journal of general practice. 2008;58(549): 242-7.

57. Eizenga W, Hek, K., Nielen, M. et al. . Verschillen tussen praktijk en post bij kinderen met koorts [Differences between GP consultation during regular hours and at out-of-hours care]. Huisarts \& Wetenschap. 2016;59(493).

58. de Bont E, Lepot J, Hendrix D, Loonen N, Guldemond-Hecker Y, Dinant G, et al. Workload and management of childhood fever at general practice out-of-hours care: an observational cohort study. BMJ open. 2015;5(5):e007365.

59. Jansen AGSC, Sanders EAM, Schilder AGM, Hoes AW, de Jong VFGM, Hak E. Primary care management of respiratory tract infections in Dutch preschool children. Scandinavian Journal of Primary Health Care. 2006;24(4):231-6.

60. Karwowska A, Nijssen-Jordan C, Johnson D, Davies HD. Parental and health care provider understanding of childhood fever: a Canadian perspective. Canadian Journal of Emergency Medicine. 2002;4(6):394-400.

61. May A, Bauchner H. Fever Phobia: The Pediatrician's Contribution. Pediatrics. 1992;90(6):851-4.

62. Poirier MP, Davis PH, Gonzalez-del Rey JA, Monroe KW. Pediatric emergency department nurses' perspectives on fever in children. Pediatric emergency care. 2000;16(1):9-12.

63. Martins $M$, Abecasis $F$. Healthcare professionals approach paediatric fever in significantly different ways and fever phobia is not just limited to parents. Acta Paediatrica. 2016;105(7):829-33. 
64. Kahan E, Gross S, Horev Z, Grosman Z, Cohen HA. Pediatrician attitudes to exclusion of ill children from childcare centers in Israel: pressure on ambulatory practices. Patient education and counseling. 2006;60(2):16470 .

65. Uijen J, van Duijn H, Kuyvenhoven M, Schellevis F, van der Wouden J. Characteristics of children consulting for cough, sore throat, or earache. British Journal of General Practice. 2008;58(549):248-54.

66. Saunders N, Tennis O, Jacobson S, Gans M, Dick P. Parents' responses to symptoms of respiratory tract infection in their children. Canadian Medical Association Journal. 2003;168(1):25-30.

67. Mohinder S, Ware R, Sloots T, Nissen M, Grimwood K, Lambert S. The burden of community-managed acute respiratory infections in the first 2-years of life. Pediatric Pulmonology. 2016;51(12):1336-46.

68. Walsh A, Edwards H. Management of childhood fever by parents: literature review. Journal of advanced nursing. 2006;54(2):217-27.

69. O'Neill-Murphy K, Liebman M, Barnsteiner JH. Fever education: does it reduce parent fever anxiety? Pediatric emergency care. 2001;17(1):47-51.

70. Robinson JS, Schwartz ML, Magwene KS, Krengel SA, Tamburello D. The impact of fever health education on clinic utilization. American journal of diseases of children. 1989;143(6):698-704.

71. Francis NA, Butler CC, Hood K, Simpson S, Wood F, Nuttall J. Effect of using an interactive booklet about childhood respiratory tract infections in primary care consultations on reconsulting and antibiotic prescribing: a cluster randomised controlled trial. BMJ,. 2009;339:b2885.

72. Broome ME, Dokken DL, Broome CD, Woodring B, Stegelman MF. A study of parent/grandparent education for managing a febrile illness using the CALM approach. Journal of pediatric health care. 2003;17(4):176-83.

73. Croft DR, Knobloch MJ, Chyou PH, Ellen DV, Janette C, Davis JP, et al. Impact of a child care educational intervention on parent knowledge about appropriate antibiotic use. WMJ. 2007;106(2):78-84.

74. Besluit publieke gezondheid [Public Health Act], BWBR0024708 (2017).

75. Centraal Bureau Statistiek [Statistics Netherlands]. Ouders geven consultatiebureau gemiddeld een 7 [Parents give child health centres a 7 out of 10], Den Haag/Heerlen; 2014 30/10/2014.

76. Kuo AA, Inkelas M, Lotstein DS, Samson KM, Schor EL, Halfon N. Rethinking Well-Child Care in the United States: An International Comparison. Pediatrics. 2006;118(4):1692-702.

77. van Esso D, del Torso S, Hadjipanayis A, Biver A, Jaeger-Roman E, Wettergren B, et al. Paediatric primary care in Europe: variation between countries. Archives of disease in childhood. 2010;95(10):791-5.

78. Wieske RC, Nijnuis MG, Carmiggelt BC, Wagenaar-Fischer MM, Boere-Boonekamp MM. Preventive youth health care in 11 European countries: an exploratory analysis. International journal of public health. 2012;57(3):637-41.

79. Strangert K. Respiratory illness in preschool children with different forms of day care. Pediatrics. 1976;57(2):191-6.

80. Cordell RL, Waterman SH, Chang A, Saruwatari M, Brown M, Solomon SL. Provider-reported illness and absence due to illness among children attending child-care homes and centers in San Diego, Calif. Archives of pediatrics \& adolescent medicine. 1999;153(3):275-80.

81. Cordell RL, Thor PM, Addiss DG, Theurer J, Lichterman R, Ziliak SR, et al. Impact of a massive waterborne cryptosporidiosis outbreak on child care facilities in metropolitan Milwaukee, Wisconsin. Pediatr Infect Dis J. 1997;16(7):639-44.

82. Centraal Bureau Statistiek [Statistics Netherlands]. De arbeidsmarkt in cijfers 2016. Den Haag/Heerlen: Centraal Bureau Statistiek [Statistics Netherlands],; 2017.

83. Sociaal en Cultureel Planbureau [The Netherlands Institute for Social Research]. Landelijk ramingsmodel kinderopvang 2002-2010 [National estimation of childcare 2002-2010],. Sociaal en Cultureel Planbureau [The Netherlands Institute for Social Research],; 2003.

84. Centraal Bureau Statistiek [Statistics Netherlands]. Formele kinderopvang; kinderen, uren, soort opvang, vorm opvang, regio [Formal childcare; children, hours, type and extent of care, region]. Den Haag/Heerlen 2018 03/07/2018.

85. Ministerie Sociale Zaken en Werkgelegenheid [Ministry of Social Affairs and Employment]. Overzicht maatregelen Wet innovatie en kwaliteit kinderopvang, 2019 en 2023 [Overview measures Act innovation 
and quality childcare 2019 and 2023]. Den Haag: Ministerie Sociale Zaken en Werkgelegenheid [Ministry of Social Affairs and Employment]; 2018.

86. Centraal Bureau Statistiek [Statistics Netherlands]. Meer kinderen naar kinderopvang [More children attending childcare],. Den Haag/Heerlen; 2016 10/06/2016.

87. Centraal Bureau Statistiek [Statistics Netherlands]. Recordaantal kinderen met kinderopvangtoeslag [Record number of children with childcare allowance]. Den Haag/Heerlen; 2018.

88. Centraal Bureau Statistiek [Statistics Netherlands]. Jongeren ( 0 tot 25 jaar); geslacht, leeftijd, migratieachtergrond, regio's [young people (0 to 25 years); gender, age, migration background, regions], Den Haag/Heerlen; 2018 08/06/2018.

89. Wet Kinderopvang [Childcare Act], Stb. 2017/252 (2018).

90. RIVM [National Institute for Public Health and the Environment]. Informatie over ziektebeelden voor kinderdagverblijven, peuterspeelzalen en buitenschoolse opvang [Information about syndromes for child day care centers, preschools and school care]. Amsterdam 2016. p. 9-10.

91. Bartholomew Eldredge LK. Planning Health Promotion Programs : An Intervention Mapping Approach. San Francisco, CA: Jossey-Bass; 2016. 
Part 1: Needs assessment 


\section{Chapter 2}

Childhood fever: a qualitative study on GPs' experiences during out-of-hours care

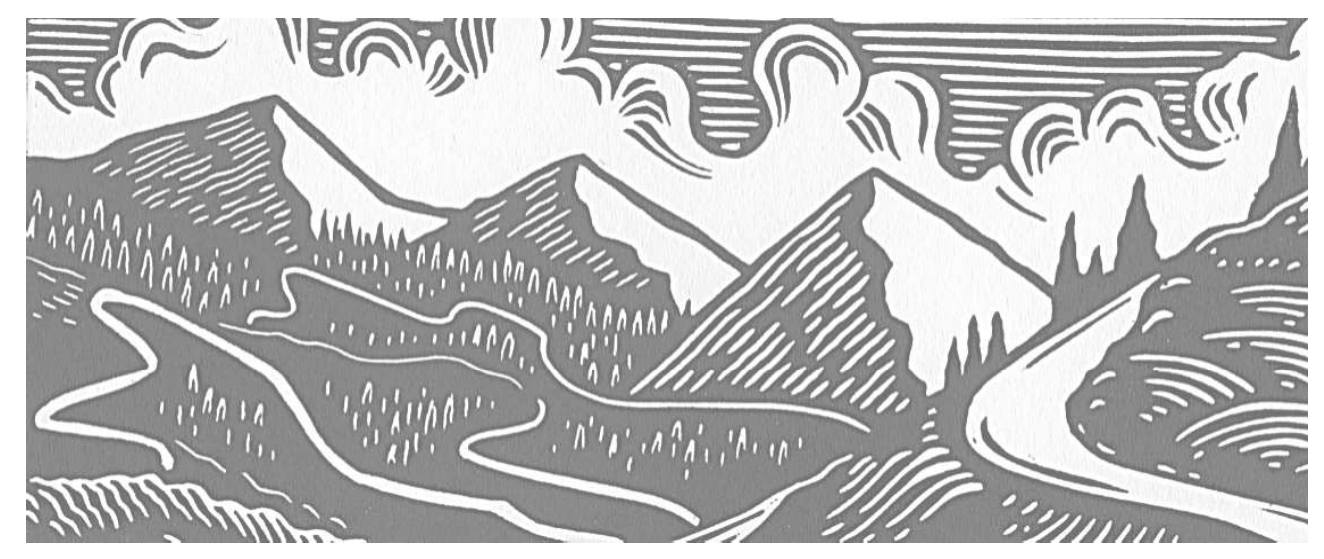

Eefje de Bont, Kirsten Peetoom, Albine Moser, Nick Francis, Geert-Jan Dinant, Jochen Cals. Childhood fever: a qualitative study on GPs' experiences during out-of-hours care.

Published in: Family Practice. 2015 Aug;32(4):449-5 


\section{ABSTRACT}

Background Fever in children is common and mostly caused by self-limiting infections. However, parents of febrile children often consult in general practice, in particular during out-of-hours care. To improve management, it is important to understand experiences of GPs managing these consultations.

Objective To describe GPs' experiences regarding management of childhood fever during out-of- hours care.

Methods A descriptive qualitative study using purposeful sampling, five focus group discussions were held among 37 GPs. Analysis was based on constant comparative technique using open and axial coding.

Results Main categories were: (i) Workload and general experience; (ii) GPs' perceptions of determinants of consulting behaviour; (iii) Parents' expectations from the GP's point of view; (iv) Antibiotic prescribing decisions; (v) Uncertainty of GPs versus uncertainty of parents and (vi) Information exchange during the consultation. GPs felt management of childhood fever imposes a considerable workload. They perceived a mismatch between parental concerns and their own impression of illness severity, which combined with timepressure can lead to frustration. Diagnostic uncertainty is driven by low incidences of serious infections and dealing with parental demand for antibiotics is still challenging.

Conclusion Children with a fever account for a high workload during out-of-hours GP care, which provides a diagnostic challenge due to the low incidence of serious illnesses and lacking long-term relationship. This can lead to frustration and drives antibiotics prescription rates. Improving information exchange during consultations and in the general public to young parents, could help provide a safety net thereby enhancing selfmanagement, reducing consultations and workload, and subsequent antibiotic prescriptions. 


\section{INTRODUCTION}

Febrile illnesses are the most common reason for a child to be taken to the doctor. Childhood infections in general practice represent $60 \%$ of all consultations for children under 1 year of age and $\sim 30 \%$ for children up to 15 years [1,2]. Most guidelines are conservative concerning the use of antibiotics in these self-limiting infections [3]. However, antibiotic prescription rates for febrile children in the out- of-hours setting are on average $30-40 \%$ [4], nearly twice as high as prescription rates during routine office hours [5].

Since the year 2000, GP out-of-hours services in the Netherlands are organized in largescale cooperatives [6]. These cooperatives cover the primary care by rotating shifts of GPs during evening, nights and weekends. More than $95 \%$ of GPs participate in a cooperative, which means that patients receive care from their own GP only in a few out-of-hours contacts. In most cases, they receive care by another GP who also participates in a cooperative [7]. Furthermore, Dutch GPs function as gatekeepers for secondary care. Only those children who need treatment from a paediatrician will be referred in case the GP decides this is medically indicated.

Alongside the high number of consultations, management of children with fever can be further complicated for GPs, because of (perceived) parental expectations and anxiety [8]. During out-of-hours care GPs typically have no knowledge of the child's medical history or background, further complicating these often time-pressured consultations. We believe GPs often feel pressured to prescribe antibiotics, whilst only a limited number of parents actually expect a prescription $[9,10]$. This could imply that GPs' assumptions are not always in line with the expectations of consulting parents. All these factors together drive unnecessary antibiotic prescribing and referrals and decrease (parental) self-management.

Though we know childhood fever accounts for many consultations in out-of-hours GP care, we know little about how GPs experience these consultations and what influences their management decisions $[1,2,11]$. Actual evidence on whether they believe that the amount of consultations for febrile children create a burden during out-of-hours care and their considerations how management could generally be improved is lacking.

In order to enhance appropriate antibiotic prescribing and management in febrile children during GP out-of-hours care, it is crucial to answer the question: how do GPs experience childhood fever-related consultations during out-of-hours care and how do they believe that these consultations can be improved?

This qualitative study aims to explore the experiences of GPs regarding childhood fever consultations during out-of-hours care, thereby eliciting barriers and facilitators of good quality care including appropriate antibiotic prescribing rates and enhanced parental selfmanagement. 


\section{METHODS}

We performed a descriptive qualitative study based on naturalistic inquiry [12]. GPs were questioned about their actual experiences with febrile children during out-of-hours care since this is the best approach to achieve a deeper understanding how these consultations take place in daily practice.

\section{Setting}

The study was carried out among GPs from three different GP cooperatives in the province of Limburg in the Netherlands. This region covers a multi-ethnic population of $\sim 607000$ inhabitants with a varying degree of socio-economic status [13].

\section{Participants}

We approached existing GP groups using email, by contacting larger practices with multiple GPs or GPs involved in pharmacotherapeutic audit meeting groups. Every group that was approached agreed to participate. We used purposive sampling based on different backgrounds of the GPs, variation in experiences, size of practice and level of deprivation of the community served. Thirty-seven GPs participated, of these 24 GPs were male, mean age of all the participants was 47 years (range: $27-64$ years) and the average years of clinical experience was 17 years (range: $0.5-30$ years; equal to experience with out-of-hours care). Included were GPs participating in shifts at a GP out-of-hours service.

\section{Ethical considerations}

All participants received written information and provided written informed consent. Data were used anonymously. The study was approved by the Medical Ethics committee of the Maastricht University Medical Centre (NL 13-4-060.4).

\section{Data collection}

Data were collected from July 2013 to September 2013. A focus group guide was prepared using sensitizing concepts [14]. Questions were derived from existing literature and a priori expert discussions. Questions were directed at the different aspects of a GP's consultation, influencing factors on their management decisions during out-of-hours care and influencing factors on parental consulting behaviour and expectations from the GPs' point of view before, during and after a consultation. We performed five focus group discussions (FGD) with five to nine GPs per group, facilitated by an experienced and independent moderator. The FGD lasted around 90 minutes and were conducted in GP practices. We achieved data saturation after four FGD and performed one more to ensure maximum variation in sampling and to validate the findings. All FGD were audio recorded and transcribed verbatim by E.B.

\section{Analysis}

Data were analysed using constant comparison technique; coding and analysing took place simultaneously [15]. Every interview was coded by two researchers independently (E.B., K.P.). Inductive analysis was used, by first using open schemes. After this, axial coding was applied to relate codes to each other and form categories and subcategories $[16,17]$. NVivo 
software version 9.0 was used for analysis. Inconsistencies about coding were discussed and resolved by consensus. The coding scheme was discussed and adjusted several times among the wider research team. The analysis resulted in six main categories.

\section{Trustworthiness}

Data triangulation was enhanced by including GPs from three different cooperatives and covering different socio-economic areas. Investigator triangulation was realised by involving researchers from different backgrounds providing different perspectives and peer debriefing by discussing findings among the wider research team. Furthermore, a member check of the written transcript was performed among all participating GPs. We provided detailed information about the methodology and background information of the GPs, to help others decide whether the results are transferable to their context.

\section{RESULTS}

We identified six main categories: (i) Workload and general experience; (ii) GPs' perceptions of determinants of consulting behaviour; (iii) Parents' expectations from the GP's point of view; (iv) Antibiotic prescribing decisions; (v) Uncertainty of GPs versus uncertainty of parents and (vi) Information exchange during the consultation.

\section{Workload and general experiences}

GPs perceived that children with fever impose a considerable workload during out-of-hours shifts, especially during seasonal incidence peaks of upper respiratory tract infections.

"Especially during winter months at the GP out-of-hours centre, sometimes you see five or six of them in a row." (GP26, FGD4)

GPs generally believed there is a mismatch between parental concerns, not related to symptoms or signs, and their own impression of illness severity during the consultation. The high workload during out-of-hours care in general and the number of children that are not seriously unwell leads to frustration for almost all GPs.

"Of course the point is, in a hundred thousand cases it is nothing. Just a child with a fever. I mean, when you're doing consultations on a Saturday and you've seen thirty children and not one of them was really sick, I'm just saying. (GP1) Then you're fed up for that weekend, yes." (GP3, FGD1)

Some GPs explained that this frustration partially depended on their feeling of unwarranted use of urgent care by parents. They believed that out-of-hours care should be used for urgent medical cases and that providing reassurance to parents of a febrile child should actually take place during regular office hours.

"I believe it's completely logical that parents can consult their own GP during regular office-hours because of a fever. But it is not a medical emergency. Because I believe that we should have the time to take care of the real emergencies during out-of-hours care.... So that we can use our resources as sparingly as possible." (GP16, FGD3) 


\section{GPs' perceptions of determinants of consulting behavior}

GPs perceived four key aspects affect consulting behaviour: parental worries, lack of knowledge, influence of child day care centres, and increasing demand for 24-hour availability of medical services. According to GPs, parental worries were the major driving factors behind consultations and these worries and concerns were largely influenced by the duration of symptoms and the degree of fever.

"...That contributes considerably to parental concerns. The height of a fever itself." (GP10, FGD2)

GPs experienced a general lack of knowledge of parents when to consult a GP. They expressed that the inability of parents to employ self-management strategies seemed to increase the number of consultations.

GPs explicitly stated that according to them the impact of child day care centres on consulting behaviour has increased over time. They experienced that defensive advice of day care centres when a child is ill drives just-in-case GP consultations, which means parents follow the advice of day-care centres to have a consultation.

"And in the first hours of the evening shift there are those children who get picked up at the day care centre. They [day care centre] advise them there to call a GP because the child has a fever." (GP16, FGD3)

Especially, senior GPs said they think this has been reinforced by the emergence of GP outof-hours cooperatives. When GPs managed their own patients' out-of-hours, GPs felt parents were more reluctant to disturb their own GP out-of-hours. While GPs acknowledged that many parents express a wish for 24-hour availability of medical services, many of them agreed that out-of-hours care should be used for emergencies only. GPs in all focus groups expressed a belief that the consultation behaviour exhibited by many parents, with frequent consultations for minor illnesses, represents a failure to take responsibility for their sick children and a 'passing off' of that responsibility to a GP. According to GPs, this might also be influenced by the fact they have seen a trend in which more parents are working during the daytime and expecting care in the out-of-hours setting.

"People just show up with a child that is playing in the waiting room. He has a fever, so doctor: examine him please. They don't take any responsibility anymore for their sick child." (GP3, FGD1)

GPs mentioned seeing parents expecting a 'routine' consultation in evenings because they believed the GP out-of-hours service is there to provide care when they demand. GPs generally felt that contextual factors like the age of the child and parity of the parents contributed to this behaviour. GPs explained that this overall feeling of increasing influence of day care centres and increasing demand for 24-hour availability of medical services attributes to their frustration. Mostly because in their eyes out-of-hours care should be used for urgent medical cases and most cases of childhood fever are not a medical emergency. 


\section{Parents' expectations from the GP's point of view}

GPs had firmly held beliefs about what parents expected from a consultation from their point of view. Firstly, GPs explicitly expressed that parents expect reassurance. However, they felt that the lack of a long-term doctor-patient relationship and prior knowledge about the patient can sometimes preclude their ability to adequately reassure parents.

"Sharing uncertainty...In my own practice I can tell a mother to come back tomorrow, today I'm confident it's okay. And she trusts me so she takes him home. But when I'm at the GP out- of-hours centre that relationship isn't built in fifteen minutes and I can't do that." (GP1, FGD1)

Secondly, and related to reassurance, the value of a proper physical examination was stressed by many GPs. Some GPs said that a full physical examination was not clinically necessary for some children, because they could tell whether a child was sick by observing general behaviour. However, especially during out-of-hours care, they per-formed physical examination regularly to reassure parents.

"However, I feel us GPs don't get away with it by saying, look I see your child running around here so I can reassure you he's doing okay. Just see your own GP tomorrow. (GP28) ... So an important part of reassuring is a physical examination? (Moderator) Yes, this is a ritual in some cases because you can tell you're not going to find anything important." (GP24, FGD4)

Thirdly, most GPs said they expect that parents consult them for antibiotics based on previous experiences. However, GPs' their perception was that expectations for antibiotics have decreased over time, especially due to media attention, campaigns in the general population, and information provided during GP consultations.

"I do believe the fact that the media is telling them antibiotics are not necessary is sinking in." (GP22, FGD3)

\section{Antibiotic prescribing decisions}

GPs mentioned that the decision to prescribe antibiotics depended on different factors of which most are similar to those during routine practice, namely duration of symptoms, what parents want, self- management by parents with little effects and what has already been done by other doctors.

"I believe duration is important, if he's still making a sick impression after four or five days and he does have red eardrums than I will prescribe antibiotics yes." (GP17, FGD3)

Some GPs believed that the perceived need to obtain antibiotics was closely related to satisfaction with the consultation. This in turn may lead them to prescribing antibiotics sooner because they want to avoid a discussion with parents during these time pressured consultations.

"It has to do with the time pressure you are under. If you hav the time to explain and parents feel you understand them then I won't have to prescribe antibiotics. But if you 
only have ten minutes for a consultation and there is a huge line of patients waiting... and I would rather wait but parents insist on getting antibiotics. Well then I'm not having a discussion. Then I'll provide them with an antibiotic prescription and get them out of the door satisfied." (GP1, FGD1)

Although they acknowledged that this may play a role during all general practice consultations, they believed it to play a bigger role during out-of-hours care because of a lacking long term relationship.

"At the cooperative I tend to give in to parental wishes for antibiotics sooner than in my own practice, because in my own practice I'm not afraid to take on a fight with parents." (GP30, FGD5)

GPs often felt pressured, particularly when symptoms have lasted longer and parents had lost their patience.

"Well, if a child is acting difficult and it has an ear infection together with a fever, I feel that some parents become pushy. They think they need an antibiotic prescription because they can't go on like this." (GP15, FGD3)

Despite that assumption, still not all GPs explicitly ask if a parent expects antibiotics. However, they perceived that this has improved over time.

"In the past I assumed that this [antibiotics] was what parents wanted. And I didn't ask them directly. And nowadays I do that more often and it turns out that they do not expect antibiotics." (GP2, FGD1)

Many GPs mentioned being used as a second opinion or last resort by parents especially in situations when parents had previous negative experiences.

"It has more to do with the fact they experienced this sort of situation before when they had to come back several times. It was in fact a pneumonia... and this time they want to prevent this from happening again. Therefore, they have a different perspective." (GP9, FGD2)

Although participating GPs said they were reluctant in prescribing antibiotics themselves, it was generally agreed that antibiotics were too often inappropriately prescribed at the outof-hours services. In general, antibiotic prescribing decisions were not straightforward during out-of-hours care.

\section{Uncertainty of GPs versus uncertainty of parents}

GPs perceived that factors that make them (diagnostically) uncertain were different from factors that drive uncertainty and worries among parents. An important factor driving uncertainty for them as GPs was the low incidence of serious bacterial illnesses combined with a high workload. To illustrate this problem, GPs compared diagnosing complicated infections as searching for a needle in a haystack. They experienced that (diagnostic) uncertainty leads to extra careful management decisions and in turn to more antibiotic prescriptions. 
"I'd rather give some children antibiotics too soon, than missing one." (GP3, FGD1)

Additionally, this was further complicated by the fact that assessment and treatment was more difficult in children of whom they had no prior knowledge or relationship.

"In your own practice you can take a medical history without actually seeing the child, and then sometimes considering the illness course and knowing the family I tell them to be patient for some time." (GP9, FGD2)

GPs mentioned that fever without a focus did not directly worry them as long as the child was generally well. On the contrary, a sick child with a fever without a focus did create uncertainty and concerns among both GPs and parents because this implicated a child might need treatment or additional diagnostic testing. Hence, the general appearance of the child is an important diagnostic tool for GPs, and finding a focus was considered vital when the child is generally unwell. According to the GPs, parents use different judgement criteria. They often found the fever in itself worrying and especially the height of a fever.

"You know what I think causes this discrepancy? Parents make their assessment based on the temperature and we make our assessment based on the child's appearance." (GP1, FGD1)

In addition, GPs discussed that providing an accurate diagnosis is much more challenging when a specific focus for the fever is missing, as parents will often want to know what the cause of the fever is.

\section{Information exchange during the consultation}

Generally, GPs said that they provided information on the cause of fever to parents, the expected duration of symptoms and self-management strategies such as use of paracetamol. They mainly provide verbal information, and in some cases also written information. Reasons to provide parents with written information were mainly situations when GPs were uncertain whether parents understood what was explained. Few, mainly younger GPs, directed parents to reliable internet websites for information about childhood fever. GPs did perceive that it is more difficult to provide information during out-of- hours care, especially because they see parents for the first time.

"I also think that when parents previously had positive experiences with you [as their own GP], reassurance is probably more effective." (GP9, FGD2)

This was further complicated by the fact that consultations during out-of-hours care were often time pressured.

"Well in that case [when you would explain everything to parents] my consultations would take even longer. You don't have the time to explain everything. You make a selection of what is most necessary, and I believe that is even more important during out-of-hours care.... Because you are dealing with time pressure and you think well this is an evening or weekend shift so that is what it's about... you should provide information to parents to make it through that period." (GP4, FGD1) 
In addition to time pressure and a lacking long-term relationship, they believed it was harder to provide parents with reassurance when they couldn't provide them with information on the cause of the fever. While some GPs explained that in those cases they just tell parents it's a viral infection, there were also GPs who acknowledged that in some cases this resulted in them prescribing antibiotics, where in their own practice they probably could have reassured parents without knowing the cause of the fever.

"In those cases you see that parents find it more difficult to believe you, than when you have a real diagnosis." (GP13, FGD3)

Most GPs expressed that information exchange within these consultations needs improvement and that this would improve the management of childhood fever. However, because of a lacking long term, trusting relationship and time pressure, they acknowledged that this would be challenging. Therefore, nearly all GPs thought it was even more important to increase parents' general knowledge about fever management in children prior to their children getting sick, and they also stressed a role for the well-baby and maternity centres in this respect.

"I believe they should provide courses at the well-baby centres on what to do when your child is sick." (GP24, FGD4)

\section{DISCUSSION}

\section{Summary of main results}

GPs reported that childhood fever contributes a significant burden to their workload when providing out-of-hours care. Compared to routine daytime work, GPs feel they see more febrile children and experience more diagnostic uncertainty and that parents are more worried, expect antibiotics sooner and are not as easy to reassure in the out-of-hours setting. This, in combination with time pressured consultations and the feeling that out-ofhours care should only be used for medical emergencies can lead to frustration in GPs. GPs perceived that parental expectations for antibiotics have decreased over time, and that this is largely due to media campaigns and information provided by doctors. However, they feel overprescribing is still an important problem in these consultations. Lack of a long-term relationship and prior knowledge about the patient are important factors that make these consultations and resulting management decisions challenging. They believe this could be enhanced by improving information exchange at the point of care as well as providing young parents with information before their children get sick.

\section{Comparison with existing literature}

Fever phobia and worries of parents have been described for many years [8] and parents consider a physical examination as the most important aspect of a GPs' consultation [10]. GPs perform a physical examination, even though they regard it as providing limited additional information to the medical history and general impression of the child. GPs explained they felt frustrated by a high workload during out-of-hours care because of the fact that only few children were actually sick in their eyes and they felt that parents ought 
to visit their own GP during office hours. In other words, most GPs felt a consultation for a febrile child during out-of-hours care could be classified as unnecessary in their eyes. A previous systematic review and meta-ethnography showed that clinicians may interpret parents' efforts to establish the need for a consultation as an indicator of expecting antibiotics and parents may hear clinicians' normalising, most likely meant to be reassuring, statements as questioning the need for a consultation. This might lead to both parties feeling challenged and higher antibiotic prescription rates by GPs as a result, while in fact parents only expect reassurance from a consultation [18]. Nevertheless, there were also GPs in our study that acknowledged that parents expect reassurance and not antibiotics. However, they believed that this reassurance should take place during regular office hours by parents their own GP.

This is also a possible explanation why GPs felt that increasing influence of day care centres and the wish for a 24-hour society leads to frustration. GP cooperatives were founded to reduce the workload during out-of-hours care. Generally, by dividing shifts across 50-200 GPs, the workload has been successful reduced [7]. However, the workload coming from consultations for childhood fever specifically might have increased over time because of these stimulating factors.

Previous research has shown that incidence of, and consulting rates for febrile illness in children are high, especially in an out-of- hours setting $[1,2,11]$. However, it is also known that the rate of serious bacterial infections is very low, around 1\% [19]. Dealing with lowincidence illnesses is challenging for GPs [20]. This study confirms that this discrepancy of seeing a lot of children with a fever but only few of them actually being sick in the GPs eyes indeed proposes a diagnostic challenge. This is complicated further by a lacking long-term parental-GP relationship. This concept of trust was also found to be an important determinant of acceptance of management by parents in a previous study on antibiotics for children with respiratory tract infections [21]. We examined what this means for their management decisions, especially in terms of antibiotics. GPs felt that the high workload complicates their management because of the diagnostic challenge it provides. This concept of finding a needle in a haystack led to a feeling of being careful not to miss anything and providing a proper physical examination. Although participating GPs in this study declared that they prescribe few antibiotics, hypothetically this feeling of being extra careful could also lead to more careful management decisions and drive antibiotic prescription rates.

Interestingly, GPs in the current study state that they infrequently prescribe antibiotics and that the number of parents expecting a prescription decreased over time. On contrary, around one in three consultations for febrile children results in an antibiotic prescription [4]. This suggests that there is a discrepancy between the GPs' perception on their prescribing behaviour and their actual prescribing behaviour. An explanation could be that the GPs participating in this study are more motivated or aware of overprescribing. This could also explain why they feel that they have a lot of colleagues who are still overprescribing. However, it is also possible that they gave socially acceptable answers or are unaware of the fact that they themselves are still overprescribing. 


\section{Strengths and limitations}

This is one of the first qualitative studies that focus on workload and management of febrile children in the GP out-of-hours setting. The strength of this qualitative design is that is gives an in-depth insight into experiences of GPs when working in out-of-hours settings. Childhood fever management is complex and the choice of a qualitative design made it possible to research this complexity. Previous studies on this topic were a structured quantitative study or studies in a different setting like an emergency department where the rate of serious infections is considerably higher $[22,23]$. This study tells us something on the factors that play a role in the management decisions of these GPs when they prescribe antibiotics to children during out-of-hours care.

There were no GPs who refused to participate in our focus group discussions. We aimed to reduce the influence of the researchers' point of views and opinions by using an independent moderator asking open-ended questions. However, we cannot exclude that socially acceptable answers were given. Our heterogeneous sample improves transferability of the results. However, health care systems and perception of illness are culturally different. Despite of this, we believe that we provided enough background information to let others decide whether the results are transferable to their context. In addition, the lacking long-term relationship Dutch GPs face during out-of-hours care is something that might also play a role in countries with different out-of-hours organizational models. For example, GPs working at a NHS service during out-of-hours in the United Kingdom generally also don't have a prior relationship with a patient $[6,7]$.

\section{Implications for research and practice}

GPs feel they see many children because of a fever during out-of- hours care. It seems that few children are actually sick enough to need treatment, which leads to frustration. It also increases diagnostic uncertainty in the out-of-hours setting where patients and GPs do not know each other. Future research should further investigate parental experiences and explore cultural and national differences. In addition, it should focus on improving information on childhood fever provided in the consulting room and to the general public, especially amongst young parents. A recent study showed that parents of a febrile child might in fact have a stronger need for advice on symptomatic relief, or when they should re-consult than GPs realise [24]. We have previously shown that an information exchange tool is effective in reducing the number of antibiotic prescriptions and intention to reconsult in children with upper respiratory tract infections [25] and that such a tool can increase parental and clinician confidence in managing these illnesses [26]. We believe that this strategy could also be used in children presenting with a fever. However, this might be challenging during out- of-hours care where there is no pre-existing relationship between GPs and parents and where time is limited. Future studies should therefore also focus on providing parental education on fever and self-management to young parents in the general public. 


\section{CONCLUSION}

GPs perceived that children with a fever account for a high workload in out-of-hours GP care which can lead to frustration and provides a diagnostic challenge due to the low incidence of serious illnesses and lacking long-term relationship. These factors play an important role in the management decisions of GPs when they prescribe antibiotics to children during out-of-hours care. Improving information exchange during consultations but also in the general public, especially to young parents, could help provide a safety net and in that way enhance self-management, reduce consultation rates, thereby reducing the workload, frustration and diagnostic challenge. Leading to fewer antibiotic prescriptions. 


\section{REFERENCES}

1. National Institute of Clinical Excellence. NICE Guideline: Feverish Illness in Children. London: National Institute of Clinical Excellence; 2013.

2. Fleming DM, Smith GE, Charlton JR, Charlton J, Nicoll A. Impact of infections on primary care-greater than expected. Commun Dis Public Health 2002; 5: 7-12.

3. Berger RM, Berger MY, van Steensel-Moll HA, Dzoljic-Danilovic G, Derksen-Lubsen G. A predictive model to estimate the risk of serious bacterial infections in febrile infants. Eur J Pediatr 1996; 155: 468-73.

4. Elshout G, Kool M, Van der Wouden JC, Moll HA, Koes BW, Berger MY. Antibiotic prescription in febrile children: a cohort study during out-of- hours primary care. J Am Board Fam Med 2012; 25: 810-8.

5. Otters HB, van der Wouden JC, Schellevis FG, van Suijlekom-Smit LW, Koes BW. Trends in prescribing antibiotics for children in Dutch general practice. J Antimicrob Chemother 2004; 53: 361-6.

6. Huibers L, Giesen P, Wensing M, Grol R. Out-of-hours care in western countries: assessment of different organizational models. BMC Health Serv Res 2009; 9: 105.

7. Giesen P, Smits M, Huibers L, Grol R, Wensing M. Quality of after-hours primary care in the Netherlands: a narrative review. Ann Intern Med2011; 155: 108-13.

8. Crocetti M, Moghbeli N, Serwint J. Fever phobia revisited: have parental misconceptions about fever changed in 20 years? Pediatrics 2001; 107: 1241-6.

9. Kallestrup P, Bro F. Parents' beliefs and expectations when presenting with a febrile child at an out-of-hours general practice clinic. Br J Gen Pract 2003; 53: 43-44.

10. de Bont EG, Francis NA, Dinant GJ, Cals JW. Parents' knowledge, attitudes, and practice in childhood fever: an internet-based survey. Br J Gen Pract 2014; 64:e10-6.

11. Hay $A D$, Heron J, Ness $A$. The prevalence of symptoms and consultations in pre-school children in the Avon Longitudinal Study of Parents and Chil- dren (ALSPAC): a prospective cohort study. Fam Pract 2005; 22: 36774.

12. Lincoln Y, Guba G. Naturalistic Inquiry. Beverly Hills, CA: SAGE Publications; 1985.

13. Central Bureau of Statistics. Population of Southern Limburg. http://statline.cbs.nl/StatWeb/publication /?DM=SLNL\&PA=37259NED\&D1=0\&D2=0\&D3=55\&D4=51-52\&HDR=T\&STB=G2,G1,G3\&VW=T (accessed on 20 April 2014).

14. Bowen GA. Grounded theory and sensitizing concepts. Int J Qual Methods 2006; 5: 12-23.

15. Pope C, Ziebland S, Mays N. Qualitative research in health care. Analysing qualitative data. BMJ 2000; 320: 114-6.

16. Corbin J, Strauss A. Basics of Qualitative Research. London: SAGE Publications; 2008.

17. Charmaz K. Constructing Grounded Theory. London: SAGE Publications; 2006.

18. Cabral C, Horwood J, Hay AD, Lucas PJ. How communication affects prescription decisions in consultations for acute illness in children: a systematic review and meta-ethnography. BMC Fam Pract 2014; 15: 63.

19. Van den Bruel A, Bartholomeeusen S, Aertgeerts B, Truyers C, Buntinx F. Serious infections in children:an incidence study in family practice. BMC Fam Pract

20. $2006 ; 7: 23$

21. Buntinx F, Mant D, Van den Bruel A, Donner-Banzhof N, Dinant GJ. Dealing with low-incidence serious diseases in general practice. BrJ Gen Pract 2011; 61:43-6.

22. Brookes-Howell L, Wood F, Verheij $T$ et al. Trust, openness and continuity of care influence acceptance of antibiotics for children with respiratory tract infections: a four country qualitative study. Fam Pract 2014; 31: 102-10.

23. Sarrell M, Cohen HA, Kahan E. Physicians', nurses', and parents' attitudes to and knowledge about fever in early childhood. Patient Educ Couns 2002; 46: 61-5.

24. Poirier MP, Collins EP, McGuire E. Fever phobia: a survey of caregivers of children seen in a pediatric emergency department. Clin Pediatr (Phila) 2010; 49: 530-4. 
25. Cabral C, Ingram J, Hay AD, Horwood J; TARGET team. "They just say everything's a virus"-parent's judgment of the credibility of clinician communication in primary care consultations for respiratory tract infections in children: a qualitative study. Patient Educ Couns 2014; 95: 248-53.

26. Francis NA, Butler CC, Hood K, Simpson S, Wood F, Nuttall J. Effect of using an interactive booklet about childhood respiratory tract infections in primary care consultations on reconsulting and antibiotic prescribing: a cluster randomised controlled trial. BMJ 2009; 339: b2885.

27. Francis NA, Phillips R, Wood F, Hood K, Simpson S, Butler CC. Parents' and clinicians' views of an interactive booklet about respiratory tract infections in children: a qualitative process evaluation of the EQUIP randomised controlled trial. BMC Fam Pract 2013; 14: 182. 


\section{Chapter 3}

Childhood fever in well-child clinics:

a focus group study

among doctors and nurses

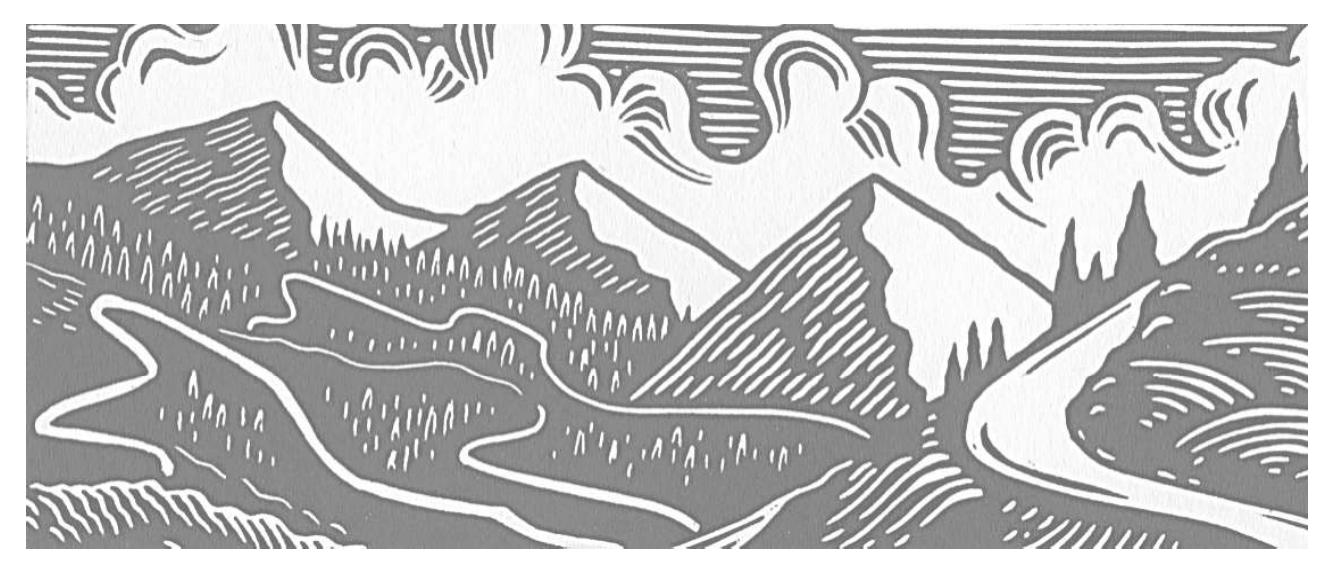

Kirsten Peetoom, Luc Ploum, Jacqueline Smits, Nicky Halbach, Geert-Jan Dinant, Jochen Cals. Childhood fever in well-child clinics: a focus group study among doctors and nurses.

Published in: BMC Health Services Research. 2016 Jul 8;16:240 


\section{ABSTRACT}

Background Fever is common in children aged 0-4 years old and often leads to parental worries and in turn, high use of healthcare services. Educating parents may have beneficial effects on their sense of coping and fever management. Most parents receive information when their child is ill but it might be more desirable to educate parents in the setting of well-child clinics prior to their child becoming ill, in order to prepare parents for future illness management. This study aims to explore experiences of well-child clinic professionals when dealing with childhood fever and current practices of fever information provision to identify starting points for future interventions.

Methods We held four focus group discussions based on naturalistic enquiry among 22 wellchild clinic professionals. Data was analysed using the constant comparative technique.

Results Well-child clinic professionals regularly received questions from parents about childhood fever and felt that parental worries were the major driving factor behind these contacts. These worries were assumed to be driven by: (1) lack of knowledge (2) experiences with fever (3) educational level and size social network (4) inconsistencies in paracetamol administration advice among healthcare professionals. Well-child clinic professionals perceive current information provision as limited and stated a need for improvement. For example, information should be consistent, easy to find and understand.

Conclusion Fever-related questions are common in well-child care and professionals perceive that most of the workload is driven by parental worries. The focus group discussions revealed a desire to optimise the current limited information provision for childhood fever. Future interventions aimed at improving information provision for fever in well-child clinics should consider parental level of knowledge, experience, educational level and social network and inconsistencies among healthcare providers. Future fever information provision should focus on improving fever management and practical skills. 


\section{INTRODUCTION}

Fever is common in children aged 0 to 4 years [1-3]. Parents' misconceptions and unrealistic concerns make them easily worried when their child has a fever [4, 5]. They worry that fever might result in serious harm such as febrile seizures, brain damage or other adverse consequences [4, 6-9]. Subsequently, these worries drive healthcare-seeking behaviour. Schmitt introduced the term "fever phobia" in 1980 to describe these unrealistic fears in parents [5]. Since then, multiple studies have shown that fever phobia is still present [4, 914]. Important drivers of fever phobia and consultations to the general practitioner (GP) are a lack of parental knowledge on coping with fever but also parents' perceived sense of control in the face of the perceived threat of an illness $[5,9,15,16]$.

Qualitative research in primary care has shown that there is a need to educate parents about fever and to influence parental perceptions of the threat posed fever. Educating parents may enhance their self-management and sense of control, reduce healthcareseeking behaviour and lower antibiotic prescriptions $[9,16,17]$. Most parents receive information at the time their child is ill but it might be more desirable to educate parents prior to their child becoming ill, in order to prepare parents for future illness management. The setting of well-child clinics (WCC) might be a good place to achieve this [12, 16-18].

WCC professionals encounter young children regularly for check-ups and information provision is an important pillar of well-child consultations $[18,19]$. In the Netherlands approximately $95 \%$ of children aged 0 to 4 visit the WCC for regular check-ups [20]. Parents tend to rely on WCC nurses for fever management advice and whether they should consult the GP or go to the hospital [21]. To illustrate, about one-third of 80,000 referrals to the GP by WCC professionals is for childhood infections [22]. Earlier studies have demonstrated that educating parents about childhood fever in the WCC setting may improve parental knowledge, attitude and use of healthcare services [23-32]. There are as yet no studies providing insight into the experiences and needs of WCC professionals in childhood fever consultations and WCC professionals' current information provision practices.

The purpose of this study was to explore well-child care professionals' experiences with childhood fever and current information provision practices when communicating with parents about fever management. By doing so, we hope to uncover barriers to and facilitators of information provision before a child's new fever episode.

\section{METHODS}

This descriptive qualitative study was based on naturalistic inquiry. Naturalistic inquiry studies real-world phenomena in natural settings and aims to inductively construct theories by means of a continuous interplay between data collection and analysis. Naturalistic inquiry includes special criteria for trustworthiness [33]. 


\section{Study setting}

Dutch youth healthcare focuses on providing preventive care services to children aged 0 to 19 years old. Children are seen for regular check-ups and vaccination jabs by specially trained doctors and nurses. WCC professionals concentrate on children aged 0 to 4 years old and see the children about 12 times. WCC professionals monitor the child's health status and development, screen for congenital disorders, provide vaccination jabs, provide parents with information and counselling and coordinate healthcare needs. In the Netherlands approximately $95 \%$ of the children aged 0 to 4 years old visit the WCC for regular check-ups [20]. Children are seen more frequently when there is need for extra care.

\section{Participants}

We selected WCC professionals providing care to children aged 0 to 4 years in the Maastricht region of the Netherlands. By doing so, we covered neighbourhoods with varying socioeconomic statuses and educational levels. A staff physician of the WCC organization emailed all 30 WCC doctors and nurses to inform them about the study and invite them to participate. Both doctors and nurses were purposefully sampled to participate in focus group discussions. We aimed to mix doctors and nurses as they work in teams at the WCC and we wanted to facilitate and foster discussion among participants by including different viewpoints and experiences. We aimed to include 4-6 participants per focus group.

\section{Data collection}

Focus groups (FG) were organised in November 2014 in Maastricht. The meetings lasted for $60 \mathrm{~min}$ each. The topic list was based on sensitizing concepts derived from scientific literature and expert discussions [34]. The topic list incorporated two main themes: (1) current experiences with childhood fever information provision to parents, and (2) exploration of starting points to improve future fever information provision (see Additional file 1). An independent and experienced moderator with a background as medical doctor led the focus group discussions. The moderator was accompanied by two observers (JS, LP) who are also MD, and the main researcher (KP) with a background in health sciences. The observers and main researcher made field notes during data collection. The focus group discussions were audio recorded and recorded on camera. We reached data saturation after three focus group discussions and performed one additional focus group to confirm the findings. JS and LP transcribed the focus group discussions verbatim and double-checked the transcripts.

\section{Data analysis}

Data collection and analysis was performed simultaneously according to constant comparative technique [35]. Categories emerged inductively from the focus group data by performing open and axial coding, and deductively through constant comparison. The topic list was discussed and adjusted among the wider research team after every focus group discussion. The data was coded by three researchers (JS, LP, KP) with NVivo version 9. We discussed the codes, main categories and subcategories extensively in the research team and inconsistencies were resolved by consensus. 


\section{Trustworthiness of data}

To achieve methodological triangulation we combined focus group discussions and field notes. Next, to accomplish data source triangulation we incorporated experiences of WCC professionals who worked at different WCC locations within different neighbourhoods with a variety of socioeconomic statuses and educational levels. Furthermore, we assembled doctors and nurses together in focus group discussions to foster discussion from different professional viewpoints. Investigator triangulation was accomplished by incorporating researchers from different backgrounds in the research team, i.e. a health scientist, two medical doctors and a general practitioner. These were all actively involved in all stages of the research process. Peer debriefing meetings were held regularly among the research team. We performed a member check of the transcript among all participants $[36,37]$.

\section{RESULTS}

\section{Sample characteristics}

A total of 22 well-child clinic professionals (seven doctors, 15 nurses) participated in four focus group discussions. The average age of participants was 45 years old and 21 were female. Average work experience at the WCC was 16.4 years, ranging from 0 to 36 years.

\section{Main category and subcategories}

The coding process yielded one main category and four subcategories. Parental worries about childhood fever emerged as the main category from the data and was seen as the major driving factor behind most fever-related contacts with the WCC. We identified 4 subcategories which are all closely related to and possible drivers of parental worries: (1) level of knowledge of parents, (2) level of experience of parents, (3) influence of educational level and social network of parents and, (4) perceived degree of inconsistency in received advice. Together with the participants we explored starting points to improve current fever information provision.

\section{Parental worries}

According to WCC professionals parents regularly contact them because they are worried about their child's fever. These questions mostly focus on the degree of fever, cause and possible consequences of fever and their uncertainty regarding self-management strategies.

"In particular when the temperature keeps on rising and reaches $40.2{ }^{\circ} \mathrm{C}$, then parents start panicking, [saying] Help, what should I do?." (Nurse 3, FG3).

WCC professionals generally feel that by asking questions, parents are seeking reassurance and to double-check if their actions and worries are legitimate.

"They just want to be heard. Or want to hear the opinion of a professional (Nurse 3, FG2).(...) Yes, they say they feel more reassured afterwards (Nurse 1, FG2). Because they know what steps to take." (Nurse 4, FG2). 
WCC professionals believe that parents tend to be very fixated on the child's temperature and are quickly worried, even when the body temperature is only slightly elevated, and overestimate the significance of an elevated body temperature as a single symptom.

"Parents' worries often start as soon as the child's temperature hits $37.8^{\circ} \mathrm{C}$ and they're like: oooohh." (Doctor 2, FG4).

WCC professionals also expressed that according to them many parents fear that the raised body temperature reflects the severity of what is causing the fever. This is reinforced by previous negative experiences and stories from people in their surroundings.

“(...)They fear febrile seizures (Nurse 1, FG3).(...) Dehydration, meningitis (Nurse 2, FG3). And spots as well." (Doctor 1, FG3).

WCC professionals perceive their clinic as easily approachable and think that as a consequence parents typically do not hesitate to contact them, including for fever-related questions. This accessibility is highly esteemed by WCC professionals because they aim to empower parents in bringing up their children. However, they also acknowledged this approachability may also wrongly reinforce help-seeking behaviour. WCC professionals also find that parents contact them because they do not feel understood or taken seriously by their own GP and hope to find reassurance by asking questions of WCC professionals.

"Their GP has said so many times there is nothing wrong with their child. And then they call us." (Doctor 2, FG1).

\section{Level of knowledge}

WCC professionals perceived that one of the major drivers of parental worries in childhood fever to be a general lack of parental knowledge regarding the definition of fever, fever pathophysiology and fever self- management strategies.

"Parents call and ask: His temperature is slightly elevated, what to do? How long do we have to wait, should we give medication, is this normal? (...) My child has 37.6 degrees Celsius; is that a fever?" (Nurse 5, FG2).

In the opinion of WCC professionals parents tend to ignore other symptoms of illness while WCC professionals themselves base their advice on the child's overall presentation. They find this even more remarkable because parents often cannot make a distinction between a slightly elevated body temperature and fever and seem to overestimate the significance of an elevated body temperature as a single symptom. Nevertheless, parents tend to take the child's temperature multiple times a day.

"They talk about fever but often parents already call us when the temperature is 37.8

${ }^{\circ} \mathrm{C}$ or $37.9{ }^{\circ} \mathrm{C}$ because they start to worry." (Nurse 4,FG1).

According to WCC professionals, parents also lack knowledge regarding pathophysiology and self-management strategies. 
"The only thing they think of is, "Fever? Oh I have to give paracetamol!" (...) But not everyone knows you have to go through this and it will pass. And also that if you do nothing, it will pass." (Nurse 1, FG2).

Parents, especially the higher-educated ones, hold strong beliefs that fever needs to be solved and that paracetamol needs to be administrated to lower the body temperature.

"Although I say to them every time not to provide paracetamol. They do it every time. The information just doesn't stick." (Nurse 1, FG1).

\section{Level of experience}

WCC professionals perceive that parental worries towards childhood fever are closely related to and driven by parents' experience of caring for feverish children. That experience is mainly determined by the number and age of children in the family and previous personal experiences with fever-related illnesses. WCC professionals receive most questions from first-time parents with no previous experience with illness in their young child.

"You have to get to know your baby. So it is more to deal with the worries of the parents than with seeing the child." (Nurse 1, FG1).

According to WCC professionals, parents gain experience and associated confidence in coping with fever within the course of taking care of one child. Therefore, the age of the child also influences the level of anxiety over fever in parents, according to them.

"The first time is fierce, and the second time too but they don't call us that quickly anymore when it happens for the third or fourth time." (Nurse 3, FG3).

Gaining experience was also felt to be closely related to gaining more knowledge on how to cope with fever episodes. The WCC professionals believe that this is why they receive fewer questions from parents with multiple children.

The level of parental worries may also be influenced by previous experiences with fever episodes. Specifically, WCC professionals stated that parental worries over childhood fever increase exponentially if parents had a bad experience with a feverish child in their social network in the past:

"If parents have seen how a child ended up in a hospital or experienced a serious condition, it plays a role when their own child starts to get ill." (Doctor 1, FG3).

Influence of educational level and social network

WCC professionals suggest a difference in parental attitude towards coping with fever between lower- and higher-educated parents, which in turn might influence the level of worries and frequency of asking questions. According to them, higher-educated parents tend to panic more quickly, act less intuitively and rely more on the Internet and the expertise of WCC professionals than lower-educated parents: 
"In my opinion the group of higher-educated parents has a lot of questions. They do not act on their intuition but want to know all the ins and outs, and are unable to let it go." (Doctor 3, FG4).

Participants provided potential explanations for this difference. They indicated that highereducated parents may tend to ask more questions about fever since an ill child disturbs their work rhythm and may prevent access to child daycare. Higher-educated parents may therefore have a stronger tendency to administer paracetamol to their feverish child.

"We have to see this more from a practical point of view: if a child doesn't get a fever, it can go to child daycare; otherwise you have to stay home from work." (Doctor 2, FG1).

Participants also indicated that the size of the social network as another explanation for this difference. According to them, higher-educated parents tend to have a smaller social network than lower-educated parents to rely on during childhood illness.

"(..)If you have grandparents who support those parents...but if you have a small network like higher-educated parents, I think they are. [Nurse 2,FG 3]: they are very worried." (Doctor 1, FG3).

Participants explained that a substantial social network may provide support by transferring knowledge and sharing experiences regarding fever. However, WCC professionals also acknowledge that the social network may boost parental worries by sharing horror stories on severe underlying illness and/or adverse events and cause more worries among parents.

\section{Inconsistent information provision}

WCC professionals stated that parental worries and the urge to ask questions may also arise from inconsistent information provision among different healthcare providers or from information sources such as the Internet.

WCC professionals experience differences in paracetamol administration recommendations between themselves and GPs, medical specialists, and chemists. This inconsistency causes worries, confusion and uncertainty about fever management among parents.

"And then they go to the chemist or GP and hear "No, that's (paracetamol dosage) really not allowed". "You gave us the wrong advice!" While it was according to our (WCC) guidelines." (Nurse 6, FG2).

WCC professionals find this difficult and try to comfort parents by explaining the differences. WCC professionals also observe that it is getting more and more common for parents to search the Internet for information when their child has a fever. However, reading information on the internet may increase parental anxiety and cause parents to contact WCC professionals to check if the information is accurate.

"Parents use Google a lot these days and: well the GP told me this but I started searching on the Internet and I read something completely different!" (Nurse 3, FG3). 


\section{Suggestions for improvement}

WCC professionals stated that currently available written information on fever aimed at parents is very limited and focuses mainly on fever as a possible side effect of vaccination jabs. More specifically, the discussions revealed a need to better inform parents. WCC professionals believe that to achieve this, it is necessary to meet certain conditions when developing a new information tool.

"Most important is that parents know where they can find the information whenever they need it. Whether they call us, whether it is described in a booklet, whether they can look it up on the Internet. If they just know where to find the most recent information." (Doctor 2, FG1).

The information should be easy to find and written in languages most frequently spoken. WCC professionals prefer a hard copy information tool with visual information to underpin their verbal information. They also want to complement the hard copy information with an accessible and readable website or mobile application. The content of the new information tool should be consistent among healthcare professionals to avoid confusion among parents. The moment at which the tool should be provided to parents was under debate and ranged from antenatal classes to prior to the first vaccination jab when the child is two months old.

"The WCC check-up at 4 weeks is a good moment. Just after the final visit of the midwife, when she (midwife) has already started talking about fever, what of course, she is going to do from now on." (Doctor 2, FG4)

\section{DISCUSSION}

According to WCC professionals, parental worries about childhood fever are the major driving factor behind most fever-related contacts with the WCC. Four subcategories were identified as possible drivers of parental worries: level of knowledge, level of experience, influence of educational level and social network, and perceived inconsistency in paracetamol administration advice among healthcare professionals. In addition, WCC professionals believe that current information provision on fever is limited and focuses mainly on fever as a side effect of vaccination jabs. WCC professionals subsequently expressed the need to improve current information provision and provided starting points in terms of its findability, language, lay-out, content and timing. It was especially mentioned that the content of information provided should become more consistent among different healthcare providers to avoid worries caused by uncertainty. The timing of information provision was under debate but leaned towards the first two months of a child's life.

According to WCC professional parents often seem to overestimate the significance of body temperature and perceive that the degree of fever indicates the severity of the underlying illness. This finding is in accordance with previous research that parental worries may arise because of the belief that fever is a disease and not just a symptom of illness. Subsequently, when parents view fever as a disease on its own, this will ultimately lead to misconceptions 
about its role in illness $[4,5]$. It is also demonstrated that parental worries lead to the increased use of healthcare services $[1,2,38]$.

Corresponding with earlier research, WCC professionals perceived they received most questions from first-time parents, with younger children causing more worries, because those parents lack own experience of coping with fever. As a consequence, parents consult a GP more often for a firstborn child than for a second or subsequent child $[39,40]$. Our study also confirms that parents feel uncertain about their actions during fever episodes and consult WCC professionals regularly for advice [4, 10, 21, 40-44].

In line with previous research, WCC professionals stated that the social network is an important source of information for parents [10, 40, 45]. WCC professionals experienced that higher-educated parents worry more quickly and tend to rely more on advice of healthcare providers and the Internet than lower-educated parents. It is known from the literature that healthcare professionals and the Internet are an important source of information for parents $[4,10,40,43,45]$. Previous research also showed that the Internet is mostly used as information source by younger parents and children [10]. WCC professionals explained the difference between higher and lower educated parents in relying on healthcare professionals by the observation that higher- educated parents seem to have a smaller social network in close proximity to rely on for advice. This observation is in accordance with previous research, which demonstrated that parents who did not graduate from high school were less likely to consult a healthcare professional and depended more on nonmedical individuals for advice. However, a lower educational level was also associated with practices that could delay care [15, 46, 47]. Differences among lower and higher educated parents in relying on the social network and healthcare professionals as important information sources should be considered when developing information provision about childhood fever.

Other explanations of why higher educated parents tend to rely more on healthcare providers may lie within the fact that education enhances parents' knowledge of fever, healthcare facilities and may improve their capability to communicate with healthcare providers [48]. Also, it may be possible that parents with a low income may tend to wait longer to avoid medical expenditures [49].

It was perceived that inconsistency in received advice, due to the use of different guidelines by WCC professionals, GPs, GPs, medical specialists, and chemists, led to confusion, more uncertainty and worries during fever episodes. Previous research already indicated that practice variations exist in treating febrile infants among pediatric emergency physicians [50]. Different studies also showed that providing conflicting information on fever management increases worries among participants, especially when the information comes from sources considered reliable and trustworthy, such as a healthcare professional [12]. Like recent qualitative research among parents presenting to GP out-of-hours services with a febrile child, WCC professionals recommended providing consistent information among different healthcare providers [51]. 
WCC professionals perceive that the information currently available on fever is very limited, differs across healthcare providers and does not focus on fever as a separate topic but mainly on fever as a possible side effect of vaccination jabs. In addition, they stated that current information provision on fever needs improvement. Previous research indicates that educational interventions seem to be most effective when they are provided in personal discussions to tailor information to needs, beliefs, experience, and skills, of endusers. In addition, information resources should be accurate, consistent, written, simple to use, and contain simple symbols, $[9,41,52,53]$. According to Cabral et al [54] interventions may be more effective if they focus on reducing uncertainty in situations when a consultation or antibiotic prescription is needed by increasing knowledge among parents and clinicians about which symptoms need medical attention.

This is the first qualitative study to explore the experiences of WCC professionals towards childhood fever and current information provision, to inform future interventions aimed at educating parents prior to their child's first fever episode. A strength of our study is the inclusion of WCC professionals working at different WCC locations in the region of Maastricht (the Netherlands), thereby including neighbourhoods with a variety of socioeconomic statuses. We achieved methodological and investigator triangulation, held peer debriefings with the wider research team and a member check.

Dutch WCC has specially trained doctors and nurses in preventive youth healthcare, while GPs have a gatekeeping role and mostly focus on curative youth healthcare. The tasks of Dutch WCCs do resemble the tasks of other preventive healthcare services worldwide We believe that our findings regarding information provision about childhood fever may be transferable to other countries as well.

We purposefully sampled WCC professionals from a small and deprived region in the Netherlands with a limited diversity in ethnicities. It is therefore possible that the views and experiences may differ from WCC professionals in other regions. It is important to keep in mind that the WCC professionals expressed their thoughts about possible drivers of feverrelated contacts in parents and we did not investigate the experiences of parents themselves.

\section{CONCLUSION}

Fever-related questions are common in well-child care and professionals perceive that most of the workload is driven by parental worries. Four categories were identified as possible drivers of parental worries: lack of knowledge, lack of experience or having had negative experiences with fever in the past, educational level and size of social network and inconsistencies in paracetamol administration advice. This study demonstrates that current information provision on fever is limited and current information provision need to be optimised and should acknowledge patients' characteristics and inconsistencies among healthcare providers. 


\section{Chapter 3}

Based on these results we can state that future interventions should aim to lower worries among parents. It is important not only to educate parents on an ad hoc basis when children are ill but also prior to a child's first fever episode to prepare parents for future illness. This can be achieved by tailoring interventions to the needs of parents and accounting for their level of knowledge, experience, educational level and availability of a social network. To clarify, future fever information provision should focus on improving fever management and practical skills since parents seem to lack knowledge of fever pathophysiology and self-management strategies. Particular attention should be paid to first-time parents who lack experience with childhood fever episodes and to highereducated parents with a small social network.

It is also essential that paracetamol administration advice is consistent among different healthcare professionals. Furthermore, information should be easy to find, easy to understand and verbal information provision needs to be supported by hard copy visual information and web-based applications. The timing of information provision on fever is still under debate but the tendency is to provide it within the first two months of a child's life. 


\section{REFERENCES}

1. Hay AD, Heron J, Ness A. The prevalence of symptoms and consultations in pre-school children in the Avon Longitudinal Study of Parents and Children (ALSPAC): a prospective cohort study. Fam Pract. 2005;22:36774.

2. Bruijnzeels MA, Foets M, van der Wouden JC, van den Heuvel WJ, Prins A. Everyday symptoms in childhood: occurrence and general practitioner consultation rates. Br J Gen Pract. 1998;48(426):880-4. Pubmed Central PMCID: PMC1409911, Epub 1998/05/30. eng.

3. de Bont EG, Lepot JM, Hendrix DA, Loonen N, Guldemond-Hecker Y, Dinant GJ, et al. Workload and management of childhood fever at general practice out-of-hours care: an observational cohort study. Brit Med J Open. 2015;5(5):e007365.

4. Crocetti M, Moghbeli N, Serwint J. Fever phobia revisited: have parental misconceptions about fever changed in 20 years? Pediatr. 2001;107:1241-6.

5. Schmitt BD. Fever phobia: misconceptions of parents about fevers. Am J Dis Child. 1980;134:176-81.

6. Kramer MS, Naimark L, Leduc DG. Parental fever phobia and its correlates. Pediatr. 1985;75:1110-3.

7. Zyoud SH, Al-Jabi SW, Sweileh WM, Nabulsi MM, Tubaila MF, Awang R, et al. Beliefs and practices regarding childhood fever among parents: a cross- sectional study from Palestine. Bio Med Cent Pediatr. 2013;13:66.

8. Walsh A, Edwards H, Fraser J. Parents' childhood fever management: community survey and instrument development. J Adv Nurs.2008;63:376-88.

9. Kai J. What worries parents when their preschool children are acutely ill, and why: a qualitative study. Brit Med J Open. 1996;313:983-6.

10. Karwowska A, Nijssen-Jordan C, Johnson D, Davies HD. Parental and health care provider understanding of childhood fever: a Canadian perspective. Can J of Em Med. 2002;4:394-400.

11. Purssell E. Parental fever phobia and its evolutionary correlates. J Clin Nurs. 2009;18:210-8.

12. Walsh A, Edwards H, Fraser J. Influences on parents' fever management: beliefs, experiences and information sources. J Clin Nurs. 2007;16:2331-40.

13. Purssell E, Collin J. Fever Phobia: The impact of time and mortality-a systematic review and meta-analysis. Int J Nurs Stud. 2015;56:81-9.

14. Sarrell M, Kahan E. Impact of a single-session education program on parental knowledge of and approach to childhood fever. Patient Educ Couns. 2003;51:59-63.

15. Taveras EM, Durousseau S, Flores G. Parents' beliefs and practices regarding childhood fever: a study of a multiethnic and socioeconomically diverse sample of parents. Pediatr Emerg Care. 2004;20(9):579-87. Epub 2004/12/16. eng.

16. de Bont EG, Peetoom KK, Moser A, Francis NA, Dinant GJ, Cals JW. Childhood fever: a qualitative study on GPs' experiences during out-of- hours care. J Fam Pract. 2015;32:449-55.

17. Kai J. Parents' difficulties and information needs in coping with acute illness in preschool children: a qualitative study. Brit Med J. 1996;313:987-90.

18. Kuo AA, Inkelas M, Lotstein DS, Samson KM, Schor EL, Halfon N. Rethinking well-child care in the United States: an international comparison. Pediatrics. 2006;118(4):1692-702. Epub 2006/10/04.

19. Commission of evaluation basic tasks Dutch youth healthcare. Een stevig fundament. Evaluatie van het basistakenpakket jeugdgezondheidszorg [A solid basis. Evaluation of basic tasks Dutch youth healthcare] 2013.

20. Statistics Netherlands. Parents give child health centres a 7 out of 10. 2014

21. Osman LM, Dunt D. Factors influencing mothers' decisions to consult a general practitioner about their children's illnesses. Br J Gen Pract. 1995;45:310-2.

22. Buiting E PF. Wijs verwijzen. Van het consultatiebureau rechtstreeks naar de tweede lijn [Refer wisely. From the well-child clinic straight to second line care]. Med Cont. 2002;57.

23. Herman AD, Mayer GG. Reducing the use of emergency medical resources among Head Start families: a pilot study. J Comm Health. 2004;29:197-208. 
24. Najimi A, Dolatabadi NK, Esmaeili AA, Sharifirad GR. The effect of educational program on knowledge, attitude and practice of mothers regarding prevention of febrile seizure in children. J Educ Health Promot. 2013;2:26. Pubmed Central PMCID: PMC3778569, Epub 2013/10/02. eng.

25. Stockwell MS, Catallozzi M, Larson E, Rodriguez C, Subramony A, Andres Martinez R, et al. Effect of a URIrelated educational intervention in early head start on ED visits. Pediatr. 2014;133:e1233-40.

26. Fieldston ES, Nadel FM, Alpern ER, Fiks AG, Shea JA, Alessandrini EA. Effects of an education and training intervention on caregiver knowledge of nonurgent pediatric complaints and on child health services utilization. Pediatr Emerg Care. 2013;29(3):331-6. Epub 2013/02/22. eng.

27. Morrell D, Avery AJ, Watkins C. Management of minor illness. Brit Med J. 1980;280:769-71.

28. Sides AT. Self-care education, parent knowledge and children's health care visits. J Pediatr H Care. 1988;2:135-40.

29. Usherwood T. Development and randomized controlled trial of a booklet of advice for parents. Brit J Gen Pr. 1991;41:58-62.

30. Rasmussen F. Mothers' benefit of a self-care booklet and a self-care educational session at child health centres. Soc Sc Med. 1989;29:205-12.

31. Broome ME, Dokken DL, Broome CD, Woodring B, Stegelman MF. A study of parent/grandparent education for managing a febrile illness using the CALM approach. J Ped Health Care. 2003;17:176-83.

32. Casey R, McMahon F, McCormick MC, Pasquariello Jr PS, Zavod W, King Jr FH. Fever therapy: an educational intervention for parents. Pediatr. 1984;73:600-5.

33. Lincoln YS, Guba EG. Naturalistic inquiry. Newbury Park, CA: Sage Publications; 1985.

34. Bowen G. Grounded theory and sensitizing concepts. Int J Qual Meth. 20065

35. Strauss A, Corbin J. Basics of qualitative research: Grounded theory procedures and techniques. Newbury Park, Ca, USA: Sage Publications; 1990.

36. Lincoln Y, Guba G. Naturalistic Inquiry. Beverly Hills, CA: SAGE Publications; 1985.

37. Patton MQ. Enhancing the quality and credibility of qualitative analysis. Health Serv Res. 1999;34(5 Pt 2):1189-208.

38. André M, Hedin K, Hakansson A, Molstad S, Rodhe N, Petersson C. More physician consultations and antibiotic prescriptions in families with high concern about infectious illness-adequate response to infection-prone child or self-fulfilling prophecy? Fam Pract. 2007;24:302-7.

39. van den Bosch WJ, Huygen FJ, van den Hoogen HJ, van Weel C. Morbidity in early childhood: family patterns in relation to sex, birth order, and social class. Fam Med. 1993;25:126-30.

40. Rupe A, Ahlers-Schmidt CR, Wittler R. A comparison of perceptions of fever and fever phobia by ethnicity. Clin Pediatr (Phila). 2010;49:172-6.

41. Maguire S, Ranmal R, Komulainen S, Pearse S, Maconochie I, Lakhanpaul M, et al. Which urgent care services do febrile children use and why? Arch Dis Child. 2011;96:810-6.

42. Chiappini EPA, Becherucci P, Pierattelli M, Bonsignori F, Galli L, et al. Parental and medical knowledge and management of fever in Italian pre-school children. Bio Med Cent Pediatr. 2012;12:97.

43. de Bont EG, Francis NA, Dinant GJ, Cals JW. Parents' knowledge, attitudes, and practice in childhood fever: an internet-based survey. Br J Gen Pract. 2014;64:e10-6.

44. May A, Bauchner H. Fever phobia: the pediatrician's contribution. Pediatr. 1992;90:851-4.

45. Sahm L, Kelly M, McCarthy S, O'Sullivan R, Shiely F, Romsing J. Knowledge, attitudes and beliefs of parents regarding fever in children: a Danish interview study. Acta paediatrica (Oslo, Norway: 1992). 2016;105(1):69-73. Epub 2015/08/19. eng.

46. Butler JA, Winter WD, Singer JD, Wenger M. Medical care use and expenditure among children and youth in the United States: analysis of a national probability sample. Pediatrics. 1985;76:495-507.

47. Newacheck PW, Hughes DC, Stoddard JJ. Children's access to primary care: differences by race, income, and insurance status. Pediatrics. 1996;97:26-32.

48. Webair HH, Bin-Gouth AS. Factors affecting health seeking behavior for common childhood illnesses in Yemen. Patient Prefer Adherence. 2013;7: 1129-38. Pubmed Central PMCID: PMC3810343, Epub 2013/11/05. eng. 
49. Devoe JE, Baez A, Angier H, Krois L, Edlund C, Carney PA. Insurance + access not equal to health care: typology of barriers to health care access for low- income families. Ann Fam Med. 2007;5(6):511-8. Pubmed Central PMCID: PMC2094032, Epub 2007/11/21. eng.

50. Goldman RD, Scolnik D, Chauvin-Kimoff L, Farion KJ, Ali S, Lynch T, et al. Practice variations in the treatment of febrile infants among pediatric emergency physicians. Pediatrics. 2009;124(2):439-45. Epub 2009/07/22. eng.

51. de Bont EG, Loonen N, Hendrix DA, Lepot JM, Dinant GJ, Cals JW. Childhood fever: a qualitative study on parents' expectations and experiences during general practice out-of-hours care consultations. Bio Med Cent Fam Pract. 2015;16:131.

52. Jones $\mathrm{CH}$, Neill S, Lakhanpaul M, Roland D, Singlehurst-Mooney $\mathrm{H}$, Thompson M. Information needs of parents for acute childhood illness: determining 'what, how, where and when' of safety netting using a qualitative exploration with parents and clinicians. Bio Med J Open. 2014;4: e003874.

53. Monsma J, Richerson J, Sloand E. Empowering parents for evidence-based fever management: An integrative review. J Am Assoc Nurse Pract. 2015;27(4):222-9.

54. Cabral C, Lucas PJ, Ingram J, Hay AD, Horwood J. "It's safer to ..." parent consulting and clinician antibiotic prescribing decisions for children with respiratory tract infections: An analysis across four qualitative studies. Soc Sci Medicine (1982). 2015;136-137:156-64. Epub 2015/05/26. 
Appendix 1 Topic list of the first focus group discussion

Theme 1: Experiences and current practices

- What are your experiences with childhood fever at the well-child clinic?

- What kind of questions do you receive from parents regarding fever?

- When do you receive questions from parents about fever: Prior to childhood illness to prepare for new episodes? Or when children are ill?

- How do you cope with fever-related questions from parents?

Theme 2: The need to improve information provision about fever

- What do you think of the current information provision about fever at the well-child clinic?

- Can you provide us with a detailed description of the way you provide information to parents about childhood fever?

- What is going well in the current information provision about fever?

- Do you experience barriers in the current information provision on fever?

- What do you miss in the current information provision about fever?

- Do you have any ideas on how to improve the current information provision on childhood fever?

Appendix 2 Topic list of the final focus group discussion

\section{Theme 1: Experiences and current practices}

- What are your experiences with childhood fever at the well-child clinic?

- What kind of questions do you receive from parents regarding fever?

- From who do you receive most questions?

- When do you receive questions from parents about fever: Prior to childhood illness to prepare for new episodes? Or when children are ill?

- How do you cope with fever-related questions from parents?

- Is the content or method of information provision on fever, tailored to differences among parents in terms of educational level or cultural background?

Theme 2: The need to improve information provision about fever

- What is your opinion about the current information provision on childhood fever at the well-child clinic?

- Can you provide us with a detailed description of the way you provide information to parents about childhood fever?

- What is going well in the current information provision about fever?

- Do you experience barriers in the current information provision on fever?

- What do you miss in the current information provision about fever?

- Do you have any ideas on how to improve the current information provision on childhood fever?

- How would you prefer to provide information to parents about fever? 


\title{
Chapter 4
}

\author{
Most preschool children with fever \\ and common infection symptoms \\ do not consult the family physician
}

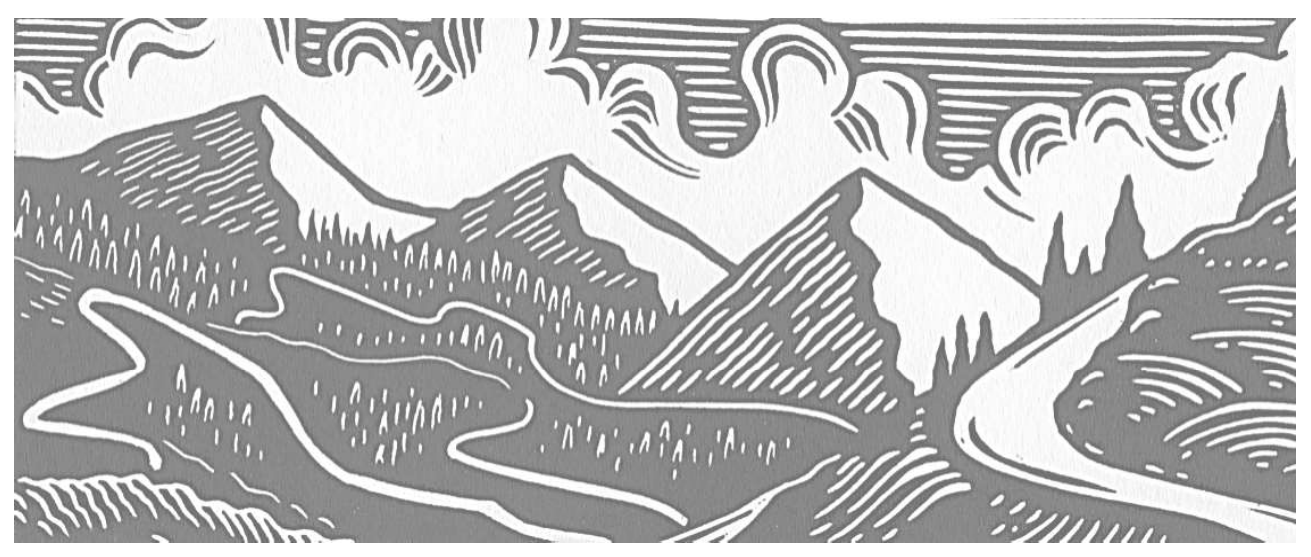

Kirsten Peetoom, Rik Crutzen, Geert-Jan Dinant, Jochen Cals. Most preschool children with fever and common infection symptoms do not consult the family physician.

Published in: Family Practice. 2018 Sep 25. 


\section{ABSTRACT}

Background Fever, cough, earache or skin infections are a common reason to consult the family physician. This study aims to provide insight in the impact of illness in children attending childcare in terms of infectious symptoms incidence, childcare absenteeism, healthcare service use, and productivity loss among parents.

Methods A cross-sectional survey study was conducted in 21 childcare centres from one organization to determine the 4-week incidence of fever and common infectious symptoms in children 0- 4 years. 1109 families were invited to fill in a symptom diary for their youngest child in childcare, by registering retrospectively the presence and duration of 14 common infectious symptoms over a 4-week period. Parents also reported infectious symptom(s) leading to a physician consultation, childcare absenteeism, and parents taking time off work. Outcomes were descriptively analysed.

Results Only $2.5 \%$ ( 13 children) of 515 children did not encounter any infectious symptoms during the 4-week period. Most common infectious symptoms originated from the upper respiratory tract. $54.6 \%$ of children experienced fever during the 4-week period. Of all children with infectious symptoms, only $26.8 \%$ consulted a FP. Most consultations were for fever and during daytime. In 4 weeks time, $32.6 \%$ of children missed at least one day at childcare due to illness (320 days). 146 parents had to take time off work (median of 2 days) and 82 parents had to arrange a babysitter for a total of 169 days [median of 1 day].

Conclusion Our results show that most preschoolers experienced infectious symptoms in a 4 week period. However, many children with fever and/or common infections actually do not consult in family practice at all. 


\section{INTRODUCTION}

Fever, cough, earache or skin infections are a common reason to consult the family physician, while it often concerns self-limiting infections, which do not require treatment [1-4]. A recent publication by Wensaas et al. showed that children with acute cough have on average infectious symptoms for 7.7 days before consulting their family physician (FP). Symptoms improved in the majority of the children post-consultation [5]. Obtaining insight in post-consultation recovery trajectories are of great importance to inform parents and clinicians about the expected natural duration of symptoms. Yet, we want to contribute to these findings by showing data on the incidence of fever, common infections, and healthcare service use among children aged 0 to 4 years old attending childcare centres during a 4-week period. Our results show that most preschoolers with fever and/or common infections actually do not consult in family practice at all.

\section{METHODS}

We conducted a survey study in 21 centres from one large commercial childcare organisation in the Southern part of province Limburg, the Netherlands, to determine the 4 -week incidence of fever and common infectious symptoms in children 0 to 4 years old. All centres used the same organization guidelines on managing ill children. We asked parents of all 1109 families, with a child attending one of the 21 centres, to fill in a symptom diary for their youngest child in childcare, by registering retrospectively the presence and duration of 14 common infectious symptoms over a 4-week period in February/March 2016. The symptom diary was completed once by the same family. In addition, we asked to write down the infectious symptom(s) leading to a physician consultation, childcare absenteeism and parents taking time off work. It was possible to report multiple symptoms. From 1109 distributed surveys, 515 (49\%) were returned. Most families had only one child in childcare $(\mathrm{N}=397)$. Based on the results of 503 out of 515 children, the average age was 1.55 (SD = 1.11) years, with $24.1 \%, 22.3 \%, 28.0 \%$ and $25.6 \%$ being $0,1,2$ and 3 years old, respectively. The average age of the child for who the survey was filled in was 1.55 (SD $=1.11$ ) years. Our symptom diary was based on previous work of the Bristol group who also published the paper on symptom trajectories [2].

\section{RESULTS}

\section{Incidence of infectious symptoms}

Only $2.5 \%$ ( 13 children) of 515 children did not encounter any infectious symptoms during the 4-week period (Table 1). A total of 281 of 515 children included in the study (54.6\%) had a fever on at least 1 day during the 4-week period, accounting for a total of 987 symptom days [median of 3 days]. Most common infectious symptoms originated from the upper respiratory tract such as runny nose in 418 of 515 children (81.2\%), while 378 of 515 children reported a cough (73.4\%). The vast majority of infectious symptom days was also attributable to respiratory tract symptoms. Approximately one in five children had gastro- 
intestinal symptoms such as diarrhea on at least one day during the 4-week period. Of the 515 children, four children were reported to have had a febrile seizure.

\section{Healthcare service use for infectious symptoms}

Of all children with infectious symptoms, $73.2 \%$ did not consult a FP for their infectious symptoms. Fever was a frequent reason for a FP consultation with 87 out of 281 febrile children (31\%) consulting. Out of 77 children with earache 29 consulted their family physician (37.7\%). Difficulties with breathing resulted in 16 out of 64 children (25\%) in a physician consultation, and in 29 out of 142 children with difficulties with eating/drinking (20.4\%). While acute cough was one of the most commonly reported symptoms in 378 out of 515 children (73.4\%), only 42 out of 378 children with a cough consulted their FP (11.1\%). Most children consulted their own family practitioner during daytime consultation hours (153 consultations for 117 children), some consulted out-of-hours (32 consultations for 27 children) and 23 children were assessed by another physician (e.g. pediatrician).

\section{Childcare absenteeism due to illness}

Although only a minority of all parents (26.8\%) attended health care services for their child with common infectious symptoms, our data did show that nearly one in three children (32.6\%) missed at least one day at childcare due to infectious symptoms, accounting for a total of 320 days during the 4-week period. In addition, 146 parents had to take time off work for a total of 312 days [median of 2 days] and 82 parents had to arrange a babysitter for a total of 169 days [median of 1 day]. Half of children who were absent from daycare because of illness consulted their FP.

\section{CONCLUSION}

Our study showed that $97 \%$ of children in childcare experienced infectious symptoms during a 4-week period. However, most of these children with infectious symptoms (e.g. respiratory tract infections) do not consult the family physician. This indicates that -despite the impact of an ill child on their family- most illnesses are managed without visits to a physician. In line with previous research, parents reported cough, fever, stomach problems, vomiting and diarrhea as most common infectious symptoms $[2,6]$. The percentage of children consulting a FP for their infectious symptoms corresponds to previous research with consultation rates ranging between $11 \%$ and $56 \%[1,2,6-8]$.

Physicians experience a high workload due to fever-related consultations in out-of-hours care $[4,9]$. Our findings confirm that fever was the most common reason for parents to consult a physician. However, the overall rate of physician consultation was rather low with $73.2 \%$ of parents not consulting a family physician while the infection incidence rate was substantial in our study. Our findings are in line with population-based physician consultations in the USA [10]. In addition, our results also showed that most parents consult during regular working hours and not during out-of-hours care. So, parents may be more cautious in seeking care than family physicians expect. However, parents' intention to consult seems to be driven by their level of worry, and a high concern about infectious 
illness is associated with more physician consultations and more antibiotic prescriptions in parents $[9,11,12]$. To illustrate this, when temperature rises, anxiety may overrule rationality since most parents believe that height of body temperature reflects severity of illness [13].

When children are ill when attending childcare centres, this impacts on parents since they often have to take time off work to care for their child. Our study showed that almost onethird of parents had to take time off work for a median of 2 days during the 4-week period or had to arrange a babysitter for a median of 1 day. Research in the Netherlands showed that children in childcare generate twice as much societal costs than home-cared children, mainly due to productivity loss in parents [14]. About half of the children who were reported absent from childcare consulted a FP in our study. This is still low compared to previous findings that $88 \%$ of parents sought medical evaluation when their child was not able to attend childcare [15].

To conclude, this letter contributes to the findings of Wensaas et al. by showing the impact of infectious symptoms in children attending childcare. In addition, having knowledge that the number of preschool children actually consulting is just the tip of the infectious symptoms' iceberg; family physicians might realize accordingly that the workload can be much higher when parents would be less cautious to consult.

Table 1 Four-week incidence and duration of childhood fever and common infections in children attending childcare and related healthcare service use

\begin{tabular}{|c|c|c|c|c|}
\hline & $\begin{array}{l}\text { Four week symptom } \\
\text { incidence } \mathbf{N}(\%)^{\mathrm{a}}\end{array}$ & $\begin{array}{c}\text { Total days, } \\
\mathbf{N}\end{array}$ & $\begin{array}{l}\text { Median days } \\
\text { (Q1-Q3) }\end{array}$ & $\begin{array}{l}\text { Reason doctor } \\
\text { consultation } \%^{\mathrm{b}}\end{array}$ \\
\hline Fever & $281(54.6 \%)$ & 987 & $3[2-4]$ & $31 \%(87 / 281)$ \\
\hline Cough & $378(73.4 \%)$ & 2912 & $7[4-10]$ & $11.1 \%(42 / 378)$ \\
\hline Stuffed nose & $349(67.8 \%)$ & 2689 & $7[3-11]$ & $1.4 \%(5 / 349)$ \\
\hline Runny nose & $418(81.2 \%)$ & 3331 & $7[4-10.25]$ & $0.7 \%(3 / 418)$ \\
\hline Sneezing & $230(44.7 \%)$ & 1358 & $5[3-10]$ & 0 \\
\hline Sore throat & $103(20.0 \%)$ & 422 & $4[2-5]$ & $9.7 \%(10 / 103)$ \\
\hline Ear ache & $77(15.0 \%)$ & 330 & $3[2-5]$ & $37.7 \%(29 / 77)$ \\
\hline Difficulties breathing & $64(12.4 \%)$ & 348 & $4[3-7]$ & $25 \%(16 / 64)$ \\
\hline Other respiratory symptoms & 8 & 73 & 8 [7-14.5] & $13^{c}$ \\
\hline Diarrhoea & $145(28.2 \%)$ & 443 & $3[2-4]$ & $5.5 \%(8 / 145)$ \\
\hline Vomiting & 98 (19.0\%) & 162 & $1[1-2]$ & $8.1 \%(8 / 98)$ \\
\hline Stomach ache & $84(16.3 \%)$ & 200 & $2[1-3]$ & $5.9 \%(5 / 84)$ \\
\hline Difficulties eating/ drinking & $142(27.6 \%)$ & 633 & $4[2-6]$ & $20.4 \%(29 / 142)$ \\
\hline Skin & $87(16.9 \%)$ & 531 & $6[2.5-10]$ & $16.1 \%(14 / 87)$ \\
\hline Eye infection & $3(0.6 \%)$ & 22 & $\mathrm{n} / \mathrm{a}$ & $5^{c}$ \\
\hline Urinary tract infection & $2(0.4 \%)$ & 12 & $6[5-7]$ & 8 \\
\hline No infectious symptoms & $13(2.5 \%)$ & $\mathrm{n} / \mathrm{a}$ & $\mathrm{n} / \mathrm{a}$ & 0 \\
\hline \multicolumn{5}{|c|}{$\begin{array}{l}{ }^{a} \text { Parents reported for most children more than one symptom during the 4-week registration period so the total } \\
\text { number of children experiencing single symptoms exceeds total number of children in survey }(N=515) \text {. } \\
{ }^{b} \text { Number of children for whom the symptom was mentioned as reason to consult a GP divided by the total } \\
\text { number of children with this symptom. This may have been in combination with other symptoms. } \\
\text { 'Some parents mentioned flu or infected eyes or urinary tract infection as reason to consult a physician but did } \\
\text { not mention the presence in the symptom diary. }\end{array}$} \\
\hline
\end{tabular}




\section{REFERENCES}

1. Bruijnzeels $M$, Foets $M$, van der Wouden J, van den Heuvel W, Prins A. Everyday symptoms in childhood: occurrence and general practitioner consultation rates. British Journal of General Practice. 1998;48(426):880-

2. Hay A, Heron J, Ness A. The prevalence of symptoms and consultations in pre-school children in the Avon Longitudinal Study of Parents and Children (ALSPAC): a prospective cohort study. Family practice. 2005;22(4):367-74

3. National Institute for Health and Care Excellence. Feverish illness in children: Assessment and initial management in children younger than 5 years. Manchester, United Kingdom; 2013. Report No.: CG160.

4. de Bont E, Lepot J, Hendrix D, Loonen N, Guldemond-Hecker Y, Dinant G, et al. Workload and management of childhood fever at general practice out-of-hours care: an observational cohort study. BMJ open. 2015;5(5):e007365.

5. Wensaas K-A, Heron J, Redmond N, Turnbull S, Christensen H, Thornton H, et al. Post-consultation illness trajectories in children with acute cough and respiratory tract infection: prospective cohort study. Family practice [Internet]. 2018:[1-8 pp.]. Available from: http://dx.doi.org/10.1093/fampra/cmy021.

6. Sarna, M., Ware, R. S., Sloots, T. P., Nissen, M. D., Grimwood, K., \& Lambert, S. B. (2016). The burden of community-managed acute respiratory infections in the first 2-years of life. Pediatric pulmonology, 51(12), 1336-1346.

7. Uijen J, van Duijn H, Kuyvenhoven M, Schellevis F, van der Wouden J. Characteristics of children consulting for cough, sore throat, or earache. British Journal of General Practice. 2008;58(549):248-54.

8. Saunders N, Tennis O, Jacobson S, Gans M, Dick P. Parents' responses to symptoms of respiratory tract infection in their children. Canadian Medical Association Journal. 2003;168(1):25-30.

9. de Bont EG, Peetoom KK, Moser A, Francis NA, Dinant GJ, Cals JW. Childhood fever: a qualitative study on GPs' experiences during out-of-hours care. Fam Pract.2015;32(4):449-55.

10. Dovey S, Weitzman M, Fryer G, Green L, Yawn B, Lanier D, et al. The Ecology of Medical Care for Children in the United States. Pediatrics. 2003;111(5):1024-9.

11. Andre M, Hedin K, Hakansson A, Molstad S, Rodhe N, Petersson C. More physician consultations and antibiotic prescriptions in families with high concern about infectious illness--adequate response to infectionprone child or self-fulfilling prophecy? Family practice. 2007;24(4):302-7.

12. Peetoom K, Ploum L, Smits J, Halbach N, Dinant G, Cals J. Childhood fever in well-child clinics: a focus group study among doctors and nurses. BMC Health Services Research. 2016;16:240.

13. de Bont E, Loonen N, Hendrix D, Lepot J, Dinant G, Cals J. Childhood fever: a qualitative study on parents' expectations and experiences during general practice out-of-hours care consultations. BMC family practice. 2015;16:131.

14. Enserink R, Lugnér A, Suijkerbuijk A, Bruijning-Verhagen P, Smit HA, van Pelt W. Gastrointestinal and Respiratory Illness in Children That Do and Do Not Attend Child Day Care Centers: A Cost-of-Illness Study. PLOS ONE. 2014;9(8):e104940.

15. Hashikawa AN, Brousseau DC, Singer DC, Gebremariam A, Davis MM. Emergency Department and Urgent Care for Children Excluded From Child Care. Pediatrics. 2014;134(1):e120-e7 


\section{Chapter 5}

\section{"I am not a doctor", views of childcare staff on decision-making on febrile children: a qualitative study}

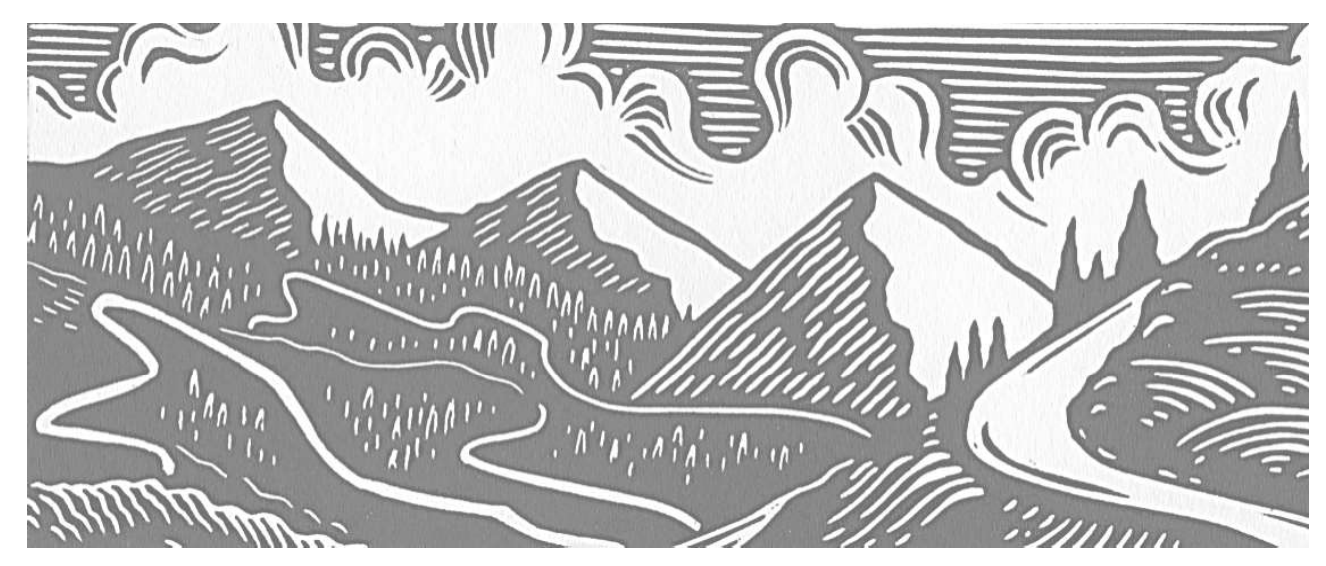

Kirsten Peetoom, Rik Crutzen, Inge Alleleijn, Luc Laumen, Albine Moser, Geert-Jan Dinant, Jochen Cals "I'm not a doctor...", Attitudes of child care providers towards childhood fever decision-making: a qualitative study.

Submitted. 


\section{ABSTRACT}

Children attending childcare are more prone to acquire infections. Fever and common infections in childhood cause substantial absenteeism among children from childcare, as well as more healthcare use and higher productivity loss in parents compared to homecared children. Previous research showed that childcare staff drive absenteeism and healthcare use. This study obtained in-depth insight into the experiences and knowledge of childcare staff underlying their decision-making process and advising of parents regarding childhood fever, which is useful to inform future interventions. Semi-structured interviews were conducted in 20 childcare staff from one childcare organization. Three additional interviews were conducted in another childcare organization to check completeness and transferability. Thematic analysis revealed that the decision-making process and advising parents on childhood fever is influenced by the perceived severity of child's symptoms such as height of fever, the operating protocol, their experience-based knowledge, intuitive judgement, and consultations with colleagues. Childcare staff acknowledged to advise parents defensively, e.g. sending a child home and advise parents to consult the GP, because they lack formal medical education. Additionally, childcare staff demonstrated a need to be educated on childhood fever by experts. 


\section{INTRODUCTION}

In recent decades, it has become more common that both parents within one family go to work. This results in rising numbers of dual earners receiving childcare allowance in the Netherlands together with an increasing number of children attending childcare [1-4]. Children 0 to 4 years old are susceptible to acquire fever and common infectious diseases, and particularly children attending childcare are more prone to infections than home-cared children. Children in childcare experience approximately 6-12 infection illness episodes per year, resulting in about 23 absent days from childcare [5-8]. In turn, childhood illness causes a substantial productivity loss in parents since they have to take approximately 1.5 days off from work during each child's illness episode [9-11]. This productivity loss is the main reason that societal costs for common infections are twice as high for children in childcare compared to home-cared children [9]. Children in childcare also consult the GP more often and have a higher risk for hospital referral compared to home-cared children [10, 12-14]. Childcare (CC) staff are an important source of information to parents but may also drive childcare absences, healthcare service use, and productivity loss among parents [15-19].

Most CC organizations have guidelines on coping with illness in children. However, previous quantitative studies show that CC staff may lack knowledge towards the content of these guidelines [20]. Consequently, CC staff may apply inappropriate decision-making strategies and trigger unnecessary childcare absences, healthcare service use, or antibiotic prescriptions for fever and respiratory symptoms [19, 21-24]. Accordingly, CC staff's advices may drive healthcare service use since parents may feel pressured to consult to maintain a good relationship. For example, because they have to provide a doctor's note upon return to childcare $[17,18,21,25,26]$.

To our knowledge, this is the first qualitative study to obtain insight into the experiences, knowledge, and attitudes towards decision-making and advising parents on childhood fever among childcare staff, which is also useful to inform future interventions.

\section{METHODS}

\section{Approach}

We conducted a qualitative descriptive study based on the principles of naturalistic inquiry [27]. Participants were childcare (CC) staff. Using in-depth interviews, we explored childcare staff's experiences, knowledge, and attitudes towards decision-making and advising parents on febrile children. We report our results using the consolidated criteria for reporting qualitative research [COREQ] checklist [28].

\section{Setting}

Approximately 407,000 children aged 0 to 4 years old attended formal CC centers in the Netherlands in 2017 [29]. Staff in formal CC centers are educated to provide daily care to children 0 to 4 years old, to monitor, and promote their development [30]. National guidelines on ill children exist to inform illness policy in individual CC organizations [31]. 
Municipal Public Health Services [GGD] need to be notified by CC centers when an outbreak of a specific infectious disease occurs. Subsequently, CC centers inform parents about the currently prevailing infectious disease by means of Public Health Services information leaflets [32]. This study was conducted in a large CC organization with 21 CC centers in the southern region of province Limburg (the Netherlands). In this region, about 21,000 children attend formal CC centers [29].

\section{Recruitment and respondents}

The participating CC organization was purposefully sampled. Subsequently, the quality manager of this organization approached the directors of the $21 \mathrm{CC}$ centers, in a director meeting, to participate in the study. Five CC centers indicated they were willing to participate. Every CC center determined by mutual agreement who, with a fixed tenure at that center and regardless of their years of work experience, would participate. The interviews took place during working hours in their own CC center

and a colleague replaced participants during the interview. Three out of five CC centers were located in an urban area, and the other two in a suburban region. The size of the CC centers ranged between 29 and 124 children 0 to 4 years old. We approached another CC organization in the same region to conduct three additional interviews.

\section{Data Collection}

Data were collected between April and June 2015. We interviewed four CC staff employees of each of the five participating CC centers. The topic list was developed by means of sensitizing concepts and derived from existing literature and prior team discussions [33]. The topic list included questions on experiences, knowledge, attitudes towards decisionmaking and advising parents on childhood fever. The topic list also included questions to explore their needs towards education on fever (see table 1).

Two researchers (IA, LL) performed the interviews. Both were present at all interviews, with one researcher leading the interview, while the other made field notes to capture ambiance, course of the interview, and to check comprehensiveness of obtained answers. The observer posed additional questions when necessary. Each interview lasted approximately 45 minutes. Data saturation in coding was reached after 16 interviews [34]. We performed four additional interviews to confirm our findings within this CC organization. We performed three interviews in a different CC to check if their experiences and views towards decision-making were comparable.

\section{Analysis}

Data collection and analysis were performed in parallel. The topic list was refined after each set of four interviews per CC center during team discussions. Interviews were audiorecorded and subsequently transcribed verbatim. Thematic analysis, using the constant comparison technique, was used to analyse the interviews and field notes. The interviews were inductively analysed and consisted of open and axial coding [35]. IA and LL performed independently open coding and started the axial coding process using NVivo software 
version 11.0. Subsequently, KP performed the final axial coding. The themes were discussed within the wider research team until consensus was reached.

\section{Trustworthiness}

Credibility was achieved by means of triangulation. Different methods of data collection were applied to enhance methodological triangulation, such as semi-structured interviews and field notes made by the observer. Data source triangulation was accomplished by combining experiences of staff working at different $\mathrm{CC}$ centers within two different $\mathrm{CC}$ organizations operating in different areas with a variety of socio-economic status and educational levels in the province of Limburg, the Netherlands. Next, the research team consisted of academic researchers with a background in health sciences, psychology and public health, nursing, two academic GPs, and two junior doctors to provide various perspectives that enhance investigator triangulation. We provided descriptive information on the setting, study population, and research process to safeguard transferability of results. The research team held regular meetings throughout the project to discuss methodological issues and findings. An aggregated summary of preliminary findings was sent to participants as member check.

\section{Ethical considerations}

The study was approved by the Medical Ethics Committee of Maastricht University Medical Center (METC 13-4-060.4). All the participants received verbal and written information about the study and provided written informed consent prior to the interview. Forms with personal information of the CC staff, audio recordings and transcriptions were anonymously analysed and stored.

Table 1 Topic list

\section{Knowledge and attitude}

- What are your experiences with childhood fever?

- How do you feel about fever?

- What are your views towards the use of paracetamol when a child has a fever?

- How did you obtain your knowledge about fever?

\section{Decision-making}

- How do you act when a child has a fever?

- How important is consultation with colleagues when a child is ill?

- What is your opinion regarding your organizational guidelines on ill children?

- How do you view your responsibility towards an ill child?

\section{Parental factors}

- What are the knowledge, attitudes, and practices of parents towards childhood fever?

- Can you tell us how the communication with parents goes when a child has a fever?

\section{Need for Improvement}

- Do parents need to be educated on childhood fever?

- Do you want more education on childhood fever? 


\section{RESULTS}

Four childcare (CC) staff employees participated from each of the five participating CC centers $(\mathrm{N}=20)$. They had an average age of 39.2 years and an average $\mathrm{CC}$ work experience of 17 years. Fifteen of these participants had children themselves. Three additional interviews were conducted in a different CC organization in the same region with participants having an average age of 34.7 years, an average CC work experience of 10 years and two out of three had children themselves. All participants were female.

We identified two main categories: (1) factors influencing decision-making among CC staff on childhood fever, (2) advising parents towards picking up their febrile child, or consulting a GP. Subcategories were identified for each main category (see figure 1).

\section{Factors influencing decision-making on febrile children}

According to CC staff, decision-making and advising parents on febrile children varies among CC staff. As will be shown in this section, CC staff perceive that this variation emanates from the child's illness symptoms, differences in CC staff's experiences, knowledge, and attitudes, and following the organizational guidelines on ill children versus their own intuitive judgement towards childhood fever.

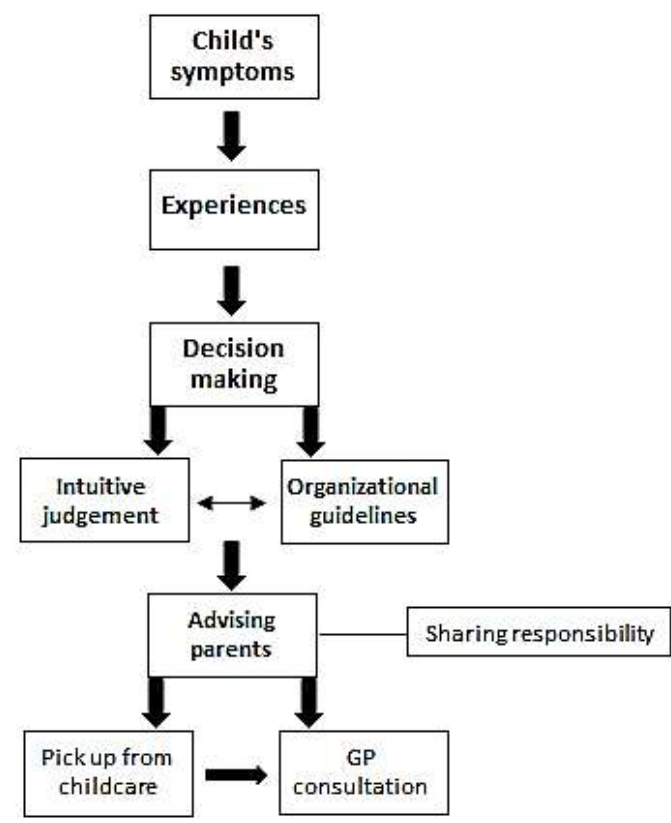

Figure 1 Overview of decision-making among childcare staff towards childhood fever 


\section{Children's symptoms}

CC staff acknowledged to frequently encounter febrile children during their work hours and they experience that children may react very differently on fever. At one end of the spectrum, children with a body temperature of $38^{\circ} \mathrm{C}$ may feel miserable and only want to sit on staff's lap. While on the other end, children with a body temperature of $40^{\circ} \mathrm{C}$ may bounce around. These different illness presentations lead to variation in decision-making since each ill child may cause a certain degree of worry in staff.

"In itself, it always remains uncertain because every child reacts differently to being ill, to the fever, or what happens at the moment [in the child], so a kind of panic always occur, I think. It involves a child and what could happen to that child, so yes." Respondent 1.1

When CC staff notice that a child is listless, has red cheeks, feels warm, or shows abnormal behavior, their first action is to measure the child's body temperature to check for fever. When a child does have a fever, $\mathrm{CC}$ staff contact the parents to inform and to discuss a plan of action. For most CC staff depends their plan of action heavily on their own personal attitude towards the height of the body temperature:

"Above $40\left({ }^{\circ} \mathrm{C}\right)$ I really think: come and pick up the child because I find that worrying at this age." Respondent 1.1

Some CC staff responded not feeling worried when a child has a fever. However, when the body temperature rises, they also acknowledged to start worrying about the possible severity of underlying causes and potential consequences.

"If that temperature goes even higher ... and that they get into a febrile seizure, or that something is going on that is developing, and that I have no idea of and because I do not see that temperature rise even higher in a fast pace." Respondent 1.4

All CC staff acknowledged they do not feel comfortable anymore in caring for an ill child when the body temperature is $39^{\circ} \mathrm{C}$ or higher because they fear a febrile seizure.

"Because as soon as a child is really over 40 or around 40 than I already have something like 'mooooh'. No febrile seizures .. no febrile seizures.." Respondent 2.2

However, some CC staff also stated that the child's behavior is more important in decisionmaking than the body temperature.

"But in my previous team, I can remember that there were differences in it. Yes, there really were employees who said g like: "Yes, he has a fever, he has to go home now." While I am again more inclined to look at ..., yes if a child can just function in the group and I do not worry about, that child may stay that way." Respondent 1.4

Organizational guidelines on ill children versus intuitive judgement

CC staff acknowledge that they see and use the organizational guidelines on ill children as an important guidance, but also as a source of protection towards parents in deciding to send a febrile child home. CC staff believe that their CC organization specifically developed 
these exclusion guidelines to protect them. For instance, most CC staff mentioned that a child has to be excluded according the guidelines when the body temperature exceeds $39^{\circ} \mathrm{C}$ to protect them against the occurrence of febrile seizures in children under their supervision.

"I think that's okay. Yes, somewhere there is a limit, of course, because than you can say: 39.5 or 39.9 and then you have to ... just 39, that is clear, is a guideline." Respondent 2.1

CC staff also thought that providing paracetamol was also not allowed anymore because of the perceived role of paracetamol in causing febrile seizures. As a result, most CC staff start to worry when they find out that a child received a paracetamol before coming to $\mathrm{CC}$ and parents did not communicate this.

So, despite the fact that the organization guidelines on ill children are perceived as a safety net, CC staff within and between different CC centers seem to differ regarding the extent in which the organizational guidelines are applied.

"Yes, because after all, everyone is different and everyone does things in her own way. Everyone senses things differently, has different norms and values and acts differently. Despite the fact that there are guidelines, everyone is different', and then it is important that you ... yes about almost everything actually discuss." Respondent 4.4

Next to decision-making based on organizational guidelines, some CC staff also acknowledged to base their decision-making on their intuitive judgement. It depends however on the child's symptoms and their experiences if the organization guidelines or their own intuitive judgement prevails in their decision-making process.

"A lot about fever and sickness, is not only, of course a bit of a protocol, but I notice that I am particularly aware of my feeling and my sense of responsibility ... yes. If I have the feeling, I can bear this responsibility and I see what happens here, that it's fine. But if I have somewhat the idea of: this rises above what I think I know, I'm like, someone else has to take that responsibility." Respondent 1.4

\section{Experience-based decision-making}

Related to basing their decisions on their intuitive judgement, almost all CC staff mentioned that their decision-making on ill children emanates from experience-based knowledge, obtained either at work or at home, and not through formal medical education.

"It is actually my own experience and interest what I know or say, but yes, at work we occasionally get information about the guidelines and so on but not actually about the how and what. How it works. Actually, we receive very little information about it at work." Respondent 5.1

In addition, CC staff also acknowledged that discussions with their CC colleagues, mainly based on sharing experiences, influences their decision-making. These discussions take 
place during periodical meetings with the complete team, but more often among colleagues when a child becomes ill.

"Yes you look at a given moment through certain glasses, shall I say and you see your own things and your own.. yes, feeling also plays along. And another person looks differently through those glasses so by communicating and discussing with each other yes .. do you think of 'oh yes what she says, is also true' or what she says 'yes, you are right '. So at a certain moment you will reach a better conclusion." Respondent 3.1

They also felt that it was important to discuss ill children with colleagues but also admitted to rely on the experiences and views of more experienced colleagues when they were feeling not that certain.

"I also acted upon ill children when I just started here but I left it more to my colleagues or I asked for more help: Would it be this? Or shall I do this and this?" Respondent 4.4

The interviews showed as well that decision-making on febrile children may be influenced by experiences in other $\mathrm{CC}$ centers. For example, one CC staff noticed to act extra cautiously towards febrile children due to experiences of colleagues with febrile seizures in other centers.

"Not from my own experience but l've heard it from colleagues from another center, that febrile seizures occur a lot and that it is horrifying to witness. I am now really aware of that it can happen here too. That's why I think it is important that parents report paracetamol provision to us. So I can work out when the body temperature will peak again and when I have to be extra focused on their behavior." Respondent 1.1

\section{Advising parents}

According to CC staff, the child's symptoms influences decision-making, but also advising parents. CC staff receive questions from parents on what disease is causing the symptoms, management strategies, and if GP consultation is needed. CC staff admitted as well to regularly advise parents to pick up their ill child, as they believe that an ill child is more comfortable at home, or to consult a GP. CC staff acknowledged that - when they do not feel comfortable anymore to care for an ill child - they urge parents to pick up the child when the body temperature is $39^{\circ} \mathrm{C}$ or higher, or when a child cannot join the group activities.

"When I have the feeling that I can bear this responsibility and I see what happens here, that's fine. But if I have the slightest idea of: this rises above what I think I know, then I have something like, someone else has to take that responsibility." Respondent 1.3

CC staff mostly stated to try to take the situation of parents into account when a child is mildly ill and try to keep the child at the CC center, as long as possible. Especially when they know that parents have no safety net to pick up their ill child. 
"There are also parents who just do not have that possibility [asking family members to pick up the child]. They have no network nearby and yes, they really indicate: I'm sorry, but I have to choose to let the child stay." Respondent 1.1

However, CC staff expressed to feel sometimes uncomfortable in advising parents as they experience that one group of parents is eager to learn from CC staff, especially when they have a young firstborn child, while other parents show to be less open to receiving CC staff's advices.

"There are parents who really ask for advice: how do you deal with that? Especially if it is a first child, a smaller child. They really do ask: how do you deal with that? So that they can also get advice from us ... There are also parents who just really in their own way, I will say, deal with that child and expect to continue their way here." Respondent 1.1

In addition, CC staff acknowledged to sometimes experience difficulties regarding parents and picking up their ill child. To clarify, they experience that one group of parents is coming straight away when CC staff call them, while other parents tend to delay the moment to pick up their child as long as possible. In the latter, CC staff felt their worries increased the longer it takes until the parents come to pick up the child.

"You sometimes notice that it is actually .. yes that it really does not come true. And than you try a bit of a .. yes it is a tricky one, because sometimes you really do not trust it and then you said: yes, I really want them to be picked up." Respondent 4.2

CC staff regularly advise parents to consult the GP - when parents pick up their ill child especially when they think the body temperature is becoming too high, when the duration of symptoms is taking too long, when the child's behavior is very abnormal. CC staff acknowledged that their advices are mostly experience-based. However, they feel they lack medical knowledge to diagnose a child with certainty. As a result, CC staff provide defensive advices (e.g. consult a GP) to protect themselves from giving wrong advices. All CC staff independently stated throughout their interviews:

"I am not a doctor".

"I would not want that there is more going on, that is overlooked, because I have said that it is only this or that. (...) Yes, I have something like: I can give my advice and my opinion, I cannot diagnose. (..) So yes, I always give that to parents." Respondent 4.3

They often advice parents to follow their intuition if they hesitate to consult the GP. This largely relates to the defensive attitude of CC staff and their strong feeling as they do not want to be held responsible if the clinical situation deteriorates.

"If your [of parents] feeling is: this is not right. Than call the GP. Saying this to parents can make an important difference." Respondent 4.3

Accordingly, CC staff demonstrated a need to receive education by experts to increase knowledge in coping with febrile children. 
"I think that it [information by experts] can make CC staff feel more secure in acting in situations that are different than others, yes, in case of illness, yes. And that would not even be ... not so very stupid then something very specific to fever, because it is of course so general, the fever piece." Respondent 1.4

CC staff also indicate that parents would benefit from education on fever, as they notice large differences among parents in fever knowledge and management. However, CC staff would not feel confident to provide this education themselves.

"No, I [CC staff] would rather let someone else do that who has really knowledge and understanding. Who can explain fever, its course, consequences and strategies, and who really knows what he says." Respondent 2.3

\section{DISCUSSION}

According to $\mathrm{CC}$ staff, decision-making and advising on childhood fever varies among staff members and depends on the child's symptoms and the staff's experiences with febrile children. In addition, children's symptoms in combination with the staff's experience-based knowledge determine if they follow the organizational guidelines on ill children or their own intuitive judgement. CC staff lack formal medical education and their decision-making is therefore mainly based on experience-based knowledge and discussions with colleagues. CC staff acknowledged to advise parents defensively in order to protect themselves of giving wrong advices. CC staff express the need to be educated on fever by experts. In their opinion, parents should also be educated on fever management. However, CC staff do not feel confident enough to educate parents themselves.

\section{Comparison with literature}

In line with previous research, fever, and particularly a high fever, showed to be an important symptom in deciding if a child has to be send home $[20,21,24,36,37]$. Participants admitted to send febrile children home because fever increased their worries. However, fever itself was for some CC staff not always worrisome and they perceived the child's illness behavior as a more important indicator for their decision. In accordance with another study, most CC staff felt that an ill child should be cared for at home [38]. Despite this, when the fever increases, all CC staff in our study preferred to send a febrile child home. Our findings confirm earlier findings that fear of fever may be more a cultural trait within their organization and not individually learned, since consultations and sharing experiences with colleagues were experienced as vital in decision-making processes on febrile children [39].

In accordance with an earlier vignette survey, $\mathrm{CC}$ staff perceived that most decisions were experience-based and that less experienced childcare staff tended to rely on more experienced colleagues. More years of work experience increased their own perceived degree of certainty towards decision-making on ill children. However, and in contrast with the same study, experienced participants demonstrated still a high level of worries regarding childhood fever, especially when they have had negative experiences in the past. 
Thus, inappropriate decisions were not less likely in more experienced staff due to their fear of fever [40].

CC staff in our study also acknowledged that the child's symptoms, and especially the height of fever, determined if the organizational guideline or their intuitive judgement guided their decision-making. The interviews showed however that most participants falsely assumed that the organizational guideline contained $39^{\circ} \mathrm{C}$ as cut-off point for sending children home. CC staff perceived this presumed cut-off point as a way to protect them against the occurrence of febrile seizures under their supervision. $\mathrm{CC}$ staff also thought that providing paracetamol was not allowed because of the perceived role of paracetamol in causing febrile seizures, while this reasoning is not based on current scientific evidence [41, 42]. Successively, and in line with previous research, the current organizational guideline seems to be based on "common sense" and incorrect beliefs, instead of on scientific evidence [21].

As a result, CC staff frequently require GP consultation and antibiotics on return $[18,19,36$, 37]. CC staff in our study acknowledged that transferring liability is an important driver underlying these advices. CC staff lack medical education and are afraid to provide a wrong diagnosis, because they advise parents now mainly based on their experiences. Therefore, CC staff tend to advise parents defensively on the child's illness. Some participants also acknowledged that advising parents was sometimes perceived as difficult, especially when parents are not open to advice. A previous survey among CC staff, parents, and pediatricians also showed that most believed that staff lacked knowledge to care for mildly ill children [20]. This feeling is not strange since previous research showed that most parents, pediatricians and also CC staff were not convinced that staff possessed enough knowledge to care for mildly ill children and believed that staff might be held legally responsible when something bad happens to an ill child [20].

Furthermore, previous research indicates that decision-making might vary between different CC organizations and that CC staff are consistent in which child has to be temporarily excluded from childcare due to illness $[20,21]$. However, our study showed that CC staff within one organization might vary as well in decision-making on childhood fever. This variation occurs as the extent of the child's symptoms influence the decision of $\mathrm{CC}$ staff to follow the organizational guideline or their intuitive judgement. Accordingly, another study showed that healthcare professionals such as pediatricians may base their decisions on common sense as well and not on guidelines [43]. An important difference is however, that pediatricians are medically educated and possess appropriate knowledge towards childhood fever, while CC staff in our study did not receive any formal medical education. Another study shows as well that it is common that CC staff do not receive formal education on fever management and on CC attendance [22]. Subsequently, it is not surprising that CC staff demonstrated a need to receive more education from experts and a little confidence towards educating parents themselves.

\section{Strengths/limitations}

This study is the first qualitative exploration of the decision-making process on childhood fever among CC staff. The interviews enabled us to obtain insight into which factors 
influence decision-making and advising on childhood fever and, more importantly, how these factors are related to each other. Another strength of our study is that participants were interviewed in their own CC center to feel more at ease. Next, CC staff of five different CC centers participated in the study to ensure that our analysis incorporated views from different contexts. However, it is possible that statements of $\mathrm{CC}$ staff reflect the prevailing culture towards fever in an individual center. To tackle this, we asked CC staff to compare their own decision-making process to those of their close colleagues and to different $\mathrm{CC}$ centers. In addition, since participation was decided based on mutual agreement within one center, some selection bias may have occurred. We conducted three additional interviews in another CC organization serving as double-check. The findings showed to be comparable in both CC organizations, which indicates that our findings are transferable to other Dutch CC organizations. However, findings are possibly not one-to-one transferable to other countries, due to differences in national guidelines and healthcare systems. However, while other studies provided insight in appropriateness of decision-making on specific infectious symptoms, we mainly focused on fever management.

\section{CONCLUSIONS AND IMPLICATIONS}

Childcare staff acknowledge to vary in decision-making and advising parents on childhood fever. This variation emanates from their perceived severity of a child's symptoms such as height of fever, the operating protocol, their experience-based knowledge, intuitive judgement, and consultations of colleagues. Their intuitive judgement is mainly based on previous experiences and on discussions with colleagues since CC staff lack medical education. Consequently, CC staff are reluctant to advise parents on fever management and self-management strategies and they tend to frequently advise parents to consult the GP to transfer liability. In addition, CC staff have a low self-efficacy towards educating parents. CC staff should be educated on fever pathophysiology and fever management (e.g. when to consult a doctor) to stimulate that their decision-making and advices to parents are more evidence-based and less experience-based. 


\section{REFERENCES}

1. Centraal Bureau Statistiek [Statistics Netherlands]. Meer tweeverdieners met een voltijdbaan én een grote deeltijdbaan [More two-income households with a full-time job and a large part-time job]. Den Haag/Heerlen; 2015 29/01/2015.

2. Centraal Bureau Statistiek [Statistics Netherlands]. Recordaantal kinderen met kinderopvangtoeslag [Record number of children with childcare allowance]. Den Haag/Heerlen; 2018.

3. Centraal Bureau Statistiek [Statistics Netherlands]. De arbeidsmarkt in cijfers 2016. Den Haag/Heerlen: Centraal Bureau Statistiek [Statistics Netherlands],; 2017.

4. Sociaal en Cultureel Planbureau [The Netherlands Institute for Social Research]. Landelijk ramingsmode kinderopvang 2002-2010 [National estimation of childcare 2002-2010],. Sociaal en Cultureel Planbureau [The Netherlands Institute for Social Research],; 2003.

5. Roberts L, Smith W, Jorm L, Patel M, Douglas RM, McGilchrist C. Effect of infection control measures on the frequency of upper respiratory infection in child care: a randomized, controlled trial. Pediatrics. 2000;105(4 Pt 1):738-42.

6. Pönkä A, Nurmi T, Salminen E, Nykyri E. Infections and other illnesses of children in day-care centers in Helsinki. I: Incidences and effects of home and day-care center variables. Infection. 1991;19(4):230-6.

7. Zomer TP, Erasmus V, Looman CW, Tjon-A-Tsien A, Van Beeck EF, De Graaf JM, et al. A hand hygiene intervention to reduce infections in child daycare: a randomized controlled trial. Epidemiol Infect. 2015;143(12):2494-502.

8. Uhari M, Mottonen M. An open randomized controlled trial of infection prevention in child day-care centers. The Pediatric Infectious Disease Journal,. 1999;18(8):672-7.

9. Enserink R, Lugnér A, Suijkerbuijk A, Bruijning-Verhagen P, Smit HA, van Pelt W. Gastrointestinal and Respiratory Illness in Children That Do and Do Not Attend Child Day Care Centers: A Cost-of-Illness Study. PLOS ONE. 2014;9(8):e104940.

10. Silverstein M, Sales AE, Koepsell TD. Health care utilization and expenditures associated with child care attendance: a nationally representative sample. Pediatrics. 2003;111(4 Pt 1):e371-5.

11. Hay AD, Redmond NM, Turnbull S, Christensen $H$, Thornton $H$, Little $P$, et al. Development and internal validation of a clinical rule to improve antibiotic use in children presenting to primary care with acute respiratory tract infection and cough: a prognostic cohort study. The Lancet Respiratory medicine. 2016;4(11):902-10.

12. de Hoog ML, Venekamp RP, van der Ent CK, Schilder A, Sanders EA, Damoiseaux RA, et al. Impact of early daycare on healthcare resource use related to upper respiratory tract infections during childhood prospective WHISTLER cohort study. BMC medicine. 2014;12:107.

13. van de Pol AC, van der Gugten AC, van der Ent CK, Schilder AG, Benthem EM, Smit HA, et al. Referrals for recurrent respiratory tract infections including otitis media in young children. International journal of pediatric otorhinolaryngology. 2013;77(6):906-10.

14. Bell DM, Gleiber DW, Mercer AA, Phifer R, Guinter RH, Cohen AJ, et al. Illness Associated with Child Day Care: A Study of Incidence and Cost. American Journal of Public Health. 1989;79(4):479-84.

15. Ingram J, Cabral C, Hay AD, Lucas PJ, Horwood J. Parents' information needs, self-efficacy and influences on consulting for childhood respiratory tract infections: a qualitative study. BMC family practice. 2013;14:106.

16. Shapiro ED, Kuritsky J, Potter J. Policies for the exclusion of ill children from group day care: an unresolved dilemma. Reviews of infectious diseases. 1986;8(4):622-5.

17. Ertmann RK, Soderstrom M, Reventlow S. Parents' motivation for seeing a physician. Scandinavian journal of primary health care. $2005 ; 23(3): 154-8$.

18. Skull SA, Ford-Jones EL, Kulin NA, Einarson TR, Wang EE. Child care center staff contribute to physician visits and pressure for antibiotic prescription. Archives of Pediatrics \& Adolescent Medicine,. 2000;154(2):180-3.

19. Rooshenas L, Wood F, Brookes-Howell L, Evans MR, Butler CC. The influence of children's day care on antibiotic seeking: a mixed methods study. British Journal of General Practice. 2014;64(622):e302-12. 
20. Copeland KA, Duggan AK, Shope TR. Knowledge and beliefs about guidelines for exclusion of ill children from child care. Ambulatory Pediatrics. 2005;5(6):365-71.

21. Kahan E, Gross S, Cohen HA. Exclusion of ill children from child-care centers in Israel. Patient education and counseling. 2005;56(1):93-7.

22. Hashikawa AN, Stevens MW, Juhn YJ, Nimmer M, Copeland K, Simpson P, et al. Self-Report of Child Care Directors Regarding Return-to-Care. Pediatrics. 2012;130(6):1046-52.

23. Pappas DE, Schwartz RH, Sheridan MJ, Hayden GF. Medical exclusion of sick children from child care centers: a plea for reconciliation. Southern Medical Journal,. 2000;93(6):575-8.

24. Landis SE, Earp JA, Sharp M. Day-care center exclusion of sick children: comparison of opinions of day-care staff, working mothers, and pediatricians. Pediatrics. 1988;81(5):662-7.

25. Hashikawa AN, Brousseau DC, Singer DC, Gebremariam A, Davis MM. Emergency Department and Urgent Care for Children Excluded From Child Care. Pediatrics. 2014;134(1):e120-7.

26. Slack-Smith LM, Read AW, Stanley FJ. Parental attitudes to health of children in child-care centres and options when children are ill. Journal of paediatrics and child health. 2000;36(6):577-80.

27. Lincoln Y, \& Guba, G,. Naturalistic Inquiry,. California, USA: SAGE Publications; 1985.

28. Tong A, Sainsbury., P, Craig, J,. Consolidated criteria for reporting qualitative research (COREQ): a 32-item checklist for interviews and focus groups. International Journal for Quality in Health Care.2007;19(6):34957.

29. Centraal Bureau Statistiek [Statistics Netherlands]. Formele kinderopvang; kinderen, uren, soort opvang, vorm opvang, regio [Formal childcare; children, hours, type and extent of care, region]. Den Haag/Heerlen 2018 03/07/2018

30. Wet Kinderopvang [Childcare Act], Stb. 2017/252 (2018).

31. RIVM [National Institute for Public Health and the Environment]. Informatie over ziektebeelden voor kinderdagverblijven, peuterspeelzalen en buitenschoolse opvang [Information about syndromes for child day care centers, preschools and school care]. Amsterdam 2016. p. 9-10.

32. GGD Zuid-Limburg [Municipal public health services South Limburg]. Deurbriefjes voor kindercentra [Door notes for childcare centers], Heerlen [Available from: https://www.ggdzl.nl/professionals/infectieziekten/ deurbriefjes-voor-kindercentra/

33. Bowen GA. Grounded Theory and Sensitizing Concepts. International Journal of Qualitative Methods. 2006;5(3):12-23.

34. Polit DF, Beck CT. Nursing research: Generating and assessing evidence for nursing practice. Philidelphia USA: Lippincott Williams \& Wilkins; 2008.

35. Strauss A, Corbin, J,. Basics of qualitative research: Grounded theory procedures and techniques. California, USA, : Sage Publications, Inc.; 1990.

36. Sticher B, Bielicki J, Berger C. Temporary exclusion of ill children from childcare centres in Switzerland: practice, problems and potential solutions. BMC Health Services Research. 2018;18:25.

37. M'ikanatha NM, Gasink LB, Kunselman A, Warren K, Lautenbach E. Child Care Center Exclusion Policies and Directors' Opinions on the Use of Antibiotics. Infection control and hospital epidemiology : the official journal of the Society of Hospital Epidemiologists of America. 2010;31(4):408-11.

38. Friedman JF, Lee GM, Kleinman KP, Finkelstein JA. Child care center policies and practices for management of ill children. Ambulatory pediatrics. 2004;4(5):455-60.

39. Pursell E \& Collin J. Fever Phobia: The impact of time and mortality-a systematic review and meta-analysis. International Journal of Nursing Studies. 2016;56:81-9.

40. Hashikawa AN, Juhn YJ, Nimmer M, Copeland K, Shun-Hwa L, Simpson P, et al. Unnecessary Child Care Exclusions in a State That Endorses National Exclusion Guidelines. Pediatrics. 2010;125(5):1003-9.

41. The Dutch College of General Practitioners [NHG]. My child has a febrile seizure [Mijn kind heeft een koortsstuip].

42. Offringa M, Newton R. Prophylactic drug management for febrile seizures in children (Review). EvidenceBased Child Health: A Cochrane Review Journal. 2013;8(4):1376-485. 
Chapter 5

43. Kahan E, Gross S, Horev Z, Grosman Z, Cohen HA. Pediatrician attitudes to exclusion of ill children from childcare centers in Israel: pressure on ambulatory practices. Patient education and counseling. 2006;60(2):16470 . 


\section{Chapter 6}

\section{Does well-child care education improve consultations and medication management for childhood fever and common infections? \\ A systematic review}

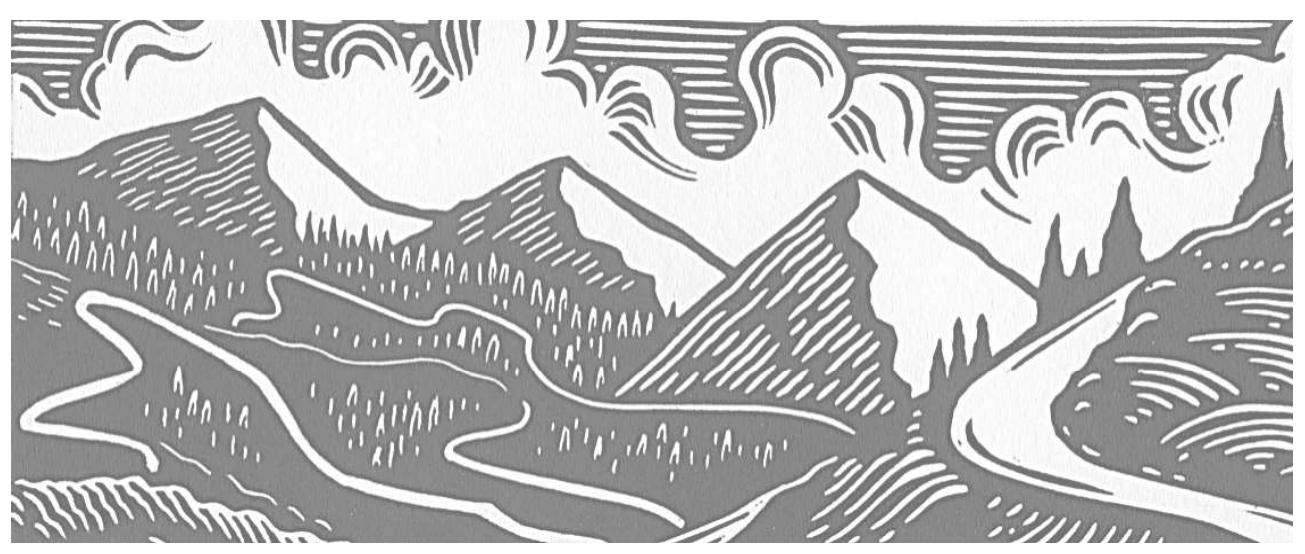

Kirsten Peetoom, Jacqueline Smits, Luc Ploum, Jan Verbakel, Geert-Jan Dinant, Jochen Cals. Does well-child care education improve consultations and medication management for childhood fever and common infections? A systematic review.

Published in: Arch Dis Child. 2017 Mar;102(3):261-267. 


\section{ABSTRACT}

Background Fever is common in preschool children and is often caused by benign selflimiting infections. Parents' lack of knowledge and fever phobia leads to high healthcare consumption.

Objective To systematically review the effect of providing educational interventions about childhood fever and common infections in well-child clinics (WCCS), prior to illness episodes, on parental practices: healthcare-seeking behaviour (frequency of physician consultations, appropriateness of consultations) and medication management.

Design Medline, Embase, CINAHL, PsycINFO, Cochrane Library, Web of Science were searched. We included randomised controlled trials evaluating interventions in WCC settings focusing on educating parents prior to new illness episodes to improve parental practices during episodes of childhood fever and common infections. Data were extracted on study design, sample characteristics, type of intervention, outcome measures and results.

Results Eight studies were eligible for data extraction. Educating parents, in WCCs, prior to new episodes of childhood fever and common infections reduces daytime physician consultations of parents, home visits and telephone consultations, and enhances medication management. However, single and multicomponent interventions vary in effectiveness in reducing the frequency of daytime physician consultations and differ in their potential to reduce the number of home visits and general practitioner out-of-hours contacts. Only multicomponent interventions achieved a reduction in telephone consultations and improved medication management.

Conclusion Educating parents in WCCs prior to episodes of childhood fever and common infections showed potential to improve parental practices in terms of healthcare-seeking behaviour and medication management. 


\section{INTRODUCTION}

Fever is common in children aged 0-4 years and leads to a high consumption of healthcare services and medication [1-6]. A lack of knowledge regarding the pathophysiology and management of fever is an important driver of fever phobia among parents [2,7], and subsequently leads to increased healthcare-seeking behaviour [1, 6, 8]. Parents tend to rely on family, friends, well-child clinic (WCC) nurses or local pharmacists for guidance when an acute illness worries them, and often consult a general practitioner (GP) or are advised to do so $[9,10]$. When consulting, parents expect physical examination, reassurance, information and practical guidance on fever management from their physician, especially when anxious about a possible severe underlying condition [6, 11-17]

Previous research suggests that educating parents during consultations reduces parental uncertainty and anxiety, improves fever management, and thus may lead to fewer visits to healthcare professionals [18-20]. In addition, two recent systematic reviews in primary care showed that educating parents during primary care consultations may lead to reductions in (re)consultation rates, and antibiotic and prescription use [21, 22].

However, some studies underline the importance of providing education prior to new episodes of fever and common childhood infections to better prepare parents $[2,8,16,21$, 23]. Preventive information provision on childhood fever and common infections might be most successful when embedded in routine care in WCC settings. In many countries, children aged 0-4 years visit the WCC on set occasions for development check-ups, vaccinations and information provision [24, 25]. Yet, an overview is needed to inform future interventions in countries where information provision on fever is not formally part of the WCC.

The aim of this study is to systematically review the effect of providing educational interventions about childhood fever and common infections in WCCs, prior to illness episodes on parental practices: healthcare-seeking behaviour (frequency of physician consultations) and medication management.

\section{METHODS}

We performed our systematic literature review in accordance with the Preferred Reporting Items for Systematic Reviews and Meta-Analyses [26].

\section{Search strategy and selection criteria}

In September 2014 we conducted a systematic search of the literature in the scientific databases Medline, Embase, CINAHL, PsycINFO, Cochrane Library and Web of Science. The search was limited to articles published after January 1980. We used a combination of varying terms for parents, children, healthcare professionals, fever, common childhood infections, educational interventions, knowledge, attitudes and practices. Both MeSH terms and free search terms were used in Medline. Common childhood infections were defined as frequently occurring and mostly self-limiting infections of the respiratory, urinary and 
gastrointestinal tracts. Limits were applied for HIV, HIV/AIDS, human papillomavirus (HPV), hepatitis, malaria and sexually transmitted diseases. See online supplementary appendix 2 for the search strategy. A total of six articles were added based on expert opinion.

We included randomised controlled trials (RCTs) published in English, Dutch, German or French. Included studies had to investigate the effect of providing an educational intervention about childhood fever and common infections in WCC settings, prior to a child's new fever episode, on parental healthcare seeking practices in WCC settings. Articles were included if they reported on the outcome 'parental practices' which was defined as actual use of healthcare services by parents for childhood fever and common infections. We explicitly excluded articles focusing on changing practices of healthcare providers, parental self-reported care-seeking behaviour, or when education was provided to parents during, instead of prior to, a child's illness episode.

\section{Study selection}

We first filtered the list of retrieved titles by removing duplicates. The three authors (JJMS, LLP and KKBP) independently screened the remaining titles according to our inclusion criteria. Titles were deliberately screened broadly with regard to study setting due to international differences in the organisation and provision of preventive healthcare services for children which can be delivered, for example, by paediatricians and Head Start agencies (USA), primary care physicians (UK), or specially trained WCC doctors and nurses (the Netherlands) [25]. Title screening of the first 250 studies was performed by all three authors and agreement was reached on all relevant studies. The remaining 4262 studies were equally divided between JJMS and LLP for additional title screening and KKBP screened all 4512 titles. All titles were screened by at least two authors. After title selection, we narrowed our inclusion criteria to only including RCT studies investigating interventions for educating parents, prior to childhood illness episodes of fever and common infections, aimed at improving parental care-seeking behaviour. Abstract and full-text screening were performed by JJMS and LLP, and studies were included after deliberation with a third reviewer (KKBP). Disagreement was resolved after each stage of the selection process by means of discussion with the broader research team. We reviewed the reference lists of all included full-text papers for additional potentially relevant papers.

\section{Data extraction and synthesis}

Data extraction was carried out independently by JJMS and LLP, and checked by KKBP. Data were extracted from each article and encompassed study design, follow-up period, setting and population, type of intervention, method of outcome assessment, and outcomes of interest (table 1). Main effects on parental care-seeking practices were extracted and subdivided into two main outcome measures: (1) frequency of physician consultations, including daytime consultations to GP, physician or (paediatric) emergency department, telephone consultations, home visits, out-of-hours consultations, and appropriateness of consultations; (2) medication management (table 2). We recalculated study outcomes into relative risks and their $95 \% \mathrm{Cls}$ in order to perform a meta-analysis when appropriate. 
The type of intervention was classified either as 'single' or 'multicomponent' based on the mode of distribution to parents. An intervention was classified as single when the intervention was distributed to parents without any reinforcement and consisted of one specific intervention component, for example, a booklet. An intervention was categorised as multicomponent when the intervention was actively distributed or reinforced during individual or group educational meetings, for example, educational sessions accompanied with written materials. Any disagreements were discussed and resolved by consensus.

\section{Quality assessment}

The quality of included RCT studies was independently assessed by three reviewers (JJMS, LLP and KKBP) according to the criteria of the Cochrane risk of bias tool (table 3 and see online supplementary appendix 1) [36]. We contacted the authors of included articles to request missing information on methodological characteristics.

\section{RESULTS}

The literature search identified 4512 unique references, of which 43 studies met the eligibility criteria for full-text screening (see figure 1). Eight studies were eligible for data extraction.

The main characteristics of included studies are presented in table 1. Two studies described the effects of single component interventions that consisted of providing a booklet together with a cover letter without explicit reinforcement to parents [27, 28]. A total of six studies described the effects of multicomponent interventions (table 2). Education was focused on common childhood infections [27, 28, 30, 31, 35], fever management [29], upper respiratory infections [34], and management of febrile seizures [33]. Population sample sizes ranged from 88 to 999 , covering a total of 3154 individual household members. The follow-up varied between 1 month [33], 4-7 months [29, 30, 34, 35, 37], and 12 months $[27,28]$. It was not possible to perform a meta-analysis due to a wide range of reported outcome measures.

\section{Risk of bias appraisal}

The risk of bias appraisal is presented in table 3 . More than half of the included studies were assessed as having a low risk of bias [27, 28, 30,31,34]. A high risk of bias was appraised in two studies in terms of sequence generation and management of incomplete data $[29,35]$. The risk of bias was unclear for the study of Najimi due to under-reporting of methodological characteristics [33]. We contacted six authors for additional information about missing methodological characteristics, however only Rasmussen, Usherwood and Casey responded.

\section{Frequency of physician consultations}

A total of seven studies examined the effect of an educational intervention on frequency of physician consultations (see table 1). A reduction in physician consultations was found by six studies $[27,29,30,31,34,35]$. Morrell demonstrated that parents in the intervention group initiated fewer GP consultations for fever, sore throat, diarrhoea and vomiting [27], 
and Robbins observed a significant reduction in the median number of child health clinic consultations [31]. Rasmussen demonstrated that mothers who received the intervention would follow recommendations about when to contact healthcare services significantly better than controls. It was also observed that mothers who read the booklet were less prone to seek medical care when not recommended by the booklet [30].

Stockwell demonstrated a significant decrease in paediatric emergency department (PED) consultations for upper respiratory infections ( $R R=0.58,95 \% \mathrm{Cl} 0.33$ to 1.00 ), with most PED consultations for children aged 6 months to 48 months. The number of PED consultations decreased proportionally with an increasing number of educational group sessions attended by parents [34]. Herman (high risk of bias) found a significant decrease of $37.5 \%$ in physician consultations and $48 \%$ in emergency department (ED) consultations [32], and Casey (high risk of bias) observed that the intervention group inappropriately consulted the physician in significantly fewer instances, $9.5 \%$ compared with $38.5 \%$ for controls [29].

However, Usherwood found no significant differences in mean frequency of GP consultations per household or consultations across all sites combined [28]. Morrell found no significant reduction in the mean number of GP consultations for all symptoms combined [27], and Robbins did not encounter a reduction in GP routine appointments [31].

\section{Frequency of home visits}

A total of three studies examined the effect of an educational intervention on the frequency of daytime GP home visits (table 2). Morrell [27] and Usherwood [28] both demonstrated significant effects on home visits, while Robbins found no significant results [31]. Morrell observed a statistically significant lower number of home visits in the intervention group ( $R R=0.65,95 \% \mathrm{Cl} 0.44$ to 0.83 ) [27]. Usherwood demonstrated a statistically significant lower mean number of GP daytime home visits in households with one to two children, which was mainly due to a reduction in the number of consultations for fever, cough and sore throat. However, this trend was inverted for households with three children [28].

\section{Telephone consultations}

A total of three studies examined the effect on the frequency of telephone contacts and showed varying results (see table 2). Herman and Casey both demonstrated significant reductions in GP telephone consultations. Herman demonstrated a $55 \%$ reduction in telephone consultations while Casey observed more appropriate telephone consultations in the intervention group of $26.1 \%$ versus $56.1 \%$ (control). However, both studies were also appraised as having a high risk of bias $[29,35]$. Robbins did not find a significant difference in telephone calls to nurses or health visitors [31].

\section{Out-of-hours contacts}

A total of two studies examined the effect on the frequency of GP out-of-hours consultations. Usherwood demonstrated a significant increase in the mean frequency of GP out-of-hours consultations, mainly for fever and for diarrhea [28], while Robbins did not observe an effect on the frequency of GP out-of-hours consultations [31]. 


\section{Medication management}

A total of four studies examined the effect on medication management and demonstrated predominantly significant effects (table 2). Stockwell's intervention group used significantly less inappropriate over-the-counter medication during illness episodes for children aged $<2$ years (OR $0.29,95 \% \mathrm{Cl} 0.09$ to 0.95 ) and made significantly less use of an incorrect dosing tool to provide the correct dosage of medication to children $<4$ years (OR $0.24,95 \% \mathrm{Cl} 0.08$ to 0.74 ). The number of households who administered non-prescribed antibiotics to their child aged $<4$ years was low and did not differ significantly [34]. The intervention group in the study by Casey administered significantly fewer incorrect doses of antipyretic medications to children during fever episodes [29]. Najimi (unclear risk of bias) demonstrated a significant effect on the number of correct practices for preventing febrile seizures, with $85.41 \%$ of the intervention group performing correct practices versus $80.94 \%$ by controls [33]. Robbins demonstrated no significant difference in prescription rates for antibiotics and other prescription medication [31].

\section{Single versus multicomponent interventions}

Both single and multicomponent interventions demonstrated varying results towards reducing the frequency of GP consultations [27, 28, 30, 31, 34, 35]. Single interventions investigating the effects of distributing a booklet to parents without any reinforcement, proved to be successful in reducing the frequency of home visits [27. 28] and initial GP consultations for fever, sore throat, diarrhoea and vomiting [27]. However, Usherwood's intervention also resulted in an increased use of out-of-hours consultations for febrile children and more GP daytime consultations for larger families [28]. Single interventions did not focus on reducing the frequency of telephone consultations or improving medication management.

Multicomponent interventions proved to be successful in reducing consultations to the physician, and in reducing telephone consultations [31,34,35]. However, the decrease in telephone consultations was only observed in studies with a high risk of bias $[29,35]$. Also, significant changes in medication management were observed alongside less inappropriate use of antipyretic medication [29] and over-the-counter medication, less use of an incorrect dosing tool [34], and more appropriate behaviour in the prevention of febrile seizures [33]. Multicomponent interventions were not successful in reducing the number of home visits or GP routine appointments. 


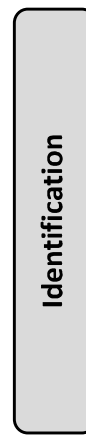

$$
\begin{aligned}
& \text { Records identified } \\
& \text { through database } \\
& \text { searching }(n=6252)
\end{aligned}
$$

\section{Additional records} identified through

other sources $(n=6)$
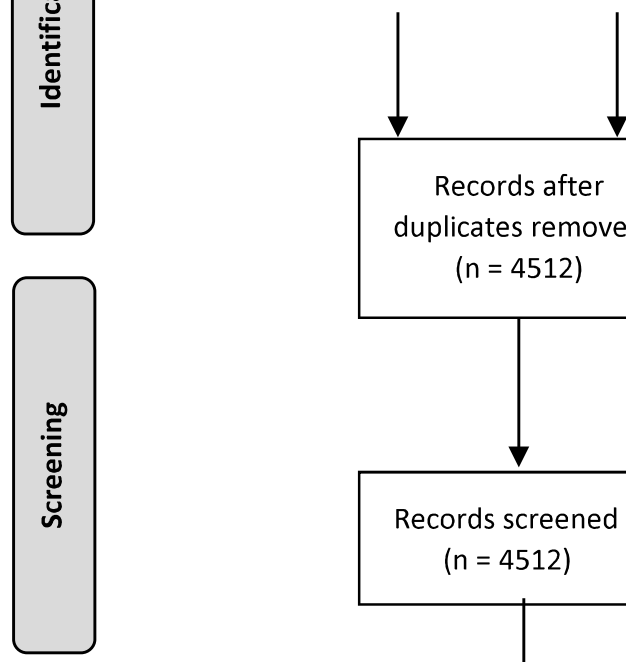

Records after duplicates removed $(n=4512)$
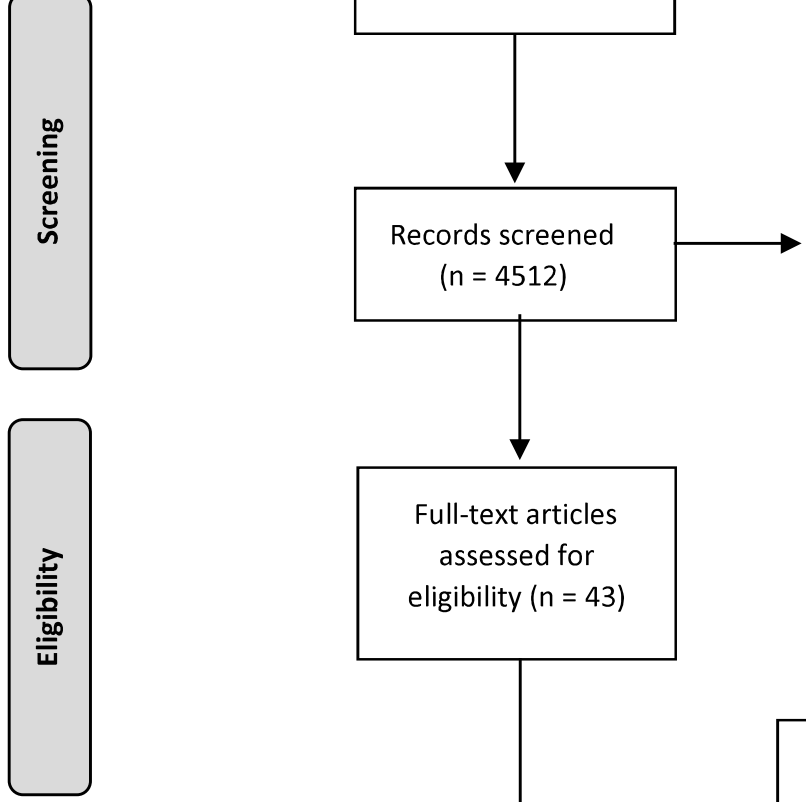

Records excluded by title and abstract screening ( $n=4475)$
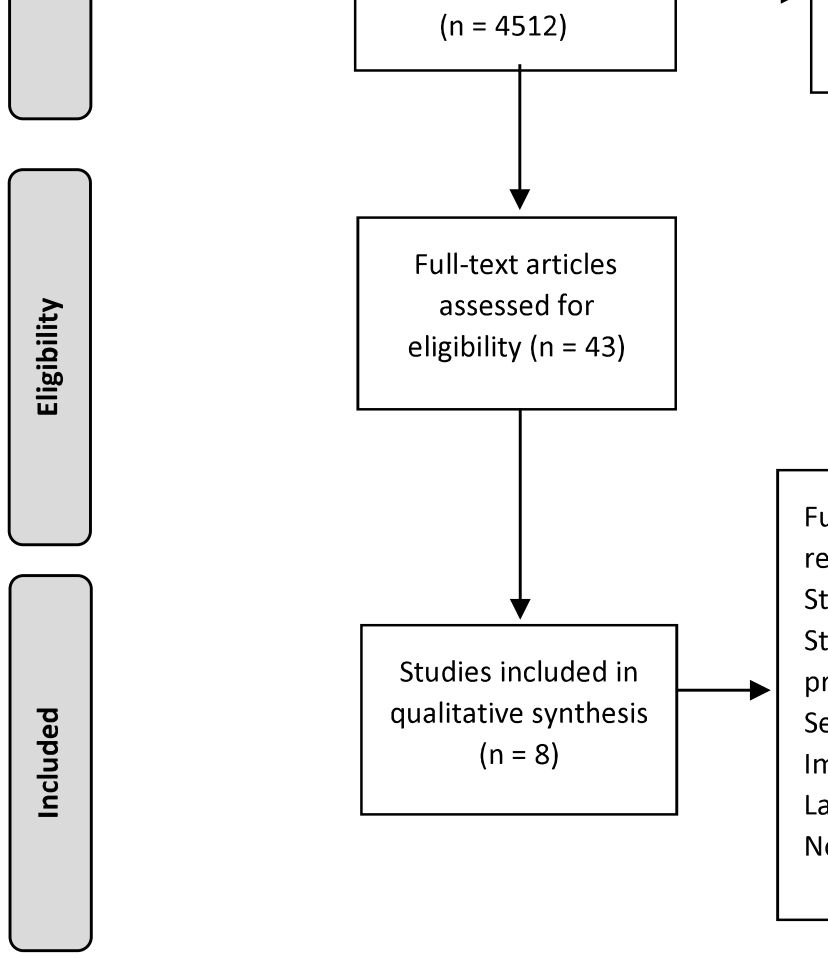

Full-text articles assessed for eligibility $(n=43)$

Full-text articles excluded, with reasons $(n=35)$ based on:

Study population (ill children): 12 Study population (healthcare professional):

Setting:

Immunization:

Language:

Not actual use of health care: 5

Figure 1 Flow diagram of study selection 


\begin{tabular}{|c|c|c|c|c|c|c|}
\hline 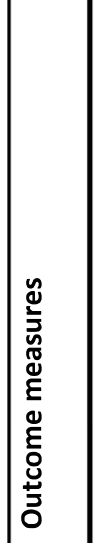 & 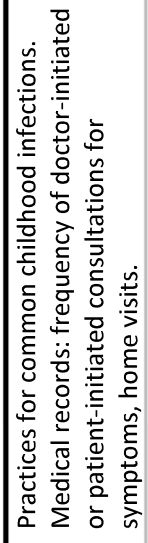 & 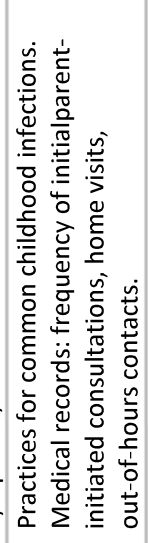 & 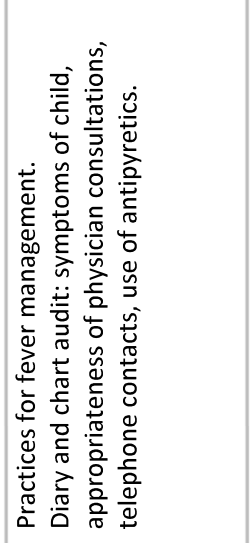 & 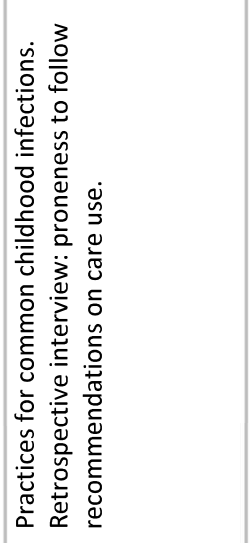 & 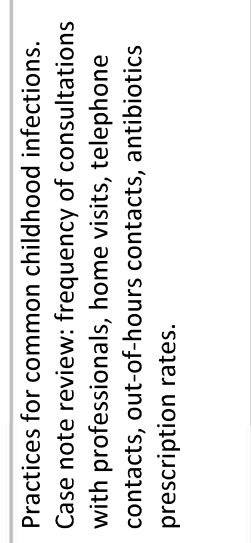 & 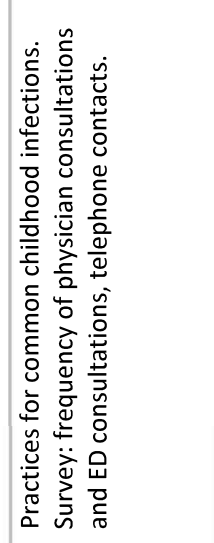 \\
\hline 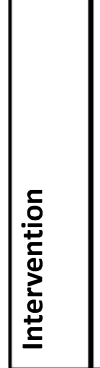 & 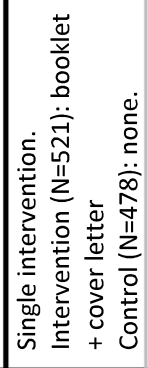 & 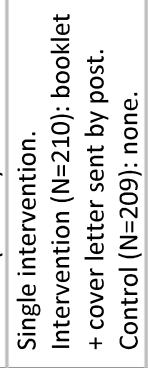 & 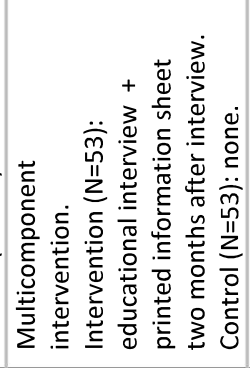 & 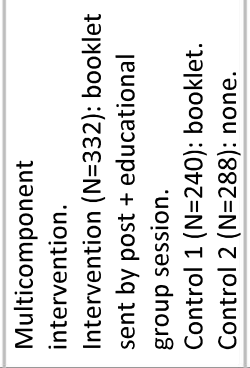 & 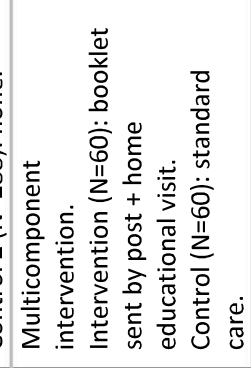 & 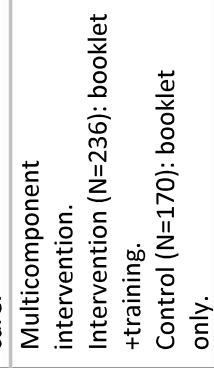 \\
\hline 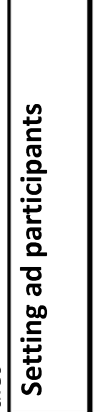 & 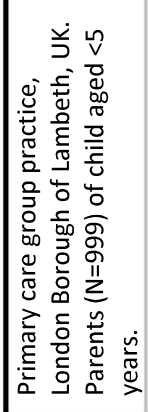 & 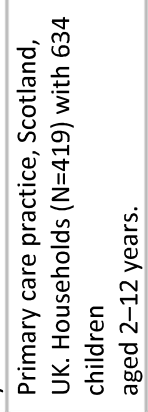 & 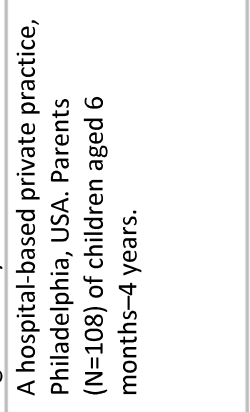 & 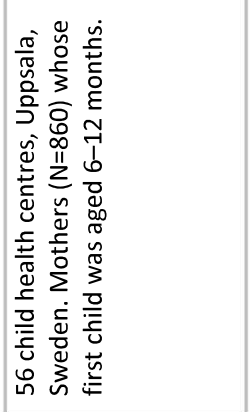 & 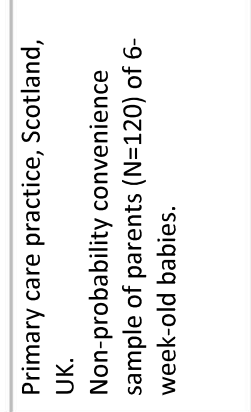 & 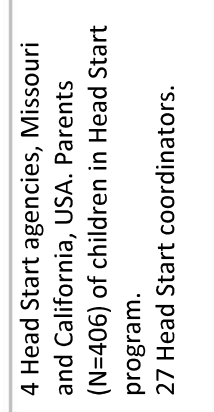 \\
\hline 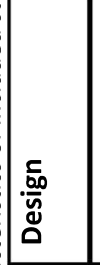 & 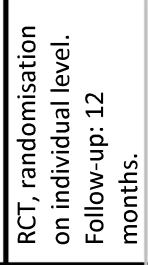 & 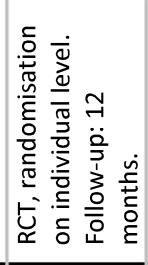 & 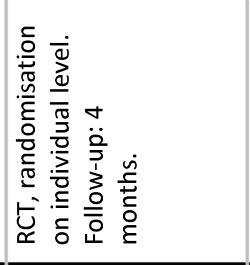 & 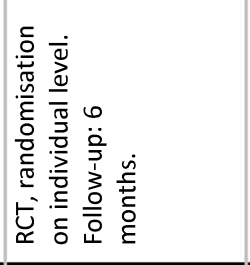 & 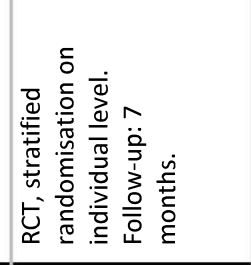 & 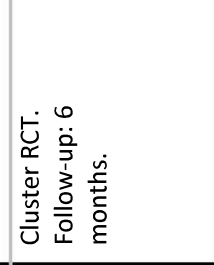 \\
\hline 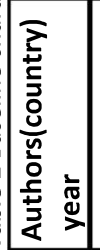 & 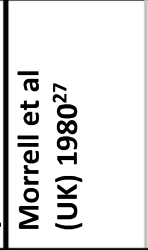 & 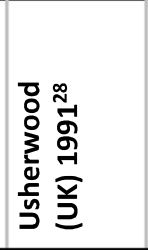 & 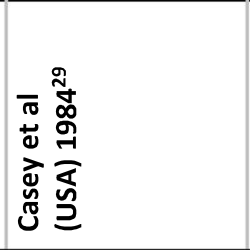 & 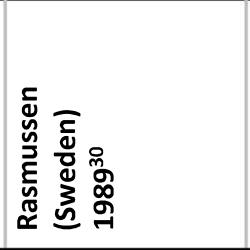 & 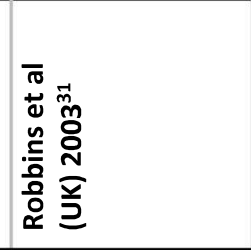 & 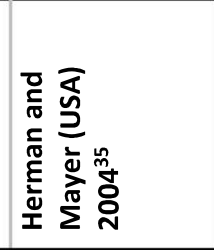 \\
\hline
\end{tabular}




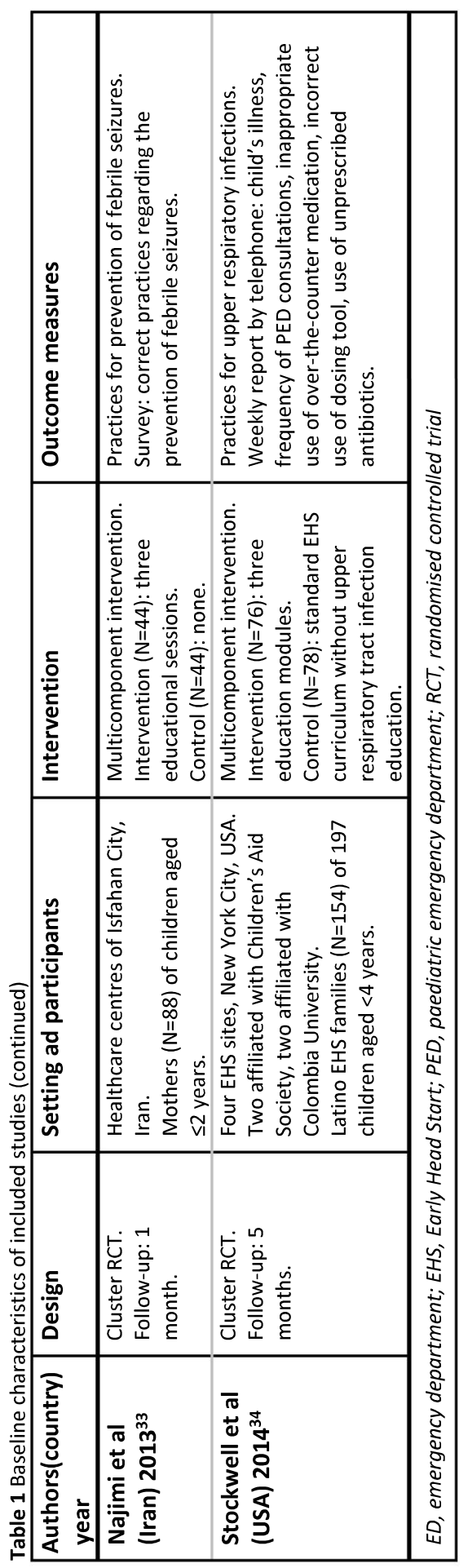




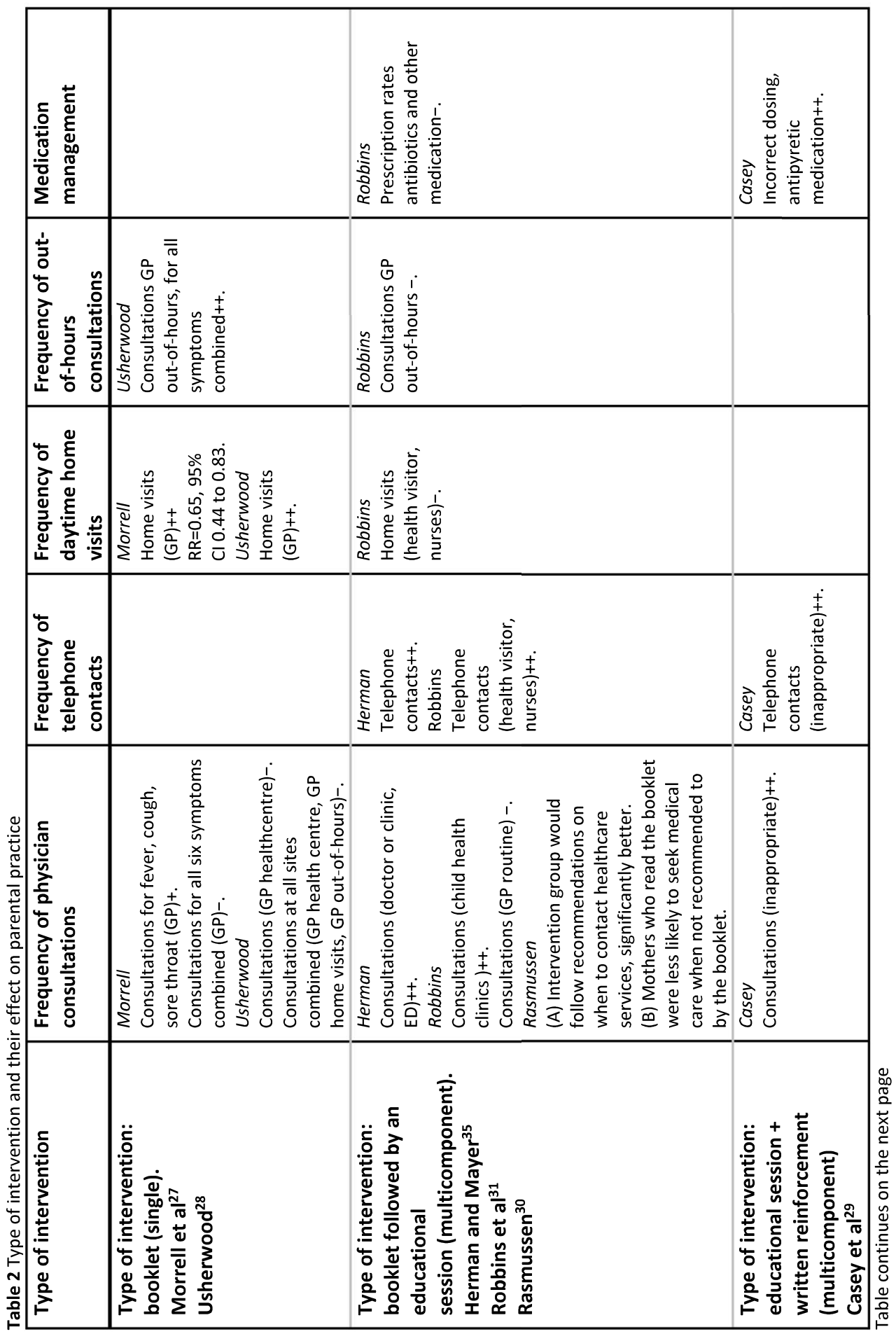




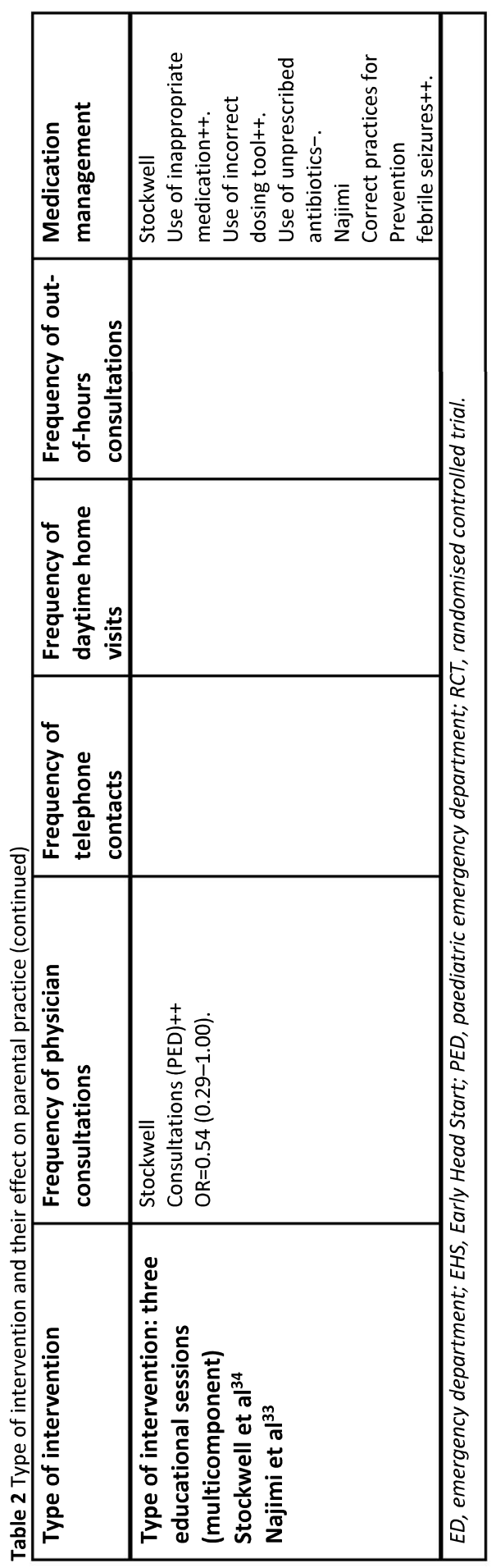




\begin{tabular}{|c|c|c|c|c|c|c|c|c|}
\hline 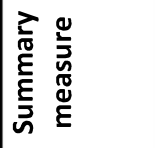 & |3 & 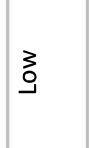 & 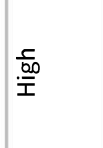 & 3 & 3 & $\frac{\frac{c}{\underline{b 00}}}{\frac{100}{I}}$ & 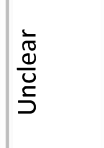 & a \\
\hline 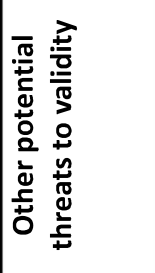 & 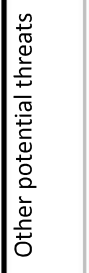 & 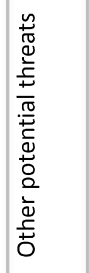 & 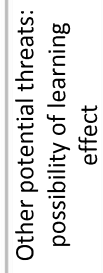 & 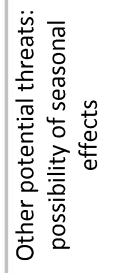 & 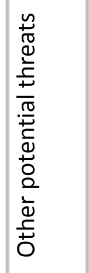 & 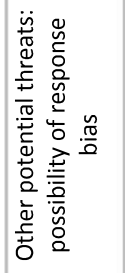 & 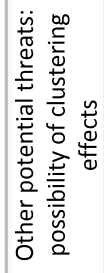 & 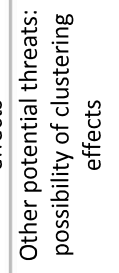 \\
\hline 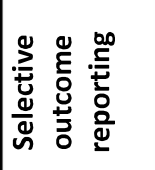 & $\mid \begin{array}{l}3 \\
0\end{array}$ & $\int_{0}^{3}$ & $3_{0}^{3}$ & $3_{0}^{3}$ & 3 & o & 3 & 吕 \\
\hline 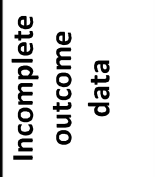 & |3 & $\int_{0}^{3}$ & $3_{3}^{3}$ & o & 3 & 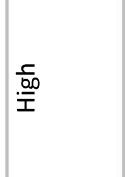 & o & $3_{0}^{3}$ \\
\hline 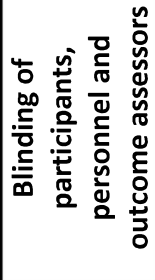 & 3. & 吕 & 3 & o & 3 & 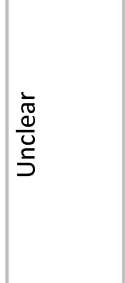 & 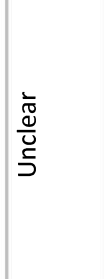 & כo \\
\hline 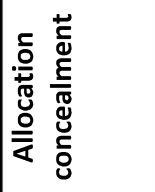 & 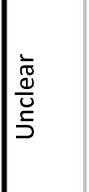 & 3 & 3 & 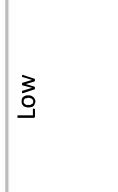 & $b_{0}^{3}$ & 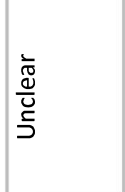 & z & 当 \\
\hline 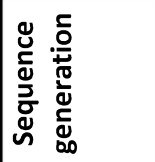 & 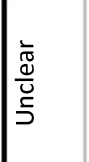 & $3_{0}^{3}$ & $\frac{\stackrel{c}{b 00}}{\frac{b 0}{I}}$ & 3 & 3 & 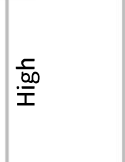 & 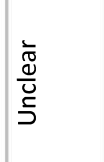 & 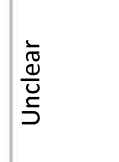 \\
\hline & 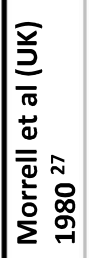 & 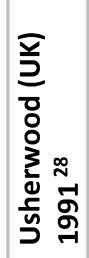 & 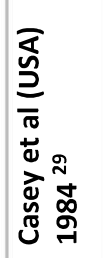 & 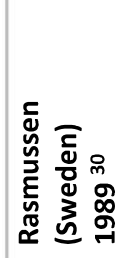 & 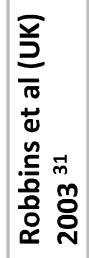 & 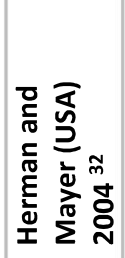 & 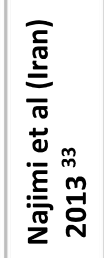 & 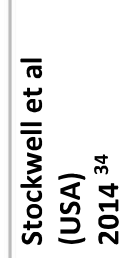 \\
\hline
\end{tabular}




\section{DISCUSSION}

WCC interventions demonstrated predominantly positive effects of educating parents prior to new episodes of childhood fever and common infections on healthcare seeking (physician consultations, telephone consultations, home visits) and medication management. However, interventions do differ in their potential to improve healthcare-seeking behaviour. To clarify, single and multicomponent interventions show contradictory results in reducing the number of daytime physician consultations and home visits. In addition, not all observed effects were beneficial since the significant reduction in daytime home visits in the study of Usherwood was offset by a significant increase in GP out-of-hours consultation. Changing healthcare-seeking behaviour in terms of telephone consultations and medication management was only targeted by multicomponent interventions.

The results of these included RCT studies are in line with four non-RCT studies, which also investigated the effects of educational interventions on the frequency of physician consultations for childhood infections and also varied in their potential to improve physician consultations and telephone contacts [32, 37-39]. In addition, two other recent systematic reviews in primary care also showed that educating parents may lead to reductions in (re)consultation rates, and antibiotics and prescription use [21, 22].

Educating parents about childhood fever and common infections happens in a wide variety of healthcare settings, with the setting of WCCs being just one example. Our review shows that WCC may be a good place to educate parents on fever and common infections prior to new illness episodes. In our search we identified one study in the setting of child daycare centres [40], which mainly focused on promoting hygiene measures to reduce contagion at daycare centres, with favourable effects on sickness absence, physician consultations and antibiotic prescriptions. Since fever is common in children aged $\mathbf{0 - 4}$ years, child day care centres may also be considered a good place for educating parents on fever and common infections.

To our knowledge, this is the first review reporting on the effectiveness of interventions aimed at educating parents, in WCCs, prior to episodes of childhood fever and common infections. Our search strategy was guided by a comprehensive list of key terms and our search was complemented with expert advice and snowballing. However, articles might have been overlooked due to our choice of keywords. In the selection process we only included RCT studies and appraised the potential threats of validity by means of the Cochrane tool to estimate true effects of the interventions. Our findings are restricted to countries with an organisation structure of WCC services similar to the Netherlands and the findings may be less generalisable to low income and middle income countries.

We chose physician consultations as our primary outcome measure. Although we identified many studies evaluating the effects of education on knowledge and attitudes towards fever management, only a limited number of studies actually monitored healthcare-seeking practices of parents. Since increased knowledge and changing attitudes towards childhood fever may change actual healthcare-seeking behaviour, we believe that practice-related 
outcomes are most relevant to know. Therefore, we chose to only include RCT studies that measured parental practices such as care seeking and medication management and not knowledge or attitudes.

Our review demonstrated predominantly positive results of educating parents prior to new episodes of childhood fever and common infections in the WCC setting on healthcareseeking and medication management. However, a number of included RCTs suffered from a high risk of bias and not all outcome measures were investigated by both single and multicomponent interventions. Also results between and within studies differed for specific outcome measures. As a result, it was not possible to perform a meta-analysis due to a wide range of differences in outcome measures under study.

Based on this review, it is difficult to decide if future interventions should focus more on single interventions without reinforcement or more comprehensive multicomponent interventions to improve the healthcare-seeking behaviour of parents. In that respect, our findings are not in line with recent research in which it was concluded that the most effective interventions are multicomponent, structured, relevant, reinforced over time and use personal discussions to adapt information to individual needs [41].

Educating parents by means of actively exchanging information prior to new illness episodes on childhood fever and common infections, either through single or multicomponent interventions, has the potential to change parental practices, and more specifically healthcare-seeking behaviour. 


\section{REFERENCES}

Schmitt BD. Fever phobia: misconceptions of parents about fevers. Am J Dis Child 1980;134:176-81.

2 Schmitt BD. Fever in childhood. Pediatr 1984;74(Pt 2):929-36.

3 Bruijnzeels MA, Foets M, van der Wouden JC, et al. Everyday symptoms in childhood: occurrence and general practitioner consultation rates. Br J Gen Pract 1998;48:880-4.

4 Hay AD, Heron J, Ness A. The prevalence of symptoms and consultations in pre-school children in the Avon Longitudinal Study of Parents and Children (ALSPAC): a prospective cohort study. Fam Pract 2005;22:36774.

5 André $\mathrm{M}$, Hedin $\mathrm{K}$, Hakansson A, et al. More physician consultations and antibiotic prescriptions in families with high concern about infectious illness-adequate response to infection-prone child or self-fulfilling prophecy? Fam Pract 2007;24:302-7.

6 Maguire S, Ranmal R, Komulainen S, et al. Which urgent care services do febrile children use and why? Arch Dis Child 2011;96:810-16

7 Crocetti M, Moghbeli N, Serwint J. Fever phobia revisited: have parental misconceptions about fever changed in 20 years? Pediatr 2001;107:1241-6.

8 Walsh A, Edwards H. Management of childhood fever by parents: literature review.

J Adv Nurs 2006;54:217-27.

9 Kai J. Parents' difficulties and information needs in coping with acute illness in preschool children: a qualitative study. BMJ 1996;313:987-90.

10 Osman LM, Dunt D. Factors influencing mothers' decisions to consult a general practitioner about their children's illnesses. Br J Gen Pract 1995;45:310-12.

11 Kai J. What worries parents when their preschool children are acutely ill, and why: a qualitative study. BMJ 1996;313:983-6.

12 Wyke S, Hewison J, Russell IT. Respiratory illness in children: what makes parents decide to consult? Br J Gen Pract 1990;40:226-9.

13 Butler CC, Rollnick S, Pill R, et al. Understanding the culture of prescribing: qualitative study of general practitioners' and patients' perceptions of antibiotics for sore throats. Brit Med J (Clin Res Ed) 1998;317:637-42.

14 Cunningham-Burley S, Irvine S. "And have you done anything so far?" An examination of lay treatment of children's symptoms. Br Med J (Clin Res Ed) 1987;295:700-2.

15 Kallestrup P, Bro F. Parents' beliefs and expectations when presenting with a febrile child at an out-of-hours general practice clinic. Br J Gen Pract 2003;53:43-4.

16 de Bont EG, Peetoom KK, Moser A, et al. Childhood fever: a qualitative study on GPs' experiences during out-of-hours care. Fam Pract 2015;32:449-55.

17 de Bont EG, Francis NA, Dinant GJ, et al. Parents' knowledge, attitudes, and practice in childhood fever: an internet-based survey. Br J Gen Pract 2014;64: e10-16.

18 Roberts CR, Imrey PB, Turner JD, et al. Reducing physician visits for colds through consumer education. JAMA 1983;250:1986-9.

19 Francis NA, Butler CC, Hood K, et al. Effect of using an interactive booklet about childhood respiratory tract infections in primary care consultations on reconsulting and antibiotic prescribing: a cluster randomised controlled trial. BMJ 2009;339: b2885.

20 Sarrell M, Kahan E. Impact of a single-session education program on parental knowledge of and approach to childhood fever. Patient Educ Couns 2003;51:59-63.

21 Andrews T, Thompson M, Buckley DI, et al. Interventions to influence consulting and antibiotic use for acute respiratory tract infections in children: a systematic review and meta-analysis. PLoS ONE 2012;7:e30334.

22 de Bont EG, Alink M, Falkenberg FC, et al. Patient information leaflets to reduce antibiotic use and reconsultation rates in general practice: a systematic review. Brit Med J Open 2015;5:e007612.

23 Robinson JS, Schwartz ML, Magwene KS, et al. The impact of fever health education on clinic utilization. Am J Dis Child 1989;143:698-704 
24 Commission of evaluation basic tasks Dutch youth healthcare. Een stevig fundament. Evaluatie van het basistakenpakket jeugdgezondheidszorg (A solid basis. Evaluation of basic tasks Dutch youth healthcare). 2013

25 Kuo AA, Inkelas M, Lotstein DS, et al. Rethinking well-child care in the United States: an international comparison. Pediatrics 2006;118:1692-702.

26 Liberati A, Altman DG, Tetzlaff J, et al. The PRISMA statement for reporting systematic reviews and metaanalyses of studies that evaluate health care interventions: explanation and elaboration. PLoS Med 2009;6:e1000100.

27 Morrell DC, Avery AJ, Watkins CJ. Management of minor illness. Br Med J 1980;280:769-71.

28 Usherwood TP. Development and randomized controlled trial of a booklet of advice for parents. Br J Gen Pract 1991;41:58-62.

29 Casey R, McMahon F, McCormick MC, et al. Fever therapy: an educational intervention for parents. Pediatrics 1984;73:600-5.

30 Rasmussen F. Mothers' benefit of a self-care booklet and a self-care educational session at child health centres. Soc Sci Med 1989;29:205-12.

31 Robbins H, Hundley V, Osman LM. Minor illness education for parents of young children. J Adv Nurs 2003;44:238-47.

32 Herman A, Jackson P. Empowering low-income parents with skills to reduce excess pediatric emergency room and clinic visits through a tailored low literacy training intervention. J Health Commun 2010;15:895910.

33 Najimi A, Dolatabadi NK, Esmaeili AA, et al. The effect of educational program on knowledge, attitude and practice of mothers regarding prevention of febrile seizure in children. J Educ Health Promot 2013;2:26.

34 Stockwell MS, Catallozzi M, Larson E, et al. Effect of a URI-related educational intervention in early head start on ED visits. Pediatr 2014;133:e1233-40.

35 Herman AD, Mayer GG. Reducing the use of emergency medical resources among Head Start families: a pilot study. J Comm Health 2004;29:197-208.

36 Higgins JPTAD, Sterne JAC. On behalf of the Cochrane Statistical Methods Group and the Cochrane Bias Methods Group. Chapter 8: assessing risk of bias in included studies. In: Higgins JPTDA, Sterne JAC, eds. Cochrane Handbook for Systematic Reviews of Interventions, 2011.

37 McWilliams DB, Jacobson RM, Van Houten HK, et al. A program of anticipatory guidance for the prevention of emergency department visits for ear pain. Arch Pediatr Adolesc Med 2008;162:151-6.

38 Fieldston ES, Nadel FM, Alpern ER, et al. Effects of an education and training intervention on caregiver knowledge of nonurgent pediatric complaints and on child health services utilization. Pediatr Emerg Care 2013;29:331-6.

39 Sides AT. Self-care education, parent knowledge, and children's health care visits. Pediatr Health Care 1988;2:135-40.

40 Hedin K, Petersson C, Cars H, et al. Infection prevention at day-care centres: feasibility and possible effects of intervention. Scand J Prim Health Care 2006;24:44-9.

41 Monsma J, Richerson J, Sloand E. Empowering parents for evidence-based fever management: an integrative review. Journal of the American Association of Nurse Practitioners, 27: 222-229. 


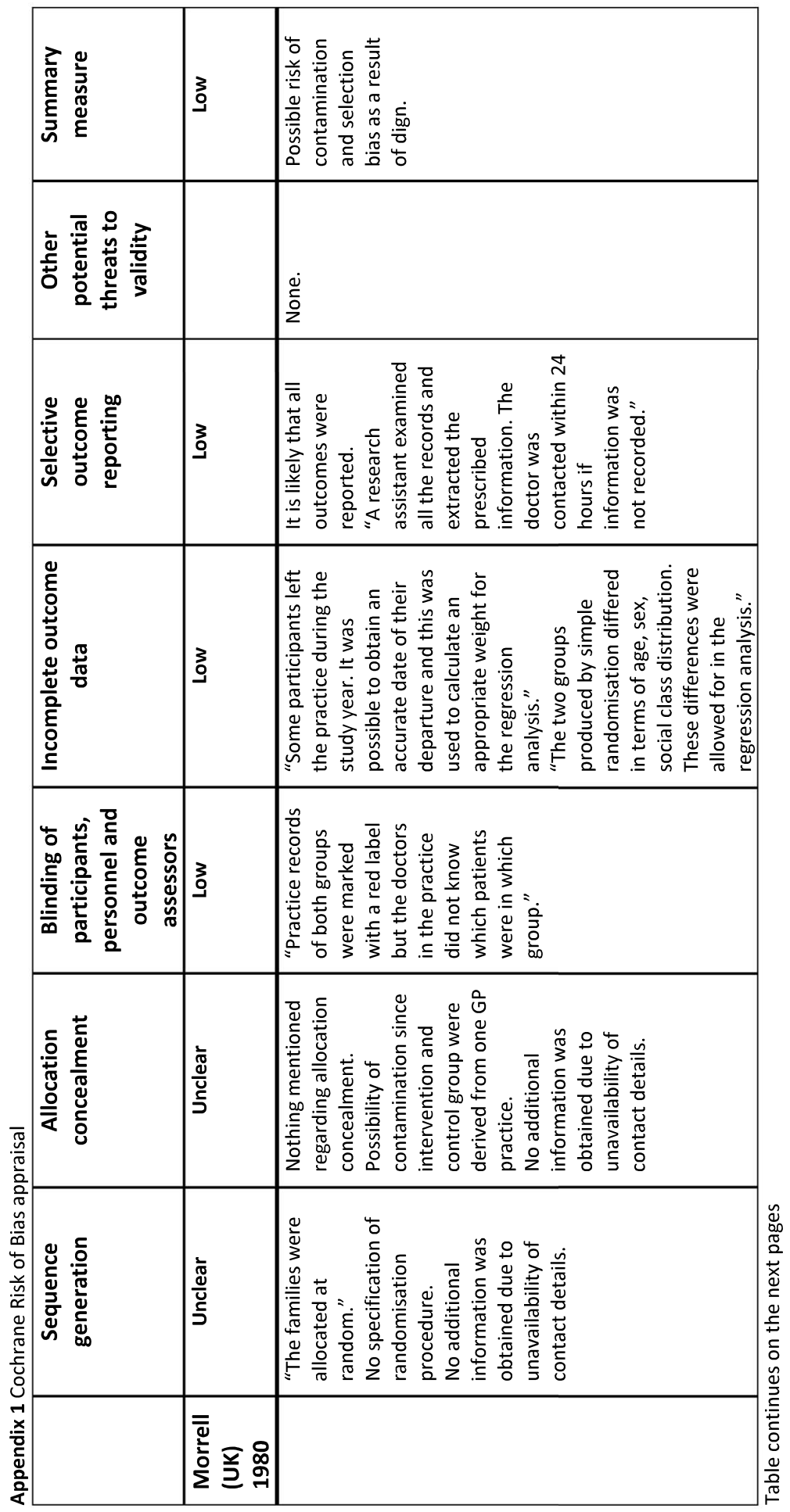




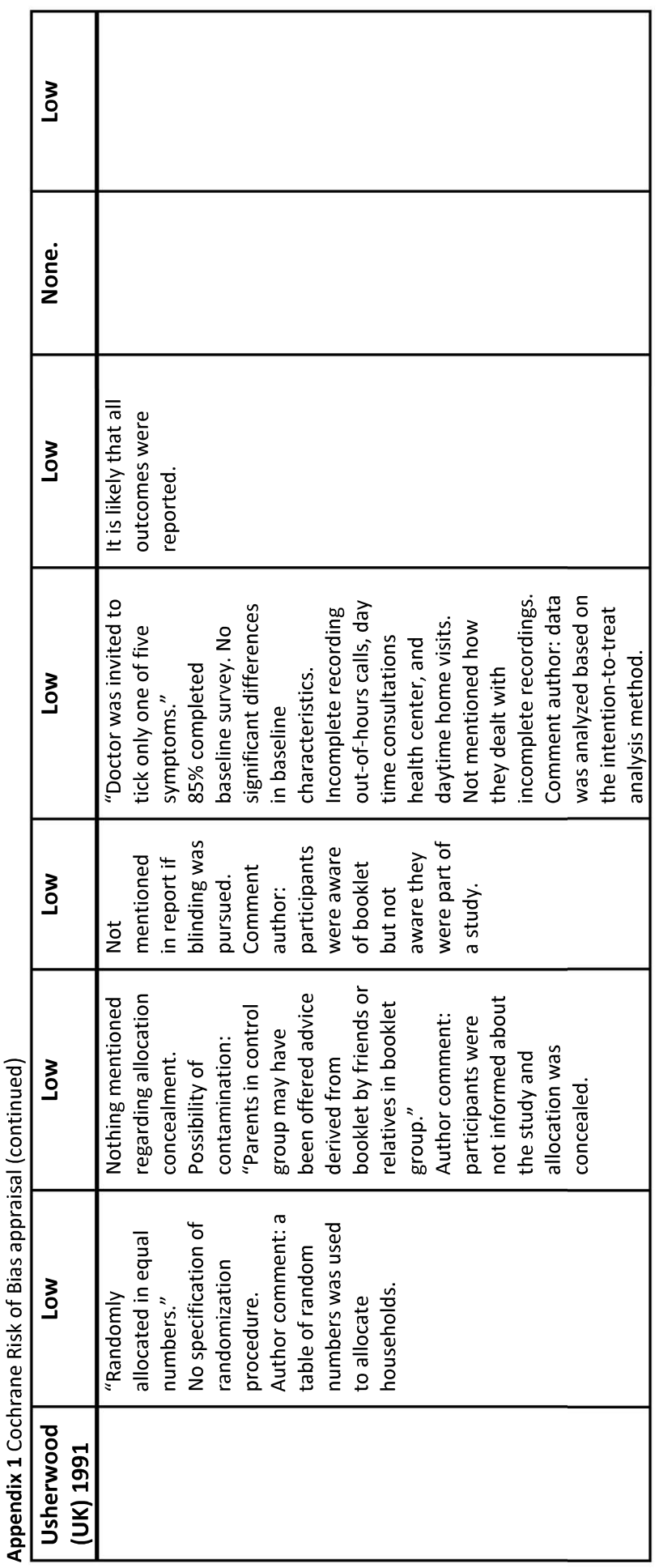




\begin{tabular}{|c|c|}
\hline 点 & 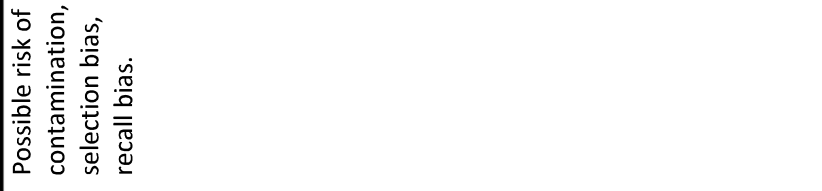 \\
\hline 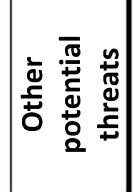 & 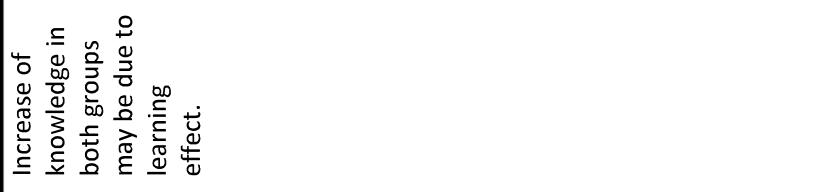 \\
\hline 艿 & 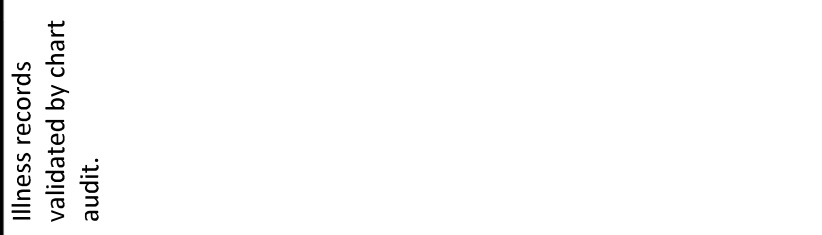 \\
\hline בِ & 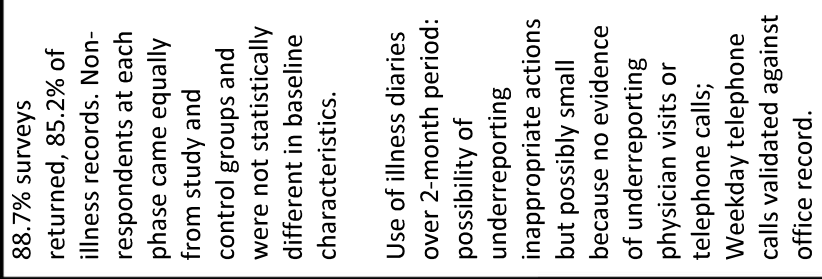 \\
\hline 3 & 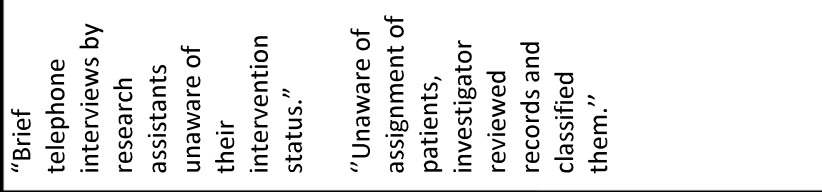 \\
\hline o & 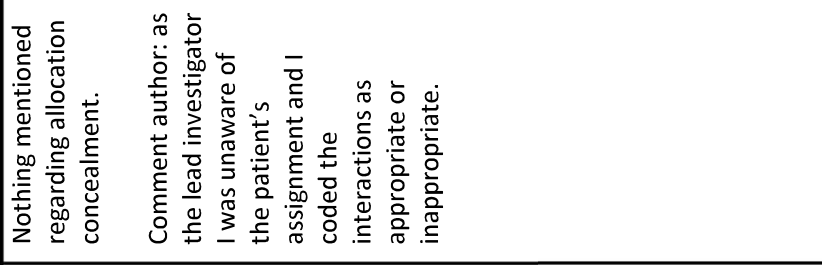 \\
\hline $\mid \frac{5}{\overline{\underline{D o p}}}$ & 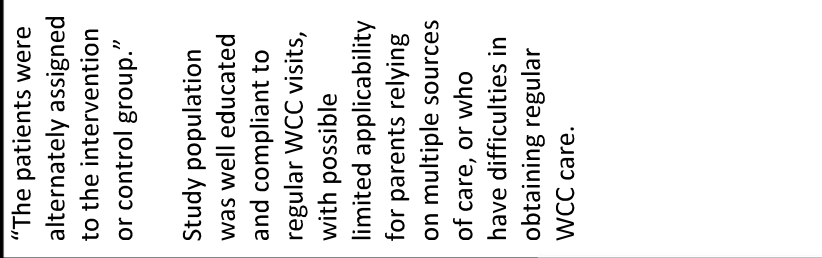 \\
\hline 离 & \\
\hline
\end{tabular}




\begin{tabular}{|c|c|c|c|}
\hline 3 & 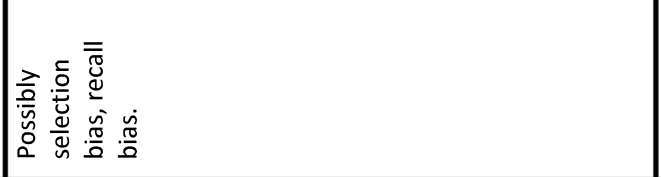 & $\underline{3}$ & 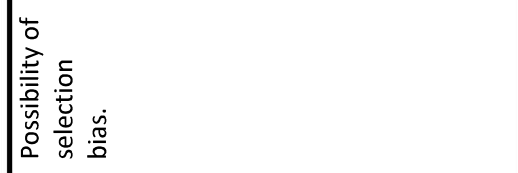 \\
\hline 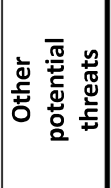 & 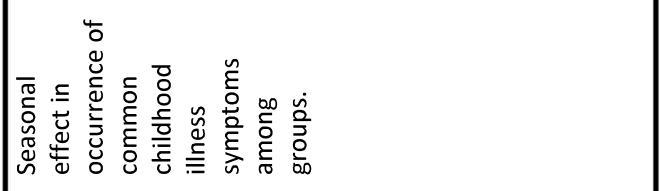 & $\mid \frac{\dddot{0}}{2}$ & \\
\hline zo & 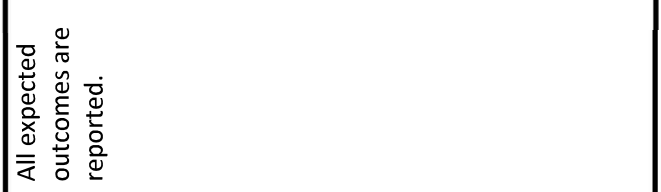 & ż & 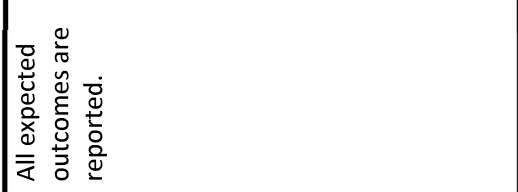 \\
\hline 3 & 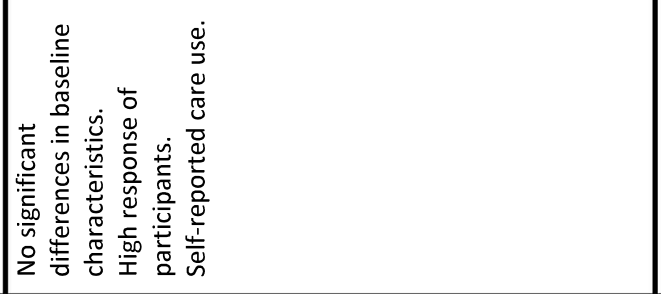 & ż & 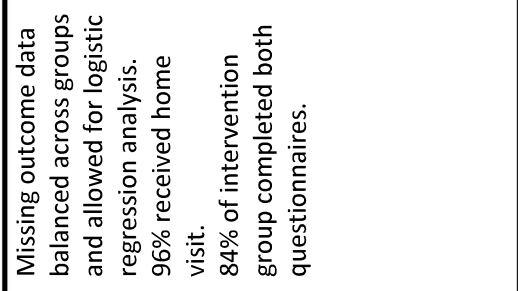 \\
\hline 3 & 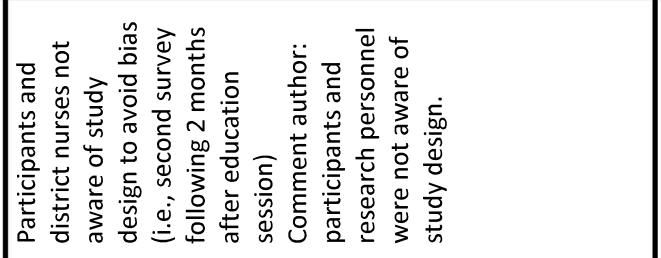 & 3 & 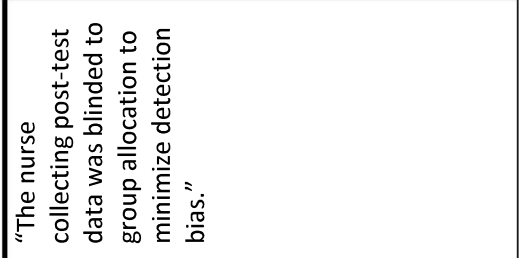 \\
\hline & 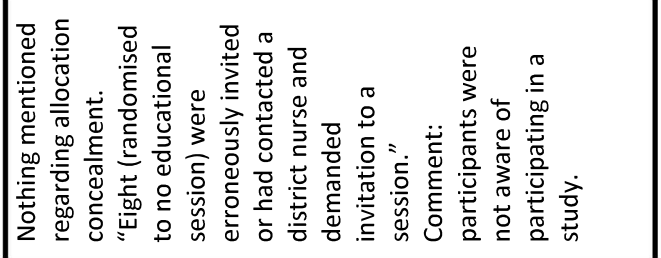 & 3 & 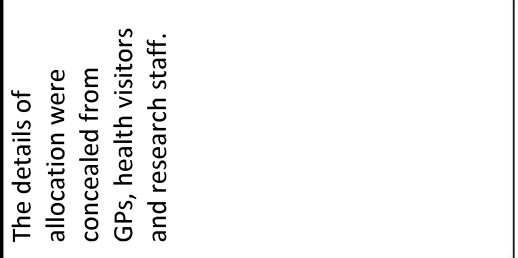 \\
\hline & 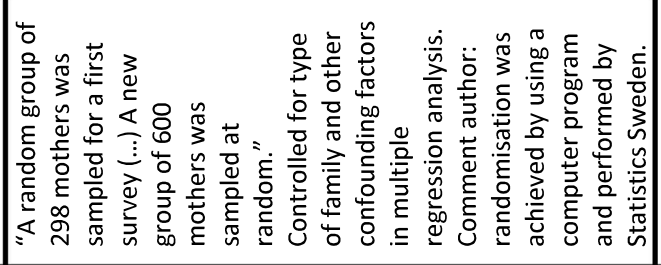 & 3 & 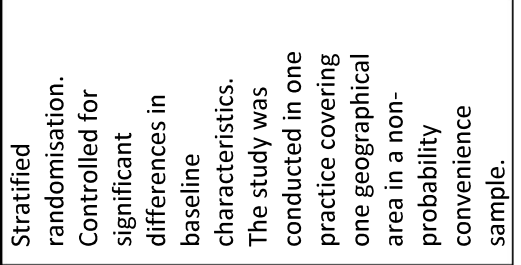 \\
\hline 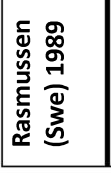 & & 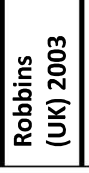 & \\
\hline
\end{tabular}




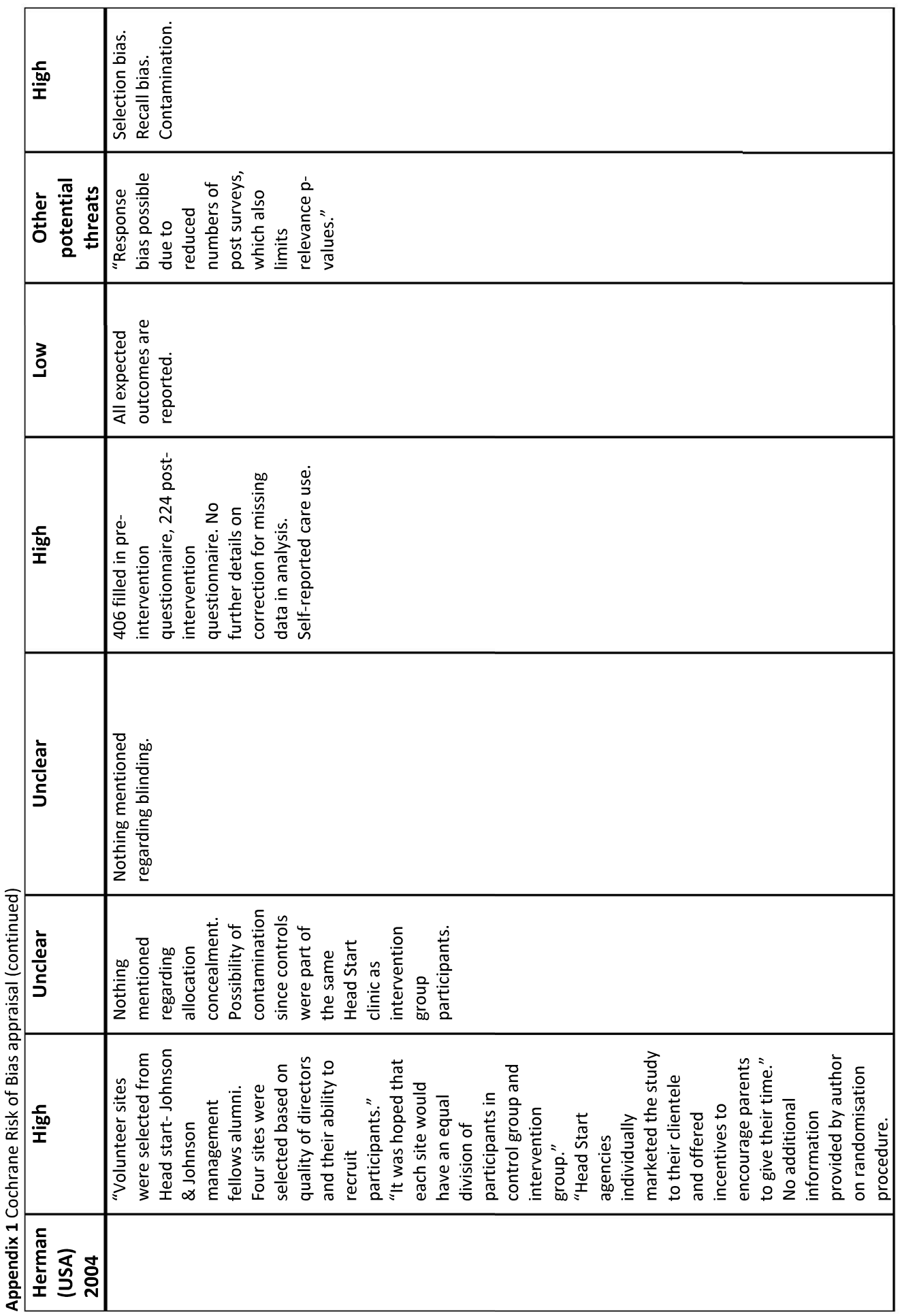




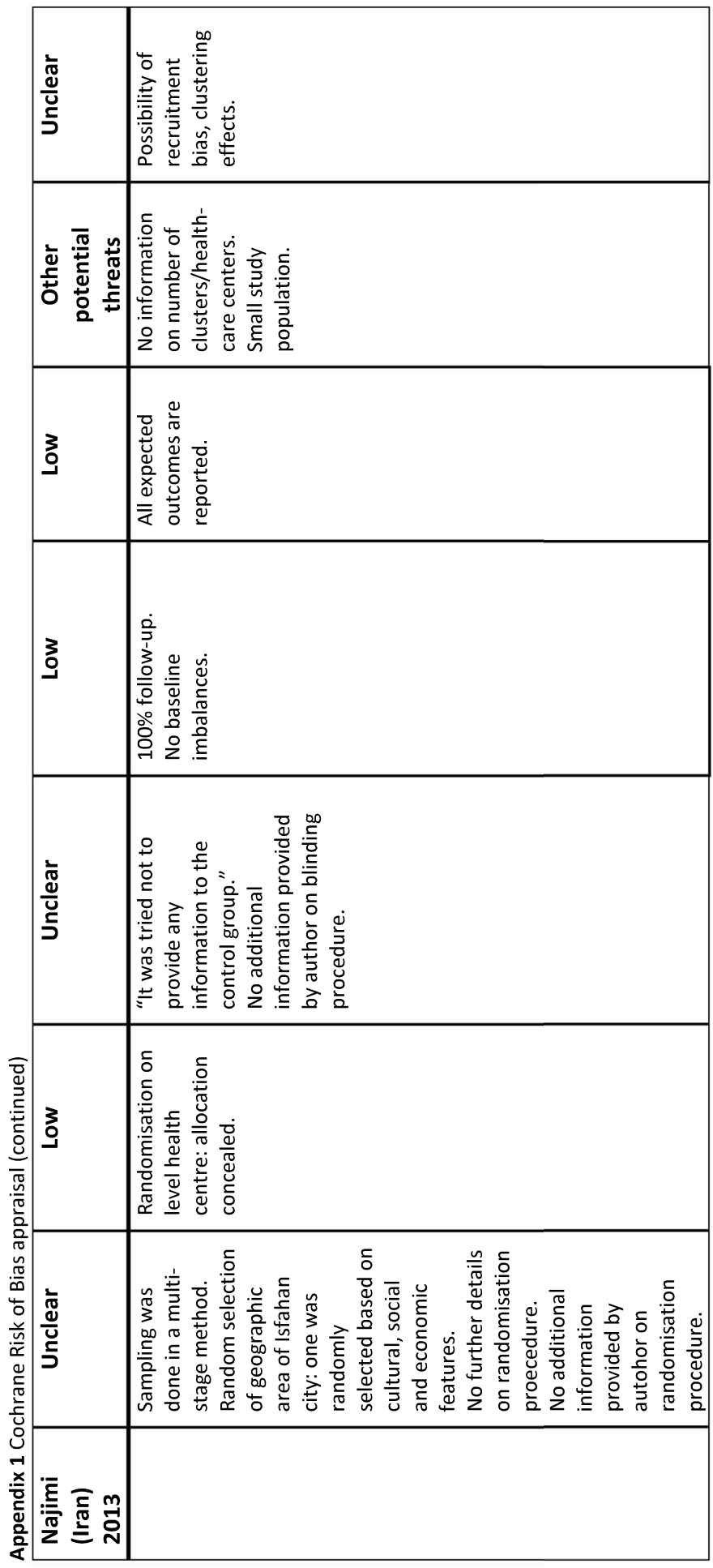




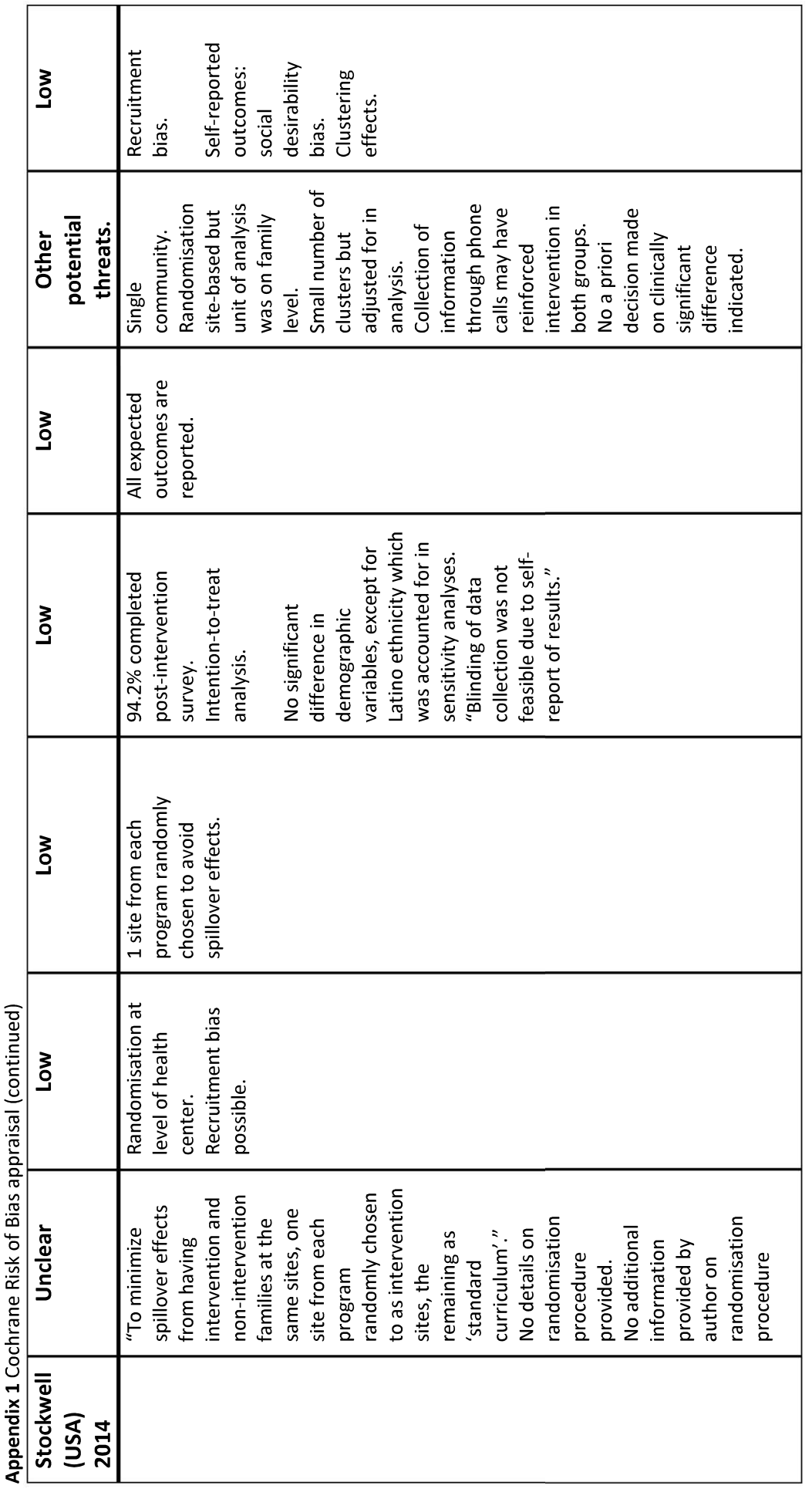




\section{Appendix 2 Search strategy}

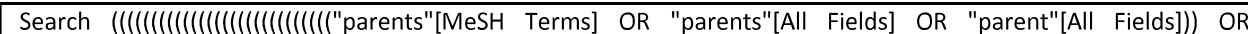
("caregivers"[MeSH Terms] OR "caregivers"[All Fields] OR "caregiver"[All Fields])) OR ("mothers"[MeSH Terms] OR "mothers"[All Fields] OR "mother"[All Fields])) OR ("fathers"[MeSH Terms] OR "fathers"[All Fields] OR "father"[All Fields])) $O R$ "mom"[All Fields]) OR "moms"[All Fields]) OR "dad"[All Fields]) OR "dads"[All Fields]) OR ("pediatrics"[MeSH Terms] OR "pediatrics"[All Fields] OR "pediatric"[All Fields])) OR ("pediatrics"[MeSH Terms] OR "pediatrics"[All Fields] OR "paediatric"[All Fields])) OR ("paediatrics"[All Fields] OR "pediatrics"[MeSH Terms] OR "pediatrics"[All Fields])) OR "pediatric doctor"[All Fields]) OR "paediatrician"[All Fields]) OR "pediatrician"[All Fields]) OR ("physicians"[MeSH Terms] OR "physicians"[All Fields] OR "doctor"[All Fields])) OR ("physicians"[MeSH Terms] OR "physicians"[All Fields] OR "physician"[All Fields])) OR ("general practitioners"[MeSH Terms] OR ("general"[All Fields] AND "practitioners"[All Fields]) OR "general practitioners"[All Fields] OR ("general"[All Fields] AND "practitioner"[All Fields]) OR "general practitioner"[All Fields])) OR ("general practice"[MeSH Terms] OR ("general"[All Fields] AND "practice"[All Fields]) OR "general practice"[All Fields])) OR ("physicians, family"[MeSH Terms] OR ("physicians"[All Fields] AND "family"[All Fields]) OR "family physicians"[All Fields] OR ("family"[All Fields] AND "physician"[All Fields]) OR "family physician"[All Fields])) OR ("primary health care"[MeSH Terms] OR ("primary"[All Fields] AND "health"[All Fields] AND "care"[All Fields]) OR "primary health care"[All Fields] OR ("primary"[All Fields] AND "care"[All Fields]) OR "primary care"[All Fields])) OR ("primary health care"[MeSH Terms] OR ("primary"[All Fields] AND "health"[All Fields] AND "care"[All Fields]) OR "primary health care"[All Fields])) OR "primary health care worker"[All Fields]) OR ("nurses"[MeSH Terms] OR "nurses"[All Fields] OR "nurse"[All Fields])))

AND ((()(()(()(("child"[MeSH Terms] OR "child"[All Fields] OR "children"[All Fields])) OR ("infant"[MeSH Terms] OR "infant"[All Fields] OR "infants"[All Fields])) OR ("infant, newborn"[MeSH Terms] OR ("infant"[All Fields] AND "newborn"[All Fields]) OR "newborn infant"[All Fields] OR "baby"[All Fields] OR "infant"[MeSH Terms] OR "infant"[All Fields])) OR ("infant"[MeSH Terms] OR "infant"[All Fields] OR "babies"[All Fields])) OR "toddler"[All Fields]) OR "toddlers"[All Fields]) OR "infancy"[All Fields]) OR ("child, preschool"[MeSH Terms] OR ("child"[All Fields] AND "preschool"[All Fields]) OR "preschool child"[All Fields] OR ("preschool"[All Fields] AND "children"[All Fields]) OR "preschool children"[All Fields])) OR ("child, preschool"[MeSH Terms] OR ("child"[All Fields] AND "preschool"[All Fields]) $O R$ "preschool child"[All Fields] OR "preschooler"[All Fields])) OR ("child, preschool"[MeSH Terms] OR ("child"[All Fields] AND "preschool"[All Fields]) OR "preschool child"[All Fields] OR "preschoolers"[All Fields])) OR "schoolchild"[All Fields]) OR "schoolchildren"[All Fields]))

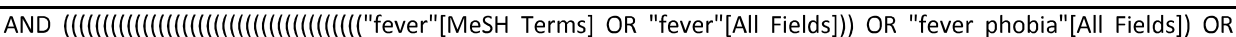
("fever"[MeSH Terms] OR "fever"[All Fields] OR "febrile"[All Fields])) OR "febrile illness"[All Fields]) OR "febrile illnesses"[All Fields]) OR ("fever"[MeSH Terms] OR "fever"[All Fields] OR "feverish"[All Fields])) OR ("fever"[MeSH Terms] OR "fever"[All Fields] OR ("high"[All Fields]

AND "diseases"[All Fields]) OR "virus diseases"[All Fields] OR ("virus"[All Fields] AND "disease"[All Fields]) OR "virus disease"[All Fields])) OR ("virus diseases"[MeSH Terms] OR ("virus"[All Fields] AND "diseases"[All Fields]) OR "virus diseases"[All Fields] OR ("virus"[All Fields] AND "infection"[All Fields]) OR "virus infection"[All Fields])) OR "virus infections"[All Fields]) OR ("virus diseases"[MeSH Terms] OR ("virus"[All Fields] AND "diseases"[All Fields]) OR "virus diseases"[All Fields] OR ("viral"[All Fields] AND "disease"[All Fields]) OR "viral disease"[All Fields])) OR ("virus diseases"[MeSH Terms] OR ("virus"[All Fields] AND "diseases"[All Fields]) OR "virus diseases"[All Fields] OR ("viral"[All Fields] AND "diseases"[All Fields]) OR "viral diseases"[All Fields])) OR ("virus diseases"[MeSH Terms] OR ("virus"[All Fields] AND "diseases"[All Fields]) OR "virus diseases"[All Fields] OR ("viral"[All Fields] AND "infection"[All Fields]) OR "viral infection"[All Fields])) OR ("virus diseases"[MeSH Terms] OR ("virus"[All Fields] AND "diseases"[All Fields]) OR "virus diseases"[All Fields] OR ("viral"[All Fields] AND "infections"[All Fields]) OR "viral infections"[All Fields])) OR ("respiratory tract infections"[MeSH Terms] OR ("respiratory"[All Fields] AND "tract"[All Fields] AND "infections"[All Fields]) OR "respiratory tract infections"[All Fields] OR ("respiratory"[All Fields] AND "infection"[All Fields]) OR "respiratory infection"[All Fields])) OR ("respiratory tract infections"[MeSH Terms] OR ("respiratory"[All Fields] AND "tract"[All Fields] AND "infections"[All Fields]) OR "respiratory tract infections"[All Fields] OR ("respiratory"[All Fields] AND "infections"[All Fields]) OR "respiratory infections"[All Fields])) OR ("respiratory tract infections"[MeSH Terms] OR ("respiratory"[All Fields] AND "tract"[All Fields] AND "infections"[All Fields]) OR "respiratory tract infections"[All Fields] OR ("respiratory"[All Fields] AND "tract"[All Fields] AND "infection"[All Fields]) OR "respiratory tract infection"[All Fields])) OR ("respiratory tract infections"[MeSH Terms] OR ("respiratory"[All Fields] AND "tract"[All Fields] AND "infections"[All Fields]) OR "respiratory tract infections"[All Fields] OR ("upper"[All Fields] AND "respiratory"[All Fields] AND "tract"[All Fields] AND "infection"[All Fields]) OR "upper respiratory tract infection"[All 


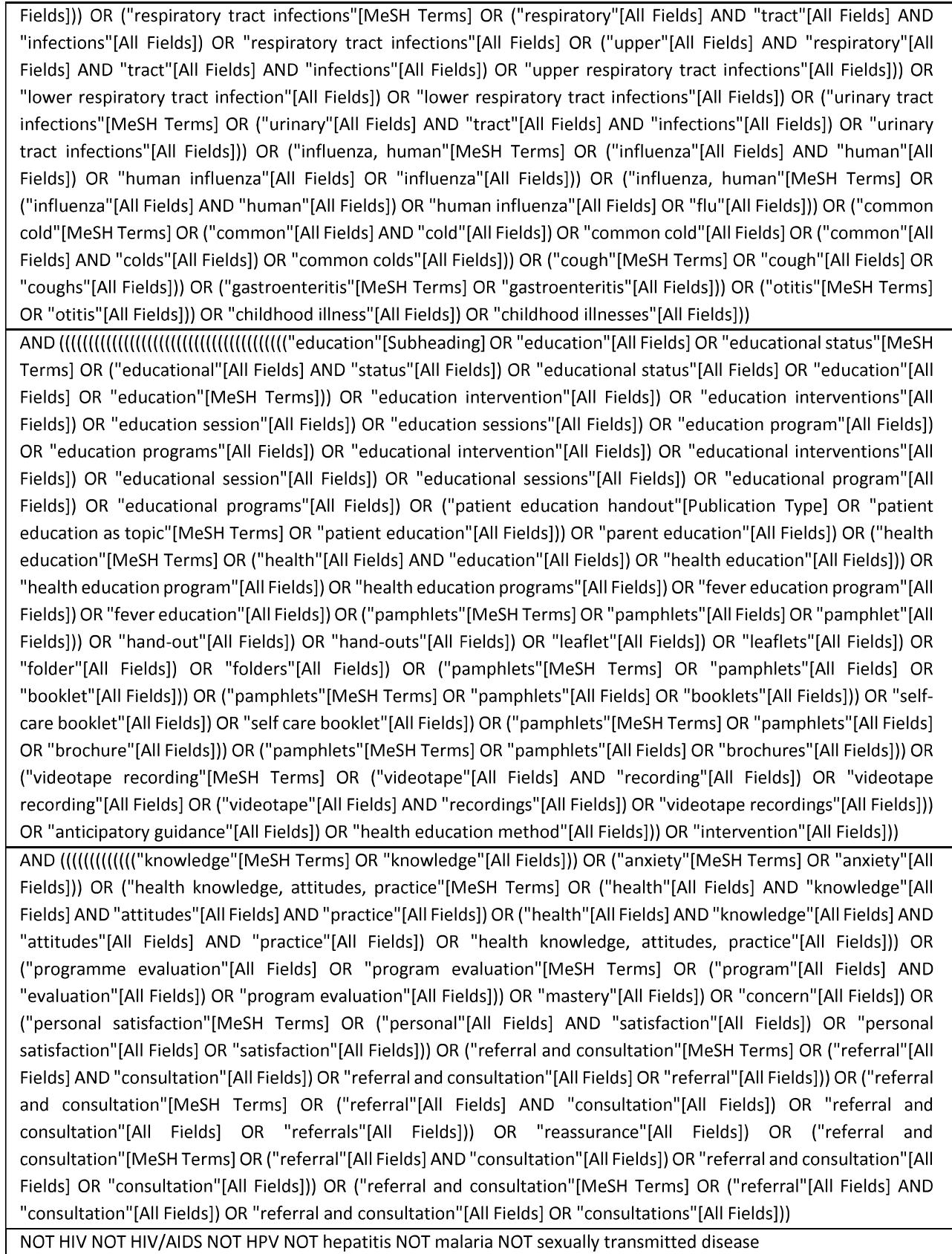




\section{Part 2: Development and evaluation of a multicomponent intervention}




\section{Chapter 7}

\section{Optimising decision making on illness absenteeism due to fever and common infections within childcare centres: development of a multicomponent intervention and study protocol of a cluster randomised controlled trial}

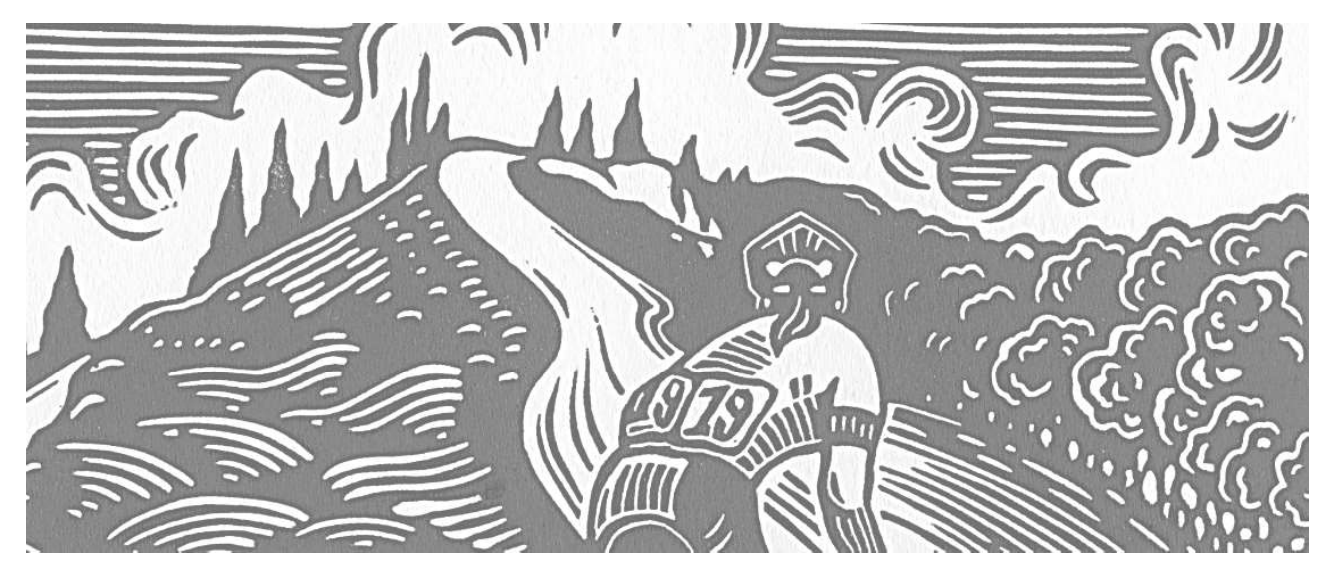

Kirsten Peetoom, Rik Crutzen, Jolijn Bohnen, Rachèl Verhoeven, Marjorie NelissenVrancken, Bjorn Winkens, Geert-Jan Dinant, Jochen Cals. Optimising decision making on illness absenteeism due to fever and common infections within childcare centres: development of a multicomponent intervention and study protocol of a cluster randomised controlled trial.

Published in: BMC Public Health. 2017 Jul 26;18(1):61 


\section{ABSTRACT}

Background Evidence has shown that children 0-4 year-old attending childcare are prone to acquire infections compared to children cared for at home, with fever being the most common symptom. Illness absenteeism due to fever and common infections is substantial and mostly driven by unrealistic concerns and negative attitude towards fever of both childcare staff and parents, resulting in illness absenteeism from childcare, work absenteeism among parents and healthcare service use. The objective of this study is to optimise decision making among childcare staff on illness absenteeism due to fever and common infections in childcare. Underlying determinants of behavioural change were targeted by means of a multicomponent intervention.

Methods A multicomponent intervention was developed to improve decision making, using the stepwise approach of Intervention Mapping, and in close collaboration with stakeholders and experts. The intervention consisted of 1) a two-hour educational session on fever among childcare staff; 2) an online video for childcare staff and parents emphasising key information of the educational session; 3) a decision tool for childcare staff and parents in the format of a traffic light system to estimate the severity of illness and corresponding advices for childcare staff and parents; 4) an information booklet regarding childhood fever, common infections, and selfmanagement strategies for childcare staff and parents. The multicomponent intervention will be evaluated in a cluster randomised trial with a 12-week follow-up period and absenteeism due to illness (defined as the percentage of childcare days absent due to illness on the total of childcare days during a 12-week period) as primary outcome measure. Secondary outcome measures are: incidence rate and duration of illness episodes, knowledge, attitude, self-efficacy, and risk perception on fever and common infections of childcare staff and parents, healthcare service use in general and paracetamol use, and work absenteeism of parents.

Discussion This study aims to develop a multicomponent intervention and to evaluate to what extent illness absenteeism due to fever and common infections can be affected by implementing a multicomponent intervention addressing decision making and underlying determinants among childcare staff and parents of children attending daycare. 


\section{INTRODUCTION}

Infectious diseases, such as fever, are common in children 0-4 year-old. Especially children who attend childcare are more prone to acquire respiratory and gastrointestinal infections compared to home-cared children, particularly during the age of $0-2$ years [1-4]. This may be explained by the fact that their immunological and respiratory tract system is still developing when attending childcare. In addition, children in childcare encounter a higher amount of microbes and have more frequent and more close contacts with other children compared to home-cared children [1, 5-10].

Infectious diseases are a common reason for illness absenteeism in childcare, with children in childcare experiencing on average 6.6-11.4 illness episodes per year, constituting an average illness absenteeism from childcare of 22.9 days [4, 5, 11, 12]. Societal costs for infectious diseases are twice as high per illness episode in children attending childcare as non-attenders, constituting a total economic burden of $€ 97$ million per year in The Netherlands. This burden is mostly due to work absenteeism among parents, with an average of 1.5 work days lost per child's illness episode [2].

The decision regarding illness absenteeism due to fever and common infections may be driven by both parents and childcare staff. Elevated temperature or fever can create a range of concerns among those caring for the child. At the core of these concerns is the misconception that the temperature elevation represents the severity of underlying illness, rather than a relatively benign symptom resulting from an infectious disease. In addition, harmful consequences of fever are feared and body temperature is measured several times per day to monitor disease progression [13-25]. The term fever phobia has been used to describe an exaggerated, unrealistic and unfounded fear of fever expressed by parents, healthcare professionals and childcare staff [24]. An important driver of fever phobia is a lack of knowledge regarding fever pathophysiology, but also previous (negative) experiences, beliefs, sense of personal control, perceived threat of illness, inconsistencies in healthcare providers' advices, and the concern of not recognising a serious illness on time [14-16, 25-29]. In turn, fever phobia influences general practitioner (GP) consultations for childhood fever [5, 6, 22, 30-33]. Similarly, fever phobia is present in childcare staff and causes substantial illness absenteeism in children, work absenteeism among parents and healthcare service consultations by referring parents to the $\operatorname{GP}[2,6,13,16,17,20,33-37]$. Despite the development of several educational interventions, fever phobia, misconceptions and unrealistic concerns are still present in parents, healthcare professionals and childcare staff [36, 38-40].

Educational interventions on fever and common infections targeting childcare staff are scarce and focus merely on hygiene prevention [12, 30, 41-43]. These hygiene prevention interventions are successful in reducing illness incidences rates, children's illness absenteeism and parents' work absenteeism [12, 30, 41, 42]. However, educational interventions for childcare staff regarding fever pathophysiology, infectious diseases and self-management strategies could be beneficial for diminishing fever phobia, since childcare 
staff strongly influence childcare illness absenteeism, work absenteeism for parents, and parental healthcare seeking behaviour [34].

As such, it is hypothesised that educating childcare staff on fever and infectious diseases may optimise decision making processes on illness absenteeism due to fever and common childhood infections, resulting in reduced childcare absenteeism, work absenteeism and use of healthcare services. To achieve this, it is important to obtain insight in which behavioural determinants influence decision making on illness absenteeism in childcare, and to target these determinants in the intervention. As childcare staff are also an important source of information for parents [33], it is expected that improved behavioural determinants of decision making among childcare staff will result in improved parental decision making on illness absenteeism.

This paper describes the development of a multicomponent intervention aiming to optimise decision making among childcare staff on illness absenteeism due to fever and common infections in 0-4 year-old attending childcare, and describes the study protocol of the cluster randomised trial evaluating the developed multicomponent intervention in childcare.

\section{METHODS}

This section describes the development of a multicomponent intervention, based on the Intervention Mapping approach (IM), a protocol for developing theory-based and evidencebased interventions [44]), followed by the study protocol of the cluster randomised trial (cluster RCT) for evaluating the multicomponent intervention in childcare. The study protocol is reported according the guidelines of Standard Protocol Items: Recommendations for Interventional Trials (SPIRIT) [45, 46].

\section{Development of multicomponent intervention}

A multicomponent intervention was developed using $\mathrm{IM}$ with the aim to target underlying determinants of behavioural change of childcare staff in order to optimise their decision making with respect to illness absenteeism due to fever and common infections in childcare.

The first step of the development process was the assessment of extensive needs to explore difficulties towards childhood fever, causes, consequences and implications for practice by means of a systematic review, a survey study among parents of children visiting childcare, and three qualitative studies among general practitioners, well-child clinic professionals, and childcare staff $[17,25,39]$. Initial data analyses from the qualitative study among childcare staff showed that fever phobia was common and emanated from a lack of knowledge and education on fever and common childhood infections [unpublished observations]. Childcare staff expressed that their current knowledge was merely experience-based, both individually and as group sharing experiences, and guided by the operating protocol of their childcare organisation. An uncomfortable feeling was also expressed in case of an increase in the child's body temperature, caused by the concern that an increased temperature would represent the severity of illness. This finding was similar to previous studies $[15,16,18,19,24,25]$. In agreement with another study, data 
from the qualitative study demonstrated that body temperature is frequently measured to monitor illness progression gives a sense of control over the illness [14]. Like parents, childcare staff especially fear febrile seizures as a result of an elevating body temperature and irregular administration of paracetamol [16]. In response to their concerns, childcare staff prefer to exclude children with a fever from childcare and return the responsibility to the parents. In agreement with previous research [17, 34], parents are also actively advised by the childcare staff to consult the GP for a check-up.

These research data demonstrate that decision making on illness absenteeism due to fever and common infections in childcare is a behavioural outcome, which could be optimised in order to reduce childcare absence, healthcare service use, and work absenteeism. Based on data from the needs assessment, the development and evaluation of the intervention will focus on the following four behavioural determinants that are fundamental for the decision making process on illness absenteeism within childcare: knowledge, attitude, self-efficacy and risk perception. Knowledge on pathophysiology of fever, febrile seizures and selfmanagement strategies such as paracetamol use is seen as prerequisite for changing attitude $[47,48]$. Attitude concerns an individual's evaluation of performing a behaviour by balancing pros and cons [47]. For example, childcare staff showed a negative attitude towards fever, resulting in concerns, cautious behaviour and the tendency to send febrile children home. Self-efficacy is defined as the belief in the ability to perform a certain behaviour in a specific situation [44]. For example, childcare staff showed to act cautiously when a child has a (high) fever as they feel insecure in advising parents on GP consultation or paracetamol use, because they are not medically educated and measure body temperature several times per day to monitor illness progression. Risk perception relates to the assessment of risks towards performing a certain behaviour. For example, childcare staff perceive fever and febrile seizures as harmful to the child's health while fever and most febrile seizures are not harmful in itself. Additional file 1 presents an overview of all change objectives (i.e., what has to change at the determinant level) and performance objectives (i.e., sub-behaviours that are essential to achieve the desired behavioural outcome.

Subsequently, theory-based methods were selected and translated into practical applications to target all four behavioural determinants (Additional file 2) and resulted in a multicomponent intervention, including: 1) a two-hour educational session on fever among childcare staff; 2 ) an online video for childcare staff and parents emphasising key messages of the educational session; 3 ) a decision tool in the format of a traffic light system to estimate the severity of illness and corresponding advices by childcare staff and parents; 4) an information booklet regarding childhood fever and common infections for childcare staff and parents.

\section{Educational session}

The two-hour educational session involved a group meeting with childcare staff from one or more childcare intervention centres. Three main topics were discussed: pathophysiology of fever, treatment of fever, and febrile seizures. These topics were based on data from the qualitative study among childcare staff and existing scientific literature $[15,40,49,50]$. The 
session aimed to discuss existing and widely held misconceptions on childhood fever, as described in Additional file 1. The content provided in the educational session was based on the current guideline "Childhood Fever" of the Dutch College of General Practitioners (NHG) and the content of the interactive booklet on childhood fever [51, 52]. The educational session included quiz questions on pathophysiology of fever, febrile seizures and selfmanagement strategies such as the correlation between the height of fever and illness' severity, and was led by an experienced moderator with a background in pharmacy [HN] and a general practitioner was present to answer medical related questions. The principal investigator [KP] was present to provide more information on the project, and to introduce, explain and practice the use of the decision tool.

\section{Online video}

Based on the information provided during the educational sessions, questions asked by childcare staff during the session and take home messages formulated by the childcare staff, an online video of $7 \mathrm{~min}$ was composed using written text, illustrations and animations to convey information. The aim of this video was to further educate participating staff about fever pathophysiology, treatment of fever, and decision making regarding childcare attendance. This video was sent to childcare staff and parents approximately 6 weeks after the educational session. The video served as a booster regarding the information discussed during the educational session.

\section{Decision tool}

The aim of the decision tool is to support childcare staff and parents in assessing the illness severity of the child's symptoms, as well as to guide them towards accompanying advices regarding childcare attendance, and selfmanagement strategies (paracetamol use and GP consultation) in order to optimise their decision making on illness absenteeism from fever and common infections. The decision tool is based on the current guideline "Childhood Fever" of the Dutch College of General Practitioners (NHG) [52], Dutch Public Health Services [53], and the operation protocol on illness from the participating childcare organisation. The decision tool was designed based on the traffic light system developed by de Bont et al. [51] and aims to support with assessing the degree of severity of the child's illness based on behavioural and physical symptoms of the child. The severity was categorised using the traffic light colours with "Green" representing mild and harmless symptoms, "orange" representing mild to moderate symptoms, and "red" representing alarm signals. Based on these colour categories, the decision making processes among childcare staff and parents could be optimised regarding childcare attendance, paracetamol use and GP consultations. Figure 1 presents a schematic overview of the decision tool. 


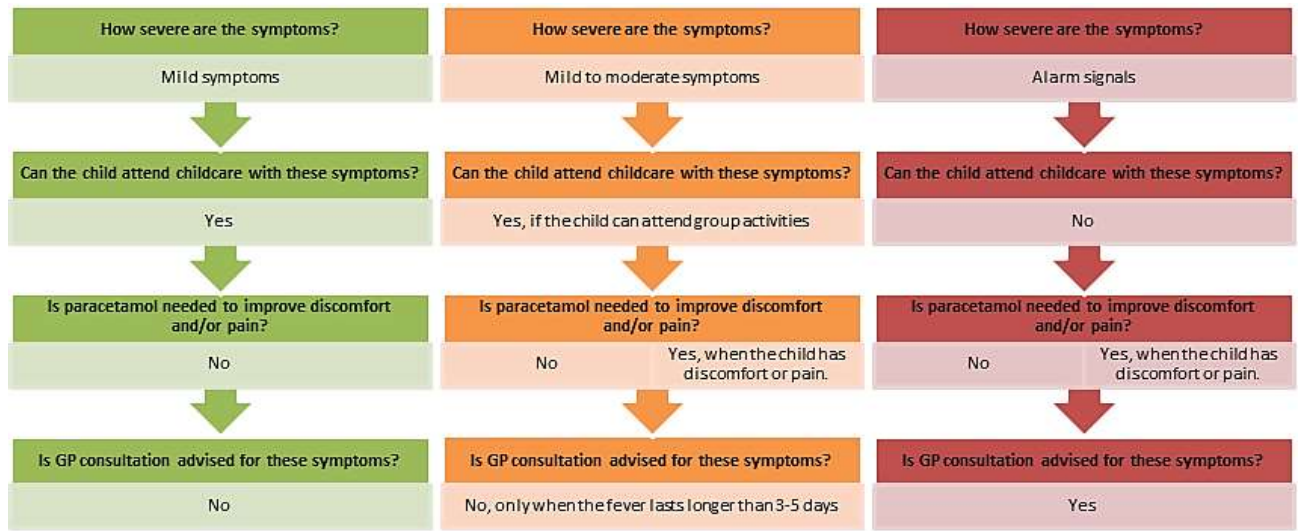

Figure 1 Schematic overview of the decision tool on illness severity and accompanying advices

\section{Interactive information booklet}

The interactive information booklet is an existing intervention, which was developed using a multistage process and evaluated in a large cluster randomised controlled trial in $20 \mathrm{GP}$ out-of-hours services in The Netherlands between November 2015 - April 2016 [51]. The booklet contains a traffic light system for childhood fever in combination with other infectious symptoms, which provides advice on whether to consult a GP (red) or use selfmanagement strategies (green, orange) for childhood fever in general. Furthermore, it provides information on the benefits and harms of antibiotic treatment, an overview of natural duration of common infections in children, and it presents a table with weightbanded paracetamol dosage schemes. The content of the interactive information booklet is in line with current guidelines of the Dutch College of General Practitioners (NHG) [52].

A pilot study was conducted in order to evaluate the individual components of the intervention in an independent childcare organisation in the region of South-Limburg in November 2016, which will not participate in the trial. This childcare organisation consists of six childcare centres, five pre-school playgroups, and eight school care facilities. According to this pilot study, the order of the educational session was changed and the text and lay-out of the decision tool, survey and the registration form were edited. Furthermore, the decision tool was pretested to several end-users of the participating childcare organisation in order to verify whether the method, content and lay-out matched the requirements of end-users.

\section{CLUSTER RANDOMISED CONTROLLED TRIAL}

\section{Study setting}

Approximately $45 \%$ of 0-4 year-old children attend any form of childcare in The Netherlands [54], of which $79 \%$ attend childcare provided by commercial organisations. In such centres, educated staff care for, and contribute to the development and upbringing of children, until they progress to primary school [55]. Other forms of childcare in The Netherlands are host 
parents (16.5\%), or the combination of commercial childcare and host parents (4.8\%) [54]. This trial will be conducted in a large commercial childcare organisation in the Southern part of province Limburg, The Netherlands (Meerwaarde in ' $n$ Kinderleven (MIK) childcare organisation, Maastricht, The Netherlands). This organisation provides childcare to approximately 1380 children aged 0-4 years, distributed over 21 childcare centres. In addition, they facilitate pre-school playgroups and school care facilities. This part of The Netherlands has a wide variety of social economic status (SES), with more parents with a lower SES living in the larger cities [56].

\section{Participants}

From the 21 childcare centres eligible for this study, 18 centres agreed to participate. The site managers of the participating childcare centres will be informed about the study content by means of written information and verbal elucidation. Childcare staff and parents with children at the participating childcare centres will be informed about the study content by means of a written information letter via email. All childcare staff with permanent tenure, fixed replacements and trainees working at the participating childcare centres are eligible to participate in the educational session. The other individual components of the intervention will be made available to all eligible childcare staff at intervention centres regardless of their employment and to parents of children attending the participating childcare centres. All children attending the participating childcare centres and their parents are eligible to participate in this study. It should be noted that children with chronic medical conditions will not be excluded from participation, because the focus of this study is on illness absenteeism from common infectious diseases among 0-4 year-old children, which also occur in children with chronic diseases. Children are excluded from the illness registration when they reach the age of 4 years and leave childcare to progress onto preschool.

\section{Outcomes}

The primary outcome is absenteeism due to illness, defined as the percentage of days that the child is absent from childcare due to illness from the total number of childcare days during a 12-week period. This primary outcome will be used to evaluate the potential behavioural change in decision making on illness absenteeism, resulting from the multicomponent intervention that was developed to target behavioural determinants such as knowledge, attitude, self-efficacy and risk perception.

Secondary outcome measures are: 1 ) knowledge, attitude, self-efficacy and risk perception towards fever and common infections are measured among childcare staff and parents; 2) incidence rate of fever and common childhood infections; 3 ) number and duration of illness episodes in children who are called in ill or sent home because of illness during the study period, and whose parents complete a survey on this illness episode; 4) work absenteeism among parents who complete a survey when their child is called in ill or sent home because of illness during the study period; 5) healthcare service use for fever and/or common infections in children who are called in ill or sent home because of illness during the study period and of which parents complete an additional survey on this illness episode, 6) 
paracetamol use for fever and/or common infections in children who are called in ill or sent home because of illness during the study period and whose parents complete an additional survey on this illness episode.

Secondary outcomes will be measured using two different surveys on different time points and for a different target group (Table 1). Survey 1 measures number and duration of illness episodes (3), work absenteeism (4), healthcare service (5), and paracetamol. Survey 1 is only sent to parents of which the child was ill during the study period and provided informed consent. The content of this survey is in line with surveys used in previous studies [19, 34, $42,57,58]$. Survey 2 measures knowledge, attitude, self-efficacy and risk perception among childcare staff, whereas survey 3 measures these behavioural determinants among parents. Three vignettes were included to evaluate the decision making process of childcare staff and/or parents in three different cases of ill children based on the traffic light system that was implemented in the decision tool. These surveys on knowledge, attitude, self-efficacy, and risk perception for childcare staff and parents are developed based on previous research [19, 34, 58-61]. Survey items were operationalised according theories' definitions of behavioural determinants. Subsequently, survey items were piloted among childcare staff to check understandibility and interpretation of items [62].

\section{Sample size}

Our primary outcome is absenteeism due to illness, defined as the percentage of childcare days absent due to illness on the total of childcare days during a 12-week period. We performed a pilot study among parents with children attending 21 childcare centres of MIK in Spring 2016 to calculate illness absenteeism. For this pilot study, an average 4-week illness absenteeism of $9.9 \%(s d=18.035)$ was reported [unpublished observations], which was in agreement with the absenteeism rate reported by Hedin et al. in Swedish children [63]. To calculate our sample size we assumed an illness absenteeism of $9.9 \%$ in the control group. This cluster RCT aims to achieve a clinically significant reduction of illness absenteeism due to fever and common infections by $4.5 \%$ in the intervention group [4, 30, 64]. To obtain this difference with $80 \%$ power, assuming a within group SD of 18.035 and a significance level $\alpha$ of $0.05,253$ participants per group (506 in total) are required (PS Power and Sample size program, independent-samples t-test). Due to cluster (childcare location) randomisation, where we assume a mean number of 55 children per cluster and an intracluster coefficient of 0.01 into account, based on our pilot and previous literature [65], this number increases to 390 participants per group. After correction for $10 \%$ loss to follow-up and $10 \%$ efficiency loss based on unequal cluster sizes [66], the required sample size is 482 participants per group (total $n=964$ ). To meet this sample size, this study aims to recruit 18 clusters (childcare location) with 55 participating children per cluster, resulting in 990 children.

\section{Allocation}

Stratified block randomisation is conducted at the level of childcare centres, with nine centres randomised to our multicomponent intervention and nine centres randomised to care-as-usual (control). Intervention centres will receive all four components of the 
multicomponent intervention, control centres will provide care as usual. Stratification is based on size of childcare centres regarding number of children attending a childcare centre. A small childcare centre is defined as having fewer than 65 children attending childcare, while a large childcare centre is defined as having more than 65 children attending childcare. The randomisation procedure is conducted by an independent researcher via http:// www.randomization.com/. Childcare staff and parents will not be blinded after intervention allocation due to the nature of the multicomponent intervention. However, they are blinded to the primary outcome measure. Researchers will be blinded during data analysis to the allocation status of childcare centres.

\section{Data collection}

See Table 1 for an overview of enrolment, intervention allocation, and outcome measurements.

\section{Primary outcome measure}

A standardised paper-based illness registration form is developed in close collaboration with the participating childcare organisation (see Additional file 3). Six booklets each comprising 2 weeks of childcare will be provided to all participating childcare groups for the study period of 12 weeks. Childcare staff will register childcare attendance, childcare absenteeism because of illness, and absenteeism due to other reasons (e.g. holiday) on a daily basis. When children are called in ill or sent home ill, childcare staff will register initials of the child, infection symptoms and how many days the child is (partially) absent due to illness. In addition, childcare staff in the intervention group will also record decision tool use. Childcare staff in both groups will receive training and feedback on registration during a 2-week run-in period before the actual start of the trial (see Table 1). This method of illness registration is comparable to other studies $[63,67,68]$.

\section{Survey 1 following child's illness episode}

Parents will receive an electronic survey when their child was called in ill or is sent home from childcare because of illness when parents provide consent to receive this additional survey during the 12 -week study period. Parents will receive this survey within 14 days after each time their child becomes ill, followed by a total of two reminders which are sent out every 3 days.

\section{Survey 2 and 3 on knowledge, attitude, self-efficacy, and risk perception}

Knowledge, attitude, self-efficacy and risk perception towards fever will be measured by means of 7-point likert scales in a survey that is distributed electronically and on paper. Childcare staff in intervention and control group will receive this survey at baseline (TO) and after the 12-week study period (T6) to measure the change in behavioural determinants between and within intervention and control group. Parents will receive the survey at T6 to measure the difference in behavioural determinants between intervention and control group. 
Table 1 Time schedule of enrolment, intervention allocation, and outcome assessments

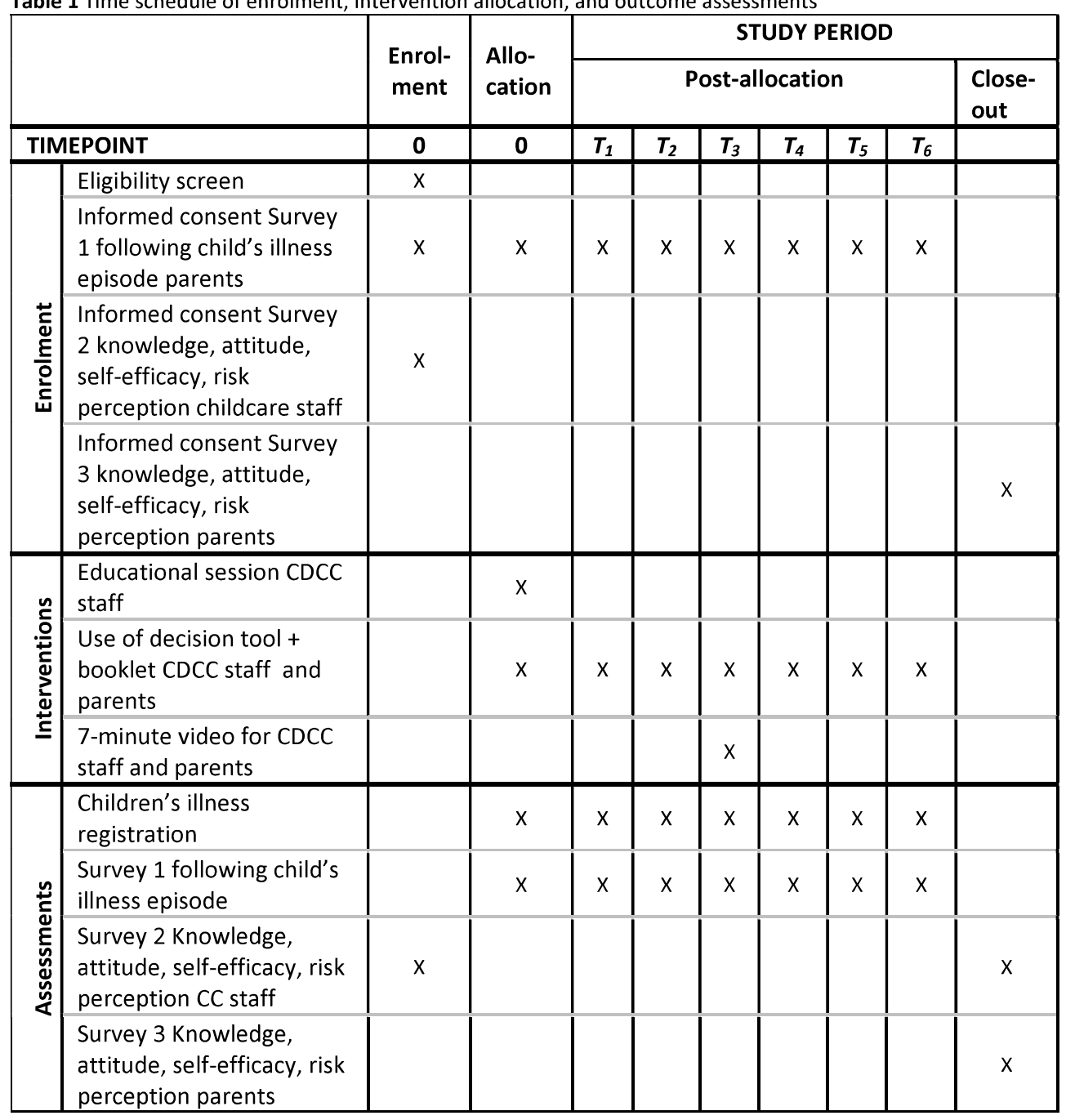

\section{Analysis}

Statistical analysis will be performed with SPSS version 21.0 and a two-sided $p$-value smaller than or equal to 0.05 will be considered statistically significant. Due to repeated measures (every 2 weeks for 12-weeks study period) and possible missing data, the primary outcome measure will be analysed using linear mixed models, where the covariance structure of the repeated measures will be chosen based on the lowest Bayes information criterion (BIC). Illness absenteeism will be computed every 2 weeks of registration for each location to take into account fixed closing days of the childcare centre during public holidays. Missing outcome data will not be imputed, since a likelihood based approach will be used with linear mixed models. No missingness in the explanatory variables such as group (intervention or 
control), time $(0,2, \ldots, 12$ weeks), group*time, and stratification variable cluster size (large or small) is expected.

Secondary outcome measures will be analysed on different levels and in different ways. The survey on knowledge, attitude and practices for childcare staff will be analysed on three levels. Time is the lowest level (level 1), which is nested within staff members (level 2), which are again nested within location (level 3). Linear mixed models will be used for numerical outcomes and logistic mixed models or generalized estimating equations (GEE) for categorical outcomes, where an unstructured covariance structure will be used in case of 2 or three repeated measures, otherwise the covariance structure of the repeated measures will be chosen based on the lowest BIC. In addition, a random intercept on location level will be included to account for the nesting of staff members within a location. The same survey will be analysed for parents on two levels with parents as lowest level (level 1), which is nested in location (level 2), because only a post-allocation measurement will be performed to compare parents in intervention group with those in control group. In this case, a random intercept on location level is included in the model to account for the nesting of parents within a location. Survey outcomes are measured on 7-point likert scales and the average outcome (sd) will be calculated per item after assessing scale quality. The parent survey following child's illness absenteeism will be analysed by using descriptive statistics. All data will be obtained, managed and monitored according to the guidelines of Good Clinical Practice.

\section{DISCUSSION}

This paper describes the development and study protocol for the evaluation of a multicomponent intervention in a cluster randomised trial that aims to improve decision making among childcare staff on illness absenteeism due to fever and common infections in childcare. The Intervention Mapping approach was used to systematically develop the intervention, according to the needs requirements of the end-users. A multicomponent intervention is developed to target the different behavioural determinants of decision making in several ways. This approach incorporated an extensive needs assessment based on results of own previous research and the available evidence from the scientific literature. The development included further a close collaboration with experts and end-users, and was pilot tested in a childcare organisation that will not take part in the main trial.

The content of the intervention is consistent with current guidelines of the Dutch College of General Practitioners, Dutch Public Health Services, and the operating protocol on illness from the participating childcare organisation. The multicomponent intervention will be evaluated in a cluster randomised controlled trial with nine childcare centres receiving the intervention and nine provide care-as-usual. There is a risk of contamination since childcare replacement staff may work in both intervention and control centres. Yet, we think this risk is minimal as the vast majority of staff works in one centre only. Furthermore, to minimise this risk only permanent staff and fixed replacements will be allowed to attend the educational session. We chose to plan daily registration of absenteeism by childcare staff 
to minimise recall bias. Recall bias for secondary outcomes reported by parents will be minimised by sending out the survey within 2 weeks of illness of their child, followed by reminders every 3 days. Childcare staff will be blinded to the primary outcome measure to avoid bias.

Education on fever pathophysiology, febrile seizures, and self-management strategies is not structurally part of the training opportunities in Dutch childcare centres. This multicomponent intervention is in particular developed to educate childcare staff and parents on fever pathophysiology and self-management strategies by providing more background information and a newly developed decision tool. It was anticipated that optimising (determinants of) decision making among childcare staff and parents on illness absenteeism due to fever and common infections in childcare, may lead to substantial reductions in absenteeism from childcare, work absenteeism from parents, and high healthcare service use. 


\section{REFERENCES}

1. Nesti MM, Goldbaum M. Infectious diseases and daycare and preschool education. J Pediatr. 2007;83(4):299_ 312.

2. Enserink R, Lugnér A, Suijkerbuijk A, Bruijning-Verhagen $P$, Smit HA. Gastrointestinal and respiratory illness in children that do and do not attend child day care centers: a cost-of-illness study. PLoS One. 2014; 9(8):e104940.

3. Kotch JB, Weigle KA, Weber DJ, Clifford RM, Harms TO, Loda FA, Gallagher PN Jr, Edwards RW, LaBorde D, McMurray MP, et al. Evaluation of an hygienic intervention in child day-care centers. Pediatrics. 1994;94(6 Pt 2):991-4.

4. Roberts L, Smith W, Jorm L, Patel M, Douglas RM, McGilchrist C. Effect of infection control measures on the frequency of upper respiratory infection in child care: a randomized, controlled trial. Pediatrics. 2000;105(4 Pt 1):738-42.

5. Pönkä A, Nurmi T, Salminen E, Nykyri E. Infections and other illnesses of children in day-care centers in Helsinki. I: incidences and effects of home and day-care center variables. Infection. 1991;19(4):230-6.

6. Hay AD, Heron J, Ness A. The prevalence of symptoms and consultations in pre-school children in the Avon longitudinal study of parents and children (ALSPAC): a prospective cohort study. Fam Pract. 2005;22(4):36774.

7. National Institute of Child Health and Human Development Early Child Care Research Network. Child care and common communicable illnesses: results from the National Institute of Child Health and Human Development study of early child care. Arch Pediatr Adolesc Med. 2001;155(4):481-8.

8. Brady MT. Infectious disease in pediatric out-of-home child care. Am J Infect Control. 2005;33(5):276-85.

9. Klein JO. Infectious diseases and day care. Rev Infect Dis. 1986;8(4):521-6.

10. Marbury MC, Maldonado G, Waller L. Lower respiratory illness, recurrent wheezing, and day care attendance. Am J Respir Crit Care Med. 1997;155(1):156-61.

11. Zomer TP, Erasmus V, Looman CW, Tjon ATA, Van Beeck EF, De Graaf JM, Van Beeck AH, Richardus JH, Voeten HA. A hand hygiene intervention to reduce infections in child daycare: a randomized controlled trial. Epidemiol Infect. 2015;143(12):2494-502.

12. Uhari M, Mottonen M. An open randomized controlled trial of infection prevention in child day-care centers. Pediatr Infect Dis J. 1999;18(8):672-7.

13. Schmitt BD. Fever phobia: misconceptions of parents about fevers. Am J Dis Child. 1980;134(2):176-81.

14. Kai J. What worries parents when their preschool children are acutely ill, and why: a qualitative study. BMJ. 1996;313(7063):983-6.

15. Sarrell M, Cohen HA, Kahan E. Physicians', nurses', and parents' attitudes to and knowledge about fever in early childhood. Patient Educ Couns. 2002;46

16. Crocetti $M$, Moghbeli N, Serwint J. Fever phobia revisited: have parental misconceptions about fever changed in 20 years? Pediatrics. 2001;107(6):1241-6.

17. de Bont EG, Peetoom KK, Moser A, Francis NA, Dinant GJ, Cals JW. Childhood fever: a qualitative study on GPs' experiences during out-ofhours care. Fam Pract. 2015;32(4):449-55.

18. de Bont EG, Loonen N, Hendrix DA, Lepot JM, Dinant GJ, Cals JW. Childhood fever: a qualitative study on parents' expectations and experiences during general practice out-of-hours care consultations. BMC Fam Pract. 2015;16:131.

19. Walsh AM, Edwards HE, Courtney MD, Wilson JE, Monaghan SJ. Fever management: paediatric nurses' knowledge, attitudes and influencing factors. J Adv Nurs. 2005;49(5):453-64.

20. Landis SE, Earp JAL, Sharp M. Day-care Center exclusion of sick children: comparison of opinions of day-care staff, working mothers, and Pediatricians. Pediatrics. 1988;81(5):662-7.

21. Martins M, Abecasis F. Healthcare professionals approach paediatric fever in significantly different ways and fever phobia is not just limited to parents. Acta Paediatr. 2016;105(7):829-33.

22. Karwowska A, Nijssen-Jordan C, Johnson D, Davies HD. Parental and health care provider understanding of childhood fever: a Canadian perspective. CJEM. 2002;4:394-400. 
23. Lagerlov $\mathrm{P}$, Helseth $\mathrm{S}$, Holager $\mathrm{T}$. Childhood illnesses and the use of paracetamol (acetaminophen): a qualitative study of parents' management of common childhood illnesses. Fam Pract. 2003;20(6): 717-23.

24. Schmitt BD. Fever phobia: misconceptions of parents about fever. Am J Dis Child. 1980;134:176-81.

25. Peetoom KK, Ploum LJ, Smits JJ, Halbach NS, Dinant GJ, Cals JW. Childhood fever in well-child clinics: a focus group study among doctors and nurses. BMC Health Serv Res. 2016;16:240.

26. Ingram J, Cabral C, Hay AD, Lucas PJ, Horwood J. Parents' information needs, self-efficacy and influences on consulting for childhood respiratory tract infections: a qualitative study. BMC Fam Pract. 2013;14(1):106.

27. Blumenthal I. What parents think of fever. Fam Pract. 1998;15:513-18.

28. Walsh A, Edwards H, Fraser J. Influences on parents' fever management:beliefs, experiences and information sources. J Clin Nurs. 2007;16:2331-40. 29. Kelly M, McCarthy S, O'Sullivan R, Shiely F, Larkin P, Brenner M, Sahm U. Drivers for inappropriate fever management in children: a systematic review. Int J Clin Pharm. 2016;38(4):761-70.

29. Pönkä A, Poussa T, Laosmaa M. The effect of enhanced hygiene practices on absences due to infectious diseases among children in day care centers in Helsinki. Infection. 2004;32(1):2-7.

30. Bruijnzeels MA, Foets M, van der Wouden JC, van den Heuvel WJ, Prins A. Everyday symptoms in childhood: occurrence and general practitioner consultation rates. Br J Gen Pract. 1998;48(426):880-4.

31. National Institute for Health and Care Excellence [NICE]. NICE guideline: feverish illness in children. London: NICE; 2013.

32. Finkelstein JA, Dutta-Linn M, Meyer R, Goldman R. Childhood infections, antibiotics, and resistance: what are parents saying now? Clin Pediatr (Phila). 2014;53(2):145-50.

33. Skull S, Ford-Jones L, Kulin NA, Einarson TR, Wang EEL. Child care center staff contribute to physician visits and pressure for antibiotic prescription. Arch pediatr adolesc med. 2000;154:180-183. J Arch Ped Adolesc Med. 2000;154(Feb 2000):180-3.

34. Silverstein $M$, Sales $A E$, Koepsell TD. Health care utilization and expenditures associated with child care attendance: a nationally representative sample. Pediatrics. 2003;111(4 Pt 1):e371-5.

35. Monsma J, Richerson J, Sloand E. Empowering parents for evidence-based fever management: an integrative review. J Am Assoc Nurse Pract. 2015;27(4):222-9.

36. Rooshenas L, Wood F, Brookes-Howell L, Evans MR, Butler CC. The influence of children's day care on antibiotic seeking: a mixed methods study. Br J Gen Pract. 2014;64(622):e302-12.

37. Andrews T, Thompson M, Buckley DI, Heneghan C, Deyo R, Redmond N, Lucas PJ, Blair PS, Hay AD. Interventions to influence consulting and antibiotic use for acute respiratory tract infections in children: a systematic review and meta-analysis. PLoS One. 2012:7(1).

38. Peetoom KKB, Smits JJM, Ploum LJL, Verbakel JY, Dinant GJ, Cals JWL. Does well-child care education improve consultations and medication management for childhood fever and common infections? A systematic review. Arch Dis Child. 2016;120:261-67.

39. Kelly L, Morin K, Young D. Improving caretakers' knowledge of fever management in preschool children: is it possible? J Pediatr Health Care. 1996;10(4):167-73.

40. Lennell A, Kuhlmann-Berenzon S, Geli P, Hedin K, Petersson C, Cars O, Mannerquist K, Burman LG, Fredlund $\mathrm{H}$. Alcohol-based hand-disinfection reduced children's absence from Swedish day care centers. Acta Paediatr. 2008;97(12):1672-80.

41. Hedin K, Petersson C, Cars H, Beckman A, Hakansson A. Infection prevention at day-care centres: feasibility and possible effects of intervention. Scand J Prim Health Care. 2006;24(1):44-9.

42. Willmott MNA, Busse H, MacArthur GJ, Brookes S, Campbell R. Effectiveness of hand hygiene interventions in reducing illness absence among children in educational settings: a systematic review and meta-analysis. Arch Dis Child. 2015;101:42-50.

43. Bartholomew L, Parcel GS, Kok G, Gottlieb NH. Planning health promotion programs: an intervention mapping approach. 4th ed. San Francisco: JosseyBass \& Pfeiffer Imprints, Wiley; 2016.

44. Chan A-W, Tetzlaff JM, Gøtzsche PC, et al. SPIRIT 2013 explanation and elaboration: guidance for protocols of clinical trials. The BMJ. 2013;346:e7586. doi:10.1136/bmj.e7586. 
45. Chan A, Tetzlaff JM, Altman DG, et al. Spirit 2013 statement: defining standard protocol items for clinical trials. Ann Intern Med. 2013;158(3):200-7.

46. Ajzen I. Attitudes, personality, and behavior. Chicago: Dorsey Press; 1988

47. Ajzen I. The theory of planned behavior. Organ Behav Hum Decis Process. 1991;50(2):179-211.

48. Schmitt BD. Fever in childhood. Pediatrics. 1984;74(5 Pt 2):929-36.

49. Richardson M, Purssell E: Who's afraid of fever? ADC 2015.

50. de Bont EG, Dinant GJ, Elshout G, van Well G, Francis NA, Winkens B, Cals JW. An illness-focused interactive booklet to optimise management and medication for childhood fever and infections in out-of-hours primary care: study protocol for a cluster randomised trial. Trials. 2016;17(1):547.

51. Berger MY, Berghuis ICA, Eizenga WH, Elshout G, Gul N, Kool M, Oostenbrink R, Opstelten W, Oteman N. NHG-Standaard Kinderen met koorts. Huisarts en Wetenschap. Houten: Bohn Stafleu van Loghum; 2016;11:484-91.

52. National Centre for Hygiene and Safety [LCHV]. Information about syndromes for child daycare centers, preschools and schoolcare. [Informatie over ziektebeelden voor kinderdagverblijven, peuterspeelzalen en buitenschoolse opvang]. Amsterdam: National Institute for Public Health and the Environment [RIVM]; 2016. p. 1-39.

53. Statistics Netherlands [CBS]. More children visit child day care [Meer kinderen naar kinderopvang]. Den Haag/Heerlen: Statistics Netherlands [CBS]. 2016. https://www.cbs.nl/nl-nl/nieuws/2016/23/meerkinderen-naarkinderopvang. Accessed 31 Mar 2017.

54. Childcare act and quality requirements of preschools [Wet kinderopvang en kwaliteitseisen peuterspeelzalen]. 2004. http://wetten.overheid.nl/BWBR0017017/ 2017-01-01\#SlotformulierEn Ondertekening. Accessed 31 Mar 2017

55. Social economic status; regional and international; regional [Sociaaleconomische status; Regionaal \& Internationaal; Regionaal].

56. [https://www.volksgezondheidenzorg.info/onderwerp/sociaaleconomische status/ regionaalinternationaal/regionaal\#node-gemiddeld-gestandaardiseerdinkomen-gemeente]. Accessed 30 Mar 2017.

57. Yin JK, Salkeld G, Lambert SB, Dierig A, Heron L, Leask J, Yui Kwan Chow M, Booy R. Estimates and determinants of economic impacts from influenzalike illnesses caused by respiratory viruses in Australian children attending childcare: a cohort study. Influenza Other Respir Viruses. 2013;7(6):1103-12.

58. Lagerlov $P$, Loeb $M$, Slettevoll J, Lingjaerde OC, Fetveit A. Severity of illness and the use of paracetamol in febrile preschool children; a case simulation study of parents' assessments. Fam Pract. 2006;23(6):618-23.

59. Chiappini E, Parretti A, Becherucci P, Pierattelli M, Bonsignori F, Galli L, de Martino M. Parental and medical knowledge and management of fever in Italian pre-school children. BMC Pediatr. 2012;12(1):97.

60. de Bont EG, Francis NA, Dinant GJ, Cals JW. Parents' knowledge, attitudes, and practice in childhood fever: an internet-based survey. Br J Gen Pract. 2014;64(618):e10-6.

61. Wigton RS, Darr CA, Corbett KK, Nickol DR, Gonzales R. How do Community practitioners decide whether to prescribe antibiotics for acute respiratory tract infections? J Gen Intern Med. 2008;23(10):1615-20.

62. Peters GY, Crutzen R. Pragmatic nihilism: how a theory of nothing can help health psychology progress. Health Psychol Rev. 2017;11(2):103-21.

63. Hedin K, Cars O, Rolfhamre PG, Ekdahl K, Fredlund H, Petersson C. Sickness absence in daycare and reported hygiene routines. Prim Health Care Res Dev. 2010;11(2):180-6.

64. McConnochie KM, Wood NE, Kitzman HJ, Herendeen NE, Roy J, Roghmann KJ. Telemedicine reduces absence resulting from illness in urban child care: evaluation of an innovation. Pediatrics. 2005;115(5):1273-82.

65. Adams G, Gulliford MC, Ukoumunne OC, Eldridge S, Chinn S, Campbell MJ. Patterns of intra-cluster correlation from primary care research to inform study design and analysis. J Clin Epidemiol. 2004;57(8):78594.

66. van Breukelen GJ, Candel MJ, Berger MP. Relative efficiency of unequal cluster sizes for variance component estimation in cluster randomized and multicentre trials. Stat Methods Med Res. 2008;17(4):439-58. 
67. Bowen A, Ma H, Ou J, Billheimer W, Long T, Mintz E, Hoekstra RM, Luby S. A cluster-randomized controlled trial evaluating the effect of a handwashing promotion program in Chinese primary schools. Am J of Trop Med and Hyg. 2007;76(6):1166-73.

68. Enserink R, Noel H, Friesema IH, de Jager CM, Kooistra-Smid AM, Kortbeek LM, Duizer E, van der Sande MA Smit HA, Pelt W. The KIzSS network, a sentinel surveillance system for infectious diseases in day care centers: study protocol. BMC Infect Dis. 2012;12(1):259. 


\begin{tabular}{|c|c|c|c|}
\hline & 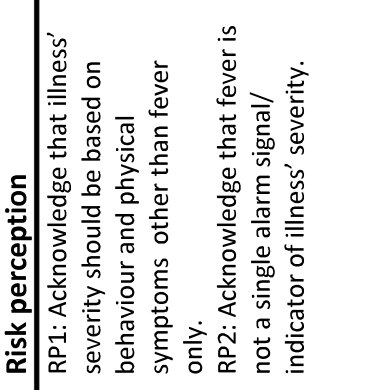 & 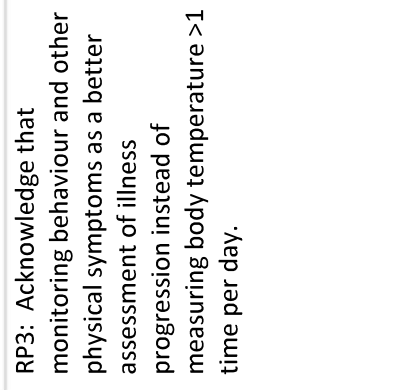 & 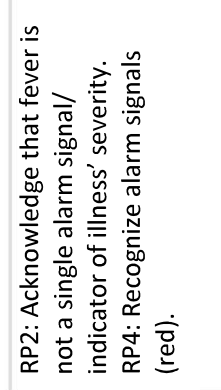 \\
\hline & 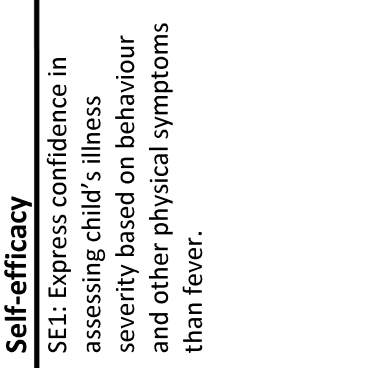 & 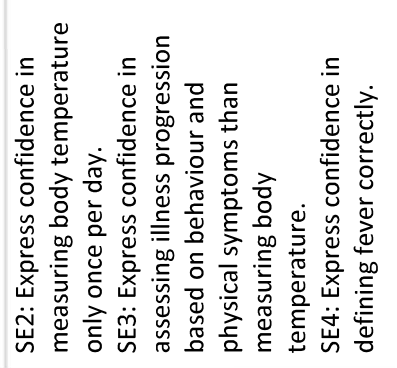 & 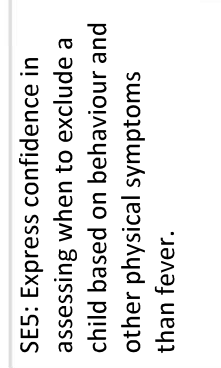 \\
\hline & 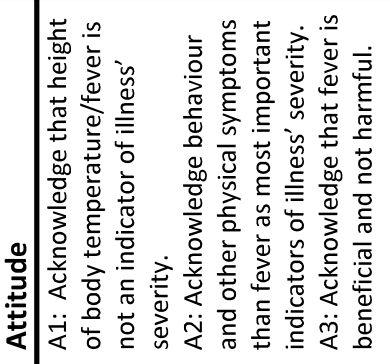 & 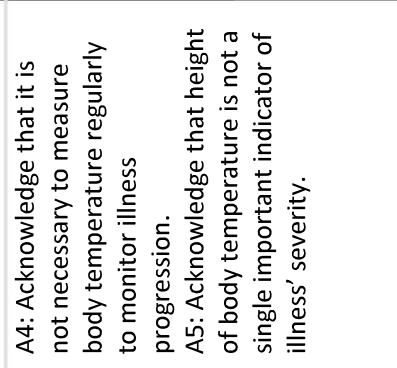 & 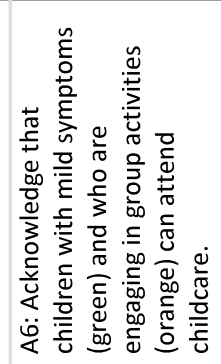 \\
\hline 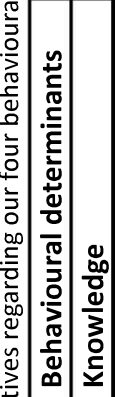 & 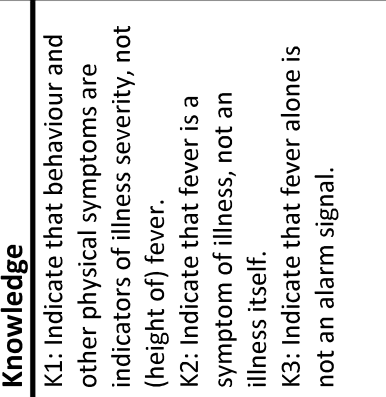 & 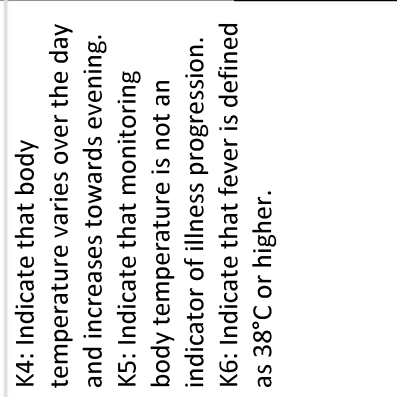 & 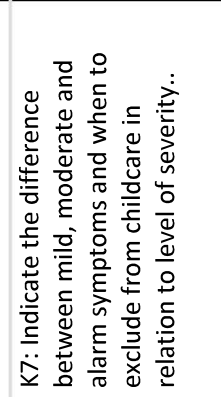 \\
\hline 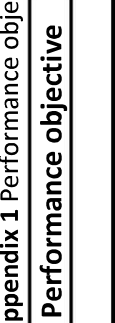 & 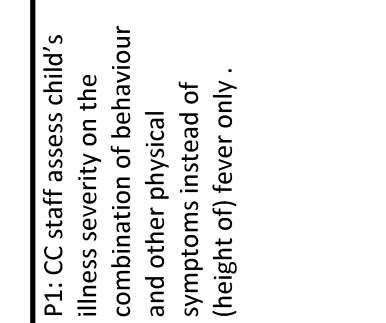 & 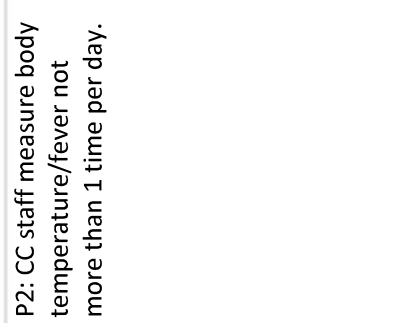 & 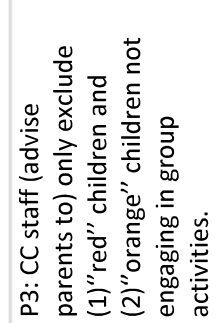 \\
\hline
\end{tabular}




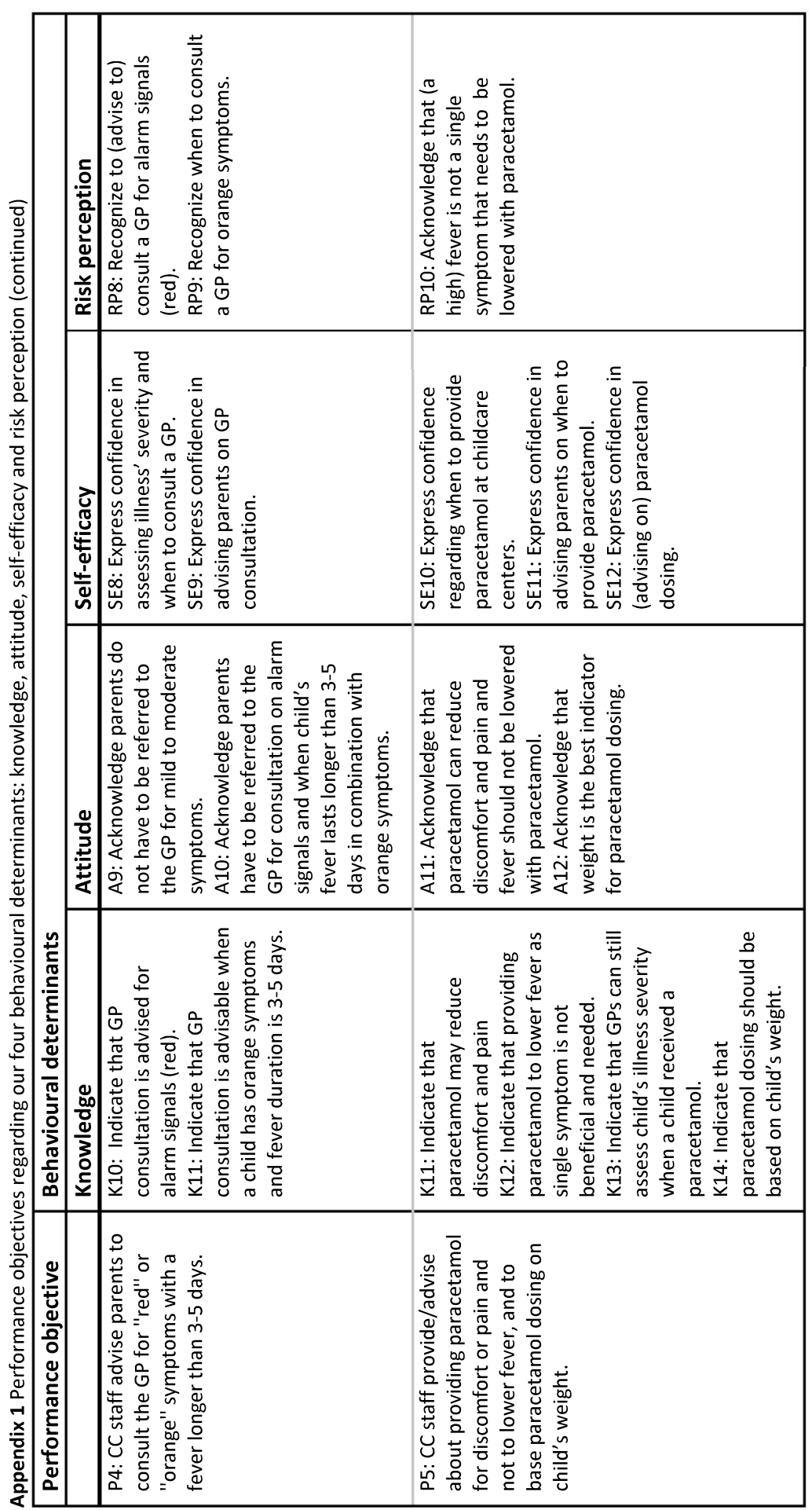




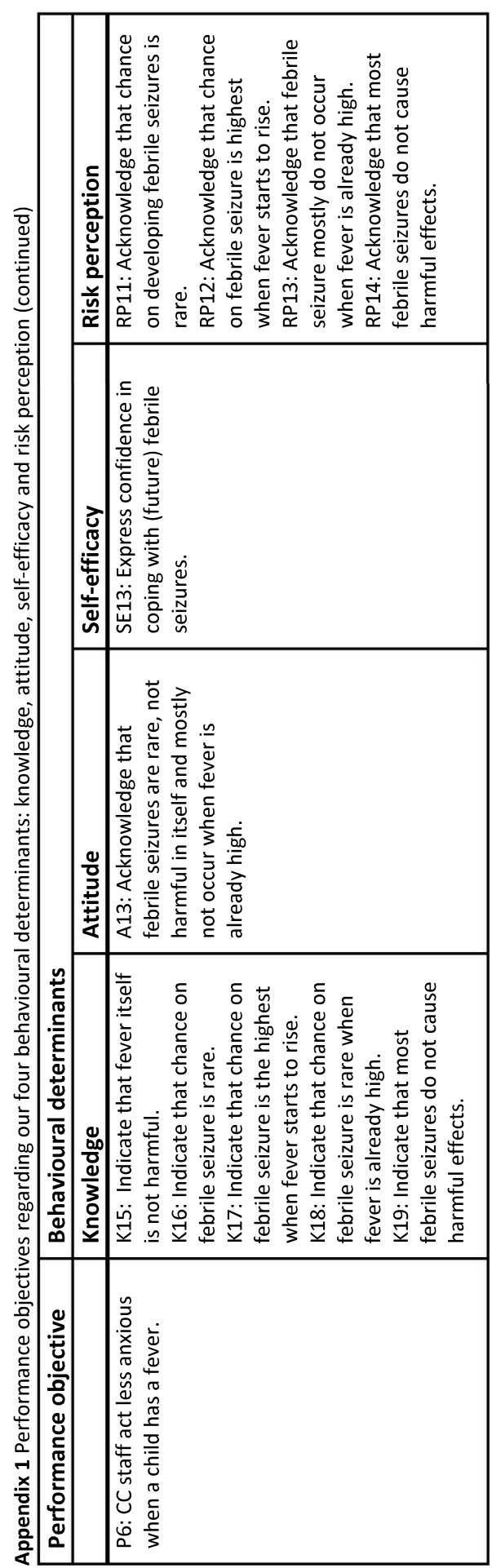




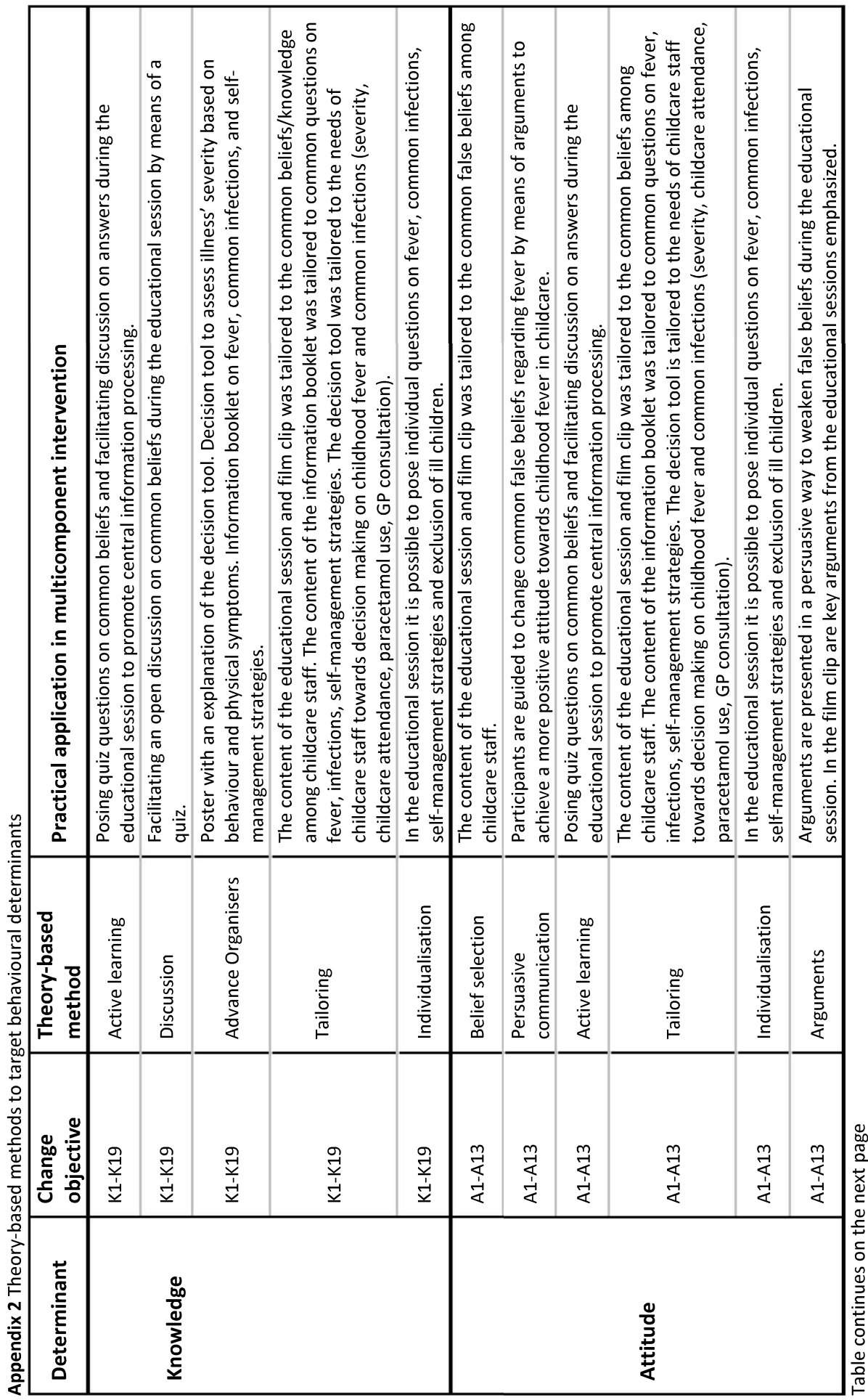




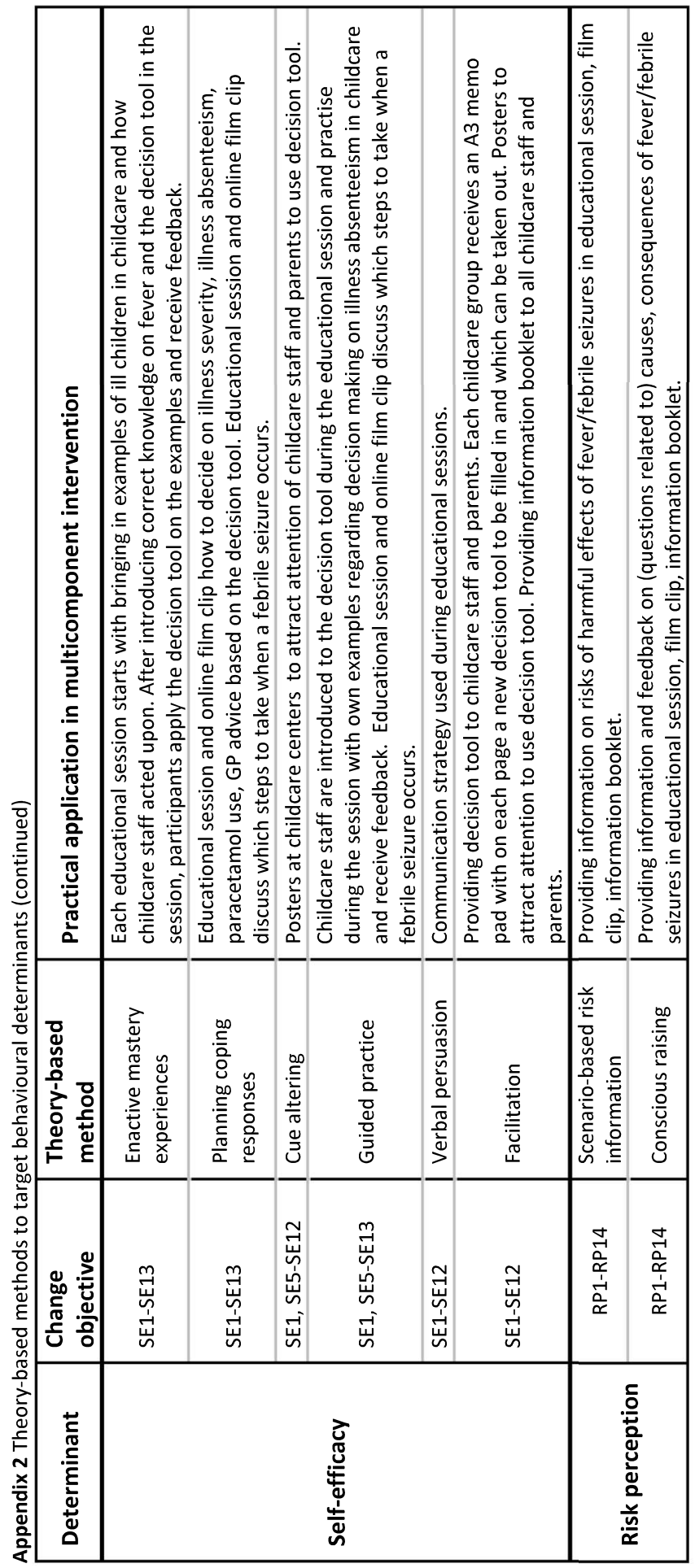


Appendix 3 Format registration booklet illness absenteeism

\begin{tabular}{|c|c|}
\hline $\begin{array}{l}\text { Childcare group } \\
\text { number: }\end{array}$ & First name childcare staff \\
\hline $\begin{array}{l}\text { Number of children who attend childcare for } 2 \\
\text { dayparts today } \\
\text { Number of children who attend childcare for } 1 \text { daypart } \\
\text { today } \\
\text { Number of children absent because of another reason } \\
\text { than illness }\end{array}$ & $\begin{array}{l}\text { Number: } \\
\text { Number: } \\
\text { Number: } \\
\text { Total Dayparts missed: }\end{array}$ \\
\hline \multicolumn{2}{|c|}{ Children who were called in sick } \\
\hline How many children were called in ill today? & Number: \\
\hline Initials child 1: & Initials child 3: \\
\hline \multicolumn{2}{|l|}{ Most important symptom (see table) } \\
\hline Child 2: & Child 3: \\
\hline \multicolumn{2}{|l|}{ How many dayparts were missed due to illness? } \\
\hline Child 2: & Child 3: \\
\hline \multicolumn{2}{|c|}{ Did you use (together with parent) the decision tool to take a decision? } \\
\hline Child 1: yes/no & Child 3: yes/no \\
\hline \multicolumn{2}{|c|}{ Children who felt ill at childcare } \\
\hline How many children were called in ill today? & Number: \\
\hline \multicolumn{2}{|l|}{ Most important symptom (see table) } \\
\hline Child 2: & Child 3: \\
\hline \multicolumn{2}{|c|}{ Did you have contact with the parent do decide on a plan of action? } \\
\hline Child 1: yes/no & Child 3: yes/no \\
\hline \multicolumn{2}{|c|}{ Did you use (together with parent) the decision tool to take a decision? } \\
\hline Child 1: yes/no & Child 3: yes/no \\
\hline \multicolumn{2}{|l|}{ Did you provide paracetamol to the child? } \\
\hline Child 1: yes/no & Child 3: yes/no \\
\hline \multicolumn{2}{|c|}{ Children who were sent home due to illness } \\
\hline $\begin{array}{l}\text { How many children were sent home because of } \\
\text { illness? }\end{array}$ & Number: \\
\hline \multicolumn{2}{|l|}{ Most important symptom (see table) } \\
\hline Child 2: & Child 3: \\
\hline \multicolumn{2}{|c|}{ Did you have contact with the parent do decide on a plan of action? } \\
\hline Child 1: yes/no & Child 3: yes/no \\
\hline \multicolumn{2}{|c|}{ Did you use (together with parent) the decision tool to take a decision? } \\
\hline Child 1: yes/no & Child 3: yes/no \\
\hline \multicolumn{2}{|l|}{ Did you provide paracetamol to the child? } \\
\hline Child 1: yes/no & Child 3: yes/no \\
\hline \multicolumn{2}{|c|}{ Paracetamol } \\
\hline $\begin{array}{l}\text { How many children received paracetamol before } \\
\text { childcare attendance? }\end{array}$ & Number: \\
\hline
\end{tabular}


Chapter 8 


\section{Chapter 8}

\section{Optimising decision-making among childcare staff on fever and common infections: cluster randomised controlled trial}

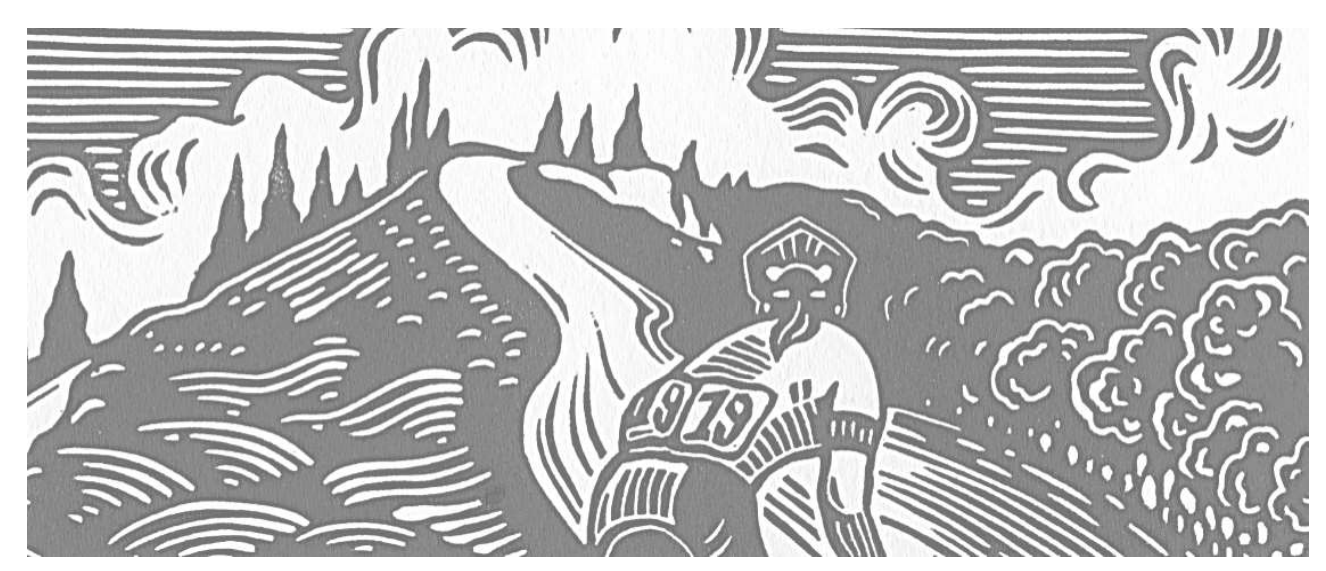

Kirsten Peetoom, Rik Crutzen, Rachèl Verhoeven, Jolijn Bohnen, Bjorn Winkens, Geert-Jan Dinant, Jochen Cals. Optimizing decision-making among childcare staff on fever and common infections: cluster randomised controlled trial.

Published in: European Journal Public Health. 2018 Nov 27 [Epub ahead of print]. 


\section{ABSTRACT}

Background Children 0-4 years attending childcare are more prone to acquire infections than home-cared children. Childcare illness absenteeism due to fever is mostly driven by fear towards fever in childcare staff and parents. This may cause high childcare absenteeism, healthcare service use, and work absenteeism in parents. This study evaluates a multicomponent intervention targeting determinants of decision- making among childcare staff on illness absenteeism due to fever and common infections.

Methods The multicomponent intervention was developed based on the Intervention Mapping approach and consisted of 1) an educational session; 2) a decision tool; 3) an information booklet; 4) an online video. The intervention was evaluated in a cluster randomised controlled trial in Southern Netherlands. Nine centres received the intervention and nine provided childcare-as-usual. Primary outcome measure was the percentage of illness absenteeism on cluster level, defined as number of childcare days absent due to illness on total of registered childcare contract days in a 12-week period. Secondary outcome measures included intended behaviour, attitude, risk perception, knowledge, and self-efficacy of childcare staff. Outcomes were analysed using linear mixed models accounting for clustering. Knowledge was descriptively analysed.

Results Overall illness absenteeism was comparable in intervention (2.95\%) and control group (2.52\%). Secondary outcomes showed significant improvements in intervention group regarding intended behaviour, two of three attitude dimensions. Knowledge increased compared to control but no differences regarding self-efficacy were observed.

Conclusion The intervention was not effective in reducing illness absenteeism. However, the intervention improved determinants of decision-making such as intended behaviour, attitude, and knowledge on fever. 


\section{INTRODUCTION}

Children 0-4 years attending childcare (CC) centres are more prone to acquire infectious diseases [1-5]. They experience approximately 6-12 infectious illness episodes per year, on average resulting in absenteeism of 23 CC days [4, 6-8]. CC children also have higher healthcare consumption compared to home-cared children [5, 9-14]. Furthermore, due to an average work absenteeism of 1.5 days among parents per illness episode, CC children generate twice as much societal costs compared to home-cared children [2].

Organisational exclusion policies regarding ill children and defensive advices from CC staff drive children's CC absenteeism and healthcare consumption $[9,10,15-20]$. On the one hand, exclusion policies are important in CC staff's decision-making since CC staff lack formal education on ill children. On the other hand, CC staff perceive that they mainly base decisions on their intuitive judgment $[18,21]$. These judgments emanate from experiences gained by themselves or by colleagues. However, these experiences may also increase their level of concerns since previous negative affect decision-making and lead to defensive advising. For example, CC staff urge parents to pick up the ill child when they do not feel comfortable anymore to take care of a child with a body temperature exceeding $38^{\circ} \mathrm{C}[18]$. CC staff's decisions are also influenced by incomplete knowledge, the belief that an ill child is better off at home, perceived contagiousness of illness symptoms, the belief that ill children increase workload, that they do not feel confident in monitoring ill children, or feel pressured by parents who have to work [10, 16, 21-23]. Most CC staff fear that a high fever resembles illness severity, or may cause febrile seizures. These misconceptions may fuel CC staff's worries and in turn, lead to more illness absenteeism and healthcare consumption $[16,17,24]$. Parents perceive CC staff as an important source of information and support, but may feel pressured by CC staff to consult a doctor $[15,16]$.

CC staff's concerns towards fever result in varying decision-making on CC absenteeism, a high healthcare service use, and productivity loss among parents. However, educational interventions for CC staff on decision-making towards fever and common infections are scarce. Existing interventions focus primarily on improving hygiene practices to reduce illness absenteeism in CC children [25]. Three studies focus on changing behavioural determinants underlying hygiene practices $[7,8,26]$. It is obvious to target determinants of a certain behaviour to develop interventions since determinants influence behaviour. For example, knowledge is a prerequisite for changing attitude and affects risk perception. In turn, these determinants influence an individual's intention to perform certain behaviour $[27,28]$. We hypothesise that an intervention aimed at improving determinants of decisionmaking in CC staff reduces illness absenteeism for fever and common infections in children attending childcare [29]. This study therefore aims to evaluate a multicomponent intervention to support CC staff in decision-making regarding illness absenteeism due to fever and common infections. 


\section{METHODS}

\section{Study design}

Between January - May 2017, we conducted a cluster randomised controlled trial in childcare $(\mathrm{CC})$ centres to evaluate a multicomponent intervention $(\mathrm{MCl})$ in comparison with the control centres that provided childcare-as-usual. The intervention was developed based on the stepwise approach of Intervention Mapping to improve determinants of decisionmaking (intended behaviour, attitude, risk perception, knowledge, and self-efficacy) among CC staff. The study protocol of the trial, including the development and behavioural determinant selection, has been published previously [29].

\section{Study setting and participants}

A total of 21 CC centres in Southern Netherlands were eligible to participate in the study. Of those, 18 consented to participate. CC staff and location managers were informed about the study by means of written information. All CC staff in the intervention group, regardless of whether they were tenured, replacements for a fixed period, or trainees, were eligible to take part in the educational session. All children attending these CC centres, including children with chronic medical conditions, were eligible to be included in the study. In the Netherlands, unpaid parental leave is set at a maximum of 26 workweeks per year. However, this parental leave is preplanned. When a child becomes ill, parents can fall back on short-term sick leave in consultation with the employer [30].

\section{Intervention}

The development and content of $\mathrm{MCl}$ has been described elsewhere [29]. The intervention consisted of 1) an educational session (targeted at childcare staff); 2) a decision tool (staff; parents); 3) an information booklet (staff; parents); 4) an online video (staff; parents). The educational session and information booklet were provided to staff in intervention CC centres in January. The educational session focused on discussing beliefs towards three topics: pathophysiology of fever, treatment of fever, and febrile seizures. Also part of the educational session was the explanation of the decision tool to assess illness severity and to provide accompanying advices on CC attendance, paracetamol provision, and GP consultation. An ill child may increase workload for childcare staff. Therefore, we included in "orange" that a child can attend childcare as long as staff think that a child can attend group activities (see appendix 4). The decision tool was made available to CC staff and parents in February. Staff and parents received an information booklet with more background information on fever pathophysiology, duration of infectious symptoms, treatment strategies, included a traffic light system to decide when to consult the GP, or apply self-management strategies. The short online video consisted of key messages from the educational session, information booklet and instructions towards the use of the decision tool and was made available to CC staff and parents in March.

\section{Outcome measures}

The primary outcome measure, illness absenteeism, was expressed as a percentage and operationalised as the total number of CC days absent due to illness on the total number of 
CC contract days, for both the intervention and the control group. This outcome measure was also used in previous studies in childcare [31-33]. Illness absenteeism was calculated for six separate periods of two weeks, because registration booklets were provided every two weeks to minimize recall bias. Secondary outcome measures: 1 ) determinants of decision-making on illness absenteeism, namely intended behaviour, attitude, risk perception, knowledge, and self-efficacy among CC staff.

\section{Sample size}

Details of the sample size calculation can be found in the protocol [29]. A total of 964 participants were required to detect a difference in illness absenteeism of $4.5 \%$ (SD=18.0\%) with $80 \%$ Power, assuming an $\alpha$ of 0.05 , intra-cluster correlation of 0.01 , and on average 55 participants per location, $10 \%$ efficiency loss due to unequal cluster sizes, and $10 \%$ dropout.

\section{Randomisation}

Stratified block randomisation was conducted at centre level and based on number of children attending a CC centre $(<65$ or $>65)$. Nine centres were randomised to the intervention and nine to the control condition. Randomisation was performed by an independent researcher via www.randomization.com. CC staff were not blinded to the intervention allocation due to the nature of $\mathrm{MCl}$, but were blinded to the primary outcome measure.

\section{Data collection}

In line with previous research, CC staff registered on a daily basis how many children were present and absent to calculate the total number of CC contract days, number of children absent due to illness or other reasons (e.g. holiday), by means of a standardised paperbased illness registration form [26, 31, 33, 34]. Absence data was double-checked with the organisation's own registry on childcare absences. Secondary outcomes were measured by means of a survey at baseline and after the 12-week study period among CC staff. Intended behaviour, attitude, risk perception, and self-efficacy were measured on 7-point Likert scales. Intended behaviour among CC staff was measured according to a vignette that described an ill child with an illness severity belonging to category "orange" when consulting the decision tool [see table 2 and appendix 4]. Knowledge was measured on a 3point scale with items covering specific topics addressed by $\mathrm{MCl}$. Exposure to $\mathrm{MCl}$ was assessed by "yes/no". Perceived usefulness was evaluated on a VAS-scale. Determinants of decision-making among parents will be reported elsewhere.

\section{Statistical analysis}

The number of children attending CC centres varied during the study period, because children $>4$ years leave $\mathrm{CC}$ for preschool, while children $<4$ years enter $\mathrm{CC}$ and thus our study. Therefore, the number of registered $\mathrm{CC}$ contract days was used to calculate the primary outcome measure: the total number of days absent within 2 weeks divided by the total number of contract days within 2 weeks for each CC centre. The 12-week illness absenteeism rate was calculated based on six periods of two weeks. The primary outcome measure was analysed using linear mixed models with group (intervention/control), time 
(categorical), group*time, and stratification variable cluster size as fixed factors. The covariance structure for repeated measures with the smallest Bayes Information Criterion (BIC), e.g. unstructured or (heterogeneous) first-order auto-regression, was reported. In case of a non-significant interaction between group and time, the overall group effect (model without interaction) is presented.

Secondary outcomes were analysed using a three level (time, childcare staff, location) linear mixed model. The fixed factors were the same as for the primary outcome, but an unstructured covariance structure was used for the two repeated measures. Additionally, a random intercept on location level was included to account for nesting of staff within a location. Dimensionality was assessed for attitude, risk perception and self-efficacy by means of factor analysis [35]. In addition, means were calculated for separate items for dimensions within these determinants, and for survey items measuring intended behaviour. Missing data were imputed when a dimension consisted of more than three completed items. Sensitivity analyses were performed by adding age, years of work experience, number of work hours per week or educational level separately to the model. Knowledge was analysed descriptively analysed because of the nature of questions and answer options. All data were obtained, managed, and monitored according to the guidelines of Good Clinical Practice and analysed using IBM SPSS Statistics for Windows (version 23.0. Armonk, NY:IBM Corp.), and reported following CONSORT statement and extension for regarding cluster randomised trials [36]. A two-sided $p$-value $\leq 0.05$ was considered statistically significant.

\section{Research ethics and consent}

The study was approved by the medical ethical committee of Zuyderland, Heerlen, the Netherlands [METC 14-N-171]. CC staff provided informed consent to fill in the survey at baseline and after 12 weeks. All data were anonymised and only used for study purposes.

\section{RESULTS}

\section{Baseline characteristics}

Following randomisation, $9 \mathrm{CC}$ centres including 92 staff received $\mathrm{MCl}$, and $9 \mathrm{CC}$ centres with 94 staff provided childcare-as-usual. See figure 1 for baseline characteristics of clusters.

\section{Primary outcome measure}

CC children in the intervention group reported 12,269 contract days during the 12-week trial period, with 380 absences $(2.95 \%, \mathrm{~N}=330$ called in ill, $\mathrm{N}=50$ sent home ill), and 60 children who felt ill but remained present at the CC during that period. CC children in the control group reported 13,583 contract days, with 370 absences $(2.52 \% \mathrm{~N}=330$ called in ill, $\mathrm{N}=40$ sent home ill) and 19 children who felt ill but stayed at the CC during that period (see figure 1). The linear mixed model showed that overall 12- week illness absenteeism was comparable for the intervention and the control group (effect $0.53 \%, 95 \% \mathrm{Cl}-1.36 \%$ to $0.30 \%)$. In addition, six separate measurement periods of two weeks showed in both groups that illness absenteeism was highest during the first four weeks and a downward trend was 
observed in the following eight weeks (see figure 2). No significant differences in illness absenteeism were observed between both groups for the six separate two-week periods (table 1).

\section{Determinants of behaviour change among CC staff}

A total of $71 \mathrm{CC}$ staff ( $77.2 \%)$ in the intervention group and $68 \mathrm{CC}$ staff $(72.3 \%)$ in the control group participated in both the baseline survey and post-measurement (table 3). Reasons for not filling in both surveys were long-term illness absenteeism, pregnancy leave, holiday, or change of work.

Regarding intended behaviour, the post-measurement showed that CC staff in the intervention group assessed the child in the proposed vignette as less ill and $70 \%$ of respondents indicated correctly that the child was experiencing "orange" symptoms. In addition, fewer respondents reported assessing illness severity solely based on a body temperature of $39^{\circ} \mathrm{C}$. Also more CC staff agreed that a child with these "orange" symptoms could stay at the CC, more staff wanted to administer paracetamol, and less CC staff would advise parents to consult the GP (table 2).

We observed significant improvements in the intervention group compared to the control group regarding "general attitude towards fever" ( $p \leq 0.001)$ and "attitude towards perceived harmful consequences of fever" ( $p \leq 0.001)$. "Attitude towards paracetamol use in febrile children" was comparable for the intervention and the control group $(p=0.16)$ (table 2).

At baseline, intervention and control group demonstrated a high level on both dimensions of self-efficacy. The post-measurement showed a positive trend in the intervention compared to control group for both domains (table 2). Sensitivity analyses showed that after adding age, years of work experience, number of work hours per week, or educational level to the model, similar results are found for attitude, risk perception, and self-efficacy dimensions.

An increase of $9.6 \%$ was observed in defining fever correctly as $38^{\circ} \mathrm{C}$ or higher in the intervention group compared to baseline. Furthermore, improvement in knowledge statements was observed. See appendices 1 - 3 for results on item level regarding attitude, risk perception, self-efficacy, and knowledge.

Exposure to and use of individual intervention components

Exposure to individual components was high for the educational session (98.6\%) and booklet ( $88.7 \%$ ).The decision tool was used by $62.3 \%$ of respondents and the booklet by $71.4 \%$. The perceived usefulness for individual components ranged between $85.1 \%$ and $96.8 \%$ (see table 3 ). 


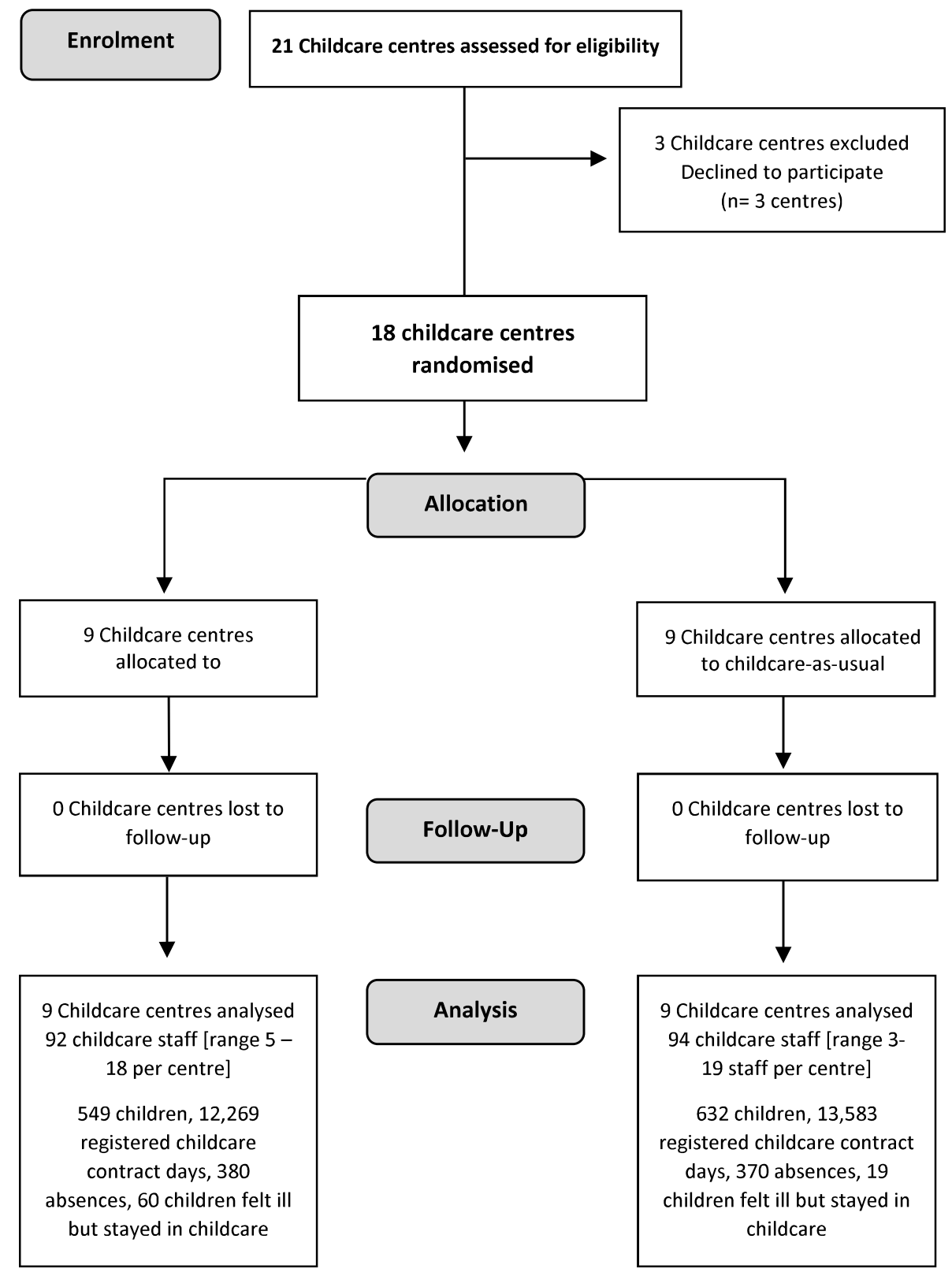

Figure 1 CONSORT flow diagram of cluster randomised controlled trial 


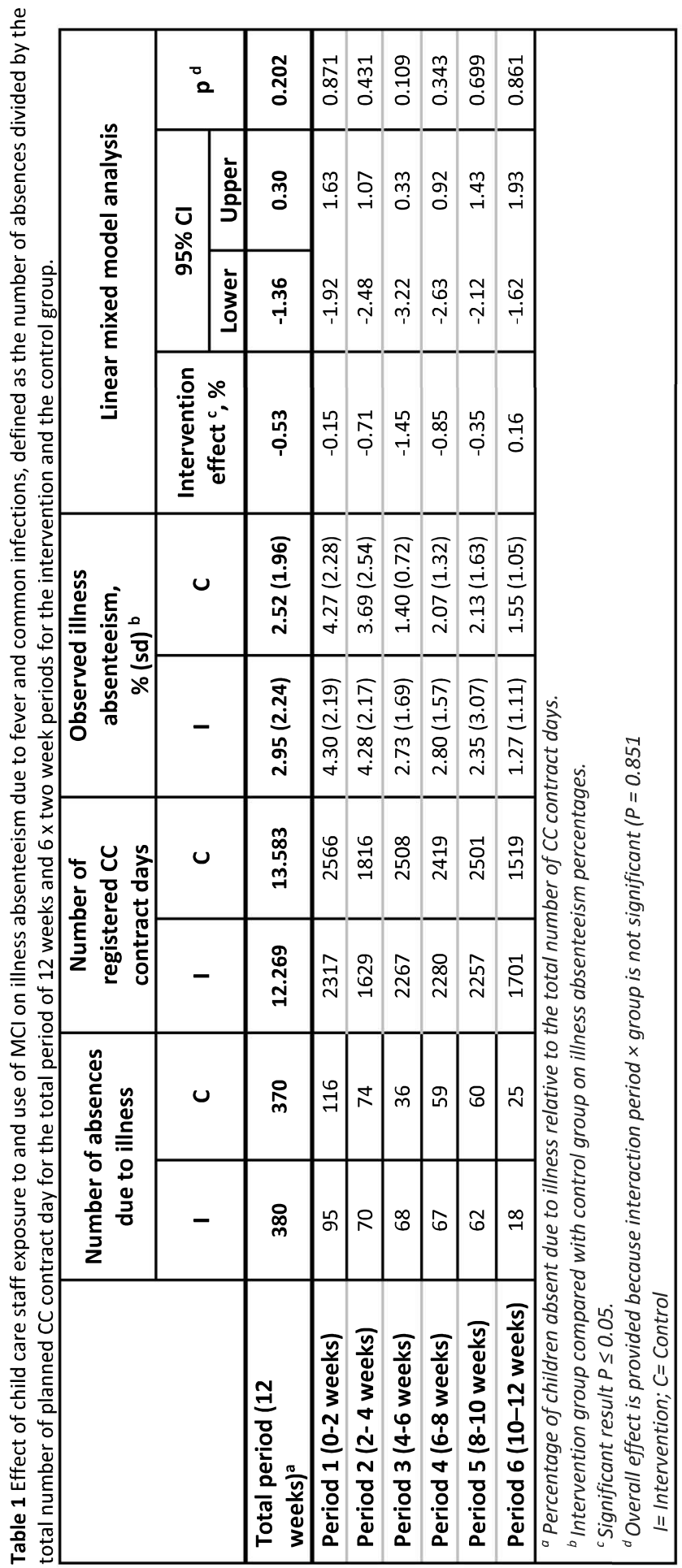




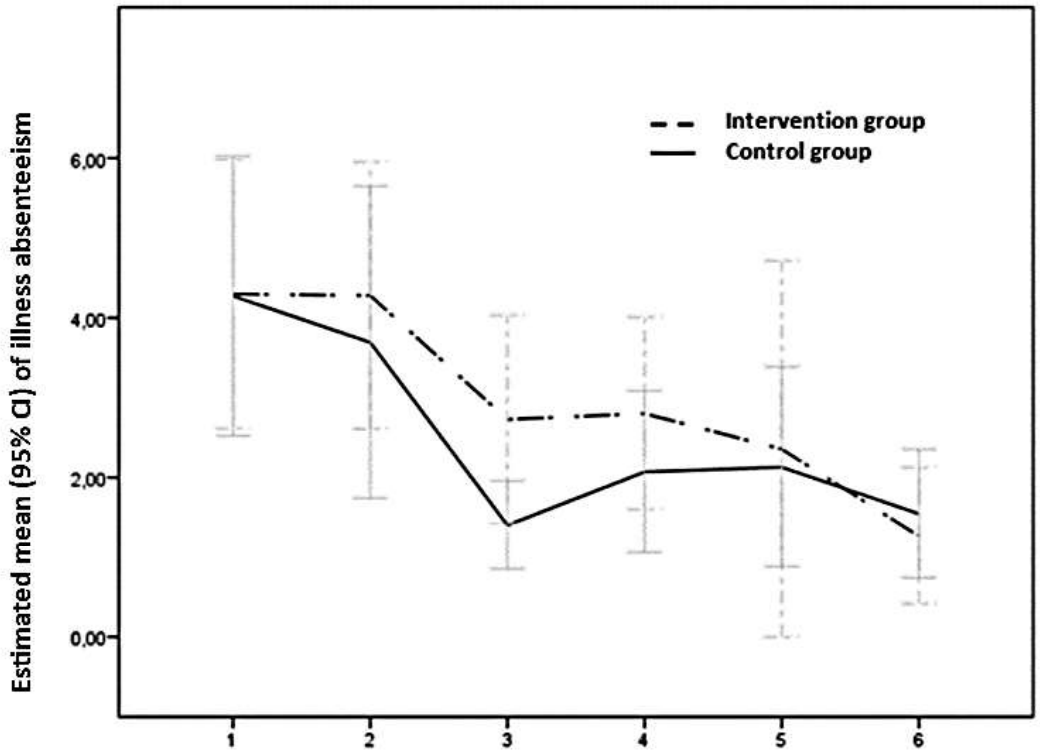

Figure 2 measurement of illness absenteeism at each period of two weeks ( $6 x$ two weeks) between January and May 2017 


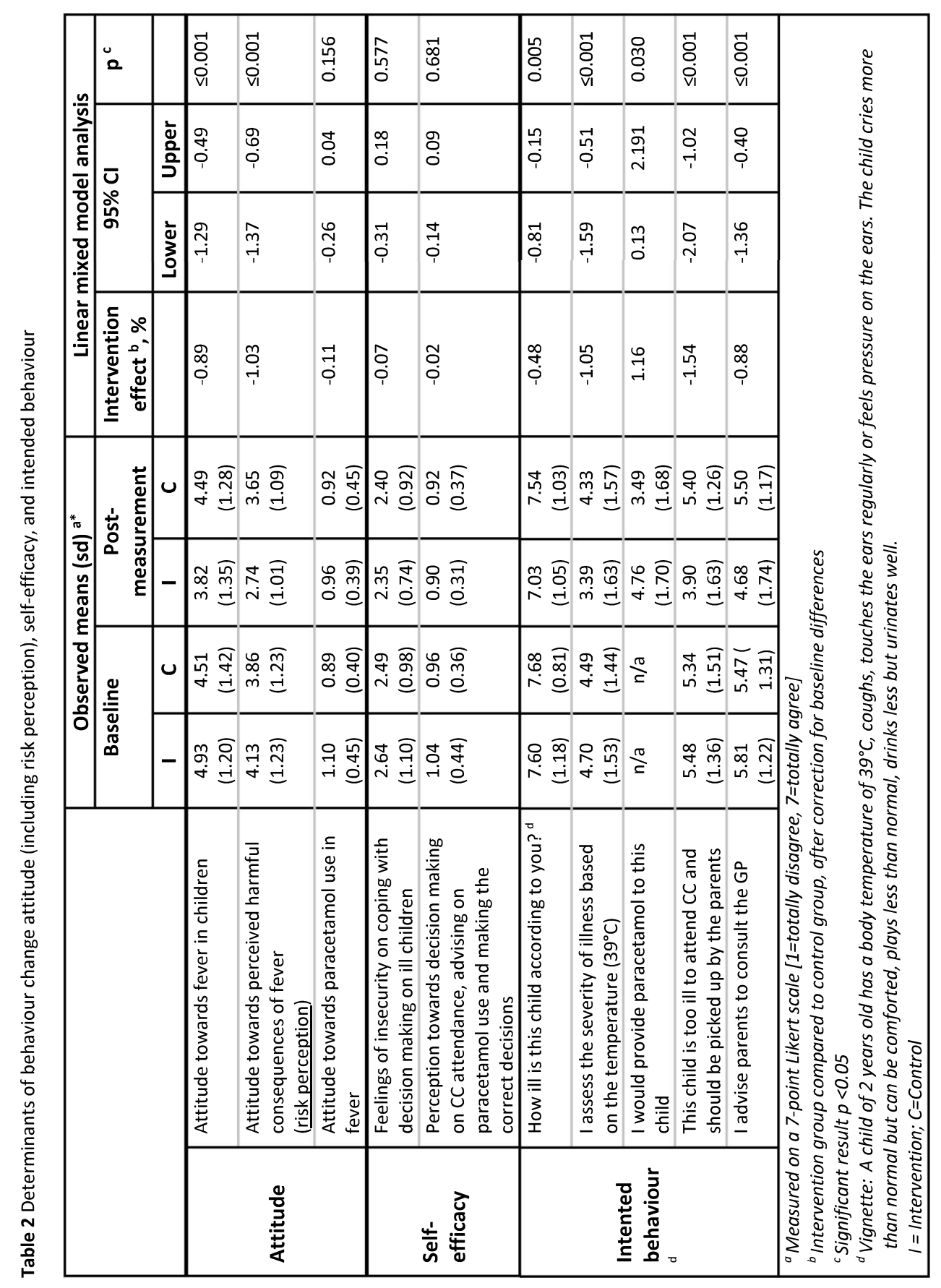


Table 3 Exposure to individual components of intervention and perceived usefulness

\begin{tabular}{|l|l|l|l|l|l|}
\hline & & $\begin{array}{l}\text { Response } \\
\mathbf{N}(\%)\end{array}$ & $\begin{array}{l}\text { Exposure to } \\
\text { individual } \\
\text { components } \\
\mathbf{N}(\%)\end{array}$ & $\begin{array}{l}\text { Use of } \\
\text { individual } \\
\text { components } \\
\mathbf{N}(\%)\end{array}$ & $\begin{array}{l}\text { Perceived as } \\
\text { useful by users } \\
\mathbf{N}(\%)\end{array}$ \\
\hline $\begin{array}{l}\text { Intervention } \\
\text { group (N=92) }\end{array}$ & $\begin{array}{l}\text { Educational } \\
\text { session }\end{array}$ & $\begin{array}{l}\text { Decision } \\
\text { tool }\end{array}$ & $71(77.2 \%)$ & $\mathrm{n} / \mathrm{a}$ & $61 / 63(96.8 \%)$ \\
\hline $\begin{array}{l}\text { Booklet } \\
\text { Video }\end{array}$ & & $69 / 71(88.7 \%)$ & $53 / 69(62.3 \%)$ & $57 / 67(85.1 \%)$ \\
\hline $\begin{array}{l}\text { Control group } \\
\text { (N=94) }\end{array}$ & & $68(72.3 \%)$ & $n / a$ & $50 / 70(71.4 \%)$ & $62 / 67(92.5 \%)$ \\
\hline
\end{tabular}

\section{DISCUSSION}

\section{Summary of results}

The multicomponent intervention was not successful in reducing illness absenteeism due to fever and common infections in children attending childcare. However, providing $\mathrm{MCl}$ improved behavioural determinants such as intended behaviour, attitude towards fever, and risk perception among CC staff. The intervention also increased knowledge among CC staff.

\section{Comparison with other studies}

CC illness absenteeism was comparable for children in the intervention and control group. Importantly, we observed that less children were absent due to fever and common infections in both groups than expected. The overall illness absenteeism in our 12-week trial was $2.95 \%$ and $2.52 \%$ for the intervention and control group, respectively. However, we expected that approximately $10 \%$ of the registered childcare contract days would be missed due to illness in the control group, based on a pilot one-month period the year preceding the trial, and earlier research [29] [31]. One explanation may be that the overall incidence of infectious symptoms of respiratory-and gastro-intestinal tract infections was substantially lower in winter 2016-2017 than during our pilot in March 2016. In addition, an overall downward trend in illness absenteeism was observed in both groups during the 12week trial period, which is in line with observations that the 2017 flu season ended earlier than in previous years [37].

Previous research showed that organisational exclusion policies regarding ill children are an important guidance for CC staff, but the childcare staff also acknowledged that their intuitive judgement prevails when they do not feel comfortable anymore. For example, when the child's body temperature exceeds $38^{\circ} \mathrm{C}$ because they fear febrile seizures or serious illnesses [18]. As a result, childcare staff may base their decisions on illness absenteeism on their intuitive judgement, inappropriate beliefs and knowledge [16, 21]. $\mathrm{MCl}$ was successful in targeting determinants of decision-making with significant improvements regarding intended behaviour, attitude towards fever, and risk perception. 
For example, we saw a significant reduction in CC staff's intention to assess severity of symptoms based on solely the body temperature $\left(39^{\circ} \mathrm{C}\right)$, their intention to send a child home with "orange" illness symptoms, and to advise parents to consult a general practitioner for these symptoms. In addition, their knowledge on fever improved. The results also show that more children who felt ill in the intervention group stayed in childcare compared to the control group. This may suggest that childcare staff in the intervention group were less reluctant to keep ill children under their watch than the control CC centres. Unfortunately, we do not know if children in intervention and control group differed in illness severity and if this may explain the difference. Related to this, childcare staff face a dilemma when a child is ill; an ill child in childcare may increase workload, while sending home the ill child will decrease their workload. Therefore, we included that a staff's decision needs to consider if a child can participate in group activities.

Despite the improvements in the behavioural determinants, no change was observed in illness absenteeism due to fever and common infections. This is in line with previous research where also significant changes in behavioural determinants were observed but no significant reductions in illness absenteeism $[26,38]$. One explanation may be that changing complex decision-making processes takes longer than 12 weeks. In addition, only half of intentions are translated into actions [39].

\section{Strengths and limitations}

To our knowledge, this is the first educational intervention targeting determinants of decision-making on illness absenteeism among $\mathrm{CC}$ staff. $\mathrm{MCl}$ was tailored to determinants of decision-making among CC staff by means of the Intervention Mapping approach. In addition, the content and lay-out of the intervention and outcome measurement tools were developed in close collaboration with stakeholders to increase usability and uptake. As a result, $\mathrm{MCl}$ was perceived as useful by CC staff and the majority was in favor to keep on using the educational materials in their $\mathrm{CC}$ centre. This also indicates that $\mathrm{CC}$ staff perceive childhood fever and common infections as an important topic that needs attention. However, our results also show that not all participants were exposed to or used the intervention.

IIIness absenteeism was registered by CC staff to achieve complete absence data [31, 40]. Yet, as many parents called their child ill via the digital portal and did not provide details on reasons for illness absence, we could not determine if reasons for illness absenteeism differed between intervention and control group. In addition, it was difficult to establish for which illness severity category CC staff especially use the decision tool and to assess if their decision-making processes changed.

To keep the daily registration of absenteeism concise and anonymous, we decided not to ask childcare staff to register baseline characteristics of the ill child. As a result, it was not possible to assess if children in intervention and control group were comparable in age division. However, since we randomised the childcare centres to either intervention or control group, we assume that the age division will be comparable in both intervention and control group. 


\section{Implications for practice}

Little research focused up to now on improving behavioural determinants in CC staff to alter their decision-making process on ill children. Our positive results in changing behavioural determinants of decision-making show that CC staff are open to modify current views. Future research should focus on exposing all participants to the intervention and to enhance self-efficacy, an important determinant in the process of translating intention into action. It is also important to target communication with parents in the decision-making process. In addition, revising organisational exclusion policies and childcare staff's educational program is needed since these elements foster CC staff's knowledge and in turn, fearful attitude towards fever.

\section{CONCLUSION}

We aimed to support CC staff in the decision-making process by developing a multicomponent intervention based on the Intervention Mapping approach, and in close collaboration with stakeholders, and focused on improving their intended behaviour, knowledge, attitude, risk perception, and selfefficacy. Despite these efforts and significant improvements on intended behaviour, attitude, risk perception, and an increased knowledge level, the multicomponent intervention was not successful in reducing illness absenteeism due to fever and common infections in children attending childcare. The timing and duration of the trial may explain the gap between changing behavioural change determinants and actual behaviour. 


\section{REFERENCES}

1. Nesti MM, Goldbaum M. Infectious diseases and daycare and preschool education. J Pediatr (Rio J) 2007;83(4):299-312.

2. Enserink R, Lugner A, Suijkerbuijk A, Bruijning-Verhagen P, Smit HA, van Pelt W. Gastrointestinal and Respiratory Illness in Children That Do and Do Not Attend Child Day Care Centers: A Cost-of-Illness Study. PLOS ONE. 2014;9(8):e104940.

3. Kotch JB, Weigle KA, Weber DJ, Clifford RM, Harms TO, Loda FA, et al. Evaluation of an hygienic intervention in child day-care centers. Pediatrics. 1994;94(6 Pt 2):991-4.

4. Roberts L, Smith W, Jorm L, Patel M, Douglas RM, McGilchrist C. Effect of infection control measures on the frequency of upper respiratory infection in child care: a randomized, controlled trial. Pediatrics. 2000;105(4 Pt 1):738-42.

5. Castillo-Aguas Gd, Gallego-Iborra A, Gutierrez-Olid M, Perez-Gonzalez O, Moreno-Munoz G, LedesmaAlbarran JM. Infectious morbidity and resource use in children under 2 years old at childcare centres. J Paediatr Child Health. 2017;53(2):116-22.

6. Pönka A, Nurmi T, Salminen E, Nykyri E. Infections and other illnesses of children in day-care centers in Helsinki. I: Incidences and effects of home and day-care center variables. Infection. 1991;19(4):230-6.

7. Zomer TP, Erasmus V, Looman CW, Tjon-A-Tsien A, Van Beeck EF, De Graaf JM, et al. A hand hygiene intervention to reduce infections in child daycare: a randomized controlled trial. Epidemiol Infect. 2015;143(12):2494-502.

8. Uhari M, Mottonen M. An open randomized controlled trial of infection prevention in child daycare centers. Pediatr Infect Dis J. 1999;18(8):672-7.

9. Silverstein M, Sales AE, Koepsell TD. Health care utilization and expenditures associated with child care attendance: a nationally representative sample. Pediatrics. 2003;111(4 Pt 1):e371-5.

10. de Jong BM, van der Ent CK, van der Zalm MM, van Putte-Katier N, Verheij TJ, Kimpen JL, et al. Respiratory symptoms in young infancy: child, parent and physician related determinants of drug prescription in primary care. Pharmacoepidemiol Drug Saf. 2009;18(7):610-8.

11. Lu N, Samuels ME. Increased health care utilization associated with child day care among health maintenance organization and Medicaid enrollees. Ambul Child Health. 2001;7(3-4):219-30.

12. de Hoog ML, Venekamp RP, van der Ent CK, Schilder A, Sanders EA, Damoiseaux RA, et al. Impact of early daycare on healthcare resource use related to upper respiratory tract infections during childhood: prospective WHISTLER cohort study. BMC medicine. 2014;12:107.

13. Hjern A, Haglund B, Rasmussen F, Rosen M. Socio-economic differences in daycare arrangements and use of medical care and antibiotics in Swedish preschool children. Acta Paediatr. 2000;89(10):1250-6.

14. Hedin K, Andre M, Hakansson A, Molstad S, Rodhe N, Petersson C. Physician consultation and antibiotic prescription in Swedish infants: population-based comparison of group daycare and home care. Acta paediatr, . 2007;96(7):1059-63.

15. Ertmann RK, Soderstrom M, Reventlow S. Parents' motivation for seeing a physician. Scand J Prim Health Care. 2005;23(3):154-8.

16. Skull SA, Ford-Jones EL, Kulin NA, Einarson TR, Wang EE. Child care center staff contribute to physician visits and pressure for antibiotic prescription. Arch Pediatr Adolesc Med. 2000;154(2):180-3.

17. Hay A, Heron J, Ness A. The prevalence of symptoms and consultations in pre-school children in the Avon Longitudinal Study of Parents and Children (ALSPAC): a prospective cohort study. Fam Pract, 2005;22(4):367-74.

18. Peetoom K, Crutzen, R, Alleleijn, I, Laumen, L, Moser, A, Dinant, GJ, Cals, J,. "I am not a doctor", views of childcare staff towards decision-making on febrile children: a qualitative study. 2018.

19. de Bont EGPM, Peetoom KKB, Moser A, Francis NA, Dinant G-J, Cals JWL. Childhood fever: a qualitative study on GPs' experiences during out-of-hours care. Family practice. 2015;32(4):449-55. 
20. Rooshenas L, Wood F, Brookes-Howell L, Evans MR, Butler CC. The influence of children's day care on antibiotic seeking: a mixed methods study. The British journal of general practice : the journal of the Royal College of General Practitioners. 2014;64(622):e302-e12.

21. Kahan E, Gross S, Cohen HA. Exclusion of ill children from child-care centers in Israel. Patient Educ Couns. 2005;56(1):93-7.

22. Friedman JF, Lee GM, Kleinman KP, Finkelstein JA. Child care center policies and practices for management of ill children. Ambul Pediatr. 2004;4(5):455-60.

23. Copeland KA, Duggan AK, Shope TR. Knowledge and beliefs about guidelines for exclusion of ill children from child care. Ambul Pediatr. 2005;5(6):365-71.

24. Landis SE, Earp JA, Sharp M. Day-care center exclusion of sick children: comparison of opinions of day-care staff, working mothers, and pediatricians. Pediatrics. 1988;81(5):662-7.

25. Willmott M, Nicholson A, Busse H, MacArthur GJ, Brookes S, Campbell R. Effectiveness of hand hygiene interventions in reducing illness absence among children in educational settings: a systematic review and meta-analysis. Arch Dis Child. 2016;101(1):42-50.

26. Rosen L, Manor O, Engelhard D, Brody D, Rosen B, Peleg H, et al. Can a handwashing intervention make a difference? Results from a randomized controlled trial in Jerusalem preschools. Prev Med. 2006;42(1):2732.

27. Ajzen I. Attitudes, personality, and behavior. Chicago: Dorsey Press; 1988.

28. Ajzen I. The theory of planned behavior. Organizational Behavior and Human Decision Processes. 1991;50:179-211.

29. Peetoom KKB, Crutzen R, Bohnen J, Verhoeven R, Nelissen-Vrancken H, Winkens B, Dinant GJ, Cals J. Optimising decision making on illness absenteeism due to fever and common infections within childcare centres: development of a multicomponent intervention and study protocol of a cluster randomized controlled trial. BMC Public Health. 2017;18(1):61.

30. Karu M, Tremblay D-G. Fathers on parental leave: an analysis of rights and take-up in 29 countries. Community, Work \& Family. 2018;21(3):344-62.

31. Hedin K CO, Rolfhamre PG, Ekdahl K, Fredlund H, Petersson C. Sickness absence in daycare and reported hygiene routines. Prim Health Care Res Dev. 2010;11(2):180-6.

32. Rasmussen F., Bondestam M. Pre-school children's absenteeism from Swedish municipal daycare centres because of illness in 1977 and 1990. Geographical variations and characteristics of the daycare centres Scand J Soc Med. 1993;22(1):20-6

33. Mottonen $\mathrm{M}$, Uhari M. Absences for sickness among children in day care. Acta paediatrica (Oslo, Norway: 1992). 1992;81(11):929-32.

34. Carabin H, Gyorkos TW, Soto JC, Joseph L, Payment P, Collet JP. Effectiveness of a training program in reducing infections in toddlers attending day care centers. Epidemiol. 1999;10(3):219-27.

35. Crutzen R, Peters G-JY. Scale quality: alpha is an inadequate estimate and factor-analytic evidence is needed first of all. Health Psychol Rev. 2017;11(3):242-7.

36. Campbell MK, Piaggio G, Elbourne DR, Altman DG. Consort 2010 statement: extension to cluster randomised trials. BMJ : British Medical Journal. 2012;345.

37. Hooiveld M, Donker GA, Schellevis FG. Wekelijkse surveillance cijfers [weekly surveillance update]. Utrecht: NIVEL [Netherlands institute for health services research]; 2017 15/11/2017.

38. Hedin K, Petersson C, Cars H, Beckman A, Hakansson A. Infection prevention at day-care centres: feasibility and possible effects of intervention. Scand J Prim Health Care. 2006;24(1):44-9.

39. Sheeran P, Webb TL. The Intention-Behavior Gap. Social and Personality Psychology Compass 2016;10(9):503-18.

40. Pönka A, Poussa T, Laosmaa M. The effect of enhanced hygiene practices on absences due to infectious diseases among children in day care centers in Helsinki. Infection. 2004;32(1):2-7. 


\begin{tabular}{|c|c|c|c|c|c|c|c|c|c|c|c|}
\hline \multirow{4}{*}{ 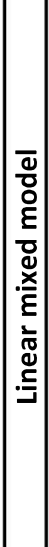 } & 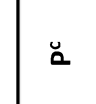 & $\begin{array}{l}\overrightarrow{0} \\
\dot{0} \\
\dot{v}\end{array}$ & $\begin{array}{l}\infty \\
\stackrel{0}{0} \\
0\end{array}$ & $\begin{array}{l}\overrightarrow{0} \\
\dot{0} \\
\dot{v}\end{array}$ & $\begin{array}{l}\tilde{O} \\
\stackrel{0}{0}\end{array}$ & $\begin{array}{l}\overrightarrow{0} \\
\dot{0} \\
\dot{v}\end{array}$ & $\begin{array}{l}\vec{z} \\
\dot{0} \\
\dot{v}\end{array}$ & $\begin{array}{l}\vec{\Delta} \\
\dot{\vec{v}}\end{array}$ & $\begin{array}{l}\vec{\Delta} \\
\stackrel{\Delta}{\mathrm{v}}\end{array}$ & 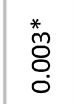 & $\begin{array}{l}\vec{y} \\
\dot{\leftrightarrow} \\
\text { vi }\end{array}$ \\
\hline & ¿ & $\begin{array}{l}\text { gి } \\
\text { ì } \\
\end{array}$ & \begin{tabular}{l}
0 \\
\multirow{1}{*}{} \\
0 \\
1 \\
\end{tabular} & $\begin{array}{l}\text { กิ } \\
\text { ஸุ }\end{array}$ & $\begin{array}{l}\infty \\
0 \\
0 \\
i\end{array}$ & $\begin{array}{l}-1 \\
0 \\
0 \\
\end{array}$ & : & $\begin{array}{l}0 \\
\text { ㄴำ } \\
i \\
\end{array}$ & 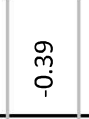 & $\begin{array}{c}\hat{N} \\
i \\
\end{array}$ & $\begin{array}{l}\infty \\
\stackrel{0}{0} \\
i\end{array}$ \\
\hline & ڤू & ని & $\begin{array}{l}\hat{O} \\
\stackrel{+}{i}\end{array}$ & $\begin{array}{l}\vec{b} \\
\stackrel{i}{i}\end{array}$ & ț & $\begin{array}{l}\stackrel{\bullet}{\circ} \\
\rightarrow \\
i\end{array}$ & $\stackrel{\hat{m}}{i}$ & 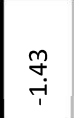 & $\underset{T}{ت}$ & $\underset{\rightarrow}{\stackrel{\overbrace{}}{i}}$ & 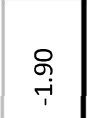 \\
\hline & 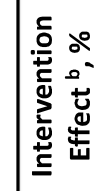 & $\begin{array}{c}\text { @ } \\
\stackrel{i}{i}\end{array}$ & $\begin{array}{l}\text { ơ } \\
\stackrel{i}{1}\end{array}$ & $\underset{i}{\stackrel{0}{i}}$ & 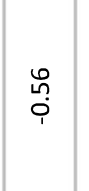 & $\stackrel{m}{\underset{十}{\rightarrow}}$ & $\stackrel{m}{i}$ & $\begin{array}{l}\text { o̊ } \\
\text { ô. } \\
\text { i. }\end{array}$ & $\begin{array}{l}\infty \\
\infty \\
i\end{array}$ & $\begin{array}{l}\stackrel{n}{n} \\
\hat{i}\end{array}$ & $\stackrel{m}{\rightarrow}$ \\
\hline \multirow{4}{*}{ 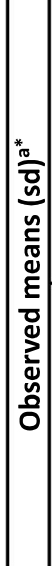 } & ט & 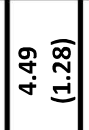 & 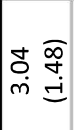 & : & 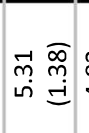 & 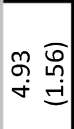 & 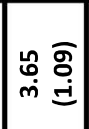 & 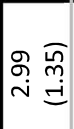 & 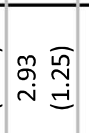 & 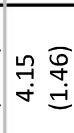 & 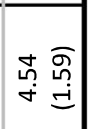 \\
\hline & - & 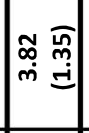 & 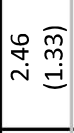 & 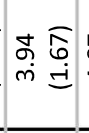 & 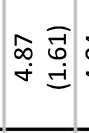 & 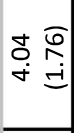 & 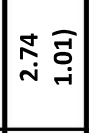 & ஓ̊ & 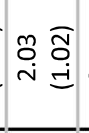 & 崫 & $\begin{array}{lll}0 & 0 \\
m & 0 \\
m & \stackrel{\Xi}{=}\end{array} \mid$ \\
\hline & u & 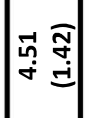 & 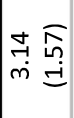 & 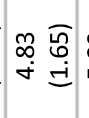 & 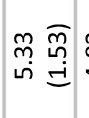 & 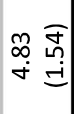 & 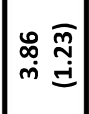 & 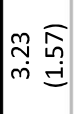 & 검 & 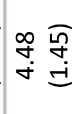 & $\begin{array}{ll}P & \bar{f} \\
\dot{f} & \stackrel{\Xi}{=}\end{array} \mid$ \\
\hline & _ & 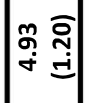 & 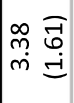 & m & : & 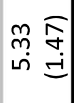 & 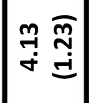 & 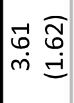 & 省 & 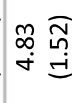 & 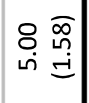 \\
\hline & 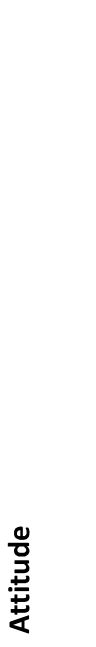 & 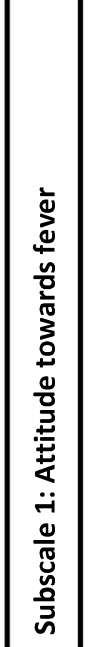 & 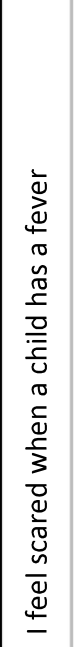 & 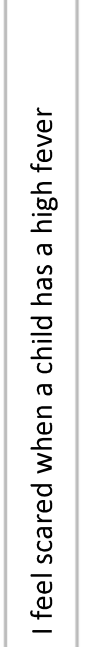 & 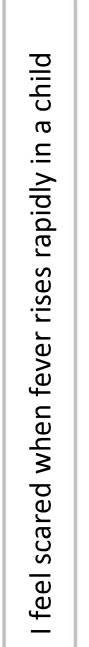 & 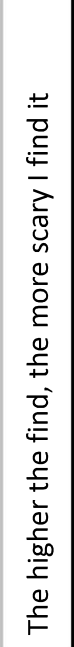 & 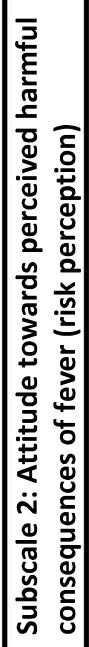 & 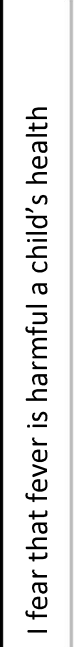 & 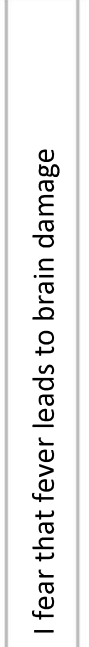 & 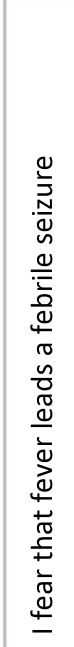 & 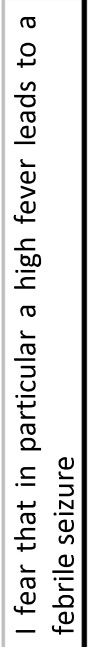 \\
\hline
\end{tabular}




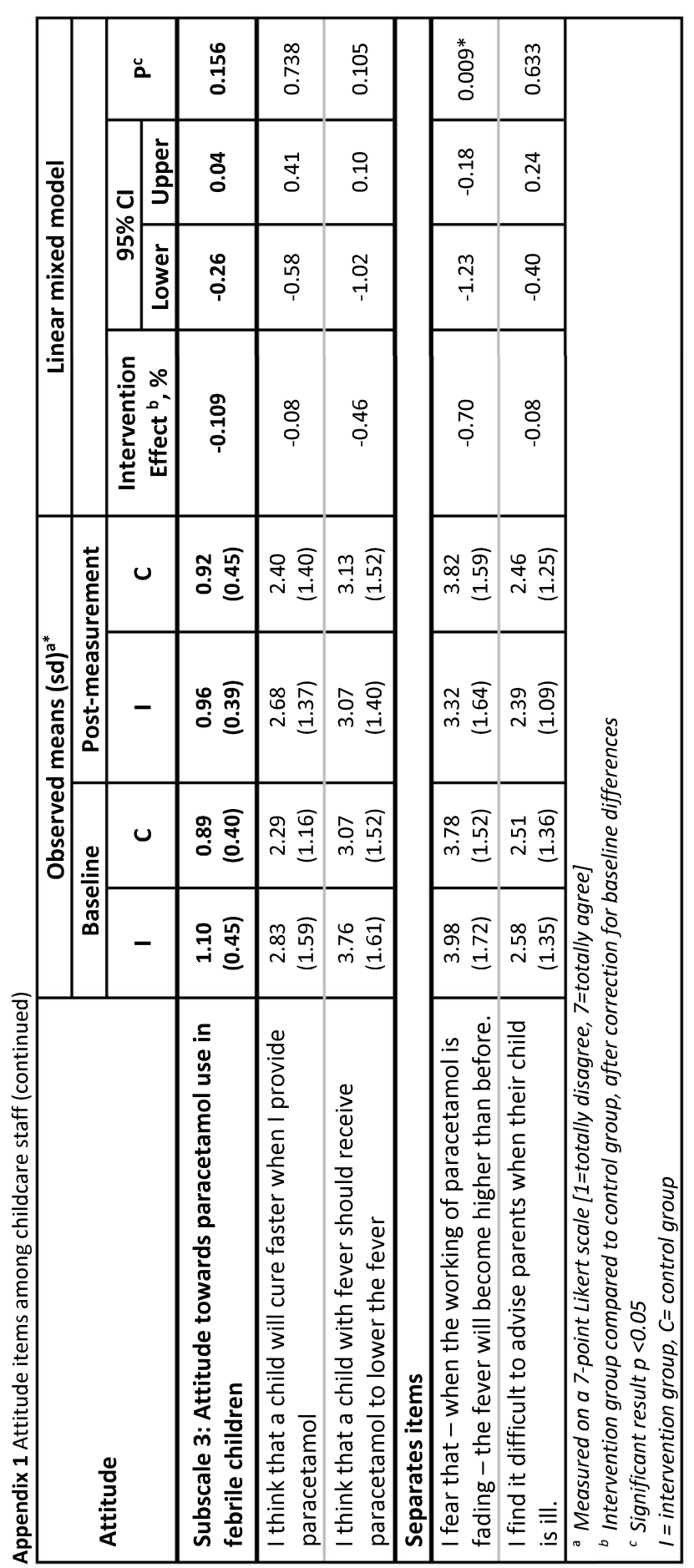




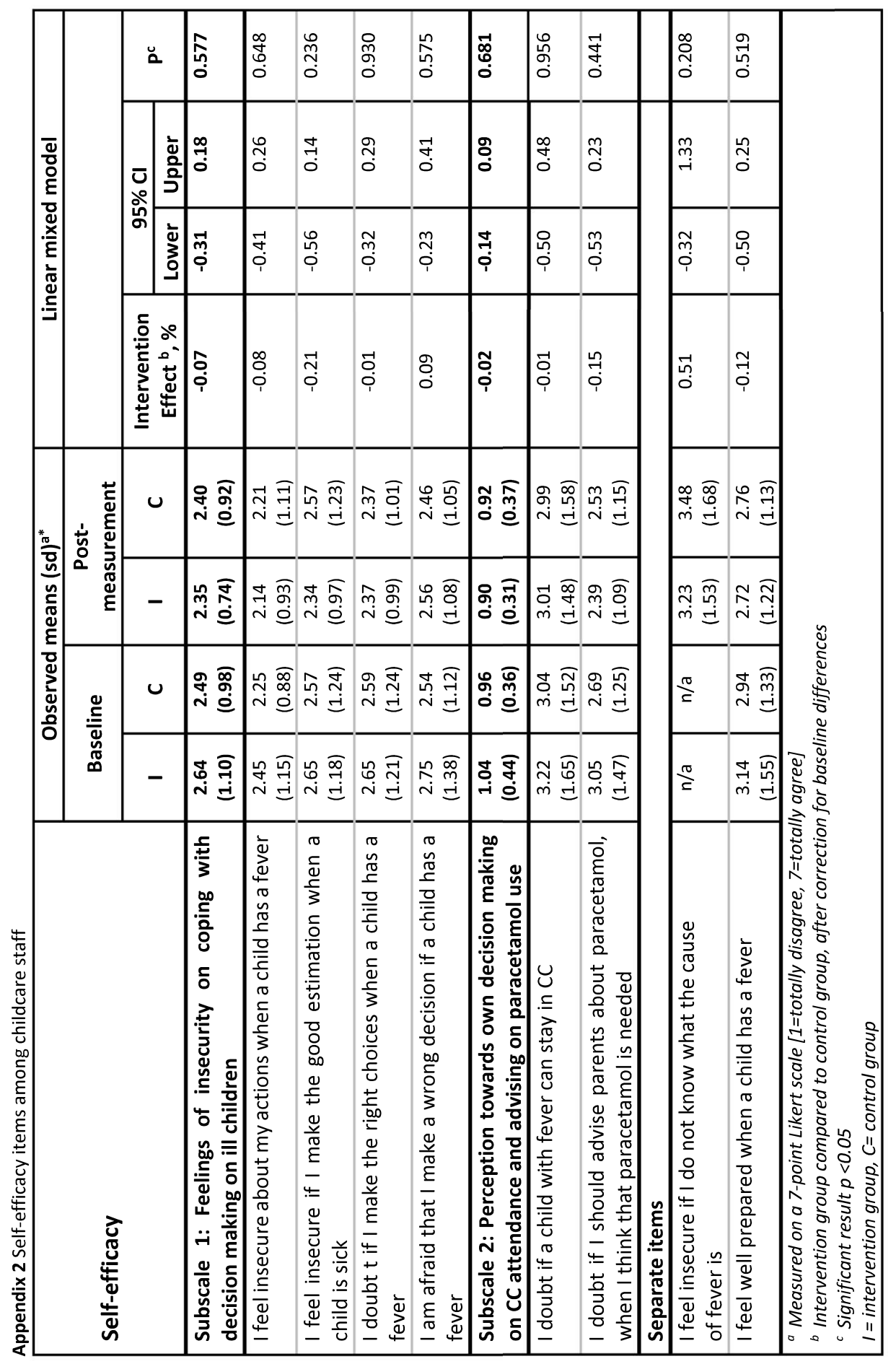


Appendix 3 Knowledge items among childcare staff

\begin{tabular}{|c|c|c|c|}
\hline \multirow{3}{*}{ Knowledge } & \multicolumn{3}{|c|}{ Difference in knowledge scores \% } \\
\hline & \multicolumn{3}{|c|}{ Intervention group } \\
\hline & Yes & No & $\begin{array}{l}\text { I don't } \\
\text { know }\end{array}$ \\
\hline \multicolumn{4}{|l|}{ Fever pathophysiology } \\
\hline Fever can be defined as $38^{\circ} \mathrm{C}$ and higher (definition) & $\uparrow 9.6 \%$ & & \\
\hline The higher the fever, the more severe underlying disease (1), No & $\downarrow 16.2 \%$ & $\uparrow 23.5 \%$ & $\downarrow 7.5 \%$ \\
\hline Fever can be useful for an ill child's recovery (2), Yes & 个 $8.9 \%$ & $\downarrow 1.6 \%$ & $\downarrow 7.1 \%$ \\
\hline A child can get a fever caused by an infection (3), Yes (baseline $95 \%$ ) & $\uparrow 0.3 \%$ & $\downarrow 3.6 \%$ & 个3.0\% \\
\hline A child can get fever after immunization (4), Yes & $\downarrow 5.8 \%$ & 个7.0\% & $\downarrow 1.2 \%$ \\
\hline Fever is caused by a bacterium or virus (5), Yes & $\uparrow 6.3 \%$ & $\uparrow 2.5 \%$ & $\downarrow 8.9 \%$ \\
\hline Fever can be caused by teething ( 6$)$, No & $\downarrow 46.8 \%$ & 个50.6\% & $\downarrow 3.9 \%$ \\
\hline \multicolumn{4}{|l|}{ Febrile seizures } \\
\hline $\begin{array}{l}\text { A febrile seizure can develop when body temperature quickly rises } \\
\text { (7), Yes }\end{array}$ & $\downarrow 12.5 \%$ & $\uparrow 21.1 \%$ & $\downarrow$ \\
\hline A febrile seizure can develop when fever just starts to rise (8), Yes & 个31.8\% & $\downarrow 16.6 \%$ & $\downarrow 15.2 \%$ \\
\hline Febrile seizures occur rarely (9) & $\uparrow 34.5 \%$ & $\downarrow 25.2 \%$ & $\downarrow 9.3 \%$ \\
\hline $\begin{array}{l}\text { One febrile seizure can lead to harmful consequences for a child's } \\
\text { health (10) }\end{array}$ & $\downarrow 9.5 \%$ & $\uparrow 41 \%$ & $\downarrow 31.5 \%$ \\
\hline \multicolumn{4}{|l|}{ Treatment strategies } \\
\hline Every febrile child has to be treated with paracetamol (11), No & $\uparrow 1.8 \%$ & 个3.7\% & $\downarrow 5.5 \%$ \\
\hline $\begin{array}{l}\text { Antibiotics are only used to cure bacterial infections (12) (baseline } \\
81 \%) \text {, Yes }\end{array}$ & $\uparrow 3.5 \%$ & $\uparrow 0.2 \%$ & $\downarrow 3.7 \%$ \\
\hline $\begin{array}{l}\text { Fever needs to be lowered with paracetamol to prevent that body } \\
\text { temperature becomes too high (13), No }\end{array}$ & $\downarrow 21.0 \%$ & $\uparrow 36.0 \%$ & $\downarrow 15.1 \%$ \\
\hline It is enough to measure fever one time per day (14), Yes & 个36.2\% & $\downarrow 29.1 \%$ & $\downarrow 7.1 \%$ \\
\hline $\begin{array}{l}\text { The dosing of paracetamol can best be based on the child's weight } \\
\text { (15), Yes }\end{array}$ & $\uparrow 16.8 \%$ & $\downarrow 5.3 \%$ & $\uparrow 11.5 \%$ \\
\hline
\end{tabular}




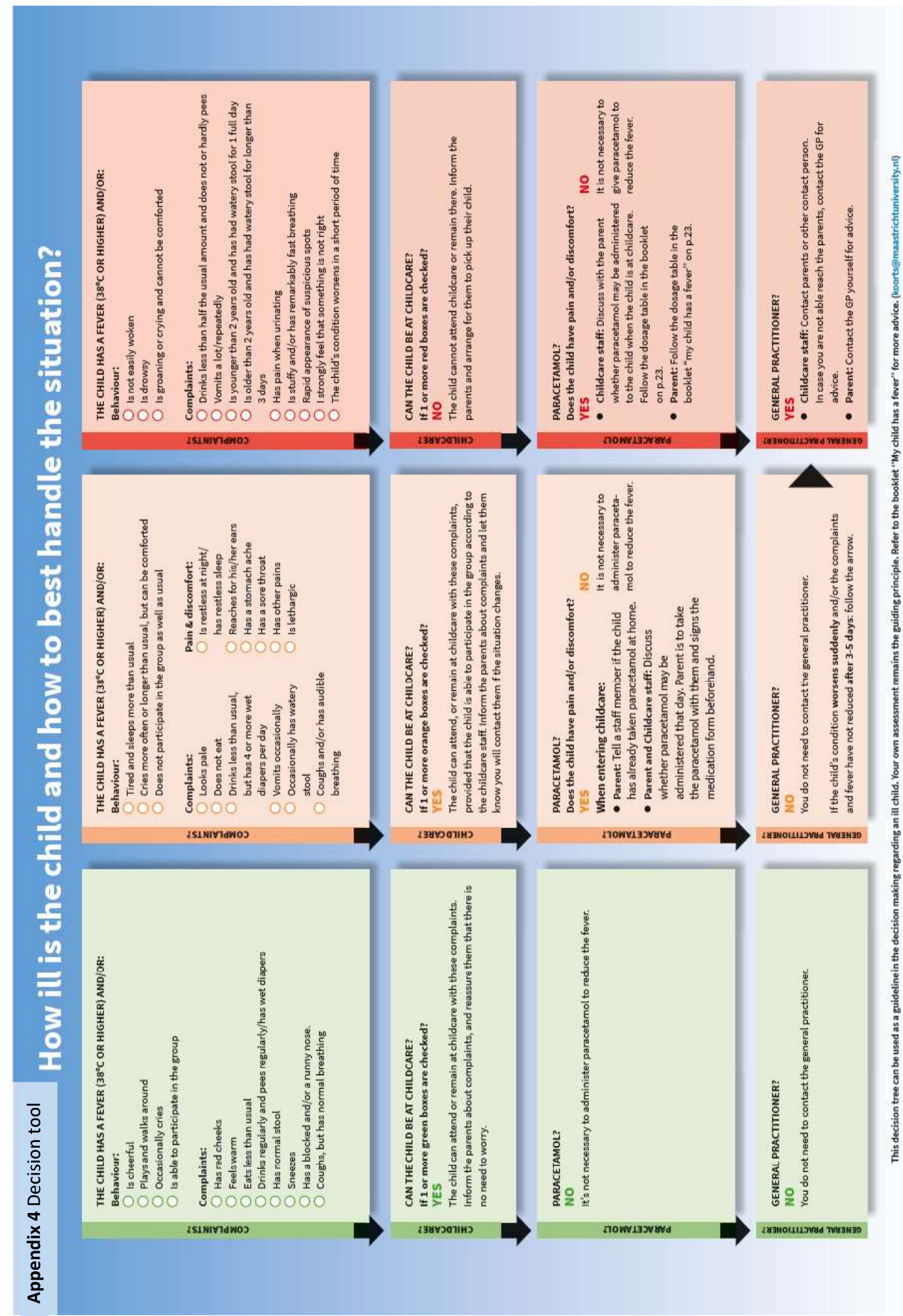


Chapter 9

General Discussion 


\section{GENERAL DISCUSSION}

The objective of this dissertation was to explore the potential of improving childhood fever management in children under 4 years old in well-child clinics and childcare centres. We conducted an extensive needs assessment among GPs, well-child clinic professionals, childcare staff and parents, and performed a systematic review into the effects of educating parents in well-child clinics on fever. Based on these findings, we developed a multicomponent intervention to support childcare staff in decision-making on illness absenteeism due to childhood fever and common infections, and evaluated the effects in a cluster randomised controlled trial. To achieve this, we applied the stepwise Intervention Mapping approach to develop, implement and evaluate a multicomponent intervention to support childcare staff and parents in childhood fever management [1].

The general discussion starts with a summary of main findings, followed by methodological considerations regarding Intervention Mapping as the approach to develop our intervention. Subsequently, a discussion follows regarding outcomes on parental level, the design of the intervention study, illness absenteeism as primary outcome, and the 'intention-behaviour' gap. Specific strengths and limitations for each study are described in chapters 2 - 8. The general discussion ends with implications for research and practice, valorisation of results, and a general conclusion.

\section{MAIN FINDINGS}

\section{Part 1: Needs assessment}

According to GPs (chapter 2) and well-child clinic professionals (chapter 3), childhood fever contributes to a substantial workload. Parental worries were identified as the most important driver of fever-related contacts (chapter 2 and 3). GPs perceived that parental worries are influenced by a lack of knowledge when to consult a doctor, by defensive advices from childcare staff, and parents' expectation of 24/7 care (chapter 2). Well-child clinic professionals observed that parental worries increase when parents lack experience, have a high educational level combined with a small social network, or when parents receive inconsistent paracetamol advice from healthcare professionals (chapter 3 ).

GPs believe that information exchange with parents on fever should be improved at the point of care, but also believe that young parents should be informed before their children become ill, for example in well-child clinics (chapter 2). However, well-child clinic professionals perceive their own current information provision on fever as limited, since it mainly focuses on fever as a side effect of immunisation. Subsequently, future information provision should incorporate patients' characteristics (experience, educational level, size social network) and obviate inconsistencies among healthcare providers (chapter 3 ). Our systematic review (chapter 6) demonstrates that educating parents in well-child clinics, prior to illness episodes, reduces healthcare service use and improves medication management. 
Beyond professionals managing children in health care settings (GPs and well-child clinic professionals), childcare staff are another important group of professionals influencing fever management decisions among parents. GPs perceive that childcare staff increase worries in parents by providing defensive advices (chapter 2). According to childcare staff (chapter 5), their decision-making and advices to parents on childhood fever are influenced by their perceived severity of children's symptoms such as height of fever, organisational guidelines on illness management, their experience-based knowledge, their intuitive judgement, and consultations with colleagues. Childcare staff also acknowledge to advise parents defensively because they are not medically educated. Additionally, childcare staff demonstrated a need to be educated on childhood fever by experts.

A cross-sectional survey among parents showed that almost all children in childcare $198 \%$ of 515 children) experienced infectious symptoms and that $27 \%$ consulted a GP during a 4 week period (chapter 4). Fever was the most frequent reason for a GP consultation. Onein-three children were absent for at least one day from childcare due to illness (320 days) and 146 parents had to take time off work (312 days).

Part 2: Development and evaluation of a multicomponent intervention

Based on the findings from our needs assessment (chapter 2-6), we developed a multicomponent intervention to improve decision-making among childcare staff on fever and common infections in childcare centres, by means of Intervention Mapping, and in close collaboration with stakeholders and experts. Children's illness absenteeism due to fever or common infections was chosen as the primary outcome measure. In addition, the needs assessment identified attitude, risk perception, knowledge, and self-efficacy as behavioural determinants of decision-making on illness absenteeism. Therefore, our multicomponent intervention targeted these determinants (and they were included as secondary outcome measures in the trial). Intended behaviour was measured since knowledge, attitude, risk perception, and self-efficacy affect intention to perform certain behaviour. In turn, intention is an important predictor of actually performing behaviour. To target these behavioural determinants, we developed a multicomponent intervention consisting of an educational session for childcare staff, a decision tool for staff and parents, an information booklet for staff and parents, and a short online video for staff and parents. Chapter 7 describes the development process of the multicomponent intervention and the study protocol of the trial.

The multicomponent intervention was evaluated in a cluster randomised controlled trial in 18 childcare centres in Southern Netherlands, between January and May 2017 (chapter 8). Nine childcare centres received the multicomponent intervention and nine provided childcare-as-usual. The linear mixed model showed a comparable 12-week illness absenteeism rate for the intervention (2.95\%) and control group (2.52\%). Childcare staff's general attitude towards fever and their attitude towards perceived harmful consequences of fever (risk perception) improved significantly compared to the control group. Their knowledge increased as well. Their attitude towards paracetamol use in febrile children was comparable for both groups. Self-efficacy showed a non-significant increase in the 
intervention group. Subsequently, their intended behaviour of childcare staff also improved significantly.

\section{METHODOLOGICAL CONSIDERATIONS}

This chapter continues with first discussing Intervention Mapping as approach to develop the multicomponent intervention, including why we chose childcare staff as target group, and selection of outcome measures. Secondly, we reflect on the design of our evaluation study, and thirdly, why the improvement in determinants of decision-making did not result in reducing illness absenteeism among children attending childcare.

\section{Development of the intervention using Intervention Mapping}

We applied the stepwise approach of Intervention Mapping to develop a theory- and evidence-based multicomponent intervention, in close collaboration with stakeholders and experts [1]. Fever management in young children is a multidimensional process involving different stakeholders, such as parents, family, childcare staff, and healthcare professionals. Obtaining insight in the degree and nature of stakeholders' experiences, beliefs, and needs was therefore an important first step to understand childhood fever management from the perspective of GPs, well-child clinic professionals, and childcare staff. Correspondingly, Intervention Mapping was a helpful tool to ensure that our intervention met the needs of the end-users.

\section{Target group}

Based on our extensive needs assessment among different stakeholders, we identified childcare staff as the primary target group of our intervention. Interviews with childcare staff revealed that they frequently advise parents to send a child home and to consult the GP. They advise parents defensively because they feel they lack formal medical education and expressed a need to be educated on childhood fever by experts [2]. These results are in line with previous research indicating that childcare staff influence childcare absenteeism, but also productivity loss, and healthcare service use among parents [2-8]. Our cross-sectional survey showed that almost all children experienced fever or childhood infections in a 4-week period. However, the results also showed that most infections are dealt within the community and were not seen by a GP [9]. In addition, parents encounter childcare staff on a daily basis and see well-child clinic professionals only at fixed times.

We hypothesised that childcare staff would benefit more from an educational intervention than well-child clinic professionals, due to their lack of medical education and a relevant role in decision-making on illness absenteeism in childcare. Also no formal education currently exists to educate Dutch childcare staff on decision-making towards childhood fever. Based on this, we chose childcare staff as primary target group. On the long run, we believe that well-child clinic professionals can benefit from using our multicomponent intervention as well, in particular the information booklet and the online video in educating parents on fever management. The intervention could also be adapted to support childcare staff and well-child clinic professionals in educating parents on childhood vaccination. 


\section{Outcome measure selection}

Illness absenteeism of children was selected as primary outcome measure to reflect changes in childcare staff's decision-making behaviour towards illness absenteeism due to childhood fever and common infections. The decisions of childcare staff influence childcare absenteeism, productivity loss among parents, and healthcare service use [2-8]. As a result, we chose to focus on decision-making towards illness absenteeism as these decisions affect productivity loss and healthcare service use such as GP consultations successively. However, despite their role in decision-making on fever and common infections, childcare staff do not receive formal medical education, which is also the case in other countries $[2,10]$. We aimed to support childcare staff in decision-making to lessen the occurrence of unwarranted decisions. For example, unwarranted decisions are excluding a child from childcare attendance that has solely a fever.

Subsequently, our needs assessment identified behavioural determinants underlying decision-making. The interview study among childcare staff revealed that childcare staff seem to lack knowledge towards fever pathophysiology. Childcare staff acknowledged that their current knowledge was merely experience-based and their decision strategies are guided by the organisational guidelines on illness management in children. However, the interviews showed that staff lacked knowledge towards the content of these guidelines. Application of the guidelines also varied according to the child's symptoms. In addition, childcare staff start to worry when the child's body temperature increases, caused by the concern that an increased temperature would represent severity of illness or lead to febrile seizures (attitude, risk perception) [2]. In response to their concerns, childcare staff tend to apply inappropriate strategies towards decision-making on childcare attendance and are cautious in advising parents to pick up their child or consult a GP to transfer liability as quick as possible (self-efficacy) $[2,6,7,10-13]$. Successively, staff demonstrated a need to be educated by experts but also that parents should be educated on childhood fever [2]. Based on the results of our needs assessment, knowledge, attitude, risk perception, and selfefficacy were identified as underlying behavioural determinants [14].

\section{Comparable educational interventions}

To our knowledge, this is the first educational intervention targeting decision-making among childcare staff on illness absenteeism due to fever and common infections, and its determinants. Other existing educational interventions on fever and common infections for childcare staff mainly focuses on improving hygiene practices [15-27]. Of these studies focusing on improving hygiene practices, only one multicomponent intervention was comparable in terms of targeting behavioural determinants to reduce illness absenteeism. In line with our own study results, this intervention improved behavioural determinants but not illness absenteeism among children [24, 25]. Another study described a positive trend in reducing illness absenteeism of children and significant improvements were found for "infection prone" children regarding illness absenteeism, doctors' consultations, and antibiotic prescriptions. Parents felt better informed after the study but no findings regarding behavioural determinants were reported [17]. Other studies on hygiene practices did not target illness absenteeism as outcome measure but focused on changing 
behavioural determinants regarding guideline compliance to reduce infections $[22,23,27$, 28]. Other studies targeted behavioural determinants to improve hand hygiene compliance but did not report results regarding these determinants [26-28]. On the level of interventions targeting parents in childcare, only one intervention was developed to improve determinants of hygiene practices. The educational session met parental needs for education and improved their knowledge and attitude. The intervention also resulted in a significant reduction in illness incidence, healthcare use, antibiotic consumption, less childcare absenteeism, and less productivity loss in parents $[29,30]$.

Even though little evidence is available, these studies show that changing behavioural determinants may have beneficial effects on behavioural outcomes. However, it does not seem common to report on outcomes regarding behavioural determinants. Based on our own needs assessment, we hypothesised that providing a decision tool, information booklet, and online video, and educating childcare staff on fever during a 2-hour educational session would improve childcare staff's knowledge, attitude, risk perception, and self-efficacy. Consecutively, we hypothesised that changing these determinants would result in a more evidence-based decision-making process and thus, less unwarranted decisions towards childcare illness absenteeism, and a lower absenteeism rate. We decided not to focus our multicomponent intervention on improving hygiene practices to reduce illness absenteeism. Predominantly, since hygiene is part of the childcare staff's formal education [31], while formal education on childhood fever is lacking [2]. Childcare staff's decision-making and advices to parents on childhood fever also seem to be influenced by their perceived severity of children's symptoms such as height of fever, organisational guidelines on illness management, their experience-based knowledge, their intuitive judgement, and consultations with colleagues. Childcare staff's decision-making is defensively since they lack medical education [2]. In other words, there seems to be more room for improvement regarding decision-making on illness absenteeism due to childhood fever and common infections in childcare staff. Next, childcare centres are already required to work according to hygiene protocols in the Netherlands and municipal health services regularly monitor the application of these protocols [32]. Based on this, we assumed that hand hygiene already receives enough attention in childcare centres. Also focusing on hand hygiene as well would make the multicomponent intervention too comprehensive.

Next, our intervention focuses primarily on decision-making towards childhood fever and common infections. The prevalence of severe infections in children is low in the Netherlands $[33,34]$. One important explanation is the existence of the national immunisation program. As a result, the occurrence of severe infections such as meningitis and whooping cough has been substantially reduced in recent decades due to the high immunisation coverage. To maintain this coverage, it is important that all children receive their vaccinations at the wellchild clinic. However, a recent report showed that the immunisation coverage in the Netherlands is still high, but declined slightly in recent years [35]. Possible influencing factors are parental beliefs towards the risks of immunisation. Our multicomponent intervention did not aim to enhance immunisation of children. However, the decision tool aimed to support childcare staff and parents in recognizing alarm signals of a severe 
infection. In addition, the decision tool aimed to lessen the occurrence of unwarranted decisions. The methods used in our intervention also showed to improve - for instance childcare staff's risk perception towards the perceived role of fever in causing febrile seizures. Consecutively, the multicomponent intervention may be a useful tool to enhance parental knowledge, attitude, risk perception, and self-efficacy towards (decision-making on) immunisation to increase coverage. Since childcare staff and parents meet each other on a regular basis, it may be considered to include education on childhood vaccination. In turn, childcare staff may contribute to educating parents on this topic and enhance immunisation coverage. As stated earlier, the intervention may also support well-child clinic professionals in educating parents on the national immunisation program.

\section{Intervention mapping}

Intervention Mapping showed to be very useful in the development process with respect to specifying performance objectives and change objectives and selecting theory- and evidence-based change methods and practical applications to address underlying behavioural determinants. We believe that applying Intervention Mapping resulted in an intervention with a specific focus on determinants underlying decision-making to have more success in supporting childcare staff in the decision-making process on fever management. To our opinion, involving childcare staff in the development process increased the chance of successful implementation by conforming to their beliefs, needs, and current organisational protocols. For example, we designed the content and lay-out of different intervention components in close collaboration with several childcare staff from the participating childcare organisation (MIK).

\section{EVALUATION OF THE MULTICOMPONENT INTERVENTION}

\section{Outcomes on parental level}

Parents may have benefited indirectly from this multicomponent intervention since childcare staff are perceived as an important source of information and may drive childcare absenteeism, healthcare service use, and productivity loss [2-8]. However, this dissertation is limited to reporting the effects of the multicomponent intervention on the level of childcare staff since our multicomponent intervention was primarily focused on childcare staff. It remains interesting to gain understanding of the results on the parental level, especially when the intervention can be further developed. We do know that the decision tool and information booklet were used by less than $40 \%$ of parents who filled in the survey. About two-third of the parents who used the decision tool and booklet perceived them as useful. The video was also perceived as useful by the few parents who saw the video. These findings indicate that the multicomponent intervention may be a useful tool to be used by parents. However, as the reported use and exposure was lower than expected, this also indicates that implementation of this intervention among parents needs to be more in line with our implementation efforts among childcare staff.

\section{Design of intervention study}

In line with previous studies evaluating educational interventions in childcare, we evaluated the multicomponent intervention in a cluster randomised controlled trial (RCT) to avoid 
contamination of intervention effects $[15-17,19,22,24,36,37]$. Targeting individual childcare staff employees but also their direct colleagues may affect the uptake of an intervention since consultations with colleagues in childcare are very common, especially when it concerns an ill child. Previous research also showed that fever phobia may be more a cultural trait than individually learned [38]. We therefore recommend to take into account currently held beliefs and attitudes towards implementation of an intervention in separate childcare staff teams and to tailor implementation strategies accordingly.

\section{Illness absenteeism}

Following our needs assessment (chapter 2-6), we defined decision-making among childcare staff on illness absenteeism due to childhood fever and common infections as our behavioural outcome of interest. As mentioned before, childcare staff may influence illness absenteeism from childcare in children, and in turn, induce productivity loss, and healthcare service use among parents [2-8]. Parental productivity loss is the most important reason that children in childcare generate twice as much societal costs compared to home-cared children [39]. Our cross-sectional study among parents of 515 children also showed that one-in-three children missed childcare due to illness in March 2016, for a total of 320 days, which constituted approximately $10 \%$ of planned contract days. In addition, 146 parents had to take 312 days off from work to care for their ill child [9]. These findings underscore that illness absenteeism has a substantial impact on productivity loss in parents. It was however not possible to gain insight in the impact of illness in our cluster RCT since the parental response on the survey following a child's illness was low with $19 \%$ in the intervention group and $11 \%$ in the control group. This might provide inaccurate estimates of the impact and lack of representativeness of the study population. This also accounts for the parental response to the survey measuring determinants of behaviour change, with $25 \%$ response in the intervention and $18 \%$ in the control group. In contrast to the regular faceto-face meetings with childcare staff, which led to a high survey response in the trial, we were not in direct contact with parents which may hampered survey response. If this trial could be repeated, more attention should be paid to actively involving parents to assess outcomes on the parental level more in-depth. In addition, also conducting a costeffectiveness analysis will lead to more insight in the societal impact of illness absenteeism in childcare. To conduct this cost-effectiveness analysis effectively and measure the impact of the intervention in terms of effectiveness and costs, more attention should be paid to engaging all stakeholders, such as parents and childcare staff.

As stated before, we aimed to support childcare staff in making evidence-based decisions towards illness absenteeism to lessen the occurrence of unwarranted decisions by providing them with a decision tool. For example, unwarranted decisions are excluding a child from childcare attendance that has a fever but no additional symptoms. It was however not possible to monitor directly the actual use of the decision tool and if less unwarranted decisions occurred. Since it was too complex to measure or observe directly if staff's decisions on ill children were unwarranted, data was self-reported by childcare staff regarding use of the decision tool. These findings indicate a low use of the decision tool among childcare staff. Despite this, the decision tool was perceived as useful according to 
the childcare staff. This finding is in line with previous research among physicians showing that half of respondents intended to use a patient decision tool, but eventually only onethird of this group actually used the tool [40]. In addition, to gain insight if the decisionmaking process changed in childcare staff, we now measured intended behaviour by means of a vignette describing a child with $39^{\circ} \mathrm{C}$ and additional 'orange' symptoms. The results show significant improvements, such as that less childcare staff tended to assess illness severity based on solely the body temperature, less advised parents to pick up their ill child or to consult a GP [41].

Consequently, it was difficult to assess if childcare staff changed their decision-making process towards fever and common infections based on the primary outcome measure. Especially since we observed an increase in knowledge and significant changes in their attitude, risk perception, and intended behaviour, which indicates an 'intention-behaviour gap'.

\section{Intention-behaviour gap}

When developing our intervention, we hypothesised that improving participants' knowledge, attitude, risk perception, and self-efficacy would change their intended behaviour, and in turn, would reduce illness absenteeism. However, despite significant improvements in the intervention group towards attitude, risk perception, intended behaviour, and more knowledge, illness absenteeism was comparable in both groups. A review showed that intention accounts for $28 \%$ of variance in behaviour. In addition, $47 \%$ of participants who intended to act, failed to translate their intention into action [42]. This finding is in line with a recent meta-analysis showing that only in half of the time intentions are translated in actual behaviour change [43]. Another study stated that a drawback of using vignettes is that these hypothetical responses may not align with actual behaviour [44].

However, and as stated earlier, it was not possible to measure the decisions of childcare staff itself, and whether these decisions were possibly unwarranted. As a proxy of actual decision-making, we used vignettes to measure their intended behaviour. The results show that childcare staff changed their intended behaviour significantly to allow a child with mild to moderate 'orange' symptoms to stay at childcare, instead of asking parents to pick up the child. This aligns with the results of the absenteeism registrations showing that, compared to control centres, more children feeling ill attending intervention centres stayed in childcare [41]. This may indicate that childcare staff started to change their decisionmaking process into the direction of sending less children home with mild to moderate symptoms. In addition, self-efficacy, attitude, and risk perception are the most important predictors of intention. Subsequently, translating intended behaviour into actual behaviour is among other factors also moderated by their self-efficacy [45]. In view of this, our multicomponent intervention resulted in a slight but not significant increase in childcare staff's self-efficacy, which may explain why we did not manage to translate their intended behaviour into less illness absenteeism. However, to achieve a significant change in decision-making, more attention should be paid to the role of self-efficacy in starting and 
maintaining new behaviour [45]. Thus, changes in attitude, knowledge, and intended behaviour are important first steps to reduce illness absenteeism on the long run, but there is room for improvement in terms of changing self-efficacy.

In addition, several barriers exist in translating intention into action, which may have played a role in the low use of the decision tool. One barrier may be that childcare staff forgot to start using the decision tool, despite our attempts to promote this. Childcare staff may have perceived this as barrier, since the decision tool was not part of their routine practices. In the post-measurement, childcare staff for example mentioned that, despite the existence of the tool, their decisions were still mainly guided by their intuitive judgement [unpublished data; [41]). Following from this, childcare staff may have been reluctant to use the tool. To accomplish this in future interventions or when developing this intervention further, attention should be paid to incorporating 'if-then' strategies that specify when, where, and how to act to achieve a goal $[46,47]$. This strategy may be especially useful to stimulate incorporating of the decision tool in daily routine of childcare staff. For example, within the educational sessions, it may be useful to pay more attention to when to use the decision tool, and subsequently, how to use the tool in those situations. We now explained the use of the decision tool and practiced with a hypothetical situation during the educational session, but we did not observe or repeat the explanation when the childcare staff were actually working with the tool during the trial. Consecutively, incorporating the use of this tool in routine care needs more guidance on an individual and group level following the educational session. In addition, placing more emphasis on results of decisionmaking itself, for instance by discussing illness absenteeism rates during the educational session, may increase the need and trigger them to use the decision tool.

\section{IMPLICATIONS FOR RESEARCH AND PRACTICE, AND VALORISATION}

The section 'methodological considerations' already included some implications for future research, such as evaluating the effects of the current intervention among parents more indepth. An important implication is that the intervention showed to improve attitude, risk perception, and knowledge. Successively, the intervention should be developed further to diminish the 'intention-behaviour gap'. In addition, a case study design was recommended to evaluate if the decision-making process changed in terms of making the correct decisions. Also a cost-effectiveness analysis is suitable for this topic due to the societal impact of an ill child on productivity loss and healthcare service use. Next, we discuss the relevance and importance of the findings for different stakeholders, and will elaborate on what changes are needed to implement the intervention, and how to achieve this.

\section{Childcare centres}

The needs assessment and trial show that decision-making on ill children occurs frequently by staff in childcare centres. Subsequently, childcare staff play an important role in children's illness absenteeism, productivity loss, and healthcare service use among parents. Despite this, childcare staff in our study did not receive any formal medical education on fever, which is also the case in other countries [10]. Since our results indicate that the 
multicomponent intervention leads to more knowledge, less fear towards fever, and significant improvements in intended behaviour, we believe this intervention should be developed further to optimise the decision-making process among childcare staff towards fever and common infections and translate these intentions into actual behaviour. To achieve this, staff's self-efficacy towards decision-making should be studied more in-depth and acted upon, for instance by incorporating 'if-then' strategies in the intervention that specify when, where, and how to act to change their routine in decision-making, and in turn, reduce illness absenteeism. The use of the decision tool was for example explained during the educational session and we practiced on a hypothetical situation with childcare staff. However, we did not actively observe or practice the decision tool when the childcare staff were actually working with the tool during the trial. Focusing more on the use in daily practice would increase the uptake of the decision tool daily routine.

In addition, the educational session needs fine-tuning before disseminating it to other childcare centres because it was developed for study purposes (e.g. for explanation of the background of study project and how to fill in registration booklets). Also, more attention needs to be paid to actively involving parents in the implementation process since our results indicated limited use by parents. We specifically think that the decision tool can function as facilitator in the communication process between staff and parents to solve or prevent disagreements on their plan of action. In addition, it should be considered to include content on immunisation in the multicomponent intervention to involve childcare staff in changing knowledge, attitude, and risk perception among parents to foster the decision-making process, and thus to increase immunisation coverage.

To achieve that the multicomponent intervention will be developed further, more support of other childcare organisations and the trade union needs to be created. This support is needed to find a company that will develop the intervention into a commercial product that can be used by every childcare centre. To achieve this, a close collaboration exists with MIK, a large childcare organisation in the Southern Netherlands. MIK has connections with other childcare organisations but also with the trade union of childcare organisations. To create nationwide support, we will translate our scientific findings into comprehensible language to inform participants but also for other childcare organisations and the trade union. This information will include our results but also which further steps are needed to translate the intervention into a product that is available for all childcare centres in the Netherlands. This information can be made public via journals especially for childcare staff and management.

\section{Well-child clinics}

Our trial focused on effects on the level of childcare centres but our needs assessment also included experiences of well-child clinics professionals. The participants demonstrated a need to improve current written information on fever for parents (chapter 3). Our systematic review also showed that providing preventive education to parents in well-child clinics has the potential to reduce healthcare service use (chapter 6). Despite this, we decided to focus on childcare centres since well-child clinic professionals are medically educated and only want an improved information tool. Dissemination and use of the 
information booklet in well-child clinics could reach the majority of parents, as well-child clinic professionals see approximately $98 \%$ of all Dutch children $0-4$ years old [48]. It should be considered to add information on immunisation to the multicomponent intervention to enhance immunisation coverage rates in children. In addition, since well-child clinic professionals perceived inconsistencies in paracetamol advices as an important driver of parental worries and thus fever-related contacts, implementation efforts should also accentuate providing consistent advices among different healthcare professionals [49].

\section{General practice}

Interviews with GPs showed a need to improve information exchange with parents on fever at the point of care, but also that parents should be informed prior to the first illness episodes by for example well-child clinic professionals. Well-child professionals namely mentioned that inconsistencies in paracetamol advices among different healthcare professionals cause worries in parents. We think it is important that all healthcare professionals are consistent in their information and advice to parents. The information booklet was also evaluated in 20 Dutch GP out-of-hours centres and resulted in less antibiotic prescriptions and less intention-to-consult among parents for similar symptoms in the future [50]. This indicates that informing parents at the point of care may also be improved by providing this booklet.

\section{Overall}

Each target group demonstrated a need to improve education on childhood fever to parents. In achieving this, it is important that all stakeholders provide the same information to parents, especially since previous research showed that fever phobia is still present in parents, childcare staff, healthcare professionals in preventive healthcare services, primary care, hospital care, pharmacists, despite the development of multiple educational interventions in recent decades. We also opt to join forces to come to one overarching intervention since the scientific literature shows many attempts to educate parents in the same way. A uniform intervention is needed to be implemented in all childcare organisations and centres in a country to avoid inconsistencies, frustrations, and especially worries. Subsequently, Internet is an often-used information source. However, many websites are not evidence-based or written by healthcare professionals. Social media also may influence worries of parents and childcare professionals. One option is to add a digital version of the decision tool to the webpage 'My child has a fever' at www.thuisarts.nl to improve information provision at the point of care but also may stimulate (consistent) communication between healthcare professionals and parents by basing decisions on the same tool. Research has showed that the webpage 'My child has a fever' at www.thuisarts.nl is among the 10 most read pages [51].

Next, the intervention may be also useful to change knowledge, attitude, risk perception, and self-efficacy among parents towards immunisation to increase coverage rates. To achieve this, the content of the intervention needs more information on immunisation and the explanation on the decision also should focus on increasing awareness why they need to be cautious on alarm signals. Consecutively, educating parents and childcare staff on 
fever, common infections, but also hygiene and immunisation can already start in primary schools, secondary schools, in prenatal clinics, and at the vocational training for childcare staff. Most importantly, educational content should be the same in all settings, in schools, and among different healthcare providers.

\section{CONCLUSION}

The multicomponent intervention based on Intervention Mapping was successful in changing underlying determinants of decision-making (knowledge, attitude, risk perception). The improvements in determinants may change childcare staff's decisionmaking process and advising to parents in the long run, since intended behaviour of childcare staff also significantly improved. Unfortunately, similar results were found regarding illness absenteeism for intervention and control group, so an intentionbehaviour gap' exists between translating changes in underlying determinants into less illness absenteeism. One way to achieve changes in determinants result in actual behaviour change is to incorporate 'if-then' strategies to increase the uptake of the decision tool in daily routine. Furthermore, if the evaluation of the intervention would be repeated, we would opt for a longer duration of the measurement period and an observational research design focusing on evaluation of the decision-making process. Further development is needed to close the 'intervention-behaviour gap' and to develop an intervention that is consistent among and for all stakeholders (childcare staff, parents, well-child clinic professionals, and GPs). 


\section{REFERENCES}

1. Bartholomew Eldredge LK. Planning Health Promotion Programs : An Intervention Mapping Approach. San Francisco, CA: Jossey-Bass; 2016.

2. Peetoom K, Crutzen, R, Alleleijn, I, Laumen, L, Moser, A, Dinant, GJ, Cals, J,. "I am not a doctor", views of childcare staff towards decision-making on febrile children: a qualitative study. Submitted. 2018

3. Ingram J, Cabral C, Hay AD, Lucas PJ, Horwood J. Parents' information needs, self-efficacy and influences on consulting for childhood respiratory tract infections: a qualitative study. BMC family practice. 2013;14:106.

4. Shapiro ED, Kuritsky J, Potter J. Policies for the exclusion of ill children from group day care: an unresolved dilemma. Reviews of infectious diseases. 1986;8(4):622-5.

5. Ertmann RK, Soderstrom M, Reventlow S. Parents' motivation for seeing a physician. Scandinavian journal of primary health care. 2005;23(3):154-8.

6. Skull SA, Ford-Jones EL, Kulin NA, Einarson TR, Wang EE. Child care center staff contribute to physician visits and pressure for antibiotic prescription. Archives of Pediatrics \& Adolescent Medicine,. 2000;154(2):180-3.

7. Rooshenas L, Wood F, Brookes-Howell L, Evans MR, Butler CC. The influence of children's day care on antibiotic seeking: a mixed methods study. British Journal of General Practice. 2014;64(622):e302-12.

8. de Bont EGPM, Peetoom KKB, Moser A, Francis NA, Dinant G-J, Cals JWL. Childhood fever: a qualitative study on GPs' experiences during out-of-hours care. BMC family practice. 2015;32(4):449-55.

9. Peetoom K, Crutzen R, Dinant GJ, Cals J. Most preschool children with fever and common infection symptoms do not consult the family physician. Family Practice,. 2018:cmy079.

10. Hashikawa AN, Stevens MW, Juhn YJ, Nimmer M, Copeland K, Simpson P, et al. Self-Report of Child Care Directors Regarding Return-to-Care. Pediatrics. 2012;130(6):1046-52.

11. Copeland KA, Duggan AK, Shope TR. Knowledge and beliefs about guidelines for exclusion of ill children from child care. Ambulatory Pediatrics. 2005;5(6):365-71.

12. Pappas DE, Schwartz RH, Sheridan MJ, Hayden GF. Medical exclusion of sick children from child care centers: a plea for reconciliation. Southern Medical Journal,. 2000;93(6):575-8.

13. Landis SE, Earp JA, Sharp M. Day-care center exclusion of sick children: comparison of opinions of day-care staff, working mothers, and pediatricians. Pediatrics. 1988;81(5):662-7.

14. Peetoom KKB, Crutzen R, Bohnen J, Verhoeven R, Nelissen-Vrancken H, Winkens B, et al. Optimising decision making on illness absenteeism due to fever and common infections within childcare centres: development of a multicomponent intervention and study protocol of a cluster randomised controlled trial. BMC Public Health. 2017;18(1):61.

15. Uhari M, Mottonen M. An open randomized controlled trial of infection prevention in child day-care centers The Pediatric Infectious Disease Journal,. 1999;18(8):672-7.

16. Pönkä $A$, Poussa $T$, Laosmaa $M$. The effect of enhanced hygiene practices on absences due to infectious diseases among children in day care centers in Helsinki. Infection. 2004;32(1):2-7.

17. Hedin K, Petersson C, Cars H, Beckman A, Hakansson A. Infection prevention at day-care centres: feasibility and possible effects of intervention. Scandinavian Journal of Primary Health Care, 2006;24(1):44-9.

18. Willmott M, Nicholson A, Busse H, MacArthur GJ, Brookes S, Campbell R. Effectiveness of hand hygiene interventions in reducing illness absence among children in educational settings: a systematic review and meta-analysis. Archives of Disease in Childhood,. 2016;101(1):42-50.

19. Lennell A, KuhImann-Berenzon S, Geli P, Hedin K, Petersson C, Cars O, et al. Alcohol-based hand-disinfection reduced children's absence from Swedish day care centers. Acta Paediatrica. 2008;97(12):1672-80

20. Roberts L, Jorm L, Patel M, Smith W, Douglas RM, McGilchrist C. Effect of infection control measures on the frequency of diarrheal episodes in child care: a randomized, controlled trial. Pediatrics. 2000;105(4 Pt 1):743-6.

21. Roberts L, Smith W, Jorm L, Patel M, Douglas RM, McGilchrist C. Effect of infection control measures on the frequency of upper respiratory infection in child care: a randomized, controlled trial. Pediatrics. 2000;105(4 Pt 1):738-42. 
22. Correa JC, Pinto D, Salas LA, Camacho JC, Rondon M, Quintero J. A cluster-randomized controlled trial of handrubs for prevention of infectious diseases among children in Colombia. Revista Panamericana de Salud Publica. 2012;31(6):476-84.

23. Ladegaard $M$, Stage V. Hand-hygiene and sickness among small children attending day care centers. An intervention study. Ugeskrift for laeger. 1999;161(31):4396-400.

24. Rosen L, Manor O, Engelhard D, Brody D, Rosen B, Peleg H, et al. Can a handwashing intervention make a difference? Results from a randomized controlled trial in Jerusalem preschools. Preventive Medicine, 2006;42(1):27-32.

25. Rosen L, Zucker D, Brody D, Engelhard D, Manor O. The effect of a handwashing intervention on preschool educator beliefs, attitudes, knowledge and self-efficacy. Health Education Research,. 2009;24(4):686-98.

26. Zomer TP, Erasmus V, Vlaar N, van Beeck EF, Tjon ATA, Richardus JH, et al. A hand hygiene intervention to decrease infections among children attending day care centers: design of a cluster randomized controlled trial. BMC Infectious Diseases, . 2013;13:259.

27. Zomer TP, Erasmus V, Looman CW, Van Beeck EF, Tjon-A-Tsien A, Richardus JH, et al. Improving hand hygiene compliance in child daycare centres: a randomized controlled trial. Epidemiology and Infection. 2016;144(12):2552-60.

28. Zomer TP, Erasmus V, Looman CW, Tjon-A-Tsien A, Van Beeck EF, De Graaf JM, et al. A hand hygiene intervention to reduce infections in child daycare: a randomized controlled trial. Epidemiology and Infection. 2015;143(12):2494-502.

29. Alexandrino AS, Santos R, Melo C, Bastos JM. Impact of caregivers' education regarding respiratory infections on the health status of day-care children: a randomized trial. Family practice. 2016;33(5):476-81.

30. Alexandrino AM, Santos RI, Melo MC, Bastos JA. Designing and evaluating a health education session on respiratory infections addressed to caregivers of children under three years of age attending day-care centres in Porto, Portugal: A community-based intervention. The European Journal of General Practice, 2017;23(1):43-50.

31. OAK. CAO Kinderopvang: Profiel pedagogisch medewerker kindercentra 0-4 jaar [Collective labor agreement childcare: Profile childcare staff employee 0-4 years],. 2011.

32. GGD Zuid-Limburg [Municipal public health services South Limburg]. Professionals; Kinderopvang [Professionals; childcare] [Available from: https://www.ggdzl.nl/ professionals/ kinderopvang/.

33. Van den Bruel A BS, Aertgeerts B, Truyers C, Buntinx F,. Serious infections in children: an incidence study in family practice. BMC Family Practice,. 2006;7(23).

34. Hoogwijs I VJ, Aertgeerts B, Bullens DM, Buntinx F, Severe infections in a paediatric emergency department. . Tijdschrift voor Geneeskunde 2014(70):362-8.

35. RIVM [National Institute for Public Health and the Environment]. Vaccinatiegraad en jaarverslag Rijksvaccinatieprogramma Nederland 2017 [Vaccination rate and annual report National vaccination program the Netherlands 2017], . Bilthoven; 2018. Contract No.: RIVM Rapport 2018-0008.

36. Torgerson DJ. Contamination in trials: is cluster randomisation the answer? BMJ. 2001; 322(7282):355-7.

37. Zhou YE, Emerson JS, Levine RS, Kihlberg CJ, Hull PC. Childhood Obesity Prevention Interventions in Childcare Settings: Systematic Review of Randomized and Nonrandomized Controlled Trials. American Journal of Health Promotion. 2014;28(4):e92-e103.

38. Pursell E \& Collin J. Fever Phobia: The impact of time and mortality-a systematic review and meta-analysis. International Journal of Nursing Studies. 2016;56:81-9.

39. Enserink R, Lugnér A, Suijkerbuijk A, Bruijning-Verhagen P, Smit HA, van Pelt W. Gastrointestinal and Respiratory IIIness in Children That Do and Do Not Attend Child Day Care Centers: A Cost-of-Illness Study. PLOS ONE. 2014;9(8):e104940.

40. Graham ID, Logan J, Bennett CL, Presseau J, O'Connor AM, Mitchell SL, et al. Physicians' intentions and use of three patient decision aids. BMC medical informatics and decision making. 2007;7:20.

41. Peetoom KKB CR, Verhoeven R, Bohnen J, Winkens B, Dinant GJ, Cals JWL. Optimising decision making among childcare staff on fever and common infections: cluster randomised controlled trial. Submitted. 2018. 
42. Sheeran P. Intention-Behavior Relations: A Conceptual and Empirical Review. European Review of Social Psychology. 2002;12(1):1-36.

43. Sheeran P, Webb TL. The Intention-Behavior Gap. Social and Personality Psychology Compass 2016;10(9):503-18.

44. Hashikawa AN, Brousseau DC, Singer DC, Gebremariam A, Davis MM. Emergency Department and Urgent Care for Children Excluded From Child Care. Pediatrics. 2014;134(1):e120-7.

45. Sniehotta FF, Scholz U, Schwarzer R. Bridging the intention-behaviour gap: Planning, self-efficacy, and action control in the adoption and maintenance of physical exercise. Psychology \& Health. 2005;20(2):143-60.

46. Gollwitzer PM. Goal achievement: The role of intentions. Wiley. W. Stroebe and M. Hewstone (Eds.), editor. New York: Wiley; 1993.

47. Gollwitzer PM, Sheeran P. Implementation Intentions and Goal Achievement: A Meta-analysis of Effects and Processes. Advances in Experimental Social Psychology. 38: Academic Press; 2006. p. 69-119.

48. Centraal Bureau Statistiek [Statistics Netherlands]. Ouders geven consultatiebureau gemiddeld een 7 [Parents give child health centres a 7 out of 10],. Den Haag/Heerlen; 2014 30/10/2014.

49. Peetoom K, Ploum L, Smits J, Halbach N, Dinant G, Cals J. Childhood fever in well-child clinics: a focus group study among doctors and nurses. BMC Health Services Research. 2016;16:240.

50. de Bont E, Dinant GJ, Elshout G, van Well G, Francis NA, Winkens B, et al. Booklet for Childhood Fever in Out-of-Hours Primary Care: A Cluster-Randomized Controlled Trial. Annals of Family Medicine, 2018;16(4):314-21.

51. Drenthen T, Beijaert RPH, Jansen PWM, Korevaar JC, Smeele IJM. Thuisarts.nl, hoe bevalt dat? Nederlands Tijdschrift voor de Geneeskunde (NTvG),. 2014;158:A8282. 
Summary 


\section{SUMMARY}

Fever is common in children 0 to 4 years old, and especially children attending childcare centres are prone to acquire infections. These children have a higher infection incidence, due to their close contact with other children, but also through indirect transmission via the environment such as toys. Subsequently, childcare staff drive childcare absenteeism for fever and common infections, productivity loss and healthcare service use among parents, while it often concerns self-limiting infections, which do not require treatment. 'Fever phobia' among parents and (health) care professionals seems to be one of the major drivers of this problem.

This dissertation aims to explore the potential of improving childhood fever management in children 0 to 4 years old in well-child clinics and childcare centres, and to evaluate the effectiveness of a newly developed multicomponent intervention targeting decision-making on childhood fever. Subsequently, this dissertation focuses on answering the following research questions:

1. What are the experiences and needs of general practitioners, well-child clinics professionals, childcare staff, and parents regarding childhood fever management?

2. What are the effects of implementing the multicomponent intervention on decision-making regarding illness absenteeism due to childhood fever and common infections, and its underlying determinants among childcare staff in childcare centres?

\section{Part 1: Needs assessment}

\section{General practitioners and well-child clinic professionals}

Two qualitative focus group studies focused on the experiences of healthcare professionals regarding childhood fever management. One study was conducted among GPs working in GP out-of-hours care ( $\mathrm{N}=37$, chapter 2$)$, and one study was conducted among well-child clinic professionals $(\mathrm{N}=22$, chapter 3$)$.

According to the GPs, childhood fever contributes to a high workload in GP out-of-hours care. Well-child clinic professionals also experience that they frequently receive feverrelated questions. Both GPs and well-child clinic professionals identified parental worries, a lack of knowledge regarding fever pathophysiology and self-management strategies such as when to consult a doctor, and a need for reassurance as important drivers of fever-related contacts. In addition, GPs perceive that an increasing number of parents consult GP out-ofhours care following advice from childcare staff. Well-child clinic professionals observed that (a lack of) experience, educational level, size of social network, and inconsistencies in paracetamol advices among healthcare professionals influence parental worries.

GPs believe that information exchange with parents on fever should be improved at the point of care, but they also believe that young parents should be informed before their children becomes ill, for example during visits to well-child clinics, to provide a safety net to 
enhance self-management, and reduce consultations and workload. However, well-child clinic professionals perceive their current information provision on fever as limited as it mainly focuses on fever related to childhood vaccination. In addition, well-child clinics acknowledged that their current information provision needs optimisation, in particular by incorporating patients' characteristics and taking into account inconsistencies among different healthcare providers. Furthermore, future information provision should focus on improving fever management and practical skills. Information should also be easy to find and understandable and verbal information needs to be supported by hard copy visual information and web-based applications. The views regarding timing of information provision on fever were mixed but the preferred timing was within the first two months of a child's life.

Based on our systematic review (chapter 6), educating parents in well-child clinics prior to new episodes of childhood fever and common infections reduces daytime physician consultations of parents, home visits and telephone consultations, and enhances medication management. However, single and multicomponent interventions vary in reducing the frequency of daytime physician consultations and differ in their potential to reduce the number of home visits and general practitioner out-of-hour contacts. For example, only multicomponent interventions in well-child clinics achieved a reduction in telephone consultations and improved medication management. Educating parents in wellchild clinics, prior to episodes of childhood fever and common infections showed potential to improve parental practices in terms of healthcare-seeking behaviour and medication management.

\section{Parents}

Chapter 4 describes a cross-sectional survey among 515 families with children attending childcare centres. The findings show that almost all children experienced infection related symptoms during the 4-week period. Most parents reported common respiratory infection symptoms in their child. More than half of the children experienced a fever. Of the children with infectious symptoms, three-quarter did not consult a GP. Fever and earchache were the most frequent reasons for GP consultation. One-in-three children were absent from childcare due to illness and a total of 146 parents (312 days) had to take time off from work.

\section{Childcare staff}

Chapter 5 describes a qualitative study among childcare staff to gain more insight into their experiences and views regarding decision-making on childhood fever. A total of 20 childcare staff employees of one large childcare organisation in the Southern part of province of Limburg, the Netherlands participated. Additionally, we interviewed three childcare employees from another childcare organisation in the same region.

Two main categories were identified: factors causing variety in (1) decision-making among childcare staff on febrile children, and (2) advising parents towards picking up their ill child or to consult a GP. According to childcare staff, decision-making and advising parents on childhood fever varies among childcare staff. This variation arises from the child's illness 
symptoms, differences in childcare staff's experiences, and following the organisational guidelines on ill children versus their own intuitive judgement towards childhood fever.

Childcare staff also felt that their experience and consultations with colleagues affected their decision-making. In addition, the child symptoms in combination with their experience-based knowledge and attitude determined if they followed the organisational guidelines on ill children or their own intuitive judgement. Childcare staff admitted to advise parents defensively to protect themselves of giving wrong advices because they lack medical education. Childcare staff expressed a need to be educated on fever by experts. In their opinion, also parents should be educated on fever management. However, childcare staff did not feel confident enough to educate parents themselves.

Part 2: Development and evaluation of a multicomponent intervention

Based on the findings of the extensive needs assessment (chapter 2-6), a multicomponent intervention was developed to improve decision-making on fever and common infections in childcare centres, by means of the stepwise approach of Intervention Mapping, and in close collaboration with stakeholders and experts. We chose to focus on decision-making among childcare staff towards illness absenteeism due to childhood fever and common infections as these decisions affect childcare absenteeism, productivity loss, and healthcare service use. Successively, illness absenteeism of children was selected as primary outcome measure to reflect changes in childcare staff's decision-making behaviour. Subsequently, and in contrast to well-child clinic professionals, childcare staff encounter parents on a daily basis, have to deal frequently with ill children, but currently do not receive any formal medical education.

Based on our needs assessment, we identified attitude, risk perception, knowledge, and self-efficacy as behavioural determinants underlying decision-making of childcare staff. The development process resulted in a multicomponent intervention targeting these behavioural determinants of decision-making, consisting of (1) an educational session for childcare staff, (2) a decision tool for staff and parents, (3) an information booklet for staff and parents, and (4) an online video for staff and parents. We hypothesised that improving behavioural determinants of decision-making reduces illness absenteeism due to childhood fever and common infection in children attending childcare.

The multicomponent intervention was evaluated in a cluster randomised controlled trial in Southern Netherlands. Nine childcare centres received the intervention and nine provided childcare-as-usual. The primary outcome was illness absenteeism defined as the percentage of childcare days absent due to illness on the total of childcare days during a 12-week period. The linear mixed model showed that overall 12-week illness absenteeism was comparable for the intervention and control group.

Among childcare staff who participated in both pre and post trial surveys the secondary outcomes 'intended behaviour', 'general attitude towards fever', and 'attitude towards perceived harmful consequences of fever' improved significantly. 'Attitude towards paracetamol use in febrile children' was comparable for both groups. Self-efficacy showed 
a non-significant increase in the intervention group. Improvements in knowledge level were also found.

\section{General discussion and valorisation}

Chapter 9 comprises the general discussion of this dissertation. First, a description of the main findings of chapter 2-8 is provided. Second, we discuss methodological considerations regarding the development process of the intervention by means of Intervention Mapping, our target group of interest, outcome measure selection, comparable educational interventions in childcare, and the added value of applying the Intervention Mapping approach. In addition, we discuss methodological considerations towards the evaluation of the intervention. More specifically, we discuss outcomes on the parental level, the design of the study, the primary outcome measure illness absenteeism, and the "intentionbehaviour gap". We also provide recommendations for future research into this intervention. Implications for scientific research and childcare practice are combined with the valorisation of results. Our study demonstrated that the intervention improves attitude, risk perception, knowledge towards fever and intended behaviour. Despite these changes, illness absenteeism was not reduced. More attention should be paid to enhancing selfefficacy by incorporating "if-then" strategies and to gain more insight in the actual decisionmaking process. Further development is needed to close the 'intervention-behaviour gap' and to develop and disseminate an intervention that is consistent among and for all stakeholders (childcare staff, parents, well-child clinic professionals, and GPs). 
Samenvatting 


\section{SAMENVATTING}

Koorts komt veel voor bij kinderen in de leeftijd van nul tot vier jaar oud. Vooral kinderen die naar het kinderdagverblijf gaan hebben vaak infecties. Deze kinderen hebben niet alleen meer kans op een infectie door het nauwe contact met andere kinderen, maar ook door de indirecte overdracht van infecties via de omgeving, zoals speelgoed. Vaak gaat het om een infectie die uit zichzelf overgaat. Wanneer een kind koorts of infectieklachten heeft op het kinderdagverblijf, dan spelen de leidsters (pedagogisch medewerkers) een rol in het ziekteverzuim van deze kinderen. Daarmee hebben zij ook een bepalende rol in het arbeidsverzuim, het productiviteitsverlies en het zorggebruik van de ouders. 'Fever phobia' bij ouders en (zorg)professionals lijkt hierin een belangrijke rol te spelen. 'Fever phobia' is een angst voor koorts die veelal voortkomt uit misvattingen.

Dit proefschrift heeft ten doel mogelijkheden in kaart te brengen om het handelen rondom een kind met koorts op het consultatiebureau en het kinderdagverblijf te verbeteren. Ook wordt het effect van een nieuw ontwikkelde multicomponente interventie, gericht op besluitvorming ten aanzien van kinderen met koorts op het kinderdagverblijf, bestudeerd.

Dit proefschrift richt zich op het beantwoorden van de volgende onderzoeksvragen:

1. Wat zijn de ervaringen en behoeften van huisartsen, artsen en verpleegkundigen werkzaam op het consultatiebureau, pedagogisch medewerkers op het kinderdagverblijf en ouders ten aanzien van handelen rondom een kind met koorts?

2. Wat zijn de effecten van het implementeren van een multicomponente interventie gericht op het verbeteren van besluitvorming door pedagogisch medewerkers op het kinderdagverblijf ten aanzien van zowel ziekteverzuim door koorts en veelvoorkomende infecties als onderliggende determinanten van besluitvorming?

\section{Deel 1: De behoeftepeiling}

\section{Huisartsen, consultatiebureauartsen en jeugdverpleegkundigen}

Er zijn twee kwalitatieve studies in de vorm van groepsgesprekken uitgevoerd om ervaringen van zorgprofessionals in kaart te brengen met betrekking tot hun handelen rondom kinderen met koorts. Eén studie is uitgevoerd onder huisartsen werkzaam op de huisartsenpost ( $N=37$, hoofdstuk 2$)$ en één studie is uitgevoerd onder artsen en verpleegkundigen werkzaam op het consultatiebureau ( $N=22$, hoofdstuk 3 ).

Volgens huisartsen leidt koorts bij kinderen tot een hoge werkbelasting op de huisartsenpost. Ook consultatiebureauartsen en jeugdverpleegkundigen ervaren dat ze regelmatig vragen van ouders krijgen over koorts. Volgens huisartsen, consultatiebureauartsen en jeugdverpleegkundigen komen deze vragen van ouders over koorts met name voort uit bezorgdheid en een behoefte om gerustgesteld te worden, maar ook uit een gebrek aan kennis over koorts (pathofysiologie) en zelfmanagementstrategieën, zoals het moment waarop de huisarts bezocht moet worden. Daarnaast ondervinden huisartsen dat een toenemend aantal ouders de huisartsenpost bezoekt op advies van het 
kinderdagverblijf. Consultatiebureauartsen en jeugdverpleegkundigen ervaren verder dat bezorgdheid van ouders beïnvloed wordt door (een gebrek aan) ervaring, opleidingsniveau, de grootte van hun sociale netwerk en de verschillende adviezen die zorgprofessionals geven met betrekking tot paracetamol.

Huisartsen zijn van mening dat ouders beter geïnformeerd kunnen worden over koorts tijdens consulten. Daarnaast vinden ze dat jonge ouders voorgelicht moeten worden voordat hun kind ziek wordt, bijvoorbeeld tijdens contactmomenten op het consultatiebureau. Door een vangnet te bieden kan hun zelfmanagement wordem verhoogd, zal het aantal huisartsconsulten verminderen en daarmee de ervaren werkbelasting. Echter, consultatiebureauartsen en jeugdverpleegkundigen vinden hun huidige informatievoorziening over koorts te beperkt omdat die zich vooral focust op koorts als bijwerking van vaccinaties. Consultatiebureauartsen en jeugdverpleegkundigen zijn daarom van mening dat hun huidige informatievoorziening over koorts eerst verbeterd moet worden. Daarbij moet rekening gehouden worden met karakteristieken van ouders; bovendien moet de informatie tussen verschillende zorgverleners overeenkomen. Daarnaast zijn ze van mening dat toekomstige informatie zich moet richten op het verbeteren van zelfmanagementstrategieën en praktische vaardigheden. Deze informatie moet eenvoudig te vinden zijn en de verbale uitleg moet ondersteund worden met visuele informatie, zowel op papier als in de vorm van een online applicatie. De mening over het beste moment waarop ouders geïnformeerd kunnen worden over koorts varieert. De voorkeur van artsen en verpleegkundigen op het consultatiebureau gaat voornamelijk uit naar de eerste twee maanden na de geboorte.

Naast deze twee kwalitatieve studies hebben we een systematisch literatuuronderzoek uitgevoerd (hoofdstuk 6). Hieruit bleek dat het voorlichten van ouders op het consultatiebureau -voorafgaand aan koorts en infecties - het aantal huisartsenconsulten overdag vermindert, evenals het aantal huisbezoeken en het aantal telefonische huisartsconsulten. Daarnaast verbetert preventief voorlichten hun medicatiemanagement. Het literatuuronderzoek liet ook zien dat simpele en complexe interventies variëren in hun effect op het verminderen van huisartsconsulten overdag en in hun potentieel om het aantal huisbezoeken en consulten op de huisartsenpost te verminderen. Alleen multicomponente interventies op het consultatiebureau reduceerden bijvoorbeeld het aantal telefonische consulten en verbeterden medicatiemanagement. Voorlichting op het consultatiebureau - voordat een kind ziek wordt - kan een positieve invloed hebben op het zorgzoekgedrag en medicatiemanagement van ouders.

\section{Ouders}

Hoofdstuk 4 beschrijft een vragenlijstonderzoek onder 515 families van wie een of meer kinderen op het kinderdagverblijf zaten. De resultaten laten zien dat bijna alle kinderen infectieklachten hadden tijdens de meetperiode van vier weken in februari en maart 2016. Luchtweginfecties werden het meest gerapporteerd door ouders en meer dan de helft van de kinderen had koorts. Driekwart van de kinderen met infectieklachten bezocht geen huisarts. Van de kinderen die wel door de huisarts gezien werden, was koorts de meest 
frequente reden. Een derde van de kinderen was afwezig van het kinderdagverblijf als gevolg van ziekte en 146 ouders hadden vrij moeten nemen (312 dagen) van hun werk omdat hun kind ziek was.

\section{Pedagogisch medewerkers}

Hoofdstuk 5 beschrijft een kwalitatief onderzoek onder pedagogisch medewerkers met het doel meer inzicht te krijgen in hun ervaringen en visie met betrekking tot besluitvorming ten aanzien van kinderen met koorts. In totaal werden twintig pedagogisch medewerkers van een grote kinderdagverblijforganisatie in Zuid-Limburg geïnterviewd. In aanvulling hierop zijn interviews afgenomen met drie pedagogisch medewerkers van een andere kinderdagverblijforganisatie uit dezelfde regio.

Op basis van de interviews werden factoren geïdentificeerd die leiden tot variatie in: (1) besluitvorming ten aanzien van kinderen met koorts door pedagogisch medewerkers, en (2) advisering van ouders met betrekking tot het ophalen van hun zieke kind of het consulteren van de huisarts. Volgens pedagogisch medewerkers variëren ze onderling in besluitvorming en advisering van ouders ten aanzien van kinderen met koorts. Deze variatie wordt beïnvloed door de symptomen gepresenteerd door het kind, verschillen in ervaring tussen pedagogisch medewerkers en de mate waarin ze de richtlijnen van de organisatie volgen met betrekking tot zieke kinderen versus hun eigen intuïtie volgen ten aanzien van koorts. Pedagogisch medewerkers ervoeren dat hun ervaring en overleg met collega's invloed heeft op hun besluitvorming. Daarnaast bepalen de symptomen van het kind, in combinatie met hun op ervaring gebaseerde kennis en attitude, of ze de richtlijnen van de organisatie volgen of hun intuïtie.

Pedagogisch medewerkers gaven ook toe ouders defensief te adviseren om zichzelf te beschermen tegen het geven van verkeerde adviezen omdat ze geen medische scholing hadden gehad. Pedagogisch medewerkers gaven aan een behoefte te hebben aan onderwijs van experts op het gebied van koorts. Daarnaast voelden ze zich niet zeker genoeg om ouders zelf te onderwijzen over koorts.

\section{Deel 2: Ontwikkeling en evaluatie van een multicomponente interventie}

Op basis van de bevindingen van de uitgebreide behoeftepeiling (hoofdstuk 2 tot en met 6) werd een multicomponente interventie ontwikkeld om de besluitvorming over koorts en veelvoorkomende infecties in kinderdagverblijven te verbeteren. Deze interventie is ontwikkeld aan de hand van de stapsgewijze benadering van Intervention Mapping en in nauwe samenwerking met belanghebbenden en experts. Hoofdstuk 7 beschrijft de ontwikkeling van de interventie. Ziekteverzuim van kinderen werd gekozen als primaire uitkomstmaat om veranderingen in de besluitvorming van pedagogisch medewerkers te weerspiegelen ten aanzien van ziekteverzuim van kinderen door koorts en veelvoorkomende infecties. We kozen ervoor om te concentreren op besluitvorming ten aanzien van ziekteverzuim, omdat deze beslissingen het productiviteitsverlies en het gebruik van de gezondheidszorg nadelig beinvloeden. Bovendien, en in tegenstelling tot consultatiebureaus, zien pedagogisch medewerkers ouders dagelijks op het 
kinderdagverblijf, moeten ze vaak omgaan met zieke kinderen, maar krijgen ze momenteel geen medische scholing.

Houding ten aanzien van koorts (attitude), risicoperceptie (risk perception), kennis (knowledge) en eigeneffectiviteitsverwachting (self-efficacy) hebben we aan de hand van de behoeftepeiling geïdentificeerd als gedragsdeterminanten/factoren die ten grondslag liggen aan de besluitvorming van pedagogisch medewerkers. De ontwikkelingsfase resulteerde in een multicomponente interventie gericht op deze gedragsdeterminanten van besluitvorming, bestaande uit (1) een scholing voor pedagogisch medewerkers werkzaam op het kinderdagverblijf, (2) een beslisboom voor pedagogisch medewerkers en ouders, (3) een informatieboekje voor pedagogisch medewerkers en ouders, en (4) een online video voor pedagogisch medewerkers en ouders. Daarbij werd verondersteld dat het verbeteren van gedragsdeterminanten van besluitvorming leidt tot een vermindering van het ziekteverzuim als gevolg van koorts en veelvoorkomende infecties bij kinderen op het kinderdagverblijf.

In hoofdstuk 8 wordt de effectiviteit van de multicomponente interventie geëvalueerd in een cluster gerandomiseerde gecontroleerde trial in Zuid-Nederland. Dit betekende dat negen kinderdagverblijven de interventie kregen en negen kinderdagverblijven standaardzorg gaven (controlegroep). De primaire uitkomst was ziekteverzuim van kinderen door koorts en veelvoorkomende infecties, gedefinieerd als het percentage afwezige kinderopvangdagen door ziekte op het totaal van de kinderopvangdagen gedurende een periode van twaalf weken. Statistische analyse middels het Lineair Mixed Model toonde aan dat het ziekteverzuim over deze periode vergelijkbaar was voor de interventie- en controlegroep. Pedagogisch medewerkers die voor en na de interventieperiode een vragenlijst invulden, verbeterden significant op secundaire uitkomsten als 'voorgenomen gedrag (intended behaviour)', 'algemene houding ten opzichte van koorts (general attitude towards fever)' en 'houding ten opzichte van mogelijke schadelijke gevolgen van koorts (risk perception)'. 'Houding ten opzichte van paracetamolgebruik bij kinderen met koorts' was vergelijkbaar voor beide groepen. 'Eigeneffectiviteitsverwachting (self-efficacy)' toonde een niet-significante toename in de interventiegroep. Verbeteringen in kennisniveau werden ook gevonden.

\section{Algemene discussie en valorisatie}

Hoofdstuk 9 beschrijft de algemene discussie van dit proefschrift. Ten eerste wordt een beschrijving gegeven van de belangrijkste bevindingen van hoofdstuk 2 tot en met 8 . Ten tweede komen methodologische overwegingen aan de orde met betrekking tot de ontwikkeling van de interventie door middel van Intervention Mapping, de doelgroep, selectie van uitkomstmaten, vergelijkbare educatieve interventies op kinderdagverblijven en de toegevoegde waarde van het toepassen van de Intervention Mapping-aanpak. Daarnaast worden methodologische overwegingen besproken met betrekking tot de evaluatie van de interventie. Daarbij staan de resultaten op het niveau van de ouders, de onderzoeksopzet, de primaire uitkomstmaat ziekteverzuim en de 'intention-behaviour gap' centraal. Ook worden aanbevelingen gegeven voor toekomstig onderzoek naar deze 
interventie. Implicaties voor wetenschappelijk onderzoek en voor kinderdagverblijven worden gecombineerd met de valorisatie van resultaten.

Dit onderzoek toont aan dat de interventie leidt tot een verbetering in de houding (attitude), risicoperceptie (risk perception), kennis (knowledge) en voorgenomen gedrag (intended behaviour) ten aanzien van koorts van pedagogisch medewerkers op het kinderdagverblijf. Ondanks deze verbeteringen was ziekteverzuim van kinderen echter niet verminderd. Er moet meer aandacht worden besteed aan het verbeteren van de eigeneffectiviteitsverwachting (self-efficacy) door het opnemen van 'als-dan'-strategieën in de interventie. Daarnaast is het nodig om meer inzicht te krijgen in het daadwerkelijke besluitvormingsproces. Verdere ontwikkeling is noodzakelijk om de 'intention-behaviour gap' te dichten en om een interventie te ontwikkelen en te verspreiden die consistent is tussen en voor alle belanghebbenden (personeel voor kinderopvang, ouders, consultatiebureauartsen, jeugdverpleeg-kundigen en huisartsen). 
Dankwoord 


\section{DANKWOORD}

Op 14 mei 2014 klonk het startschot voor mijn proefschrift en vrijdag 26 april 2019 bereik ik de finishstreep. Dit keer had ik geen tegenstanders om te verslaan, maar ik heb wel het gevoel dat ik de langste etappekoers uit mijn leven heb volbracht. Gelukkig heb ik hierbij veel hulp en ondersteuning gehad van mijn promotieteam, collega's, en een grote fanclub van familie en vrienden om deze finish te bereiken. Ik kijk met trots terug op het eindresultaat, dit proefschrift, maar ook op de weg ernaartoe. Zoals mijn fietsmaatjes weten gaan mijn trainingsroutes het liefst over de kleinste weggetjes, hier en daar van de verharde weg af, zijn ze vooral niet rechttoe rechtaan en kom je vaak een uur later thuis dan gepland. Dit is niet anders geweest tijdens mijn PhD.

Voor mij is het altijd heel normaal geweest om mijn studie te combineren met wielrennen op internationaal wedstrijdniveau. Tijdens mijn PhD deed ik niet anders en kijk ik terug op een periode waarin ik opgeleid werd tot een goede onderzoeker, maar ook een periode waarin mijn (prestatie)vermogen op de fiets toenam. Dit was alleen mogelijk doordat mijn promotieteam mij de ruimte gaf om deze twee uitersten op hoog niveau te combineren. Bedankt daarvoor!

Jochen, Geert-Jan en Rik, ik kan nog een proefschrift volschrijven over onze team overleggen die steevast begonnen met het bespreken van koersverhalen, verhalen over (verre) vakantiebestemmingen, over triatlon, of andere belangrijke zaken in het leven... Dit bleek elke keer weer een goede bodem voor een leerzame en inspiratievolle discussie over de invulling van mijn onderzoek, of het artikel waar ik op dat moment aan werkte. De teamsfeer was altijd goed, waarin ieder een andere, maar belangrijke rol had. Stelling 9 is dan ook niet zomaar gekozen: "een promotieteam is net als een wielerteam; de mix van individuele kwaliteiten leidt tot een team dat meer is dan de som der delen."

Jochen, ik zal altijd met heel veel plezier terugkijken op onze samenwerking. Op dag 1 kreeg ik een enthousiaste welkomstmail, maar ook op mijn eerste dag van mijn nieuwe baan kreeg ik een mail van je om mij succes te wensen maar dat ik vooral ook niet moest vergeten om mijn proefschrift af te ronden... Deze mails zijn tekenend voor je betrokkenheid; een kort berichtje als een nieuw onderzoeksproject gestart was, even bellen om te vragen hoe een focusgroep gegaan was, je offerde je spaarzame vrije avonden op om scholing te geven op kinderdagverblijven en stond je altijd klaar voor me als er iets was. Je kwam graag kijken als mijn wedstrijd in de buurt was en je was altijd benieuwd hoe wedstrijden waren gegaan. Om af te sluiten met een quote die ik toepasselijk vind op jou en jouw reis van co-promotor tot mijn 1e promotor: "Great men are not born great, they grow great ..." (Mario Puzo, The Godfather).

Geert-Jan, vanaf dag 1 stond je deur altijd open om even te overleggen, te sparren, om even bij te praten over mijn onderzoek, of om over je fietstochten en verre vakanties te praten. Je hield altijd de rode draad van mijn proefschrift in het oog en je blonk uit in de grammaticale puntjes op de i als het op schrijven aankwam. Ik zal ook nooit vergeten dat je 
uit je grote voorraad Schär koekjes alle lactosevrije had gevist en die op mijn bureau had gelegd. Bedankt voor de koekjes en al je andere hulp!

Rik, mijn project was al even bezig toen je hulp ingeroepen werd. Ik ben nog steeds blij met onze keuze om jou te benaderen en dat je op den duur ook officieel toetrad tot Team Peetoom. Je stond altijd klaar voor me als ik een vraag had, reageerde gemiddeld binnen 1 dagdeel op e-mails en leverde je vaak al binnen 24 uur waardevolle input op mijn papers. Naast je supersnelle efficiëntie was het ook nog eens heel prettig samenwerken met je en heb ik veel van je geleerd. Ik hoop dat we in de toekomst nog vaker kunnen samenwerken.

Naast mijn team ben ik een heel aantal dankbaar voor hun bijdrage aan de inhoud van dit proefschrift. Natuurlijk mijn buddy Eefje, bedankt dat je er altijd voor mij was en je er onder andere voor zorgde dat ik mij jarig voelde tijdens de GRIN in Oxford, met zingende onderzoekers om 00:00! Paddy, bedankt voor alle hulp en ondersteuning tijdens mijn promotietraject. Ik vond het erg fijn samenwerken met je, van het bouwen en checken van mijn datasets, tot je befaamde taalchecks en natuurlijk je betrokkenheid en interesse in mij en mijn project. Bjorn, je deur stond altijd open voor mijn vragen over statistiek en onze gesprekken gingen steevast over van linear mixed models, naar het beklimmen van de Stelvio en andere bergen, en natuurlijk een analyse van onze fietsritten op Strava. Bedankt voor al je hulp!

Tijdens mijn PhD heb ik 3 WESP-teams mogen begeleiden en hebben zij een belangrijke rol gespeeld in de totstandkoming van dit proefschrift:

Team Jolijn en Rachèl, jullie waren GOUD waard tijdens mijn effectstudie. Jullie hebben bergen werk verzet waar ik jullie altijd dankbaar voor zal zijn. Jullie hebben hele mooie PR materialen gemaakt, geholpen bij de vragenlijst, talloze ritjes gemaakt naar de kinderdagverblijven, een schitterend filmpje gemaakt dat onderdeel is van de interventie en geholpen bij de scholingen. We waren een goed team, jullie werden goede vriendinnen en ik stond er ook helemaal niet van te kijken dat Jolijn op een gegeven moment als AIOTHO bij HAG terugkeerde. Het is denk (hoop) ik nog maar een kwestie van tijd tot Rachèl terugkomt. Team Inge en Luc, jullie waren ook al zo'n powerduo waar ik louter goede herinneringen aan heb. Jullie hebben samen de pedagogisch medewerkers geïnterviewd en de weg geëffend voor de rest van mijn project. Ook op mijn nieuwe werkplek heb ik nog steeds de afbeelding van Haithi junior op mijn bureau staan, want jullie vonden "Als je een bureaubaan hebt, moet je ook een foto van je huisdier hebben en deze past heel goed bij jou". Bedankt Inge en Luc voor al jullie hulp (en Haithi!). Team Jacqueline en Luc, jullie waren mijn eerste WESP-duo en jullie begonnen al vrij snel nadat mijn PhD startte. Mede dankzij jullie hulp bij de review en de focusgroepen heeft mijn onderzoek een beslissende wending genomen. Heel veel dank voor jullie harde werk en tomeloze inzet!

Naast de WESPEN hebben Marjorie Nelissen, Nicky Halbach, Jan Verbakel en Albine Moser een belangrijke bijdrage geleverd aan de totstandkoming van mijn artikelen. Bedankt voor jullie hulp om mijn artikelen tot een hoger niveau te tillen! Marjorie, daarnaast wil ik je bedanken voor je hulp en enthousiasme bij de ontwikkeling van de interventie en het geven 
van de scholing op de kinderdagverblijven. Het was erg leuk om met je samen te werken. Nicky, dankzij jouw hulp en die van Rianne Reijs heb ik bij het consultatiebureau van Envida focusgroepen kunnen houden, dank jullie wel daarvoor! Ook wil ik graag alle artsen en verpleegkundigen bedanken die meegedaan hebben aan de focusgroepen voor jullie hulp en enthousiasme. Paul Ram en Luc Gidding, bedankt voor jullie hulp als moderator bij het uitvoeren van de focusgroepen op het consultatiebureau.

Het grootste deel van mijn onderzoek heeft zich afgespeeld op de kinderdagverblijven van MIK, een grote kinderdagverblijforganisatie in Zuid-Limburg. Ik wil in het bijzonder Annelies Snijders bedanken voor je hulp om de verschillende onderzoeksprojecten binnen MIK van de grond te krijgen. Cindy Westhovens, je was een onmisbare schakel voor ons om de verschillende locaties en PM'ers enthousiast te krijgen voor het onderzoek: bedankt voor je inzet! Daarnaast wil ik alle Locatiehoofden en Pedagogisch Medewerkers bedanken voor al jullie hulp, in het bijzonder m.b.t. het bijhouden van de talloze registratieboekjes en het invullen van de vragenlijsten. Ook wil ik natuurlijk de ouders bedanken voor het invullen van de vragenlijsten.

Tijdens (de voorbereiding van) de openbare verdediging krijg ik hulp van Team Paranimf, bestaande uit Marjolein van Rooijen en Mary Rose Postma. Jullie zijn voor mij een topcombi. Allebei proactief terwijl ik liever de kat uit de boom kijk... Jullie komen met goede ideeën en houden me scherp tussen alle ballen die ik momenteel hooghoud. Ik ben er heel trots op en ook dankbaar voor dat jullie mijn paranimfjes zijn! Lieve Marjolein, onze fietstochtjes in de vroege ochtend of na een lange werkdag zijn altijd een feestje. Zeker toen ik mijn dagen sleet met ploeteren op de laatste hoofdstukken van mijn proefschrift waren onze fietstochtjes met veel gelach en goede gesprekken goud waard! Lieve Mary Rose, het voelt altijd goed als we samen zijn. We delen dezelfde passie voor het rijden van marathons op de mountainbike. Het is volgens mij maar een kwestie van tijd totdat je mij weer lost bergop.

Lieve Maartje, Floor en Anouk (en natuurlijk ook Marjolein): ik vind het ontzettend leuk dat we elkaar hebben gevonden op HAG en regelmatig afspreken om samen te lunchen, naar de film te gaan en samen te eten. Laten we dit vooral nog heel vaak blijven doen! Bedankt voor alle support tijdens mijn $\mathrm{PhD}$ traject. Het is fijn om vriendinnen te hebben die precies weten wat het betekent om onderzoeker (in opleiding) te zijn. Lieve Maartje, we begonnen allebei in het voorjaar van 2014 bij HAG en "vonden" elkaar bij het uitje in Den Bosch. Sindsdien hebben we veel lunchwandelingetjes gemaakt, gekletst op het werk maar ook eetavondjes met onze mannen erbij gehouden. Je stond altijd klaar met goede raad en een luisterend oor. Bedankt voor alles! Lieve Floor, we kenden elkaar natuurlijk al via DM dus ik vond het dus wel heel erg leuk dat mijn "buuf" op de vakgroep kwam werken. Onze gesprekken op het werk gingen meer over fietsen (doen of over de aanschaf van een nieuwe), koken en andere dingen dan over onderzoek en dat was eerlijk gezegd altijd een fijne onderbreking. Lieve Anouk, je hebt altijd oog voor anderen (of in ieder geval voor mij). Zo krijg ik geregeld foto's van boeken die wel iets voor mij zouden kunnen zijn of vraag je 
op welk afgelegen eiland ik nu weer gefietst heb... $\mathrm{k}$ vind het zo leuk dat we vriendinnen zijn geworden.

Kamergenootjes, bedankt voor alle afleiding en tips. Angel, we hebben kamer 3.047 gedeeld vanaf mijn eerste werkdag op 14 mei 2014 tot onze laatste gezamenlijke werkdag in juli 2018. We waren in zoveel dingen tegenpolen van elkaar maar toch hebben we elkaar in het midden gevonden. Bedankt voor je luisterende oor en adviezen. Lujain, thank you for your kindness, listening and telling me more about your children, your country Saudi-Arabia and your culture. Let's meet soon for lunch! Camielle, het lijkt alweer zo lang geleden dat je voor het laatst bij ons op de kamer zat en je je proefschrift in sneltreinvaart afmaakte. Tijdens het afmaken van mijn eigen PhD dacht ik nog regelmatig terug aan onze gesprekken, bedankt!

Mark, als ik aan HAG denk, dan denk ik automatisch aan alle discussies die we gevoerd hebben over je nieuwe trainingsinzichten, wedstrijden, hoe de vorm ervoor stond, PRs, toertochten en nog veel meer. Ik kom binnenkort weer even langs voor een update en je laatste inzichten $m$.b.t. de ideale trapbeweging op de fiets.

Verder wil ik al mijn collega's bij HAG bedanken voor jullie interesse en hulp. In het bijzonder wil ik alle promovendi (of inmiddels postdoc) van HAG bedanken voor jullie gezelligheid, tips en adviezen en dat ik jullie voorzitter mocht zijn van het juniorenoverleg! Tijdens mijn PhD kwam ik ook regelmatig over de vloer bij GVO, met name voor Rik maar ook voor gezellige lunch/koffiepauzes met Dennis en Celeste, en niet te vergeten de gezamenlijke HAG-GVO borrel die Dennis en ik samen georganiseerd hebben. Wanneer is er weer eentje?

Mijn proefschrift was officieel nog niet goedgekeurd maar in september 2018 startte ik als postdoc bij het Alzheimer Centrum Limburg/vakgroep NP. Marjolein \& Frans, bedankt dat ik mij bij jullie verder kan ontwikkelen als onderzoeker. Ik ben heel blij dat ik bij jullie terecht ben gekomen. Stevie en Jeroen, ik vind het heel tof om jullie co-promotor te zijn! Verder wil ik ook al mijn lieve kamertgenootjes en collega's bij NP bedanken voor jullie tips en steun bij de laatste loodjes van mijn proefschrift. 
Zoals bijna iedereen wel weet combineerde ik mijn $\mathrm{PhD}$ met wielrennen op internationaal wedstrijdniveau. Voor mij begon vaak mijn "andere leven" als ik de kantoordeur achter mij dichttrok. Ik wil daarom mijn vaste trainingsmaatje bedanken voor de gezellige trainingsritjes waarin ook goede gesprekken gevoerd werden over mijn proefschrift (of heimelijk vermeden werden...). Bedankt Vyne van der Schoot, Mary Rose Postma, Sue van Gageldonk, Sophie von Berswordt, Evelien Ruijters, Danne Boterenbrood, Lotte van Hoek, Senna Feron, Mathea Nijmeijer, Marieke de Graaf. Op naar meer mooie trainingstochtjes in onze schitterende trainingsomgeving! Jeanine, ook al spreken we elkaar vaker naast dan op de fiets, door de fiets hebben we elkaar wel gevonden. Laten we nog heel veel JdB momentjes samen gaan hebben. Vijf uur nadat ik mijn proefschrift inleverde ging de wekker alweer voor een fantastisch weekje fietsen in Girona met Evelien, Vyne, Gijs en Maarten. Lekker sjeezen op de mtb, van het uitzicht genieten op de racer en "doen we nog een bakkie onderweg; oh en ook een broodje"? Bedankt voor de ideale afleiding na alle proefschriftstress!

Bij deze wil ik ook de begeleiding en ploeggenootjes van de wielerteams bedanken waar ik voor fietste tijdens mijn PhD, voor de ruimte die jullie mij gaven om deze twee uitersten te combineren.

Maar natuurlijk ook een speciaal bedankje voor mijn trainer Floris. Dankzij jou heb ik terwijl ik mijn proefschrift aan het afronden was- weer stappen gezet in mijn fietsprestaties. Bedankt voor het aanpassen van de schema's zodra ik er weer eens achter kwam dat niet alles tegelijk kan...

Lieve Sue, dankzij jou heeft mijn proefschrift een hele speciale voorkant gekregen die veel voor mij betekent en ook zo tekenend is voor mij, maar ook voor onze vriendschap. Je maakte de voorkant vanuit het idee dat ik ook iets gaafs aan de muur moest hebben en dat is bij deze gelukt! Bedankt!

Lieve Jan en Marian, sinds 7.5 jaar vertoef ik regelmatig op jullie boerderij of komen jullie gezellig bij ons op bezoek. Het is altijd fijn bij jullie te zijn en te voelen dat jullie trots zijn op wat we doen. Rens, je schitterende foto's waren een welkome afwisseling tijdens (het afronden van) mijn proefschrift, gracias! (Schoon)oma Riek, het is altijd een feestje om bij je te zijn en om bij je te logeren en ik vind het heel leuk hoe geïnteresseerd je bent. Ingrid, bedankt voor je hulp om van de Nederlandse samenvatting een tekst te maken die voor iedereen te begrijpen is! En natuurlijk ook de rest van de schoonfamilie: bedankt voor jullie luisterend oor.

Lieve Peter, Loek, Erik, Diny, Sjaak, Marja, Nel, Marina en Charles, lieve Peetooms en Vermeulens, we zien elkaar helaas niet vaak door de afstand maar ik kijk er al maanden naar uit om mijn promotie samen met jullie te vieren!

Lieve oma Peet, eindelijk ligt het boek voor u waar ik het al zo lang over had. Deze kan mooi bij de krantenknipsels. Opa Peet heeft dit helaas niet meer mee mogen maken maar ik weet dat hij ook trots zou zijn geweest. 
Lieve grote broer Ivar en schoonzus Maria, we zien elkaar minder vaak dan we willen maar het is altijd goed als we samen zijn. Onze discussies aan de keukentafel gaan dikwijls over het doen van onderzoek, ook al zitten we in hele andere disciplines en het is fijn om dit te kunnen delen. Tante zijn van Israe en Rayyaan en met hun spelen is ook een ideale manier om te ontspannen tussen het promoveren en koersen door!

Lieve paps en mams, dankzij jullie sta ik hier. Wie had dat ooit gedacht toen ik bleef zitten in de kleuterklas, Doctor Peetoom in 2019! Hard werken is mij met de paplepel ingegoten en daar pluk ik nog steeds de vruchten van. Het is lastig om in woorden te vangen hoe dankbaar ik jullie ben voor alles. Jullie staan altijd voor mij klaar. Ik hou van jullie.

Lieve Gijs, door jou is dit proefschrift een stuk mooier geworden, qua inhoud en ook qua lay-out. De gesprekken aan onze keukentafel, of op klapstoeltjes voor onze tent hebben er zeker aan bijgedragen dat dit proefschrift zo is geworden. Bedank voor je hulp maar bovenal bedankt dat ik door jou het leven kan leiden dat ik wil en waar ik blij van word. Als je niet was zoals je was, was het voor mij niet mogelijk geweest om te promoveren én zoveel en hard te kunnen fietsen. Zoals je mijn schaduwcoach bent in het wielrennen, ben je ook mijn belangrijkste sparringpartner geweest in dit traject. Zo gooide je bijvoorbeeld de hele introductie en discussie van mijn proefschrift om zodat het nog beter werd. Laten we nu snel weer heel veel mooie rondjes gaan mountainbiken over de meeste vette singletracks want daar is weer wat meer tijd voor. 
Curriculum Vitae 


\section{CURRICULUM VITAE}

Kirsten Peetoom was born in Badhoevedorp (Noord-Holland) on October 1st, 1988. After graduating from Amstelveen College in 2006, she obtained a propaedeutic in History (UvA, Amsterdam), after which she switched to the Bachelor Health Sciences (VU, Amsterdam). Her Bachelor internship focused on patient safety (EMGO+ institute/VUmc, Amsterdam). She graduated in Summer 2011 and moved to Maastricht to start the Health Sciences Research Master and specialized in Health

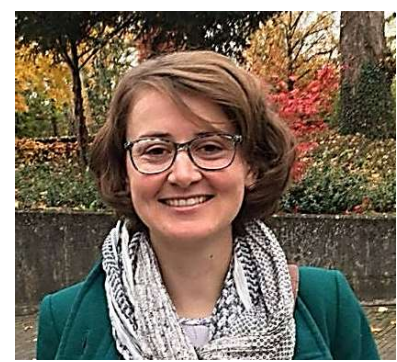
Technology Assessment. Her research master internship focused on the use of monitoring technology to support informal caregivers of people with dementia and took place at the Lectorate Technology in Care (Zuyd University of Applied Sciences). She received her Master's degree in March 2014 and started subsequently her PhD at the department of Family Medicine (Maastricht University) in May 2014. During her PhD, Kirsten chaired the PhD meetings at the department of Family Medicine and was part of the CAPHRI PhD Panel.

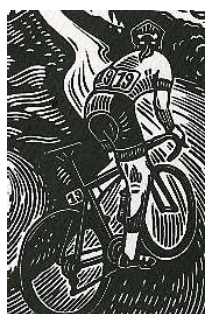

Kirsten currently works at the department of Neuropsychiatry and Psychology (Maastricht University) as postdoctoral researcher. Her research projects concern people with young-onset dementia and their caregivers.

Kirsten competes in road and mountainbike cycling races on the international level across Europe. 


\section{PUBLICATIONS}

Kirsten Peetoom, Rik Crutzen, Rachèl Verhoeven, Jolijn Bohnen, Bjorn Winkens, Geert-Jan Dinant, Jochen Cals. Optimizing decision-making among childcare staff on fever and common infections: cluster randomized controlled trial. European Journal Public Health. 2018 Nov 27. doi: 10.1093/eurpub/cky246.

Kirsten Peetoom, Rik Crutzen, Geert-Jan Dinant, Jochen Cals. Most preschool children with fever and common infection symptoms do not consult the family physician. Family Practice. 2018 Sep 25. doi:10.1093/fampra/cmy079.

Kirsten Peetoom, Rik Crutzen, Jolijn Bohnen, Rachèl Verhoeven, Marjorie NelissenVrancken, Bjorn Winkens, Geert-Jan Dinant, Jochen Cals. Optimising decision making on illness absenteeism due to fever and common infections within childcare centres: development of a multicomponent intervention and study protocol of a cluster randomised controlled trial. BMC Public Health. 2017 Jul 26;18(1):61. doi: 10.1186/s12889-017-4602-3. Erratum in: BMC Public Health. 2017 Sep 22;17 (1):736.

Kirsten Peetoom, Jacqueline Smits, Luc Ploum, Jan Verbakel, Geert-Jan Dinant, Jochen Cals. Does well-child care education improve consultations and medication management for childhood fever and common infections? A systematic review. Archives of Disease in Childhood. 2017 Mar;102(3):261-267.

Kirsten Peetoom, Luc Ploum, Jacqueline Smits, Nicky Halbach, Geert-Jan Dinant, Jochen Cals. Childhood fever in well-child clinics: a focus group study among doctors and nurses. BMC Health Services Research. 2016 Jul 8;16:240. doi: 10.1186/s12913-016-1488-1.

Jacqueline Stakenborg, Eefje de Bont, Kirsten Peetoom, Marjorie Nelissen-Vrancken, Jochen Cals. Medication management of febrile children: a qualitative study on pharmacy employees' experiences. International Journal of Clinical Pharmacy. 2016 Oct;38(5):1200-9. doi: 10.1007/s11096-016-0353-y. Epub 2016 Jul 23.

Eefje de Bont, Kirsten Peetoom, Albine Moser, Nick Francis, Geert-Jan Dinant, Jochen Cals. Childhood fever: a qualitative study on GPs' experiences during out-of-hours care. Family Practice. 2015 Aug;32(4):449-55. doi: 10.1093/fampra/cmv029.

Eefje de Bont, Kirsten Peetoom, Jochen Cals. Komt een kind bij de dokter: wat ziet de kinderarts niet? Kinderarts en wetenschap. 2015.

Kirsten Peetoom, Rik Crutzen, Geert-Jan Dinant, Jochen Cals. Kinderen met koorts en infectieklachten op het kinderdagverblijf worden meestal niet gezien door de huisarts. Accepted for publication in Huisarts \& Wetenschap.

Kirsten Peetoom, Rik Crutzen, Inge Alleleijn, Luc Laumen, Albine Moser, Geert-Jan Dinant, Jochen Cals. "I'm not a doctor...", Attitudes of child care providers towards childhood fever decision making: a qualitative study. Submitted. 
Kirsten Peetoom, Monique Lexis, Manueala Joore, Carmen Dirksen, Luc de Witte. Literature review on monitoring technologies and their outcomes in independently living elderly people. Disability and Rehabilitation: Assistive Technology. 2015 Jul;10(4):271-94.

Kirsten Peetoom, Monique Lexis, Manuela Joore, Carmen Dirksen, Luc de Witte. The perceived burden of informal caregivers of independently living elderly and their ideas about possible solutions. A mixed methods approach. Journal of Technology and Disability. 2016. 18:19-29.

\section{CONFERENCE CONTRIBUTIONS}

2016

17th General Practice Research on Infections Network Meeting 2016, Oxford, Great Britain

Educating parents about childhood fever and common infections in well-child clinics. Does it lead to reductions in physician consultations and improve medication management? A systematic review.

European Journal of Public Health, November 2016

Educating parents on childhood fever: a focus group study among well-child clinic professionals

2017

18th General Practice Research on Infections Network Meeting 2017, Oslo, Norway

Optimising decision making on illness absenteeism due to fever and common infections in child daycare: a cluster RCT 